\title{
Patient compliance in rheumatology : experiences with an electronic monitoring device
}

Citation for published version (APA):

de Klerk, E. (2002). Patient compliance in rheumatology : experiences with an electronic monitoring device. [Doctoral Thesis, Maastricht University]. Universiteit Maastricht.

https://doi.org/10.26481/dis.20021211ek

Document status and date:

Published: 01/01/2002

DOI:

10.26481/dis.20021211ek

Document Version:

Publisher's PDF, also known as Version of record

\section{Please check the document version of this publication:}

- A submitted manuscript is the version of the article upon submission and before peer-review. There can be important differences between the submitted version and the official published version of record.

People interested in the research are advised to contact the author for the final version of the publication, or visit the DOI to the publisher's website.

- The final author version and the galley proof are versions of the publication after peer review.

- The final published version features the final layout of the paper including the volume, issue and page numbers.

Link to publication

\footnotetext{
General rights rights.

- You may freely distribute the URL identifying the publication in the public portal. please follow below link for the End User Agreement:

www.umlib.nl/taverne-license

Take down policy

If you believe that this document breaches copyright please contact us at:

repository@maastrichtuniversity.nl

providing details and we will investigate your claim.
}

Copyright and moral rights for the publications made accessible in the public portal are retained by the authors and/or other copyright owners and it is a condition of accessing publications that users recognise and abide by the legal requirements associated with these

- Users may download and print one copy of any publication from the public portal for the purpose of private study or research.

- You may not further distribute the material or use it for any profit-making activity or commercial gain

If the publication is distributed under the terms of Article $25 \mathrm{fa}$ of the Dutch Copyright Act, indicated by the "Taverne" license above, 


\title{
Patient Compliance in Rheumatology
}

\section{Experiences with an Electronic Monitoring Device}

\author{
PROEFSCHRIFT \\ ter verkrijging van de graad van doctor \\ aan de Universiteit Maastricht, \\ op gezag van de Rector Magnificus, Prof. Dr. A.C. Nieuwenhuijzen Kruseman, \\ volgens het besluit van het College van Decanen, \\ in het openbaar te verdedigen \\ op woensdag 11 december 2002 om 14.00 uur
}

door

Erik de Klerk

Geboren op 31 augustus 1968 te Arnhem 


\section{Promotores}

Prof. dr. J.M.J.P. van der Linden

Prof. dr. D.M.F.M. van der Heijde

\section{Co-promotor}

Dr. R.B.M. Landewé

\section{Beoordelingscommissie}

Prof. dr. G.J. Dinant (voorzitter)

Prof. dr. J.Th.M. van Eijk

Prof. dr. H.G.M. Leufkens (Universiteit Utrecht)

Prof. dr. J.J. Rasker (Universiteit Twente)

Prof. dr. H.A.G. Struijker Boudier

Where facts are few, experts are many."

The study presented in this thesis was performed at the division of Rheumatology, department of Internal Medicine, University Hospital Maastricht.

This study was made possible by a research grant from the 'Nationaal Reumafonds', grant nr. NR 831.

- E. de Klerk, Heerlen, 2002

ISBN 90-9016402-2. 


\section{Contents}

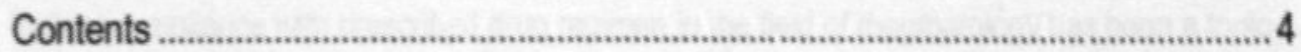

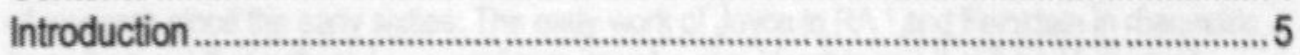

Measurement of Patient Compliance on Drug Therapy: ....................................... 9 Contending Paradigms for the Interpretation Of Data On Patient Compliance With Therapeutic Drug Regimens

Compliance monitoring of NSAID drug therapy in ankylosing spondylitis, experiences with an electronic monitoring device

Facilitated analysis of data on drug regimen compliance.

Development of a questionnaire to explore the likelihood and underlying factors for variable patient compliance on anti-rheumatic drug therapy.

Patient compliance in meumatoid arthritis, polymyalgia rheumatica and gout........93

Compliance to an oral bisphosphonate therapy in women with early postmenopausal bone loss.

Discussion and Summary of Results ............................................................123

Discussie en Samenvatting van de resultaten ...................................................129

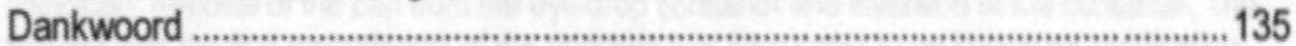

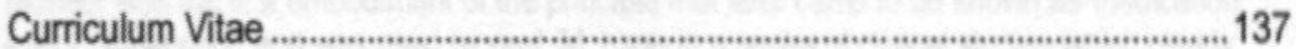




\section{Introduction}

Patient compliance with prescribed drug regimen in the field of meumatology has been a topic of research since the early sixties. The early work of Joyce in RA 1 and Feinstein in rheumatic fever ${ }^{2}$ proved that patient non-compliance may be considerable and that it had important clinical consequences. It was clear that patient compliance was a topic that warranted further research. When Belcon published his critical review to assess the magnitude and determinants of noncompliance in RA ${ }^{3}$, it became apparent that deficiencies in study methodology undermined the possibility of firm conclusions on the influence of various facbrs on compliance in RA patients.

Crucial to the study of any phenomenon is the ability to make reliable measurements. In therapeutics, it has long been difficult to assess outpatient compliance with prescribed drug regimens with sufficient scientific quality 46 .

Fortunately, in the mid-70's, the electronic revolution intersected with growing recognition of the need for practical and reliable means for measuring compliance. ALZA Corporation developed an eyedrop dispenser with integral, time-stamping microcircuitry that could compile a dosing history in ambulatory glaucoma patients. A reliably compiled dosing history is, of course, the foundation of a reliable estimate of patient compliance with the prescribed dosing regimen. The device compiled a time history of outpatients' dosing by recording times when two events coincided: removal of the cap from the eye-drop container and inversion of the container. The monitor was the first embodiment of the principle that later came to be known as 'medication event monitoring', and was used by prof. M. Kass in a series of clinical studies which clearly showed that predominance of delayed and omitted doses are the main form of non-compliance. Although Kass waited with definitive publication of these early findings because of the large size of the initial monitor, his later studies with a smaller monitor, of size, shape, and weight similar to that of conventional eyedrop dispensers, showed no striking quantitative differences in patient compliance ${ }^{7}$.

Electronic monitoring supports a quantifiable definition of patient compliance as 'the extent to which the patients' dosing history conforms to the prescribed drug regimen'. In other words, 'patient compliance' is the outcome of the comparison of two time-series. This approach has a large advantage over other widely used definitions of patient compliance such as: 'patient compliance is the patients behavior in terms of taking medication, following prescribed diets or executing medically recommended life-style changes ${ }^{6}$, because the comparison of two timeseries is objective and quantifiable. It is also clear from the definition that there are a number of different patterns of deviation from the prescribed regimen possible, all of which are dynamic over time.

While the initial ALZA monitors were large, heavy and costly to produce, commercial development of the monitors has led to the availability of electronic medication event monitors to the scientific community that are more practical to use. Its growing use over the past 15 years has led to a fairly large body of scientific evidence that variable patient compliance is a widespread phenomenon, and that the between patient variability in compliance is so large that it cannot be ignored, both in scientific clinical trials and in everyday clinical daily practice 8 . 
Prior to electronic monitoring, all methods for measuring compliance relied on the patients' recall and full co-operation with the intent of the study, thus encountering unquantifiable degrees of forgetfulness and affording patients the easy ability to censor evidence for delayed or omitted doses. As is now evident from studies using electronic monitoring, the preelectronic methods, such as returned tablet count, diaries, interviews, and self-report, give grossly exaggerated estimates of patient compliance. Now it is possible to study patient compliance with reliable methods that reveal dose timing and intervals between doses, day by day.

Next to our assessment of compliance in ankylosing spondylitis (AS) the COUGAR project (Compliance Unveiled in Gout, Arthritis and Rheumatism) is, as far as we know, the first attempt to use electronic medication event monitoring in rheumatology. The aims of the project were to:

- Acquire insight in the extent to which patients are compliant to drug therapy in the following rheumatic diseases: rheumatoid arthritis (RA), polymyalgia rheumatica (PMR) and gout.

- To develop a questionnaire to explore patient compliance.

- To find predictors for low compliance, which could be used for future development of a compliance intervention.

The resulting thesis contains 9 chapters that endeavor to realize these 3 main objectives.

Chapter 1 describes the various aspects of measurement of patient compliance with prescribed drug regimens. It is written as a practical text, giving insight into the advantages and disadvantages of the different methods of measurement and combinations thereof, as well as the applicability of the different methods of measurement in a variety of situations.

Chapter 2 is a general overview of various aspects of patient compliance, and serves as a theoretical basis for the rest of the thesis. A number of topics are discussed, among which are pharmacologic aspects of variable compliance, electronic medication event moritoring and slow-turnover chemical markers and their place in the measurement of patient compliance, consequences of poor compliance, including the relationship with pharmacological properties of drugs (forgiving vs unforgiving drugs).

Chapter 3 describes the results of compliance assessment in a phase III, randomized active controlled clinical study for the efficacy of two NSAIDs in AS. We measured compliance with the medication event monitoring system (MEMS), and provided the first overview of patient compliance with electronic monitoring in AS. While there were no differences in compliance between the two NSAID's, it is interesting to see the various deviations from prescribed dosing in a phase III clinical trial.

Chapter 4 is an extension of chapter 3 , wherein we summarize in a novel tabular form the large amount of information that is gathered by electronic monitoring. The between-patient variability is very large, ranging almost from $0 \%-100 \%$, clearly showing that analysis based on conventional averages of patient compliance do not capture the essence of the natural experiments in drug exposure that patients perform, even in a phase III clinical trial. 
Chapter 5 describes the development of the Compliance Questionnaire Rheumatology (CQR), a 19-item questionnaire designed to explore patient compliance with prescribed drug therapy in ineumatology. The chapter gives a detailed description of the development of the questionnaire, and describes the results of its validation against a surrogate gold standard.

Chapter 6 is an extension of chapter 5 , and describes the validation process of the CQR against electronically monitored dosing histories. Discriminant analysis techniques are employed to utilize fully the functionality of CQR-19, showing it to be a valid instrument.

Chapter 7 presents the main results of a series of cohort studies, which is the core of the COUGAR project. Patient compliance measured with the electronic medication event monitoring system is described for meumatoid arthritis, polymyalgia meumatica, and gout, with a number of different drugs and dosing regimens. We give a full description of the various compliance patterns in these three diseases, and explore a number of factors related to patient compliance.

Collaboration with the Diagnostic Center Eindhoven gave us the opportunity to study compliance with an oral bisphosphonate in osteoporotic, post-menopausal women in the Eindhoven Perimenopausal Osteoporosis Study (EPOS) study. As described in chapter 8, compliance in this trial was quite good, and contrasts with some of the findings in chapter 7 .

Finally, chapter 9 discusses the content of the thesis and summarizes the main findings.

\section{Literature}

1. Joyce CRB. Patient cooperation and the sensitivity of clinical trials. J. Chron. Dis. 1962; 15:1025-36.

2. Feinstein AR, Spagnuolo M. The clinical patterns of acute meumatic fever. a reappraisal. 1962. Medicine Baltimore $1993 ; 72: 272-83,262-3$

3. Belcon MC, Haynes RB, Tugwell P. A critical review of compliance studies in rheumatoid arthritis. Arthritis Rheum 1984; $27: 1227-33$

4. Dunbar J, Dunning EJ, Dwyer K. Compliance measurement with arthritis regimen. Arthritis Care Res 1989; 2:S8 16. 5. Bond CA, Monson R. Sustained improvement in drug documentation, compliance, and diseasecontrol. A four-year analysis of an ambulatory care model. Arch Intern Med 1984; 144:115962.

6. Sackett DL, Haynes RB. Compliance with therapeutic regimens. Baltimore and London: Johns Hopkins University Press, 1976.

7. Urquhart. Patient compliance with prescribed drug regimens: overview of the past 30 years of research. In: Nimmo W.S. T, G.T., ed. Clinical Measurement in Drug Evaluation: John Wiley \& Sons, 1995:213227.

8. EM Bibliography . http://www.aardex.ch/bibliography.htm. 


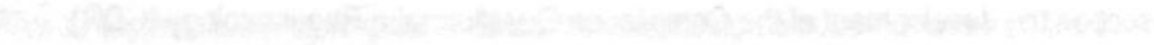

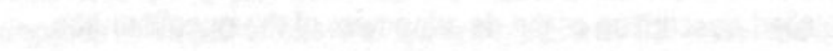




\section{Chapter 1}

\section{Measurement of Patient Compliance on Drug Therapy:}

an Overview.

\section{Erik de Klerk.}

department of Rheumatology, University Hospital Maastricht, the Netherlands.

Manuscript published as: de Klerk E. Measurement of Patient Compliance on Drug Therapy: an Overview. In: Advances in Behavioral Medicine Assessment, A. Vingerhoets, editor. Harwood Academic Publishers, 2001: 215-44.

\section{Introduction}

In modern medicine, consultation with a physician results more often than not $\mathbf{h}$ a drug prescription. Prescribing a drug does not ensure optimal intake, however. Most of the readers will have at least some experience with a drug regimen, and chances are one recalls that during the execution phase of such a prescribed regimen one or a few doses were omitted, or that the timing of the ingestion of the drug was not quite as prescribed. This phenomenon is known as variable patient compliance, and this chapter will review various aspects that are associated with this phenomenon.

The emphasis on the subject is not new at all. "Keep a watch also on the faults of the patients which often makes them lie about the taking of things prescribed", Hippocrates stated over 2,500 years ago (Hippocrates, $400 \mathrm{BC}$ ). Compliance can be studied for all medical advice, as indicated by Sackett and Haynes (1976) who defined patient compliance as: "the extent to which a person's behavior (in terms of taking medications, following diets, or executing lifestyle changes) coincides with medical or health advice".

However, the optimal execution of a drug-prescription is substantially different from following a diet or a program to quit smoking. Once acceptance of the therapy is established, the actual ingestion of a tablet or capsule is a very small act, requiring only memory and willingness to interrupt briefly ongoing activities to do so. Lifestyle changes ask much more of the recipient such as a strong determination, constant rejection of impulses to do whatever the recipient would prefer to do (such as eating or smoking) and a much more rigid execution of the correct regime (smoking a few cigarettes will by many be regarded as a total treatment failure, while missing one or a few tablets in most instances would not have such dramatic impact at all). In other words, the main errors made in drug regimen compliance are errors of omission, whereas the main errors made in the effort to follow a special diet or a smoking cessation program are errors of commission.

Therefore we propose to make a clear distinction between compliance on drug regimen, and compliance on other medical advice. This chapter will focus only on compliance on drug regimen, and following this proposal the definition: "patient compliance is the extent to which the prescribed (and presumably optimal) regimen conforms to the actual dosing history' from Urquhart and Chevalley (1988) is preferred. 


\section{Terminology}

A short note on the use of the word compliance is considered appropriate here. Several early authors in this field found the word compliance authoritarian (the doctor tells the patient what to do) and to some it implies obeisance or servility. Opponents of the word have therefore proposed a variety of alternative words including adherence, fidelity, maintenance (Feinstein, 1990), obedience (Joyce, 1962), cooperation and, more recently, concordance (Dolan-Mullen, 1997).

Although optimal therapy requires cooperation of both physician and patient, preferably on a basis of equality, none of the other proposed words appears to have any evident advantage over 'compliance'. Therefore we opted to follow the choice of the National Library of Medicine, which maintains the term Patient-Compliance as Mesh index, and indexes papers that prefer adherence or other definitions under the Mesh term patient-compliance.

\section{Aspects of noncompliance.}

Variable compliance on drug therapy includes taking too many pills or not enough pills (so called taking-compliance) and / or altering the intervals between consecutive doses (timingcompliance). It makes pharmacologically sense to take the interdose interval as starting point to describe the effects of various forms of non-compliance.

Short interdose-intervals (e.g. When extra tablets are taken) usually result in an increase efficacy but also in a higher probablitiy for adverse drug reactions and toxicity.

Longer interdose-intervals (e.g. after omission of one or more doses) can result in loss of efficacy, but in selected cases such as B-blockers also in an increase in safety problems such as rebound effects. Usually restarting therapy occurs in full-dose, and if a particular drug requires careful uptitration first-dose effects may re-occur during 'steady state therapy' for someone not informed about the actual pattern of drug-intake.

Non-compliance can thus result in a variety of effects. From a clinical point of view, an important aspect is to distinguish non-responders (patients who receive adequate therapy but do not show the clinical desirable result) from noncompliers (those that do not receive adequate therapy). Non-responders should be treated with higher doses, other drugs, or a combination of drugs while noncompliers should be helped in assuring intake. Certain adverse drug reactions and drug-related toxicity, as well as symptoms resulting from rebound effects can be labeled as drug related, while in fact they may be compliance related.

\section{Short review}

From a historical perspective, the year 1962 shows up as the year when two seminal papers discussed several important concepts related to patient compliance. Even 35 years later, several findings and conclusions still hold. Moulding described the first special-purpose device to measure timing aspects of patient compliance. The device was 'a wedding of a clock to a pill dispenser', resulting in a cabinet that stored drug dosage forms in small individual trays, with special photographic film exposed to a radioactive source until the drug was removed from the tray. The patient had to press a button to remove the drug, and such an event was thus recorded by the occurrence of evidence of radiographic rays (black notches) on the film. Omissions of dosing would be detected by the absence of black notches, in essence creating a 
bar-code of individual patient compliance. The idea was years ahead of its time, and consequently, it has never been used.

Joyce described the results of using 3 different compliance measurements (interview, pillcount, and the use of phenol red as chemical marker of ingestion) in a trial comparing phenylbutazone, a compound labeled C2041 and placebo, in patients with rheumatoid arthritis. Substantial noncompliance was noted: only $35 \%$ of all urine samples that should have contained marker were labeled "marker present" and the frequency distribution of dosing discrepancies between returned tablets and prescribed dosing ranged from 0 to almost maximal, thus showing that compliance varied markedly between individuals.

When the results of the intention-to-treat analyses were corrected for variable compliance the new compound showed a higher efficacy while at the same time showing higher toxicity. The author at that time felt the need to apologize for "presenting a result that is so agreeably acceptable to common-sense" but noted that there had been very few attempts to confirm that patients are following treatment as prescribed in diverse conditions, and that no one had tried to use this type of data to a scientific advantage. Although written over 35 years ago, unfortunately, this statement still holds true.

Since it is not possible to review all research addressing the many aspects of compliance, three prototypical studies are described in detail to illustrate the important issues regarding the measurement of patient compliance.

\section{Coronary Drug Project.}

In 1980 the data of the Coronary Drug Project, a randomized, placebo-controlled, doubleblinded, multicenter trial to evaluate the efficacy and safety of several lipid-influencing drugs in the secondary prevention of coronary heart disease (CHD), (CDP, 1973, 1974) were reanalyzed (CDP, 1980). Compliance was operationalized as the estimated number of capsules taken per day divided by the number of capsules dictated by the protocol dosage (nine per day) for each four-month period for each patient - multiplied by 100 . The cumulative percentage of compliance was then computed for each patient for the first five years of follow-up or until death, if death occurred before the $5^{\text {th }}$ anniversary of entry.

The good compliers in the active drug group had a substantially lower five-year mortality than the poor compliers ( 15.0 vs $24.6 \%$ ). However, surprisingly, the placebo group yielded similar results: $15.1 \%$ mortality for good compliers vs $28.3 \%$ mortality for poor compliers.

The authors concluded that "these findings show the serious difficulty, if not impossibility, of evaluating treatment efficacy in subgroups determined by patient responses such as compliance" (CDP, 1980).

This publication has since then served as the standard literature reference that compliance data could not be used in statistical analyses since it is a variable that is assessed postrandomization, and, given the CDP re-analyses, it must be confounded by treatment-efficacy, side-effects or other factors under scrutiny.

There are 3 important arguments against the generalization of the conclusion of this article. The first, and perhaps strongest, is that the CDP was a secondary prevention trial, implying that all 
patients who were enrolled had evidence of at least 1 myocardial infarction prior to study entry. The drug studied in the CDP, clofibrate, is expected to have only a minor effect on mortality reduction, given the severe disease state that many of the enrolled patients had (reflected by the almost $21 \%$ mortality in the placebo group) (CDP, 1974). Most, if not almost all patients were treated with much stronger mortality decreasing drugs such as loop-diuretics, digitalis etc, regardless whether randomized in the treatment- or placebo-group. Since it is reasonable to assume that compliance on one drug reflects compliance on another drug (see, for example (Cramer et al, 1995)), it is likely that the reduction in mortality in the good compliers on placebo group actually reflects good compliance on other, powerful drugs as well.

The second argument against the conclusion is related to the fact that it makes pharmacologically no sense to divide patients in good or bad compliers based on an 'more or less then $80 \%$ of all drugs taken rule'. A good example is the comparison to another field of medicine where compliance is recognized as important when looking at efficacy of the drug, the oral anti-contraceptives. Timing errors alone (taking all prescribed doses but with variable intervals) can allow for breakthrough ovulation, and thus allow for pregnancy to occur despite $100 \%$ compliance (Guillebaud, 1993). This shows the inappropriateness of the use of artificial boundaries like more or less then $80 \%$ of all drugs taken.

Another strong argument against the use of dichotomous cut-offs is the possilbe emergence of resistant strains of the Human Immunodeficiency Virus (HIV) as a result of just one 5-day drug holiday for AZT (Vanhove et al, 1996). Again, any attempt to organize data in xx\% more or less groups is likely to fail if the appropriate mechanism of action and the pharmaco-kinetics and pharmaco-dynamics are not taken into account. Compliance should be defined with the relevant pharmacological aspects in mind, and it should preferably be treated as a continuous variable instead of being dichotomized.

The third argument against the validity of the conclusions of the CDP re-analyses concerns the vague measurement instrument for compliance. Presumably the measure consisted of a pillcount, though this is not described in detail in the original publication, and we know by now that pill-counts are not very accurate as a compliance measurement instrument (Pullar, Kumar, Tindall \& Feely, 1989).

Interestingly, Feinstein (1991) noted that the investigators failed to suitably investigate the most powerful "agent" noted in the study: compliance". Compliance on placebo yielded a large reduction in mortality and thus provided a major clue to prognostic susceptibility, but this was given no further attention.

Therefore, the conclusion of this article cannot be generalized beyond secondary prevention trials, and certainly not taken as proof that compliance data should never be used to explain drug effects. A comprehensive discussion of the 'smart' use of compliance data in the analyses of clinical trials can be found in Hasford (1991).

\section{Lipid Research Clinics Primary Prevention Trial.}

The Lipid Research Clinics Coronary Primary Prevention Trial (LRCPPT), also a very large randomized, placebo controlled double blinded mulitcenter trial to test the effectiveness of cholestyramine in reducing $\mathrm{CHD}$ in middle aged men with primary hypercholesterolemia 
(LRCPPT, 1984a, 1984b). Since there is a wellestablished relation between total cholesterol levels and the incidence of CHD on the one hand, known efficacy of cholestyramine resin on total cholesterol lowering on the other hand, and the possibility of an individualized tolerance for cholestyramine, the primary intention-to-treat analyses (LRCPPT, 1984a) were accompanied by an analyses of the relationship between cholesterol lowering and a reduction in incidence of CHD (LRCPPT, 1984b).

Compliance to the prescribed doses (six packets per day) was estimated for each participant at bimonthly visits by packet count. A Cox proportional hazards model was used to quantify the parameters relating changes in lipid levels to incidence of $\mathrm{CHD}$ in each treatment group.

The results (figure 1) showed: a patient who could tolerate the 6 packets (24 gram) of cholestyramine per day could expect a $49 \%$ reduction of $\mathrm{CHD}$ incidence, contrasting with the average, ITT based estimate of a reduction of $19 \%$ in CHD, influenced by the average tolerability of appr. 3.5 packets per day. Many patients could not tolerate the full dose and therefore had a lower reduction in risk of CHD, whereas those who could tolerate the full dose benefited from more then twice the reduction in risk for $\mathrm{CHD}$.

When looking at placebo compliance, reduction in lipid levels and reduction of CHD, the authors found no effect of the placebo group on either of these variables. Since this was a primary prevention trial, where one would expect little or no concomitant 'strong', non-trial drug use, these findings thus support the argument against the conclusions of the CDP-reanalyses discussed in the previous paragraphs.

Figure 1: compliance related reduction in $\mathrm{CHD}$ incidence

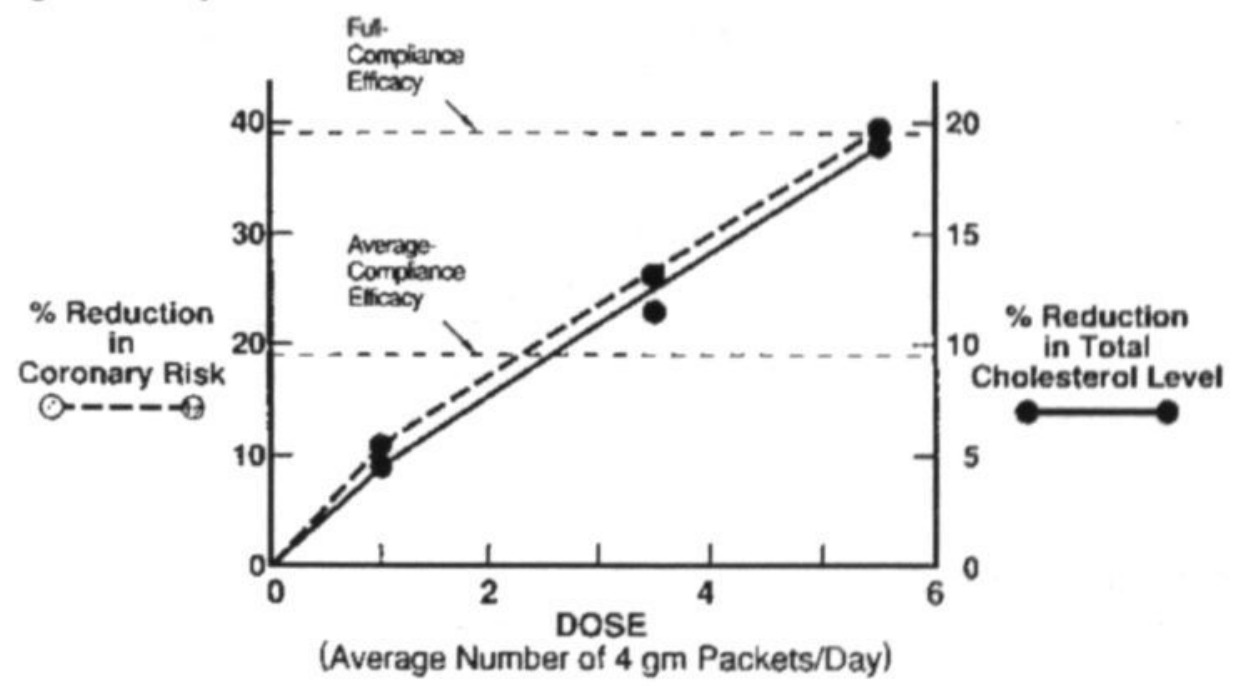

\section{3. the Leuven experience.}

Successful heart transplantation, one of the miracles of modern medicine, can only be successful if there is sufficient immunosuppression post-operation. This regimen, usually consisting of a combination of drugs among which corticosteroids and cyclosporine, has to be maintained lifelong. Unfortunately, to ensure sufficient action pharmacologic properties of cyclosporine require it to be taken every day, with no or almost no mistakes. The transplant 
team in Leuven, Belgium therefore decided to study compliance on cyclosporine in more detail (de Geest, 1996) in one-hundred and one transplant patients who were followed for an average duration of 90 days with an electronic monitoring system, described in detail below. Various compliance variables were recorded, all showing excellent compliance on group level: $99.4 \%$ of all tablets were taken, of which $98.8 \%$ on schedule. Seven of the eight rejection periods, however, were related to a few, but clinically relevant skipped doses. Compliance was therefore considered an important factor in the maintenance therapy post transplantation, and a reason to focus the management program in Leuven on optimization of patient compliance (de Geest, 1997).

It is noteworthy that the success of such a remarkable achievement of modern medicine almost completely depends on the daily act of taking a tablet at the correct moment.

\section{Compliance measurement and statistical analyses.}

The standard 'intention-to-treat analyses' (ITT), where all patients who were randomized are analyzed as having had a full treatment (thus including noncompliers, drop-outs and other protocol violations) in a trial where there is substantial variation in compliance is likely to generate a distorted estimate of both efficacy and safety of the drug. This distortion can in selected cases be both scientifically and ethically unacceptable (Feinstein, 1991; Lasagna and Hutt, 1991). Therefore, as Cox (1998) noted "The statistical challenge will be to develop methods of analysis that take due account of the complex character of compliance without analysis becoming too complicated conceptually.

Among the recent attempts to incorporate compliance data into statistical analyses is the award winning method on the recovery of the true dose-response curve from the compliance-response curves (Efron \& Feldman, 1991). Bayesian analyses lead to new estimates of the effect of receipt of treatment, and to new randomization based prodecures that yield more powerful results than those obtained by intention-to-treat analyses (Rubin, 1998). Markow chain, probability based simulation models provide accurate methods to predict compliance (de Klerk, van der Heijde, van der Linden \& Urquhart, 1997) and may lead to more effective population pharmacokinetic analyses (Girard, Sheiner, Kastrissios \& Blaschke, 1996), and highdimensional models enable comparisons of the full pattern of daily dosing indicators for subjects between groups (Vrijens \& Goetghebeur, 1997). A more extensive overview of progress in the statistical analyses of compliance data can be found in Goetghebeur \& Shapiro (1996). It is likely that this work will eventually lead to the incorporation of compliance data in the analyses of clinical trials in the future.

\section{A gold standard for compliance measurement?}

If one wants to measure patient compliance, it is wise to consider which measurement method is optimal for the given situation. The minimum requirements of a golden standard for compliance measurement would ask for (1) validity: proving ingestion of the medication and giving detailed overview of the timing of the ingestion; (2) reliability and sensitivity to change: stable results under stable compliance and differential results under variable compliance and (3) feasibility: the patient should not be aware of compliance measurement and should not be able to censor the results, the method should not be invasive nor require special equipment to collect and process that data, and the researcher / physician should always have access to the data. 
Unfortunately, no single instrument currently available has all these properties, and none is foreseeable. Therefore it is a good start to look at the instruments that are now available and describe them in terms of these requirements.

\section{Overview of assessment methods.}

It has become custom to distinguish patient compliance measurement instruments in "direct methods", those that prove that the drug reached the site of action and "indirect methods", those that do not prove ingestion. These measurement methods are summarized in table 1 , including their advantages and disadvantages.

\section{Patient interviews}

Patient interviews, although easy to perform, should be discarded as a scientific method for patient compliance. It is very easy for patients to censor the number of pills actually taken, and even with totally honest patient reports, the influence of poor memory is too large to be ignored. Note that the criticism only applies to scientific research, however. In every-day clinical practice, when patients admit non-compliance, it is of course good practice to inquire about potential barriers, and to offer practical advice to enhance compliance.

Table 1: Patient compliance measurement methods.

\begin{tabular}{|c|c|c|c|c|c|c|c|}
\hline Method ' & $\begin{array}{l}\text { Proves } \\
\text { ingestion of } \\
\text { medication }\end{array}$ & $\begin{array}{l}\text { Gives } \\
\text { detalied } \\
\text { overview on } \\
\text { fiming of } \\
\text { ingestion. }\end{array}$ & $\begin{array}{c}\text { Stable result } \\
\text { under stable } \\
\text { complance }\end{array}$ & $\begin{array}{l}\text { Diflerential } \\
\text { result under } \\
\text { variable } \\
\text { complance }\end{array}$ & $\begin{array}{l}\text { Patient is } \\
\text { aware of } \\
\text { compliance } \\
\text { measurement }\end{array}$ & $\begin{array}{l}\text { Invasive } \\
\text { method }\end{array}$ & $\begin{array}{l}\text { Masurement method } \\
\text { requires: }\end{array}$ \\
\hline 1. Interviews & no & No & yes & possible & yes & no & staff \\
\hline $\begin{array}{l}2 . \\
\text { Questionnaires }\end{array}$ & no & No & yes & possible & possible & no & questionnaire \\
\hline $\begin{array}{l}\text { 3. Diary } \\
\text { method }\end{array}$ & no & possible & yes & possible & yes & no & diary \\
\hline $\begin{array}{l}\text { 4. Physician } \\
\text { estimate }\end{array}$ & no & No & possible & possible & no & no & consultation \\
\hline $\begin{array}{l}\text { 5. Counting } \\
\text { retumed } \\
\text { medication }\end{array}$ & no & No & yes & possible & possible & no & consultation \\
\hline $\begin{array}{l}\text { 6. Electronic } \\
\text { monitoring }\end{array}$ & no & Yes & yes & yes & usually & no & electronic monitors \\
\hline $\begin{array}{l}7 . \\
\text { Concentration } \\
\text { measurement }\end{array}$ & Yes & No & possible & possible & possible & yes & $\begin{array}{l}\text { drawing blood / urine } \\
\text { sample and } \\
\text { laboratorium analyses }\end{array}$ \\
\hline $\begin{array}{l}\text { 8. Clinical } \\
\text { outcome }\end{array}$ & no & No & possible & possible & no & no & $\begin{array}{l}\text { Measurement of } \\
\text { clinical outcome }\end{array}$ \\
\hline $\begin{array}{l}\text { 9. Direct } \\
\text { observation }\end{array}$ & yes & Yes & yes & yes & Yes & no & staff, consultation \\
\hline $\begin{array}{l}\text { 10. Duration of } \\
\text { treatment }\end{array}$ & no & No & yes & possible & no & no & $\begin{array}{l}\text { datacollection of } \\
\text { prescriptions. }\end{array}$ \\
\hline
\end{tabular}

1: Description of the method can be found in the text. 
2. Questionnaires

Questionnaires designed to measure compliance and related issues such as barriers, beliefs, regimen-knowledge and other compliance influencing concepts can provide useful information. The advantages over interviews are: standardized questions for every patient, the possibility to validate the results against other compliance measurement methods such as chemical markers or electronic monitoring, and the possibility to do standardized across-group comparisons of the results. In addition, questionnaires are in general easy to administer, analyze and report from. The biggest disadvantage is of course the possibility that patients censor their report.

\section{Diary method}

Diary methods require consistent patient cooperation, especially when applied on a daily basis. Some technical aids, such as digital organizers that remind the patient when the diary has to be completed make the diary method probably a bit more reliable and valid. When applied frequently over a longer period the results can provide interesting data, and make it possible to relate self-report to clinical events. Beside this desirable property, the same advantages and disadvantages as questionnaires apply.

\section{Physician estimate}

Physicians' estimate of compliance of their patients, though a little better then a gamble, fail to provide accurate data. In one study testing physicians' ability to predict their patients' medication compliance after hospital discharge (Mushlin \& Appel, 1977), physicians at best accurately predicted $35 \%$ of the noncompliers and one half of their predictions were incorrect. Less than half of the physicians' predictions correctly discriminated between compliant and noncompliant patients and three fourths of their predictions of noncompliance were inaccurate. In this particular study the measure that was used to compare physicians' estimates was an extensive effort of the hospital staff to collect data on patients' maintenance of the schedule of return clinical visits, hand-counted medications given out at the hospital pharmacy, and routinely done pill-counts over a four-week period. The resulting data obviously lack both sensitivity and precision, and can therefore not be used as a scientific measurement instrument.

\section{Counting retumed tablets}

The so-called pill-counts have been used extensively as a routine compliance measure in clinical trials, and continue to be used, despite the widespread evidence that the data substantially over-estimate patient compliance (Pullar et al., 1989), (Waterhouse, Calzone, Mele \& Brenner, 1993). A consistant finding in these studies is that compliance reports as indicated by pill-counts are almost always higher then the reliable measures provided by low-dose phenobarbitone or electronic monitoring.

One study in which returned tablets were compared to phenobarbitone level-to-dose ratios concluded:"although return tablet count may seem attractive, simple, cheap and non-invasive, the findings of this analysis suggest that it is very inaccurate. Its continued use in clinical trials cannot be justified "(Pullar et al., 1989).

\section{Electronic Monitoring.}

Electronic monitors, i.e. normal pill-bottles fitted with a special cap that contains microelectronics designed to register time and date of every time the cap is opened have been developed for commercial use in the late1980's, and have since been widely used in many fields of medicine. Under the assumption that every opening reflects ingestion of the tablet this 
method has the advantage to give a unobtrusive, difficult to censor and very precise dosing history. In absence of better methods, this instrument is regarded as the golden standard by experts. The disadvantages are: the costs, compared to most other methods they are relatively expensive, the fact that they do not prove ingestion of the medication and the the requirement that the bottle has to be returned in order to get a read-out of the data.

\section{Direct methods}

\section{Measured concentrations of drugs in plasma}

Only a few drugs exhibit pharmaco-kinetic and pharmaco-dynamic properties that allow for a good estimation of compliance from their concentrations in plasma. This conclusion is based on the large intra and inter-patient variability between drug absorption, metabolism and excretion characteristics, and the relatively short half-life of many drugs (up to 24 hours) that do not allow accurate estimates of patient compliance over a longer period then a few days. In fact, some anecdotal evidence exists of patients in a clinical trial who only took a few doses immediately prior to the clinical visit (de Klerk, 1997) but who always maintained plasma levels in the lownormal range.

Several drugs and metabolites have been studied that, as markers, could overcome the above mentioned problems, e.g. phenobarbitone, digoxin, phenol red, disulfiram and others. Of these, only phenobarbitone has proved to be a valuable addition to the chemical markers arsenal.

\section{Other methods}

\section{Clinical outcome}

Some authors have suggested clinical outcome as a measure of compliance, starting at the notion that compliance determines (among others) plasma levels, and plasma levels determine (among others) clinical outcome. It has the attractive property of looking at the most significant parameter of compliance, but is not very precise, and offers hardly a useful concept to study compliance. Although clinical outcome as surrogate for compliance may be of some use in large epidemiological surveys, generally the complex interaction of the many factors relating to improved or deteriorating clinical condition renders this method of imited value as a stand-alone measurement of compliance (McGavock, 1996).

The interaction between various factors contributing to clinical outcome has been nicely described for theophylline (Harter \& Peck, 1991), a drug that was widely used in the treatment of asthma.

Figure 2 shows the cumulative effect of several known sources of variability in outcome of drug therapy based on data from experience with theophylline.

The percentages in the boxes are the relative contribution of various sources of variability to the cumulative total variability in clinical outcome, modeled as the $\%$ response. The drug formulation, the chemical substances that are necessary to deliver the drug in an ingestible form (chemical buffers, materials for the capsule, etc) contributes $20 \%$ to the overall variation.

Variations in compliance, with the addition of $50 \%$ to the overall variation in clinical outcome is together with the pharmacokinetic properties of the drug (the combined proces of absorption, distribution, metabolization and excretion of the drug in the body) the largest source of variation. Pharmacodynamic properties (drug-receptor interactions and intra- 
cellular mechanisms responsible for the clinical effect) contribute only $30 \%$ of the overal variation.

Figure 2: Sources of variability in drug response in the individual patient.

$\%$ Response

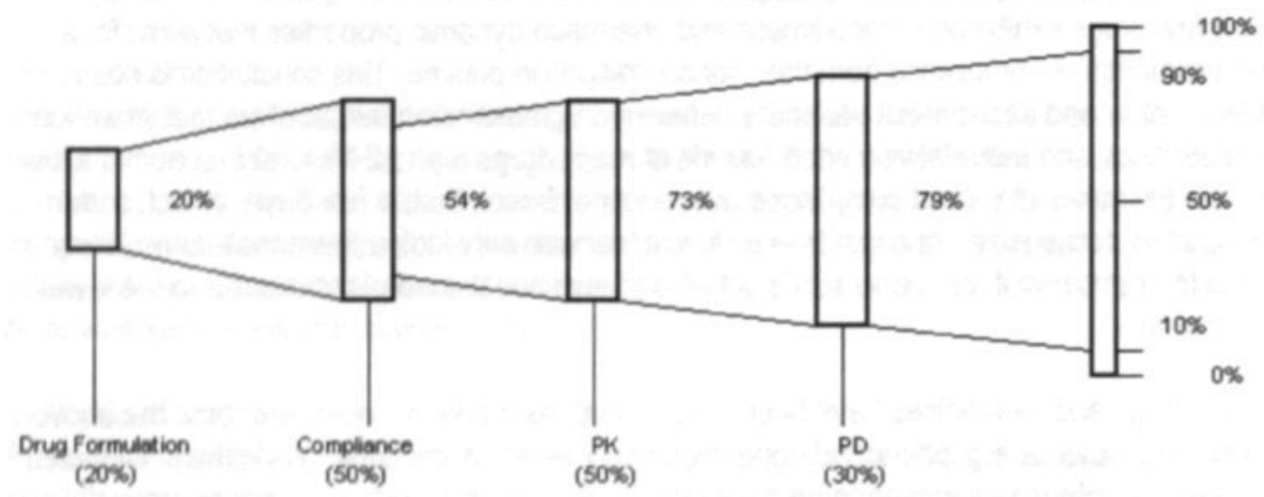

An important point that should be mentioned here was the notion that reducing variance due to minor sources resulted in a small impact on the overall variability. For example: elimination of the variance due to drug formulation (by giving the drug intravenously) reduces overall variability by only $2.19 \%$. Elimination of the variability of compliance (e.g. by directly observed therapy) would in this model result in a reduction of $17 \%$ of overall variability in clinical outcome (Harter \& Peck, 1991).

\section{Direct observation}

Direct observation of drug intake is a technique that has been developed in the United States to ensure long-term medication compliance with tuberculosis treatment. It is a cmbination of an intervention and a measurement instrument at the same time. A large retropspective analysis of all available data in one American city before and after directly observed therapy (DOT) was introduced showed that despite a higher prevalence of TBC in the population and a higher percentage of intravenous drug users and homeless among TBC patients, a rigorously executed DOT system reduced the primary resistance (13 to $6.7 \%$ ) and the acquired resistance from 14 to $2.1 \%$ compared to the period before DOT. This remarkable result was accomplished with the same hospital staff as before the DOT was started (Weis et al., 1994).

\section{Duration of treatment}

Some authors have suggested the use of the duration of treatment, for example as established in pharmacy-databases by counting the number of consecutive prescriptions as a measure of compliance (van Wanghe \& Dequeker, 1982). Although the data that are collected in this way do not comply with either of the above mentioned definitions, it is notable that drop-out of therapy is the ultimate form of non-compliance. However, the data can only be used to compare continuation of drug use between different kinds of drugs, not related to individuals, and therefore will not be considered as a compliance measurement instrument here. 


\section{Choosing the best compliance measurement instrument.}

It should be clear by now that the optimal compliance measurement instrument does not exist. Given the preceding discussion, however, it is possible to choose the instrument that fufills the desired criteria.

Some of the questions that should be asked are:

- What is the objective of measuring compliance (e.g. assuring that the drug is approximately ingested as prescribed, comparing compliance between two different formulations of the same drug, comparing 'forgiveness' for noncompliance between two drugs with the same actions but different PK and PD profiles, assessing the impact of a compliance intervention)?

- What is the desired level of precision of the instrument (is an average over a longer period of time sufficient, are exact interdose-intervals needed)?

- How important is it that ingestion is actually proven (if it is very important, then direct measurement instruments are the only choice, but fortunately many situations do not need the proof of ingestion per se)?

- How important is it that the patient is unaware of the compliance measurement (there is often a trade-off between having an unaware patient versus a lack of precision of the instrument such as the use of pharmacy databases and physician estimates)?

Some guidelines for choosing the optimal instrument:

The researcher who is focused on:

- Determining the impact of variable compliance on bulk pharmaceutical consumption will concentrate on the percentage of prescribed doses taken.

- Determining the adequacy of therapeutic response, or on distinguishing between pharmacological nonresponse and noncompliance, or on determining the limits of compliance needed for good outcome, will concentrate on dosing chronologies, long intervals between doses and the clinical events that occur in their wake.

- Predicting the likelihood of adverse reactions will concentrate on clusters of shortinterval dosing and on the occurrence of drug-holidays that may trigger adverse rebound or recurrent first-dose effects.

- The patients behavior and ways to improve compliance, or on minimizing the impact of persistent partial compliance, will concentrate on the chronology of dosing to see within-day patterns, e.g. morning-evening; to see between-day patterns, e.g. weekday-weekend and proximate-remote from scheduled visits, and to see changes with treatment duration.

- Modeling drug dosing behavior will concentrate on the probabilities of transition between correct and incorrect dosing.

modified from Urquhart, (1997)

Examples of application of compliance measurement instruments

With the preceding discussion on advantages and disadvantages of the various instruments in mind we will discuss three practical applications for compliance measurement choosen to cover a broad range of instruments: questionnaires, chemical markers and electronic monitoring. 


\section{Example 1: questionnaires}

Examples of well-designed questionnaires that were developed specifically for measuring patient compliance are the Long Term Medication Behavior Scale (LTMBS) (De Geest, et al, 1994), the Wisconsin Brief Medication Questionnaire (BMQ) (Svarstad, et al, 1996) and the Compliance Questionnaire Rheumatology (CQR) (de Klerk, 1997). Both the LTMBS and the BMQ were validated against electronic monitoring data, and will be discussed in detail below. The CQR will be validated against electronic monitoring data in the near future and is therefore not discussed in detail in the present chapter.

The development of the LTMBS questionnaire consisted of in-depth patient interviews targeted on the questions: (a) which knowledge and skills do you think are necessary in order to take your medication correctly? and (b) can you describe situations in which it is more difficult for you to take your medication correctly? The responses on the interviews were taped and transcribed, and qualitatively analyzed.

This approach yielded 13 themes, which were subsequently organized in Bandura's (1977) three dimensions: (1) personal attributes, (2) environmental factors, and (3) task-related and behavioral factors (table 2).

The 26 item LTMBS applies a 5 point Likert scale, and the total score is calculated by averaging the scores on all items so that higher scores reflect higher levels of selfefficacy, defined as the perception that one can master a certain task or perform adequately in a given situation. The internal consistency in one study with 150 renal transplant recipients, measured by Cronbach's alpha, was 0.88 (Geest, 1996).

The $B M Q$ is a 25 -item questionnaire that is divided into several sections assessing different types of compliance and patient perceived barriers to compliance. Item writing was based on the authors experience. Six sections, or 'screens' are distinguishable and are referred to as Dose-, Knowledge-, Outcome-, Recall-, Access- and Other Barriers screens. Svarstad et al (1996) used the BMQ to assess compliance in 98 patients on phosphate binders used in dialyses protocols, and validated it against electronic monitoring data.

Table 2: organization of the themes into dimensions of personal attributes in the LTMBS.

\begin{tabular}{lll}
\hline Personal attributes & Environmental factors & $\begin{array}{l}\text { Task-related and behavioral } \\
\text { factors }\end{array}$ \\
\hline - emotional distress & - routine & - medication aids \\
- perceived health scores & - distraction & - medication schedule \\
- normalcy & - cost of medication & - drug delivery system \\
- confidence in the physician & - social support & - knowledge \\
& & - side-effects.
\end{tabular}

From: De Geest et al., (1994)

The results showed that one in four patients took less then $20 \%$ of the prescribed doses, and of these 1 in 4 patients $80 \%$ were identified as noncompliers by the BMQ Dose Screen. The BMQ also clarified several potential (practical) barriers to non-compliance that can be starting points for intervention. In addition the authors found a significant negative association between compliance as measured by electronic monitoring and the BMQ Knowledge, Outcome, Recall and Access screens. 
The potential advantage of a measure like the BMQ is the applicability in any field of medicine, instead of being targeted to one specific field such as the LTMBS to transplant patients. The disadvantage is of course that specific aspects of therapy in a given field are not explored in detail, such as the discomfort of frequent toilet visits on diuretics, negative believes on the longterm effects of e.g. steroids and so on. If this is desirable, general measures like the BMQ may lack validity and sensitivity to change. In such situations, the investigators should develop medication specific modules to assess adequately such specific problems, analogous to the disease specific measures developed for quality of life

\section{Example 2: chemical markers}

A good example of what can be done with validated markers is the work of the group in Leeds (Feely et al, 1987) (Pullar et al, 1988, 1989) (Peaker et al, 1989). These investigators used lowdose phenobarbitone added to active drug to test the intake of these drugs. Phenobarbitone in a dose of $2 \mathrm{mg}$ had no pharmacological or clinical activity, has a long half-life (approximately 4 days) and there are very sensitive measurement methods that available to determine very low phenobarbitone plasma levels such as enhanced immuno-assays and HPLC (Peaker et al., 1989). The intra- and inter-patient variability is relatively low when age is taken into account. Therefore, low dose phenobarbitone, when added to another drug, reflects intake for a relatively long period ( 2 weeks), challenging the detection capabilities for the far majority of drugs currently in the market. This minimizes the sampling effect, the phenomenon that plasmalevels only reflect the drug intake during a very brief period prior to the taking of the blood sample.

One accomplishment of this method was revealing the great discrepancies between phenobarbitone data and pill-counts. Results of three studies were combined in one analysis: a study with 179 patients with type II diabetes mellitus given their usual drugs and in addition 2 $\mathrm{mg}$ phenobarbitone randomized to be taken once-, twice- or three times daily (Pullar et al, 1988), a study with 26 rheumatoid arthritis patients who had inadequate therapeutic response despite high-dose penicillamine (Pullar et al, 1988), and a study with 20 poorly controlled type II diabetes mellitus receiving glibenclamide (Feely et al, 1989). All patients were given an excess of pills to allow for detection of pill-dumping. Pill counts and levelto-dose ratio's were compared, and the results are described in table 3.

Table 3: Comparison of pill-counts and phenobarbitone level to dose ratios.

\begin{tabular}{|c|c|c|c|c|c|c|}
\hline & \multicolumn{5}{|c|}{ Compliance by pill-count } & \multirow{2}{*}{$\begin{array}{l}\text { failed to } \\
\text { retum } \\
\text { containe }\end{array}$} \\
\hline & $<30 \%$ & $30-59 \%$ & $60-89 \%$ & $90-109 \%$ & $>110 \%$ & \\
\hline PB LDR & & & & & & \\
\hline$<30 \%$ & 1 & 4 & 1 & 2 & 1 & 0 \\
\hline $30-59 \%$ & 0 & 6 & 8 & 9 & 0 & 2 \\
\hline $60-89 \%$ & 0 & 0 & 9 & 66 & 5 & 4 \\
\hline $90 \%$ or more & 0 & 0 & 4 & 84 & 4 & 6 \\
\hline
\end{tabular}

From: Pullar et al. (1989)

From this table it becomes clear that pill-counts tend to overestimate compliance compared to the marker data. It is also clear that the phenobarbitone method is capable of detecting "pilldumping". In fact, the authors were so convinced by these results that they concluded that "return tablet count grossly overestimates compliance". 


\section{Example 3: electronic monitoring}

One particularly well worked out example of a study with electronic monitoring data was a randomized, double blinded phase III study to compare the efficacy and effectiveness of once daily $20 \mathrm{mg}$ piroxicam vs once daily $20 \mathrm{mg}$ tenoxicam in ankylosing spondylitis, a painful inflammatory disorder of predominantly the spine (de Klerk \& van der Linden, 1996). Sixty-five patients were followed for an average duration of 225 with electronic monitoring. Analysis of the clinical results showed that both drugs performed equally with respect to efficacy and safety. The initial summary of compliance data are shown in table 4.

Table 4: Example of compliance data gathered with EM.

\begin{tabular}{lc}
\hline & All patients $(n=65)$ \\
\hline Days monitored & 14.607 \\
$\%$ days on which at least one dose taken & $81 \%$ \\
$\%$ days on which dose taken as prescribed & $78 \%$ \\
$\%$ days with extra doses & $3 \%$ \\
$\%$ days with missed doses & $19 \%$ \\
\hline
\end{tabular}

From: de Klerk \& van der Linden, (1996).

A subsequent effort to capture the wide variability of compliance in that trial resulted in a table summarizing both frequency and duration of drug holidays (table 5). The columns in the table reflect some basic patient identifiers, followed by the frequency of dosing omissions in drug holidays of variable length: 1-10 days, and the frequency of longer holidays. All data for individuals are shown, and the patients are rank-ordered by percentage of days in which the prescnied number or arugs were taken (faveled 'compilance f: ro emprlasize ifle amount or' variation in the table, a fictitious 'average complier' was added to the table.

The diversity of drug exposure revealed by electronic monitoring data when arranged in this format is astonishing. It captures not only the wide variability of compliance over the whole group (from almost 0 to $100 \%$ when measured as number of drugs taken correct), but also shows that patients in the lower regions of the table not only have longer holidays, but also more frequent shorter holidays.

Given the long measurement period (average 225 days) another natural question arises: can these patients be identified at an early stage during trial planning, such as a run-in period, and either be excluded or stratified (depending on trial goals and strategy) ? No specific answers to this question exist yet, but projects are under way to explore this important issue. 
Figure 3: frequency histogram of the percentages prescribed doses taken by three groups of patients with different diseases.

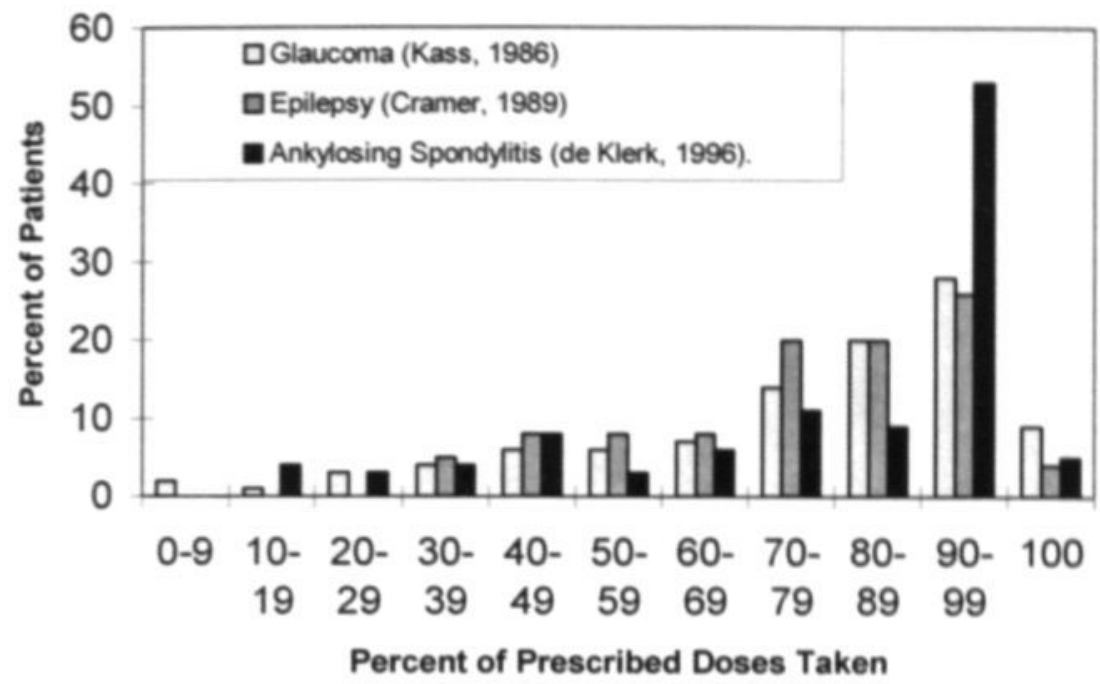

A perhaps surprising finding with the spreading use of electronic monitoring is the similarity of compliance distribution in various fields of medicine, and between very different drugs. Figure 3 is one such example, being a histogram showing the distribution of patient compliance in bands of $10 \%$ for NSAIDs in ankylosing spondylitis (de Klerk \& van der Linden, 1996), B-blocker eyedrops for open angle glaucoma (Kass et al, 1987) and anti-epileptic medication for epilepsy (Cramer et al, 1989).

Though there seems to be a small difference between the distribution in the high region, all three studies show a wide distribution of compliance in the middle and lower regions, with a substantial similarity in the distribution. Note, however, that these are three entirely different diseases in terms of symptoms and medication, expectation of the therapy, and typical age distribution of the patients. 


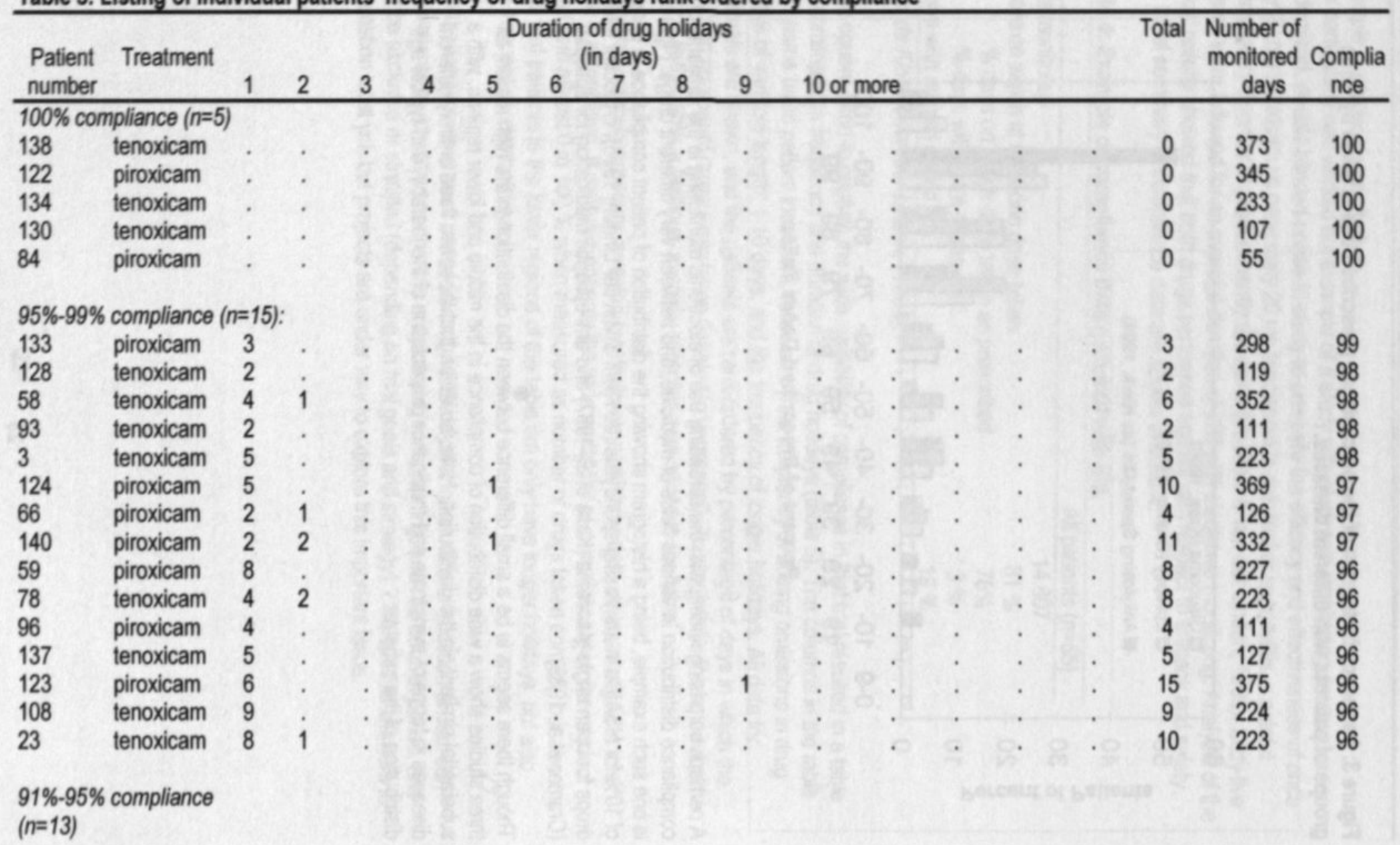


Measurement of Patient Complinge

$\begin{array}{llcl}94 & \text { tenoxicam } & 3 \\ 51 & \text { piroxicam } & 10 \\ 139 & \text { piroxicam } & 2 & \\ 68 & \text { tenoxicam } & 7 & 2 \\ 1 & \text { piroxicam } & 5 & \\ 6 & \text { tenoxicam } & 1 & 1 \\ 45 & \text { piroxicam } & 10 & 2 \\ 104 & \text { piroxicam } & 7 & 1 \\ 90 & \text { piroxicam } & 9 & 1 \\ 116 & \text { piroxicam } & 13 & 2 \\ 129 & \text { piroxicam } & 9 & 1 \\ 97 & \text { tenoxicam } & 16 & 1 \\ 14 & \text { tenoxicam } & 17 & \end{array}$

$\begin{array}{ccc}5 & 111 & 95 \\ 17 & 372 & 95 \\ 17 & 345 & 95 \\ 11 & 223 & 95 \\ 12 & 223 & 95 \\ 3 & 55 & 95 \\ 14 & 223 & 94 \\ 24 & 357 & 93 \\ 11 & 158 & 93 \\ 17 & 216 & 92 \\ 17 & 215 & 92 \\ 18 & 213 & 92 \\ 21 & 223 & 91\end{array}$

80\%-90\% compliance $(n=9)$ :

$\begin{array}{llll}67 & \text { tenoxicam } & 17 & 2 \\ 12 & \text { piroxicam } & 13 & \\ 25 & \text { piroxicam } & 14 & 3 \\ 87 & \text { tenoxicam } & 8 & 2 \\ 39 & \text { piroxicam } & 23 & 2 \\ 28 & \text { tenoxicam } & 11 & 1 \\ 88 & \text { tenoxicam } & 29 & 3 \\ 105 & \text { piroxicam } & 11 & 2 \\ 111 & \text { tenoxicam } & 17 & 4\end{array}$

$60 \%-80 \%$ compliance ( $n=11)$ :

$\begin{array}{llccc}\text { average patient } & 12 & 3 & \\ 91 & \text { piroxicam } & 31 & 8 & \\ 46 & \text { piroxicam } & 9 & & \\ 135 & \text { piroxicam } & 36 & 8 & 3\end{array}$

piroxicam 
Measumement of Patient Compliance

\begin{tabular}{|c|c|c|c|c|c|c|c|c|c|c|c|c|c|c|c|c|c|c|}
\hline 18 & piroxicam & 35 & 6 & . & 1 & 1 & . & - & . & & . & . & . & - & . & 56 & 223 & 75 \\
\hline 43 & tenoxicam & 31 & 2 & 4 & 1 & 1 & . & . & . & . & . & . & . & . & . & 56 & 223 & 75 \\
\hline 103 & tenoxicam & 9 & 2 & 2 & 1 & . & . & 1 & . & . & . & . & . & . & . & 30 & 111 & 73 \\
\hline 60 & tenoxicam & 42 & 7 & 3 & . & . & ${ }^{\circ}$ & ${ }^{\circ}$ & . & n & & & . & . & . & 65 & 229 & 72 \\
\hline 24 & piroxicam & 13 & 3 & 1 & . & . & . & . & . & . & 30 & . & . & . & . & 52 & 167 & 69 \\
\hline 126 & piroxicam & 42 & 15 & 6 & 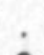 & 1 & . & . & . & . & 13 & 19 & . & . & . & 127 & 379 & 66 \\
\hline 114 & piroxicam & 26 & 2 & 2 & 2 & 1 & . & . & . & . & 31 & $\therefore$ & . & . & . & 80 & 216 & 63 \\
\hline 19 & piroxicam & 11 & 4 & 1 & . & . & . & . & . & . & 14 & 27 & . & . & . & 63 & 169 & 63 \\
\hline \multicolumn{18}{|c|}{$0 \%-60 \%$ compliance ( $n=11)$} & \\
\hline 57 & tenoxicam & 8 & 2 & 1 & 2 & 2 & 1 & . & . & . & 10 & 13 & 13 & 37 & . & 112 & 245 & 54 \\
\hline 95 & tenoxicam & 22 & 4 & 3 & 1 & . & . & 1 & 1 & . & 13 & 33 & . & . & . & 104 & 227 & 54 \\
\hline 7 & tenoxicam & 27 & 13 & 1 & 7 & 2 & . & 2 & . & 1 & . & . & . & . & . & 117 & 223 & 48 \\
\hline 121 & tenoxicam & 28 & 6 & 5 & 1 & 4 & 7 & 3 & . & . & 10 & 12 & 14 & 39 & . & 217 & 372 & 42 \\
\hline 42 & piroxicam & 18 & 8 & 4 & 7 & 1 & 6 & 1 & . & . & 10 & . & . & . & . & 132 & 225 & 41 \\
\hline 102 & piroxicam & 11 & 6 & 4 & . & 1 & 2 & 1 & 1 & 1 & 10 & 27 & . & . & . & 113 & 191 & 41 \\
\hline 131 & tenoxicam & 20 & 11 & 3 & 5 & . & 1 & . & . & 1 & 15 & 19 & 25 & 33 & 52 & 230 & 350 & 34 \\
\hline 9 & piroxicam & 6 & 5 & 2 & 4 & 2 & . & . & 1 & . & 12 & 13 & . & . & . & 81 & 122 & 34 \\
\hline 83 & tenoxicam & 11 & 3 & 2 & 1 & . & 2 & . & . & . & 12 & 111 & . & . & . & 162 & 222 & 27 \\
\hline 106 & piroxicam & 5 & 8 & 3 & $\theta^{*}$ & . & . & ${ }^{\circ}$ & . & . & 24 & 29 & . & . & . & 83 & 111 & 25 \\
\hline 4 & piroxicam & 2 & 1 & . & 1 & . & ${ }^{\circ}$ & . & . & . & 12 & 82 & . & . & . & 102 & 126 & 19 \\
\hline 32 & tenoxicam & 1 & 2 & . & . & . & 1 & . & . & . & 16 & 31 & 37 & . & . & 95 & 105 & 10 \\
\hline
\end{tabular}




\section{Conclusion}

This chapter has reviewed several aspects related to the measurement of patient compliance on drug regimen. Measurement of patient compliance in clinical trials has long been ignored, following the re-analyses of the Coronary Drug Project. However, it is now clear that the findings of this trial were not conclusive, and subsequent research has shown the great importance of accurate compliance measurement for drawing adequate results.

No gold standard for compliance measurement exists, and none is foreseeable. Therefore the advantages and disadvantages of 10 different measurement methods are discussed, and the objective of compliance measurement is emphasized. It is possible to combine instruments and tailor them to specific research questions.

Three examples of studies utilizing the various methods to their advantage are discussed, and several important aspects of the methods are described. This overview can serve as a starting point for the development of compliance-focussed research questions.

\section{Acknowledgment}

The author is indepted to John Urquhart for introducing him to the various aspects of patient compliance and for many cheerful discussions on the subject and the useful comments on the content of this chapter. In addition, the author would like to thank Désirée van der Heijde and Sjef van der Linden for reviewing the chapter. This work was completed under a grant from the Dutch Rheumatism Foundation.

\section{References}

Bandura A, Ne, A. (1977) Analysis of selfefficacy theory of behavioral change. Cognitive Therapy Research, 1. 287310.

CDP Group. (1973). The Coronary Drug Project: design, methods, and baseline results. Circulation, 478 Suppl1, 1. 179.

CDP Group. (1974). Clofibrate and niacin in coronary heart disease. Joumal of Chronic Diseases, 27, 267-285.

CDP, (1980). Influence of adherence to treatment and response of cholesterol on mortality in the coronary drug project. New England Joumal of Medicine, 303(18), 1038-1041.

Cox, D. R. (1998). Analyzing non-compliance in clinical trials. Invited discussion. Statistics in Medicine, 387-389.

Cramer, J., Vachon, L., Desforges, C., \& Sussman, N. M. (1995). Dose frequency and dose interval compliance with multiple antiepileptic medications during a controlled clinical trial. Epilepsia, 36(11), 1111-1117

Cramer, J. A., Mattson, R. H., Prevey, M. L., Scheyer, R. D., \& Ouellette, V.L. (1989). How often is medication taken as prescribed? A novel assessment technique. Journal of American Medial Association, 261(22), 3273-3277

de Geest, (1997). Personal communication with dr S. de Geest, department of public health, University of Leuven,

Belgium.

de Geest, S., Abraham, L., Gemoets, H., \& Evers, G. (1994). Development of the long-term medication behaviour selfefficacy scale: qualitative study for item development. Joumal of Advanced Nursing, 19(2), 233-238

de Geest, S. (1996). Subclinical noncompliance with immunosuppresive therapy in heart transplant recipients, a

cluster analytic study. Doctorate thesis, Katholieke Universiteit Leuven, Leuven, Belgium.

de Klerk, E. (1997). Patient compliance in hypertension. CardioTopics, 7-21.

de Klerk, E., van der Heijde, D., \& van der Linden, S. (1997). Development of a measure for exploring variable patient compliance. Arthritis and Rheumatism 40, S114.

de Klerk, E., van der Heijde, D., van der Linden, S., \& Urquhart, J. (1997, ).A Simple vet effective patient compliance simulation model. Paper presented at the Modeling and Simulation of Clinical Trials and Drug Development Congres, Washington DC, USA.

de Klerk, E., \& van der Linden, S. J. (1996). Compliance monitoring of NSAID drug therapy in ankylosing spondylitis, experiences with an electronic monitoring device. British Joumal Rheumatology, 35(1), $60-65$

Dolan-Mullen, P. (1997). Compliance becomes concordance. British Medical Joumal, 314, 691-692.

Efron, B., \& Feldman, D. (1991). Compliance as an explanatory variable in clinical trials. Joumal of the American Statistical Association., 86(413), 9-26.

Feely, M., Cooke, J., Price, D., Singleton, S., Mehta, A., Bradford, L., \& Calvert, R. (1987). Lowdose phenobarbitone as an indicator of compliance with drug therapy. British Journal of Clinical Pharmacology, 24(1), 77-83 
Feely, M., Price, D., Bodansky, H. J., \& Tindall, H. (1989). Use of a pharmacologic indicator to assess compliance with drug therapy in patients with poorly-controlled type II diabetes. British Journal of Clinical Pharmacology, 27, 101P. $102 \mathrm{P}$.

Feinstein, A. R. (1990). On white-coat effects and the electronic monitoring of compliance. Archives of Internal edicine, $150(7), 1377-1378$

Feinstein, A. R. (1991). Intent-to-treat policy for analyzing randomized trials. Statistical distortions and neglegcted clinical challenges. In J. A. Cramer \& B. Spilker (Eds.), Patient compliance in medical practice and clinical trials. (pp. 359-370). New York.: Raven Press Lidd.

Girard, P., Sheiner, L. B., Kastrissios, H., \& Blaschike, T. F. (1996). Do we need full compliance data for population pharmacokinetic analysis? Journal of Pharmacokitics and Biopharmaceutics, 24(3), 265-281.

Goetghebeur, E. J., \& Shapiro, S. H. (1996). Analysing non-compliance in clinical trials: ethical imperative or mission impossible? Statistics in Medicine, 15(24), 2813-2826

Guillebaud, J. (1993). Any questions ? British Medical Journal, $307,617$.

Harter, J. G., \& Peck, C. C. (1991). Chronobiology. Suggestions for integrating it into drug development. Annals of the New York Academia of Science, $618,563-571$

Hasford, J. (1991). Biometric issues in measuring and analyzing partial compliance in clinical trials. In J. A. Cramer \& B. Spilker (Eds.), Patient compliance in medical practice and clinical trials. (pp. 265-281). New York: Raven Press Ltd. Hippocrates. Decorum (ca 400 BC).

Joyce, C. R. B. (1962). Patient cooperation and the sensitivity of clinical trials. Joumal of Chronic Diseases, 151025 1036.

Kass, M. A., Gordon, M., Morley, R. E., Jr., Meltzer, D. W., \& Goldberg, J. J. (1987). Compliance with topical timolol treatment. American Joumal of Ophthaimology 103(2), 188-193

Lasagna, L., \& Hutt, P.B. (1991). Health care, research and regulatory impact of noncompliance. InJ. A. Cramer \& B. Spilker (Eds.), Patient compliance in medical practice and clinical trials. (pp. 393-403). New York: Raven Press Ltd.

LRCPPT, (1984a). The Lipid Research Clinics Coronary Primary Prevention Trial results. I. Reduction in incidence of coronary heart disease. Joumal of the American Medical Association, 251(3), 351-364

LRCPPT, (1984b). The Lipid Research Clinics Coronary Primary Prevention Trial results. II. The relationship of reduction in incidence of coronary heart disease to cholesterol lowering. Journal of the American Medical Association. 251(3), 365-374

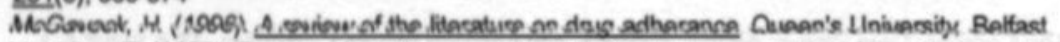
Moulding, T. (1962). Proposal for a time recording pill dispenser as a method for studying and supervising the selfadministration of drugs. American Review of Respiratory Disorders, 85, 754-757.

Mushlin, A. I., \& Appel, F. A. (1977). Diagnosing potential noncompliance. Physicians' ability in a behavioral dimension of medical care. Archives of Intemal Medicine, 137(3), 318-321

Peaker, S., Mehta, A. C., Kumar, S., \& Feely, M. (1989). Measurement of low (sub-therapeutic) phenobarbitone levels in plasma by high-performance liquid chromatography. application to patient compliance studies. Joumal of Chromatography, 497, 308-312

Pullar, T., Birtwell, A. J., Wiles, P. G., Hay, A., \& Feely, M. P. (1988). Use of a pharmacologic indicator to compare compliance with tablets prescribed to be taken once, twice, or three times daily. Clin Pharmacol Ther, 44(5), 540-545 Pullar, T., Kumar, S., Tindall, H., \& Feely, M. (1989). Time to stop counting the tablets? Clinical Pharmacololy and Therapeutics, 46(2), 163-168

Pullar, T., Peaker, S., Martin, M. F., Bird, H. A., \& Feely, M. P. (1988). The use of a phamacological indicator to investigate compliance in patients with a poor response to antirheumatic therapy. British Joumal of Rheumatology 27(5), 381-384

Rubin, D. B. (1998). More powerful randomization-based p-values in double-blind trials with non-compliance. Statistics in Medicine, 17,251-267.

Sackett, D. L., \& Haynes, R. B. (1976). Compliance with therapeutic regimens. Baltimore and London: Johns Hopkins University Press.

Svarstad, B. L., Braun-Curtin, R., \& Andress, D. (1996). Assessing barriers to patient adherance with difficult drug regimens: a new screening technique. (submitted).

Urquhart, J. (1997). The electronic medication event monitor - lessons for pharmacotherapy. Clinical Pharmacokinetics, $32,345-356$.

Urquhart, J., \& Chevalley, C. (1988). Impact of unrecognized dosing errors on the cost and effectiveness of pharmaceuticals. Drug Information Journal, 22, 363-378.

van Wanghe, P., \& Dequeker, J. (1982). Compliance and long-term effect of azathioprine in 65 ineumatoid arthritis cases. Annals of Rheumatic Disorders, 41 Suppl 1, 40-43

Vanhove, G. F., Schapiro, J. M., Winters, M. A., Merigan, T. C., \& Blaschke, T. F. (1996). Patient compliance and drug fallure in protease inhibitor monotherapy. Joumal of the Americam Medical Association, 276(24), 1955-1956 
Vhijens, B., \& Goetghebeur, E. (1997). Comparing compliance pattems between randomized treatments. Controlled Clinical Trials, 18, 187-203.

Waterhouse, D. M. Calzone, K. A., Mele, C., \& Brenner, D. E. (1993). Adherence to oral tamoxifen: a comparison of patient self-report, pill counts, and microelectronic monitoring. Joumal of Clinical Oncology, 11(6), 1189-1197 Weis, S. E., Slocum, P. C., Blais, F. X., King, B., Nunn, M., Matney, G. B., Gomez, E., \& Foresman, B. H. (1994). The effect of directly observed therapy on the rates of drug resistance and relapse in tuberculosis. New England Joumal of Medicine, 330(17), 1179-1184. 



\title{
Contending Paradigms for the Interpretation Of Data On Patient Compliance With Therapeutic Drug Regimens John Urquhart', Erik de Klerk²
}

\author{
1 Department of Epidemiology, Maastricht University, Maastricht, The Netherlands \\ ${ }^{2}$ Division of Rheumatology, Department of Internal Medicine, Academisch Ziekenhuis \\ Maastricht, Maastricht, The Netherlands
}

Manuscript published as: Urquhart J, de Klerk E. Contending paradigms for the interpretation of data on patient compliance with therapeutic drug regimens. Statistics in Medicine 1998;17: 251267.

\begin{abstract}
Electronic and chemical marker methods provide the first reliable measurements of drug exposure in ambulatory trials. These data contradict the usual claim in published drug trials of $>90 \%$ of patients having been satisfactorily compliant with the protocolspecified dosing regimen. Such exaggerated claims are based, usually, on count of returned dosing forms, which afford patients easy ability to manipulate by discarding or hoarding untaken doses.

Electronic monitoring provides, for the first time, data on intervals between doses, revealing the 'drug holiday' - 3 or more consecutive days without dosing - as a basis not only for lapsed therapeutic action, but as a pharmacodynamic trigger for hazardous rebound effects on recurrent first dose effects. Another new finding is the evident non-specificity of poor or partial compliance, the range and distributions of which appear to be hardly affected by drug, disease, prognosis, or symptoms. This finding contradicts often repeated but unsupported claims that noncompliance is a specific response to drug action, disease, prognosis or other treatmentrelated factors. New statistical methods are needed for trial design and analysis, to use drug exposure data as covariate information, to incorporate into drug labeling estimates of doserelated efficacy, holiday-related hazard, the limits of safe variation in dose-timing, and what one should best do when those limits are exceeded. Oral contraceptive labeling in the U.K. and U.S. is exemplar for this next step toward full-disclosure labeling.
\end{abstract}

\section{Introduction}

Any protocol-defined procedure has multiple modes of potential non-compliance, so there are many dimensions to the topic 'non-compliance in randomized controlled trials'. Other papers at the Limburg University symposium focused on non-compliance with various aspects of trial protocols; our focus is on non-compliance with prescribed regimens of drug administration. New methods for recording dosing histories in ambulatory patients have shown that patients noncompliance with prescribed regimens for drug administration is not dichotomous, but includes a wide spectrum of deviations from a specified regimen of drug intake during trials - mainly variations in intervals between doses, resulting in widely variable exposure to the drug. These have more or less predictable pharmacologic consequences.

Variable compliance with drug regimens has long been thought of as primarily a behavioral phenomenon: "Why do patients not take their medicines as they are supposed to? . Data from 
the new methods have catalyzed interest in the pharmacologic and therapeutic consequences of these various dosing patterns, creating one of the changes in paradigm referred to in the title. Understanding the pharmacologic and therapeutic consequences of variable exposure to a drug is basic to projecting and interpreting its medical and economic consequences.

Thus, the availability of data on ambulatory patients' ongoing dosing patterns makes possible a much richer pharmacologic and therapeutic interpretation than previously possible of events occurring in both trials and practice. Though its surface has barely been scratched, this capability has the potential to give scientific interpretation to otherwise empirical happenings, and to find rational explanations for adverse events in terms of specific pharmacodynamic triggers, particularly sudden cessation of dosing, variably long intervals between doses, and sudden resumption of fult-strength dosing, as illustrated with specific examples we describe later. Information about these pharmacodynamic triggers can, in turn, be the basis for improvement - drug delivery systems, better-designed regimens, molecular redesign, better information for prescribers and patients, and other means to achieve desired therapeutic actions with less risk.

Sound methods of measurement and observation are basic to progress in any scientific or medical field. The study of patient compliance as a determinant of drug exposure in ambulatory care had long been stymied by methods that made it easy for patients to censor evidence for delayed or omitted doses. The new methods make such censoring difficult, and reveal that delayed and omitted doses are much more common than previously believed.

\section{PHAKMALOL'URL ASPECTS}

Three basics are: (a) the drug's therapeutic actions in patients are the subject of most drug trials; (b) the time course of action of any drug depends on the size and timing of doses, the details of which differ from one drug to another; (c) the most common types of non-compliance involve longer than prescribed intervals between doses of the prescribed size.

During the interval between doses, drug actions typically rise to a peak and then commence to fall, until the next dose initiates a repeat cycle of waxing/waning actions. Recommended intervals are typically set to prevent drug actions from declining too far, in the interest of maintaining action above some minimum level. When drug actions are difficult to assess, the interdose waxing/waning of the concentration of drug in plasma is used as a surrogate to set the recommended interval between doses. When a scheduled dose is delayed, drug concentration and actions continue to decline, and, if the delay is long enough, they fade altogether, thus creating a gap in the drug's actions that will continue until dosing resumes. The consequences can range from trivial to catastrophic, for they depend on drug, disease and its severity, and the extent and severity of co-morbidity.

Drugs typically have multiple actions, some of which are therapeutically desirable, others not; thus, waxing and waning of drug actions within variably long intervals between doses has implications for both therapeutic and unwanted actions. 


\section{Rebound effects}

A further pharmacologic complexity exists with some drugs. The sudden cessation of dosing is a trigger for what are called 'rebound effects'. These are modes of drugs action that may differ qualitatively from the drug's usual therapeutic and side actions, and may be hazardous.

Rebound effects appear to have their origin in physiological counter-regulatory responses to the primary actions of the drug. Counter-regulatory responses, in tum, have their own characteristic dynamics, and may be relatively slow to develop during a course of drug treatment, and be masked by the ongoing actions of correctly administered drugs. Rebound effects appear, however, when dosing suddenly halts and drug action fades, leaving counter-regulatory effects unopposed until dosing resumes or the counter-regulatory responses fade, so the situation may persist for days or weeks. Some rebound effects are hazardous, and, in effect, represent a form of drug toxicity resulting from underdosing.

An example is the increase in beta-adrenergic receptor sensitivity to catecholamines (epinephrine, norepinephrine) that occurs during treatment with betaradrenergic blocking agents of the class that lacks intrinsic sympathomimetic actions (ISA) - so-called 'non-ISA' beta blockers ${ }^{1}$. These include the most widely used ones - propranolol, metoprolol and atenolol. The receptor increase occurs gradually over a period of several weeks. If beta-blocker administration is suddenly stopped, drug levels and beta blocking actions decline and are essentially gone within several days, but the receptors decline very slowly, taking several weeks to return to their pre-treatment baseline. During that period, the actions of physiologically secreted or exogenously administered catecholamines (epinephrine and nor-epinephrine) are exaggerated, 1 some of which are potentially hazardous, leading to high heart rates, surges in blood pressure in excess of pre-treatment values, increased aggregability of platelets, and increased risk of incident coronary artery disease ${ }^{2,3}$.

These principles have been recognized for some years, and all non-ISA beta-blockers contain label warnings against sudden discontinuation of dosing. New in this story is recognition of the incidence of multiday lapses in dosing, called 'drug holidays', that recur more or less monthly in one patient in about six, and occur occasionally in an additional one patient in about six ${ }^{4}$ - big enough minorities so that holiday-related risk can, if large enough, determine the outcome of a trial, as projected in Table 1.

Not all drugs have rebound effects; whether they do or not is an issue largely ignored in drug development, because the frequency with which patients temporarily halt their intake of drug has not yet been fully appreciated. Lasagna recently summarized the situation as follows:

'With some drugs, irregular dosing may lead to withdrawal or rebound phenomena. In the past I have often told students and physicians that a patient's condition would not improve if they failed to take a medication as prescribed, nor would they be harmed by the absence of the drug (except in the sense that no therapeutic benefit would result). It is now known, however, that with certain drugs, rebound phenomena occur when treatment is withdrawn, increasing the risk for exacerbation of the condition being treated or for some other untoward event. Although reports of rebound phenomena have focused primarily on drugs that act on the central nervous system (opiate-withdrawal syndrome), the effect is also seen in cardiovascular disease. Some examples are rebound hypertension, rebound coronary insufficiency, and exacerbation of arrhythmias' 5 . 


\section{Recurrent first-dose effects}

The drug holiday contains an additional pharmacodynamic trigger for hazardous effects of some drugs. These are agents that have so-called 'first-dose effects', in that their dosing must begin at relatively low levels and can be only gradually adjusted upwards to reach doses required for full therapeutic effect - so-called 'initial dose-titration'.

\section{Table 1. Hypothetical data to illustrate how a high-risk, holiday-induced adverse effect} can influence the outcome of a trial of a medicine that is beneficial when taken correctly.

\begin{tabular}{lcc}
\hline Compliance & Relative risk of death* & Percent of group \\
\hline Punctual & 0.5 & 30 \\
Slightly erratic & 1.0 & 30 \\
Occasional holidays & 2.0 & 20 \\
Monthly holidays & 6.0 & 20 \\
\hline & & \\
Average & 2.0 & 100 \\
\hline
\end{tabular}

* Relative to corresponding subgroups/groups of placebo recipients

All-patient average: The drug is bad for everyone

Compliance-stratification: Correctly-taken drug reduces risk. Holidays are very hazardous

With reformulation/regimen change label wamings: Satisfactory benefit / risk?

If the dose is increased too rapidly, drug-specific manifestations of toxicity appear. Examples of drugs that need initial dose-titration are peripheral vasodilators (for example, nifedipine and prazosin) and some cardiac antiarrhythmic drugs (for example, flecainide, encainide). Now that we know about the frequency of drug holidays, and their recurrence in a small but distinct minority of patients, it is logical to ask: how long a lapse in dosing is required to restore the need for initial dose-titration? If patients unwittingly allow dosing to lapse for some days and then resume dosing at the usual, full-strength level - which seems to be the usual situation ought we not to expect signs of toxicity? This question is unanswered, for the entire topic is a blank slate in clinical pharmacology. One would expect to observe the temporal sequence of drug holiday followed by signs of toxicity in drugs with first-dose effects.

\section{NEW METHODS FOR MEASURING DRUG EXPOSURE IN AMBULATORY PATIENTS}

The new methods are the low-dose slow-turnover chemical markers (phenobarbital and digoxin), and electronic monitoring applied to various types of packages. These methods are not perfect, for reasons noted below, but to create a false record of good compliance with them requires exceptional and sustained commitment. A strong consensus supports the view that they give a substantially accurate picture of drug exposure in ambulatory patients ${ }^{6-13}$.

\section{Electronic Monitoring}

Most of the new data come from electronic monitoring with a variety of devices operating on the same principle: time-and date-stamping of the occurrence of dosing-indicative maneuvers performed with the drug package - a principle called 'medication event monitoring'. Detection of the actions made with the package is done by optical or mechanical micro-switch means. The first of these was an eyedrop dispenser, the monitored actions being inversion of the dispenser 
and removal of the cap. When those two maneuvers coincide, time and date are stored in the device's memory ${ }^{14,15}$.

Inversion of an open bottle does not ensure that eyedrops are applied correctly, but only indicates that an action consistent with correct dosing has occurred. When, however, the time for a scheduled dose passes without occurrence of the maneuver, it is clear that dosing has not occurred, unless the patient is also using a second, unmonitored package.

Thus, electronic monitoring of medication events is indirect, and its interpretation as a dosing record is based on two assumptions: (a) correct dosing occurs immediately proximate to the time the monitored maneuver was executed; and (b) the monitored package is the patienfs only source of drug. Assumption (a) is undoubtedly sometimes violated, but such errors only add to the large amount of documented underdosing in ambulatory trials or practice. Assumption (b) has the potential to overestimate non-compliance, but can be minimized by careful instructions and follow-up questioning. If needed, patients can use a second monitored package, for the data from the two monitors can be merged into a single record. For some patients, it is helpful to have packages of drug at work as well as at home, or upstairs as well as downstairs etc.

Patients can, of course, willfully create a false record of dosing by performing the monitored maneuvers without taking any doses. To create a convincing record, however, the maneuvers must be done more or less on schedule - the record shows when they were done, and the timekeeping mechanism cannot be reset except by means available only at the site where the devices are manufactured. The occasional patient who does create a false but convincing record of good compliance by regular manipulation of the package would be misjudged a drug non-responder. Another form of chicanery that, but for the monitors, would have probably escaped detection, is investigator fraud, evident from the unlikely coincidence of medication event data in volunteers who were supposedly living apart from one another and thus had no basis for close synchronization of dosing times. In reality, the data and indeed the supposed volunteers were fictitious ${ }^{16}$. Dr. D. Petzinna of Bayer Forschung reported a similarly discovered fraudulent trial involving 12 supposed volunteers at the Drug Information Association symposium, 'Detection of fraud', in Paris, on 28 September 1993.

\section{History}

The first monitored eyedrop dispenser ${ }^{14,17}$ was made in the mid-1970s, just before the technological advances that began the micro-electronic era. Thus, this first device was much larger and heavier than a conventional eyedrop dispenser. Critics seized on this aspect and claimed the data were an artifact of the unusual package, so the approach was halted from 1977 to 1984 until advances in electronics and battery technology could allow the integration of medication event monitoring capability into pharmaceutical packages with little or no distortion in package size or weight 15 .

The argument about package size turned out to be spurious, and retarded the fields development by almost a decade. Even though the original device was large, the results it gave were confirmed by later studies with conventionally-sized devices ${ }^{18-20}$. By 1987, several types of monitored packages had been developed, and one of them-a cup-type package with the time-stamping microcircuitry triggered by opening and closing of the closure-became commercially available for use in clinical research $21-23$. Meanwhile, research studies were done with monitored unit-dose 'blister' packages 24.25 for oral dosage forms, and a dispenser of inhalational drugs 26 . 


\section{Informing patients}

Most studies with electronic monitoring have been done with patients informed that the package keeps a count of their doses. This information is usually conveyed without the details of the detection logic and its mechanisms, which only invite technophilic patients to dismantle the device to see how it works. Cramer has examined the question of whether dosing patterns are influenced by the knowledge that monitoring is occurring, and has conduded that they are not 27 , unless the patient's dosing record is actively used in a programme of medication management. Her data have only been reported in abstract form, and so cannot be considered definitive, but her findings are in keeping with the observations of many investigators. Some caregivers worry that the patient's privacy is exceptionally intruded upon by the collection of data on dosing times. It seems an odd focus for objection, given all the probings and peerings into the interior structure and function of patient's bodies that go on in the normal course of clinical investigation and routine care.

In the context of full disclosure for drug trials, the information that the package keeps a record of doses is only one of many things about which patients are told, and, when not accompanied by exceptional fanfare, it rarely elicits reaction of any kind. Even in countries where privacy issues are exceptionally prominent, few patients have objected" ${ }^{11}$. Most people know that drug actions are dose-dependent, and see it as common sense that anyone testing a drug in research, or monitoring a therapy in practice, would naturally want to know the doses actually taken. These attitudes were confirmed in a large public opinion survey in Germany ${ }^{28}$, where privacy is an especially sensitive topic.

\section{Slow-turnover chemical markers}

A parallel development has resulted in reliable chemical markers of drug ingestion. While this approach cannot reveal the timing of doses, it gives an almost unambiguous indication of aggregate ingestion of drug over a period whose length is approximately three times the plasma half-life of the marker. The best and most widely-used of these is low-dose phenobarbital, which has a plasma half-life of 99 hours; 29 a single determination of phenobarbital concentration in plasma reflects aggregate intake of phenobarbital marker, and thus of drug, during the prior 10 days.

\section{White-coat compliance}

Slow turnover of marker is essential for a measure of usually prevailing intake, because rapidturnover markers reflect dosing only during the day or two before blood sampling, and many partially compliant patients improve their compliance in the day or two before a scheduled visit 19,30. Called 'White-coat compliance', this behavior has many implications for once-based measurements that are influenced by recent drug intake 6,30 , and it nullifies the value of using plasma concentrations of all but the most slowly turning-over drugs as measures of compliance, when blood is sampled, as is the usual practice, at the time of scheduled visits. The vast majority of drugs have plasma half-lives that are less than 16 hours; thus, a measured concentration of such drugs in plasma reflects dosing during only the prior 48 hours or less - the peak period of white-coat compliance. The dosing reflected within this special period often exaggerates what usually prevails. 


\section{Qualification of a marker}

Feely and Pullar have provided careful qualification of phenobarbital as a marker for prior exposure to drug ${ }^{31}$; their paper can be considered the exemplar for validating the use of any drug or other ingested substance as a marker for compliance. The method is based on the pharmacokinetic principle that drug intake is equal to the product of the concentration of drug in plasma and the clearance of drug from plasma - the latter being a pharmacokinetic parameter that represents the sum of the sinks for drug, due to metabolic conversion into other substances and/or excretion via urine, bile, or other routes ${ }^{32}$. Thus, to infer drug/marker intake from a measure of drug/marker concentration, one must know or assume clearance; to use repeated measures of drug/marker concentration to estimate drug/marker intake, one must assume constancy of clearance.

As Pullar and Feely point out, it is crucial to understand the sources of variance in clearance to use the marker method. A borderline low concentration of marker may thus reflect a borderline high clearance in good compliers, or a moderate degree of underdosing with mid-range clearance. In interpreting borderline low phenobarbital concentration data, Feely and Pullar opted to err on the side of assuming variability in phenobarbital clearance, giving patients the benefit of the doubt; thus, to some extent, they underestimated the smaller lapses in dosing by classifying them as being due to variations in clearance.

\section{Main results with phenobarbital: returned tablet counts discredited.}

Marker methods require careful formulation and chemical analysis, and thus are demanding, but they provide unambiguous evidence of drug ingestion, which the electronic methods cannot. In contrast, the electronic methods show dose timing, which the markers cannot, and do not require any change in the drug dosage form. Thus the two methods give complementary data, though, to date, they have not been applied in the same subjects - one of many lacunae in this underfunded field. Pullar and Feely have reviewed the results with marker and electronic monitoring ${ }^{7}$, which alike reveal far more underdosing in drug trials than indicated by the still widely-used method of counting returned unused dosage forms ('pill counts').

The pill count method has multiple lines of evidence showing that it is not only unreliable but grossly misleading 21, 33-35, for which the strongest and most damning evidence has come from the phenobarbital marker ${ }^{36}$. Substantial numbers of patients clearly fail to return substantial numbers of untaken dosage forms, yet clinical researchers continue to use pill counts, and to report the comforting notion that the vast majority of patients in major drug trials comply satisfactorily. Diaries and interviews similarly give overestimates of compliance, as they, like pill counts, afford patients the easy ability to censor evidence of non-compliance 9, 13, 21, 33.

\section{RESULTS WITH THE NEW COMPLIANCE-MEASURING METHODS}

The patterns of compliance estimated by the new compliance-measuring methods show many more delayed and omitted doses than revealed by the older methods, as reviewed in references $4,7,8$ and 9 . The new findings can be summarized by saying that a third or more of ambulatory patients take prescribed doses at intervals that frequently are appreciably longer than prescribed - often hours, sometimes days, occasionally weeks. The intervals that stretch into days or weeks are the drug holidays referred to above.

A study of 112 German-speaking Swiss patients prescribed once-daily calcium antagonists by their own GPs showed that only one patient in six regularly took the medicine within \pm 6 hours of 24 hours throughout the one-month study ${ }^{37}$. Many others have observed the same thing in a diversity of therapeutic fields $16,18-26,32-35,38-39$ but the results in Switzerland help dispel any 
notions that special places exist where practically all patients follow dosing regimens to the letter. In some circumstances, patients may take smaller doses than prescribed, but with most regimens the path of least resistance, and thus the path most often followed, is to take the prescribed dose when the moment for dosing finally arrives. Thus, the main story is: variable intervals between doses of the size prescribed, even in the land of chronometry.

\section{SIMILARITIES IN PATTERNS OF NON-COMPLIANT DOSING IN DIVERSE THERAPEUTIC FIELDS}

The temporal patterns dosing - with delays and omissions of doses - seem to be remarkably similar across drugs, diseases, prognoses, and, surprisingly, symptoms 9, 16, 18-26, 33-35, 38. This similarity, observed in so many different settings in multiple studies and locations, was surprising, for poor compliance had previously been assumed to be a specific response to drug, disease, prognosis, or other factors. A particularly vivid finding was recently published on the dosing patterns with pain-relieving anti-inflammatory agents in a painful theumatologic condition, ankylosing spondylitis ${ }^{38}$. The observed patterns were essentially identical to those one sees in patients with asymptomatic conditions treated with drugs that have few or no perceptible effects. Figure 1 illustrates this point with data on percentages of prescribed doses taken in three studies from quite different fields of medicine: ocular hypotensive eyedrop treatment of sight-losing glaucoma; oral anti-epileptic treatment of seizure-prone epilepsy ${ }^{21}$; and oral non-steroidal anti-inflammatory treatment of ankylosing spondylitis 38 .

Yet another seeming contradiction to widely-held assumptions about drug regimen compliance has been the inability to identify obvious socio-economic or educational characteristics that would predict non-compliance $9,13,19,21$. A noteworthy observation, too, is that advanced knowledge of pharmacology and therapeutics does not guarantee punctual execution of a dosing regimen 40 , nor does a threatening prognosis 19-21, 33, 38 .

In seeking to improve compliance, a useful approach seems to be to identify some routine in the patient's life to which the taking of the medicine can be linked, by one stratagem or another. Many patients understand this intuitively, but some do not and benefit from suggestions along these lines. This approach has not been formally tested, but it has clearly been useful in individual cases. People differ, however, in the robustness of their routines and the complexity of other activities that may disrupt their routines and their compliance with prescribed drug regimens.

\section{CONSEQUENCES OF POOR COMPLIANCE}

In contrast to the across-field similarities in dosing behavior, the medical and economic consequences of these variations in dose-timing are specific to the medicine, the disease, the severity of disease, and the nature and severity of any co-morbidity. Thus, it is hard to generalize about the consequences of non-compliance, beyond the facts, already noted, that drugs cannot act in patients who do not take them, drug actions tend to be weakened and eventually fade when doses are delayed appreciably, and, in certain circumstances with certain drugs, erratic dosing triggers hazardous rebound effects.

\section{TERMINOLOGY}

In the context of evaluating consequences of poor/partial compliance, the term 'medicine' (or 'pharmaceutical') is preferable to 'drug', because formulation and regimen can play important roles in determining peaks, troughs, and rates of rise and fall in drug concentrations in blood". These kinetic factors can alter the margin for error in dose-timing and minimize the risk of 
rebound effects or rate-dependent side-effects ${ }^{42}$.43. Medicines that have a substantial margin for error in dose-timing are said to be 'forgiving'.

\section{Figure 1. Frequency histogram of the percentages of prescribed doses taken by patients with three different diseases.}

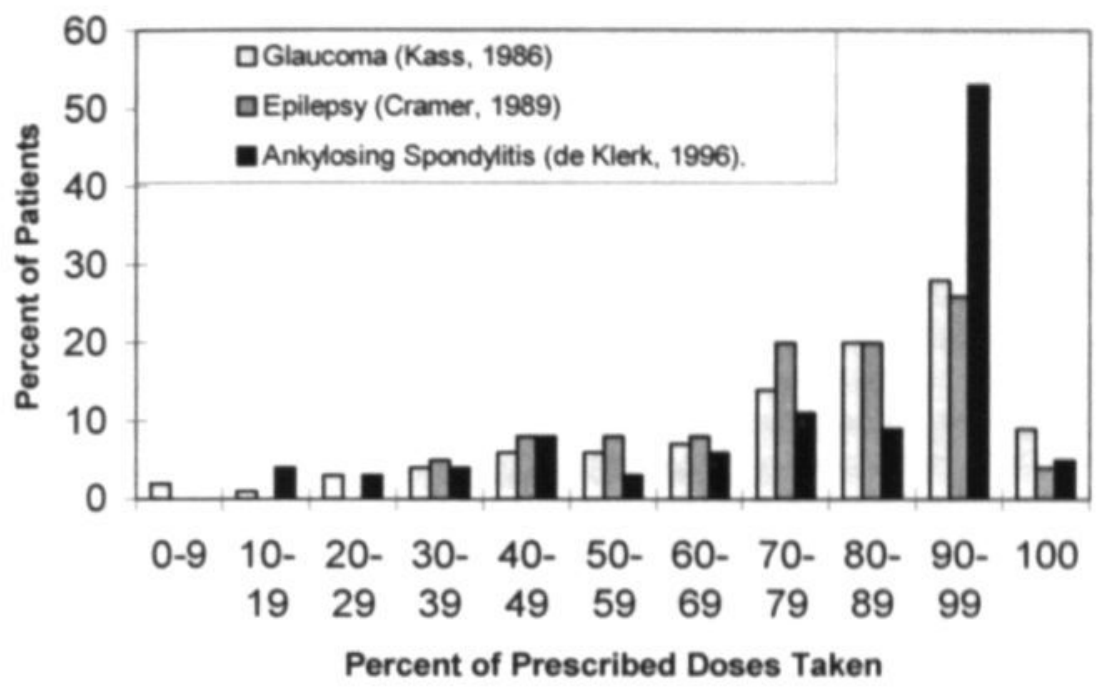

The study in glaucoma patients involved 184 patients whose compliance with topical pilocarpine eyedrop treatment was monitored for 4 weeks ${ }^{16}$. The study in epilepsy patients involved 26 patients whose compliance with oral anti-epileptic medications of various kinds was monitored for 5 months ${ }^{19}$. The study in patients with ankylosing spondylitis involved 65 patients whose compliance with one of two closely related, once-daily, non-steroidal anti-inflammatory drugs was monitored for an average duration of approximately 8 months ${ }^{34}$. Patients in the latter two studies were informed that the monitoring was occurring

\section{FORGIVING VERSUS UNFORGIVING MEDICINES}

Some medicines are remarkably forgiving of common lapses in dosing; others are surprisingly unforgiving. Oral contraceptives provide an example of each. The original oral contraceptives had very high estrogen doses and were quite forgiving of skipped doses ${ }^{44}$, but eventually were found to have an unacceptably high risk of thrombo-mbolic problems, which prompted a substantial reduction in estrogen dose. Today's low-dose oral contraceptives avoid the thrombo-embolic problems but are quite unforgiving; they carry label warnings in the U.K. that being more than 12 hours late in taking the once-daily pill calls for the use of back-up barrier contraception for the next 7 days, even though the delayed dose is taken as soon as the delay is discovered, and daily dosing continues ${ }^{45}$.

Oral contraceptives are practically the only major medicines to convey explicit instructions on what to do when doses are delayed or omitted. Understanding the consequences of missed doses began about 15 years ago, with a series of studies in which volunteers bok oral contraceptives for a period of time, followed by placebo substitutions for various periods, to 
mimic the effects of missing doses; these are reviewed by Guillebaud ${ }^{45}$. Such questions have not been on the research agenda in other fields of medicine, though recently Johnson and Whelton ${ }^{46}$ compared two beta blockers in their abilities to maintain antihypertensive and beta blocking action when placebo was substituted for the usual once-daily dose. The two likeindicated products differ greatly in their degree of forgiveness for a single missed dose. Forgiveness is a therapeutically advantageous attribute, obscured by averaging trial out-comes in all patients, regardless of compliance. Its therapeutic advantage is evident only in the large minority of patients who are partially compliant; good compliers derive no benefit from it, and it cannot create therapeutic action in patients who take little or no drug. Conversely, the concern with long-acting drugs is that they might be more likely to produce toxic effects in fully compliant patients. Thus, the proper evaluation of forgiving drugs requires stratification by compliance.

\section{Defining therapeutic benefit in the face of variable compliance.}

In contraceptive trials, non-compliance has been a recognized source of problems since the field began, so two kinds of contraceptive effectiveness have always been used: methodeffectiveness and use-effectiveness - the former reflecting how well the products work when used correctly, the latter, how well they work in a particular group of patients, with their prevailing levels of compliance. There is always some residual doubt about whether unidentified non-compliance may have allowed a few conceptions to dilute the estimate of methodeffectiveness, but a broad consensus credits correctly used oral contraceptives with providing essentially complete contraception. This view is supported by good understanding of the hormonal control of ovulation, and the blocking role played by the exogenous steroids. Thus, when disappointing responso to drug treatment raises the question 'non-responder or non-complier?', the answer with oral contraceptives is 'non-complier', unless there is evidence for problems with drug absorption. In therapeutic Fields where method-effectiveness is undefined, the question may be difficult to answer $19,21,22,47$.

The terms 'method-effectiveness' and 'use-effectiveness' are lucid but little-used in other areas of medicine than oral contraception, although Paul Meier recently embraced these terms ${ }^{48}$. Some seek to use the terms 'efficacy' and 'effectiveness' to make the same distinction, but these terms are so easily confused that they are useful only to a few mandarins.

\section{NEW INFORMATION LEADS TO NEW PARADIGMS}

One consequence of the new information has been, as noted at the outset, a shift in paradigm from an almost exclusive focus on behavioral issues to a pharmacologic /therapeutic focus. These new findings also suggest the need for changes in questions asked in pharmacologic studies.

\section{DOSE-RESPONSE VERSUS COMPLIANCE-RESPONSE}

Experimental studies to determine dose-response relations are typically done by varying the dose and holding constant the interval between doses; in contrast, patients for the most part hold the dose constant and vary the interval. What is the degree of pharmacologic in equivalence between responses to doses of $0.5 \mathrm{D}, \mathrm{D}$, and $2 \mathrm{D}$ at intervals $\mathrm{T}$ versus giving dose $\mathrm{D}$ at intervals of $2 \mathrm{~T}, \mathrm{~T}$, and $0.5 \mathrm{~T}$ ? One would expect considerable inequivalence with drugs whose actions develop relatively rapidly, for example, within the interval $T$, and relative equivalence with drugs whose actions develop slowly after a succession of doses. If one supposes, or fears, some type of confounding or interaction associated with the behavior that varies the dose intervals, then the effect of said confounding or interaction would be 
revealed in a careful comparison between the responses associated with natural versus controlled variation in intervals. There is, however, little precedent in experimental pharmacology - animal or clinical - of studying drug responses to dosing sequences commonly executed by patients. Controlled studies of this type, like the ones cited above 45,46 are needed, when ethically possible, because predictions from PKJPD models based on a imited set of temporal patterns of drug input may be at gross variance with actual responses to the common patterns of dosing practiced by patients.

\section{ON-RESPONSE VERSUS OFF-RESPONSE}

Long intervals between doses allow drug action to fade, but whether that fading occurs rapidly or slowly, and whether it is overshadowed by rebound effects, is also not a question routinely asked. Pharmacologists seem pre-occupied with studying the onset of drug action, as dosing begins, but pay little or no attention to the offset of drug action, after dosing ends. In light of actual dosing patterns, it is important to know the off-response dynamics, for it is they that determine forgiveness.

Experimental studies of off-responses should begin in pre-clinical animal pharmacology, and continue into phase I and II clinical studies. They may need to be revisited later, in light of actual data on drug exposure in phases III and IV. One must regard patients' actual patterns of drug exposure as a form of force majeure in designing pharmacodynamic studies, so that we can learn from controlled experiments what the pharmacologic and therapeutic consequences are of these patterns.

\section{Is once-daily dosing preferable?}

Affirmative answers to this question have been promoted for so long that it is widely believed to be so, and pressures are great to achieve '24-hour duration' products. There is an elaborate regulatory ritual for qualifying products for approval for this sought-for claim, but the testing almost invariably stops at the $24^{\text {th }}$ hour, as if no one ever delayed or missed a dose. What happens thereafter is left to the imagination, and some medicines undoubtedly require punctual dosing for good outcomes - hardly an auspicious attribute for an era when outcomes are finally being taken seriously. In that light, consider the conclusions of a recent study comparing oncedaily (QD) and twice-daily (BID) doses:

'Days without any dosing events were twice as often with the QD than the BID regimen. Two episodes of 3 or more subsequent days without dosing events 2 were also observed more often with the QD than the BID regimen.' 49

Levy has recently summarized the pharmacokinetic irrationality of claims that once-daily regimens are superior to more frequent dosing regimens 50 .

\section{SOME STATISTICAL CHALLENGES}

When data from electronic monitoring began to be published in the late-1980s, they led some statisticians to recognize that it was no longer tenable simply to ignore compliance, per the intention-to-treat policy, and that new statistical methods or approaches were needed. The first such work was done by Efron and Feldman ${ }^{51}$, who pointed out a previously unrecognized way to see an unbiased portion of the compliance-response relation, as an approximation of the drug's dose-response relation. The discussions of that paper, by Zeger and Liang 52 , Meier ${ }^{48}$, and Rubin ${ }^{53}$, revealed agreement as to the importance of the problems posed by non-compliant dosing, even if there was no consensus about how to analyze it. About the same time, Hasford 54.55 , Sheiner ${ }^{56}$, Sheiner and Rubin ${ }^{57}$ and Goetghebeur and Pocock 58 addressed various 
aspects of the topic. The papers at the present symposium, though not all focused on the specific problem of patient non-compliance with prescribed drug regimens, are a further step. Fundamental to any advance in statistical methodology, however, is the abandonment of easily patient-censored and otherwise unreliable methods for estimating drug exposure in clinical trials - most notably, the much-used but thoroughly discredited count of returned tablets ${ }^{8,33-36}$.

\section{DEFINITION OF 'DRUG REGIMEN COMPLIANCE'}

Given the nature of the data now available, it seems reasonable to define 'compliance' as the result of a comparison of two time series: the recorded dosing history and the prescribed regiment. In contrast, counts of returned unused dosage forms gave rise to an idea that compliance would be represented as a percentage of prescribed doses taken, which of course ignores the key pharmacologic variable: intervals between doses. Also, pill count data are usually interpreted as indicating satisfactory compliance if they indicate that at least $80 \%$ of prescribed doses were taken. The very idea of a blanket policy is pharmacologically naive, as the dosing information for oral contraceptives indicates.

A complete dosing history would include the times at which specified quantities were taken. Electronic monitoring comes close to, but does not reach, that goal, for it requires an assumption about dose quantities ingested. Studies with combined use of marker and electronic methods would help resolve residual doubts about the validity of assuming that patients take the prescribed dose at recorded times.

\section{IS VARIABLE COMPLIANCE TOO CONFOUNDED TO PERMIT PHARMACOLOGIC INTERPRETATION?}

The across-field similarity in dosing patterns indicates that poor compliance with prescribed drug regimens is a general, not a medicine-specific or situation-specific issue. That finding relieves much of the concern that compliance data are too seriously confounded to preclude interpreting them in pharmacologic terms. If important, residual confoundings really exist, they deserve study in their own right, for they are, by definition, important modifiers of drug response, and are a topic for study, not speculation.

\section{INCLUDING/EXCLUDING POOR AND PARTIAL COMPLIERS}

There is no general answer to the question of purposefully including or excluding patients with histories of certain types of compliance. If method-effectiveness is the question, something has to be done about the fact that a third or more of unselected patients delay or omit many doses. If one seeks to define potential advantages of an especially forgiving product, then patients who dose irregularly are the logical target population; on the other hand, if one is concerned that forgiving drug may be potentially harmful when taken regularly, then patients who dose regularly are the logical target population. Neither attribute would be definable by a conventional design that selected for the usual mix of good and poor compliers, analyzed by the intention-totreat policy.

Certain inclusion/exclusion criteria may result in an unrecognized selection for especially good or especially poor compliers. For example, in therapeutic areas where poor compliance has especially hazardous consequences, the recruitment of patients free of those consequences will likely yield a group of exceptionally good compliers, as Petri has described ${ }^{59}$. Another type of selection is likely in studies that focus on non-responders to a particular treatment; physicians tend to overestimate compliance 6,19.21.22, which means that a group of patients judged to be non-responders is likely to include more than the usual proportion of poor compliers. Another 
form of selection may occur in studies that call for a stepwise increase in dosage when response is inadequate at lower dose; non-compliers camouflaged as non-responders are likely to end up at the highest dose levels. Failure to understand these selection dynamics can result in various kinds of misunderstanding, and need careful metaranalysis.

\section{LABELLING ISSUES}

Drug labeling claims are based on information derived from randomized, controlled drug trials.

This linkage has both ethical and legal reinforcement in the American approach to drug regulation, which tends, because of the size of the American market, to dominate in clinical development. The legal focal point of regulation is validation of label claims in properly controlled studies; the ethical basis is the century-old policy of full disclosure in labeling. Hutt and Lasagna have pointed out a clash between statistical policy and the ethical principle of full-disclosure labeling 60 . The clash occurs when an intention-to-treat average response is translated into drug labeling to indicate the magntude of drug effect; the average response is likely to be diluted by data from the large minority of patients who underdosed, with the result that the all-patient average underestimates the consequences of following the label recommended dosing regimen. Yet a majority of patients do follow - more or less - the labelrecommended dosing, and they should have the best available estimate of methodeffectiveness. It is particularly important in primary prevention, where benefits are actuarially defined and not perceptible by patients, yet side-effects and treatment costs are both perceptible and generally dose-dependent. A compliant patient is misled if he/she knows only the intention-to-treat average benefit, but is experiencing full-dose side-effects and costs. An example of the difference between the intention-to-treat average benefit and the magnitude of benefit in full compliers is to be seen in the U.S. labeling for cholestyramine ${ }^{61}$, where the coronary risk reduction in full compliers with drug in the placebo-controlled Lipid Research Clinics-Coronary Primary Prevention Trial was double that of the intention-to-treat average 61,62: coronary risk in placebo recipients was independent of compliance with placebo 62.

\section{OVERVIEW}

The new perspectives brought by new methods of measurement underscore the importance of the drug holiday as a source of potential hazard. Another important matter is to define the degree of forgiveness for the more common lapses in dosing, answering the question 'how much compliance is enough?', and translating that answer into information on what to do when doses are missed, they so often are. It is another new paradigm for the clinical evaluation of medicines and probably the most important of those described in this paper. Interpreting the clinical correlates of variable dosing is often difficult, and so we can expect many controversies, especially in situations where multiple medicines have to be used concomitantly ${ }^{47}$. These are challenges to pharmacologists and statisticians alike - particularly so for those with a pharmacometric bent ${ }^{63}$.

\section{THE DRUG IS A COMPONENT OF THE PRODUCT BEING TESTED}

A final point concerns the role of regimen and formulation design in modulating drug action, by modifying the kinetics of drug entry into the bloodstream. The history of pharmaceutical development provides many examples of medicines whose adverse effects have been minimized or avoided by reformulation to control the kinetics of drug entry into the bloodstream 41. Now we have the added insights from dosing patterns of ambulatory patients and their 
clinical correlates. These are the starting points for redesign to improve forgiveness by widening the margin for errors in dosing.

Yet many continue to think exclusively in terms of 'the drug' when adverse events occur - even the language used implicitly ascribes everything to 'the drug', as if inept formulation and improper use had no relevance, which is simply not so. These points are discussed further in reference 41; suffice it to say here that understanding the dynamics of misuse and its impact is basic to the quest for better pharmaceuticals.

As Leape et al. have pointed out recently ${ }^{64}$, serious medication errors occur even in the intensive care units of the best hospitals, employing highly selected professionals. One response is to ban the drug or banish the person who made the mistake, but when each represents the best available, there is more to be lost than gained from doing so. Better is to understand the dynamics of error and devise systems solutions to reduce its likelihood - an approach long used in minimizing pilot error in the operation of aircraft. Modern medicines are also complex, high technology products, but they remain surprisingly primitive in certain aspects of their use, misuse, attitudes to the consequences thereof, and methods of analysis that can guide rather than hide the path to better therapy.

\section{References}

1. Rangno, R. E. and Langlois, S. Comparison of withdrawal phenomena after propranolol, metoprolol, and pindolol, American Heart Joumal, 104, $473-478$ (1982).

2. Psaty, B. M., Koepsell, T. D., Wagner, E. H., LoGerto, J. P. and Inui, T. S. The relative risk of incident coronary heart disease associated with recently stopping the use of beta blockers, Journal of the American Medical Association, 263, 1653-1657 (1990).

3. Anon. Long-term use of beta blockers: the need for sustained compliance, World Health Organization Drug Information, 4, (2), 52-53 (1990).

4. Urquhart, J. Role of patient compliance in clinical pharmacokinetics: review of recent research, Clinical Pharmacokinetics, 27, 202-215 (1994).

5. Lasagna, L. Noncompliance data and clinical outcomes: impact on health care, Primary Cardiology, 18 , (Supplement 1), 36-39 (1992).

6. Feinstein, A. R. On white-coat effects and the electronic monitoring of compliance, Archives of Internal Medicine, 150, $1377-1378(1990)$.

7. Pullar, T. and Feely, M. Problems of compliance with drug treatment: new solutions?, Pharmaceutical Journal, 245. 213-215 (1990).

8. Bond, W. S. and Hussar, D. A. Detection methods and strategies for improving medication compliance, American Joumal of Hospital Pharmacy, 48, 1978-1988 (1991).

9. Cramer, J. A. and Spilker, B. (eds), Compliance in Medical Practice and Clinical Trials, Raven Press, New York 1991.

10. Vander Stichele, R. Measurement of patient compliance and the interpretation of randomized clinical trials,

European Joumal of Clinical Pharmacology, 41, $27-35$ (1991).

11. Kruse, W. Patient compliance with dnug treatment- new perspectives on an old problem, Clinical Investigation, 70 , 163-166 (1992).

12. Rudd, P. Compliance with antihypertensive therapy. a shifting paradigm, Cardiology in Review, 2, 230240 (1994).

13. Cramer, J. A. Compliance with contraceptives and other treatments, Obstetrics and Gynecology, 88(3), Suppl., 45 125 (1996)

14. Glover, F. United States Patent 4,034,757, 1976.

15. Kass, M. A., Meltzer, D. and Gordon, M. A miniature compliance monitor for opthalmology, Archives of Opthaimology, 102, 1550 (1984).

16. Vander Stichele, R. H., Thomson, M., Verkoelen, K. and Droussin, A. M. Measuring patient compliance with electronic monitoring: lisinopril versus atenolol in essential hypertension, Posł-marketing Surveillance, 6, 77-90 (1992). 17. Kass, M. A., Zimmerman, T., Yablonski, M. and Becker, B. Compliance to pilocarpine therapy, Investigative Opthaimology (Association for Research in Vision and Opthalmology Abstracts Supplement),

108, abstract 2 (1977). 18. Kass, M. A., Meltzer, D., Gordon, M., Cooper, D. and Goldberg J. Compliance with topical pilocarpine treatment, American Joumal of Opthalmology, 101, 515.523 (1986). 
19. Kass, M. A., Gordon, M. and Meltzer, D. W. Can ophthaimologists correctly identify patients defaulting from pilocarpine therapy?, American Journal of Opthaimology, 101, 524530 (1986).

20. Kass, M. A., Gordon, M., Morley, R. E., Meltzer, D. W. and Goldberg. J. J. Compliance with topical timolol treatment, American Joumal of Opthaimology, 103, 188-193 (1987).

21. Cramer, J. A., Mattson, R. H., Prevey, M. L., Scheyer, R. D. and Ouellette, V. L. How often is medication taken as prescribed? A novel assessment technique, Joumal of the American Medical Association, 261, 32733277 (1989).

22. Kruse, W. and Weber, E. Dynamics of diug regimen compliance - its assessment by microprocessor-based monitoring, European Joumal of Clinical Pharmacology, 38, 561-565 (1990).

23. Averbuch, M., Weintraub, M. and Pollack, D. J. Compliance assessment in clinical trials: the MEMS device, Joumal of Clinical Research and Pharmacoepidemiology, 4, 199-204 (1990).

24. Eisen, S. A., Woodward, R. S., Miller, D., Spitznagel, E. and Windham, C. A. The effect of medication compliance on the control of hypertension, Joumal of General Internal Medicine, 2, 298-305 (1987).

25. Cheung, R., Dickins, J., Nicholson, P. W., Thomas, A. S. C., Smith, H. H., Larson, H. E., Deshmukh, A. A., Dobbs. R. J. and Dobbs, S. M. Compliance with antituberculous therapy, a beld trial of a pill-box with a concealed recording device, European Joumal of Clinical Pharmacology, 35, 401-407 (1988).

26. Tashkin, D. P., Rand, C., Nides, M., Simmons, M., Wise, R., Coulson, A. H., Li, V. and Gong, H., Jr. A nebulizer chronolog to monitor compliance with inhaler use, Amercian Joumal of Medicine, 91, (suppl 4A), 33S-36S (1991).

27. Cramer, J. A., Ouelette, V. L. and Mattson, R. H. The effect of microelectronic observation on compliance,

Epilepsia, 31, 617-618 (1990).

28. Compliance, Infratest AG, Munich, Germany, 1990.

29. Phenobarbital pharmacokinetic data, Table A-Il-1 in Hardman, J. G., Limbird, L. E., Molino, P. B., Ruddon, R. W. and Gilman, A. G. (eds), Goodman \& Gilmans The Pharmacological Basis of Therapeutics, 9th edn, McGrawHill, New York, 1996, p. 1770.

30. Cramer, J. A., Scheyer, R. D. and Mattson, R. H. Compliance declines between clinic visits, Archives of Intemal Medicine, 150, 1509-1510 (1990).

31. Feely, M., Cooke, J., Price, D., Singleton, S., Mehta, A., Bradford, L. and Calvert, R. Lowdose phenobarbitone as an indicator of compliance with drug therapy, British Joumal of Clinical Pharmacology, 24, 77-83 (1987).

32. Benet, L. Z., Kroetz, D. L. and Sheiner, L. B. Clearance, in Hardman, J. G., Limbird, L. E., Molinos, P. B., Ruddon, R. W. and Gilman, A. G. (eds), Goodman \& Gilmans The Pharmacological Basis of Therapeutics, $9^{\mathrm{m}}$ edn, McGraw. Hill, New York, 1996, pp. 18-20. 33. Waterhouse, D. M., Calzone, K. A., Mele, C. and Brenner, D. E. Adherence to oral tamoxifen: a comparison of patient self-report, pill counts, and microelectronic monitoring, Joumal of Clinical

Oncology, 11, 1189-1197 (1993).

34. Guerrero, D., Rudd, P., Bryant-Kosling, C. and Middleton, B. F. Antihypertensive medication-taking. Investigation of a simple regimen, American Joumal of Hypertension, 6, 586-592 (1993).

35. Kruse, W., Nikolaus, T., Rampmaier, J., Weber, E. and Schliert, G. Actual versus prescribed timing of lovastatin doses assessed by electronic compliance monitoring, European Joumal of Clinical Pharmacology, 44, 211-215 (1993). 36. Pullar, T., Kumar, S., Tindall, H. and Feely, M. Time to stop counting the tablets?, Clinical Pharmacology and Therapeutics, 46, 163-168 (1989).

37. Urquhart, J. Partial compliance in cardiovascular disease: risk implications, British Joumal of Clinical Practice, Suppl 73, 2-12 (1994).

38. de Klerk, E. and van der Linden, Sj, Compliance monitoring of NSAID drug-therapy in ankylosing spondylitis, experiences with an electronic monitoring device, British Journal of Rheumatology, 35, 6065 (1996).

39. Cramer, J. A. and Mattson, R. H. Monitoring compliance with antiepileptic drug therapy, in Cramer, J. A. and Spilker, B. (eds), Compliance in Medical Practice and Clinical 'rials, Raven Press, New York, 1991, pp. 123-137. 40. Urquhart, J. Correlates of variable patient complence in drug trials: relevance in the new health care environment, in Testa, B. and Meyer, U. A. (eds), Advances in Drug Research, Academic Press, London, 1995, pp. 238-257. 41. Urquhart, J. Time to take our medicines, seriously, Pharmaceutisch Weekblad, 127, 769-776 (1992).

42. Kleinbloesem, C. H., van Brummelen, P., Danhof, M., Faber, H., Urquhart, J. and Breimer, D. D. Rate of increase in the plasma concentration of nifedipine as a major determinant of its hemodynamic effects in humans, Clinical Pharmacology and Therapeutics, 41, 26-30 (1987).

43. Breimer, D. D. and Urquhart, J. Nifedipine GITS, Lancet, 341,306 (1993).

44. Potter, L. S. Oral contraceptive compliance and its role in the effectiveness of the method, in Cramer, J. A. and Spilker, B. (eds), Compliance in Medical Practice and Clinical 'rials, Raven Press, New York, 1991, pp. 195-207. 45. Guillebaud, J. Any questions?, British Medical Joumal, 307, 617 (1993).

46. Johnson, B. F. and Whelton, A. A study design for comparing the effects of missing daily doses of antihypertensive drugs, American Journal of Therapeutics, 1, 260-267 (1994).

47. Urquhart, J. Patient compliance as an explanatory variable in four selected cardiovascular studies, in Cramer, J. A. and Spilker, B. (eds), Compliance in Medical Practice and Clinical Trials, Raven Press, New York, 1991, pp. 301-322. 48. Meier, P. Discussion, Joumal of the American Statistical Association, 86, (413), 1922 (1991). 
49. Kruse, W., Rampmaier, J., Ullich, G. and Weber, E. Patterns of drug compliance with medication to be taken once and twice daily assessed by continuous electronic monitoring in primary care, International Joumal of Clinical Pharmacology and Therapeutics, 32, $453-457$ (1994).

50. Levy, G. A pharmacokinetic perspective on medicament noncompliance, Clinical Pharmacology and Therapeutics, 54, 242-244 (1993). 51. Efron, B. and Feldman, D. Compliance as an explanatory variable in clinical trials, Joumal of the American Statistical Association, 86, 7-17 (1991).

52. Zeger, S. L and Liang, K.Y. Comment: dose-response estimands, Joumal of the American Statistical Association, 86, 18-19 (1991).

53. Rubin, D. Comment: doseresponse estimands, Joumal of the American Statistical Association, 86, 2224 (1991).

54. Hasford, J. Biometric issues in measuring and analyzing partial compliance in clinical trials, in Cramer,J. A. and

Spilker, B. (eds), Compliance in Medical Practice and Clinical Trials, Raven Press, New York, 1991, pp. 265281.

55. Hasford, J. Compliance bei Klinischen Prufungen, in Hasford, J. and Staib, A. H. (eds), Arzneimittelpruf fungen und Good Clinical Practice, MMV Medizin Verlag, Munich, 1994, pp. 166-178.

56. Sheiner, L. B. The intellectual health of clinical drug evaluation, Clinical Pharmacology and Therapetics, 50, $4-9$ (1991).

57. Sheiner, L. B. and Rubin, D. B. Intention to treat analysis and the goals of clinical trials, Clinical Pharmacology and Therapeutics, 57, 6-15 (1995).

58. Goetghebeur, E. J.T. and Pocock, S. J. Statistical issues in allowing for noncompliance and withdrawal, Drug Information Joumal, 27, 837-845 (1993).

59. Petri, H. and Urquhart, J. Patient compliance with beta-blocker medication in general practice,

Pharmacoepidemiology and Drug Safety, 3, 251-256 (1994).

60. Lasagna, L. and Hutt, P. B. Health care, research, and regulatory impact of noncompliance, in Cramer, J. A. and Spilker, B. (eds), Compliance in Medical Practice and Clinical Trials, Raven Press, New York, 1991, pp. 393403. 61. QUESTRAN (cholestyramine), in Physicians Desk Reference, Medical Economics Co., Montvale, NJ, 1996, pp. 770-771.

62. Anon. The lipid Research Clinics Coronary Primary Prevention Trial results: (I) Reduction in incidence of coronary heart disease; (iI) The relationship of reduction in incidence of coronary heart disease to cholesterol lowering, Joumal of the American Medical Association, 251, 351-374 (1984).

63. Peck, C. C., Barr, W. H., Benet, L. Z., Collins, K., Desjardins, R. E., Furst, D. E., Harter, J. G., Levy, G., Ludden, T., Rodman, J. H., Sanathanan, L., Schentag, J. J., Shah, V. P., Sheiner, L. B., Skelly, J. P., Stanski, D. R., Temple, R. J., Viswanathan, C. T., Weissinger, J. and Yacobi, A. Opportunities for integration of pharmacokinetics, pharmacodynamics, and toxicokinetics in rational drug development, Clinical Pharmacology and Therapeutics, 51, 465-473 (1992).

64. Leape, L. L., Bates, D. W., Cullen, D. J., Cooper, J., Demonaco, G., Nemeskal, R., Petersen, L. A., Porter, K., Servi, D., Shea, B. F., Small, S. D., Sweitzer, B. J., Thompson, B. T. and Vander Vliet, M. Systems analysis of adverse drug effects, Joumal of the American Medical Association, 274, 35-43 (1995). 


\title{
Chapter 3
}

\section{Compliance monitoring of NSAID drug therapy in ankylosing spondylitis, experiences with an electronic monitoring device}

\author{
E. de Klerk, Sj. van der Linden
}

Department of Internal Medicine, Division of Rheumatology, PO Box 5800, 6202 AZ University Hospital Maastricht, Maastricht, The Netherlands

Manuscript published as: de Klerk E, van der Linden Sj. Compliance Monitoring of NSAID Drugtherapy in Ankylosing Spondylitis, Experiences with an Electronic Monitoring Device. British Joumal of Rheumatology 1996;35: 60-65.

\begin{abstract}
We conducted a randomized, controlled trial to compare once-daily $20 \mathrm{mg}$ piroxicam versus once-daily $20 \mathrm{mg}$ tenoxicam in ankylosing spondylitis. We recorded patients' dosing histories with electronic monitors for an average of 225 days (range 55-379) in 34 recipients of piroxicam and 31 recipients of tenoxicam. Dosing histories with the two agents were similar and are combined. Patients took $81 \%$ of prescribed doses; $78 \%$ once daily (as prescribed) and $3 \%$ as two or more daily doses. On $19 \%$ of all monitored days, there was no record of a dose being taken; $68 \%$ were single no-dose days, the rest (32\%) being 2 to $>10$ consecutive no-dose days. In $3 \%$ of monitored days, extra doses were evidently taken, $88 \%$ as twice daily and $12 \%$ as three or more daily doses. Only $22 \%$ of all patients (14/65) strictly complied with the regimen: one dose daily every day. The remainder alternated between no-dose days and extra-dose days. We found no correlation between patient compliance and improvement in reported pain or morning stiffness.
\end{abstract}

\section{Introduction}

Patient compliance with prescribed drug regimens can be thought of as the extent to which the history of actual dosing conforms to the prescribed regimen. Thus, the measure of compliance is a measure of the patient's exposure to drugs. Two aspects are important: taking compliance refers to the actual number of tablets taken, regardless of the timing; timing compliance refers to a preferred interval during which the drug has to be taken. The measurement of patient compliance with prescribed drug regimens improved greatly after 1986/87, since the introduction of chemical markers and electronic monitoring methods' 1 . Prior methods were subject to self-reporting bias or other potential manipulation by patients, making the data they provide less reliable. They were also limited in describing actual drug exposure: they gave no in- formation on timing compliance whatsoever.

It is now clear that variable patient compliance is a prevalent and well-documented source of variance in drug response in both clinical trials and medical practice ${ }^{26}$. Deviations in compliance, which usually take the form of underdosing in varying degrees, can be expected to result in echoing degrees of attenuation in drug response.

As Levy ${ }^{7}$ has pointed out, however, the consequences of underdosing depend on two main pharmacodynamic factors: the slope of the drug's dose response relationship and the 
positioning of the recommended dose relative to the steepest slope region of the curve. Thus, variable dosing can have much or little effect, depending on those factors.

It has been possible in certain therapeutic settings to infer the drugs dose response relationship from the correlates of variable compliance, like pill or package counts $4.8-10$, but these have been circumstances in which variable dosing appears to have been independent of disease or the patient's prior response to the drug. Such circumstances appear to have prevailed in various primary prevention trials, notably the use of lipid-lowering agents to reduce lipid levels in otherwise healthy subjects a silent end-point and thus minimize the risk of coronary heart disease - also a silent endpoint - because risk is an actuarial parameter, not something patients can perceive $4,10-12$. In such studies, the beneficial effects of the drug are imperceptible, and side-effects are minor or non-existent. Here, then, one encounters variable compliance, not as a response to the treatment, but as a seemingly independent expression of the range of patient's skills at self-organization to execute a daily schedule of dosing.

In symptomatic diseases, by contrast, both prescriber and patient look to the drug to provide relief of symptoms and perhaps some modification of underlying disease. In the treatment of meumatic diseases with non-steroidal anti-inflammatory drugs (NSAIDs), the situation is complicated by a mixture of drug effects that variably relieve the pain of the rheumatic disease and create dyspepsia and other unpleasant symptoms against two principal backdrops: (a) fluctuating disease intensity and (b) variably self-organizing to follow a daily routine of drug administration. Thus, drug intake in rheumatic disease is the resultant of a complex mixture of variable disease activity, need for symptom relief, response to administered drug and non-

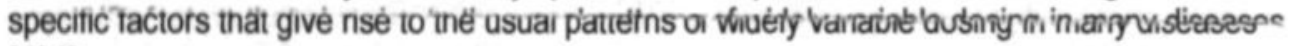
$6,13-15$,

It was in this setting that we conducted a randomized, controlled trial to assess the efficacy of prescribed once-daily $20 \mathrm{mg}$ piroxicam versus once-daily $20 \mathrm{mg}$ tenoxicam in ankylosing spondylitis (AS), with the use of electronic monitoring of compliance $1,16,17$ to assess the time history of our patients' dosing.

\section{Methods}

The study design was a three centre, double-blinded, comparative randomized trial with 140 AS patients randomized to receive one tablet of $20 \mathrm{mg}$ piroxicam daily or one tablet of $20 \mathrm{mg}$ tenoxicam daily. All patients fulfilled the modified New York criteria for AS ${ }^{18}$. The treatment duration in the trial was $1 \mathrm{yr}$, with evaluations at baseline, and at 1, 2, 4, 6, 8, 10 and 12 months after baseline.

Compliance was measured using the Medication Event Monitoring System (MEMS; APREX, Fremont, CA). This system consists of a normal pill container with a special cap, which contains an electronic device that records the time and date of every opening and closing. We assume that with every cycle of opening and closing the patient does indeed take a tablet. All patients had given their written informed consent and were told that the cap was capable of 'counting pills'. The data of the cap were downloaded onto a floppy disc and were ready for analyses in SPSS-PC version 4.0 after being decoded by APREX. The advantages and limitations of this system are described elsewhere $1,13,14,16$. The MEMS technology became available for our trial 4 months after the first patients were enrolled. The data of five caps could not be retrieved: two caps were lost and three were not readable. One patient compiled a dosing record of only 14 days after which he was advised to stop using the trial medication because of sideeffects, and 
was excluded from the analyses. Therefore, compliance data were available for 65 patients: 31 in the tenoxicam group and 34 in the piroxicam group.

Tenoxicam (Tilcotip) and piroxicam (Feldene ${ }^{*}$ ) are both NSAIDs belonging to the oxicam class. They are potent analgesic anti-inflammatory and antipyretic agents in animal models. The effects are believed to be mediated by the inhibition of cyclo-oxygenase and subsequent prostaglandin formation. The pharmacokinetic profile is characterized by complete absorption following oral administration, high protein binding $(>98.5 \%)$, low volume of distribution $(0.12$ $0.151 / \mathrm{kg})$, efficient penetration into synovial fluid, low systemic clearance $(0.1 \mathrm{Vh})$ and long elimination half-life $(60-75 \mathrm{~h})$, permitting once-daily doses (repeated once-daily administration for 10-15 days being necessary to achieve steady state). They are completely metabolized to form inactive metabolites which are excreted in urine and faeces 19.20.

Compliance was calculated as: (1) taking $\infty$ mpliance $=($ total number of doses taken)/(number of monitored days) $\times 100 \%$; (2) timing compliance $=$ (number of doses taken at $24 \pm 6 \mathrm{~h}$ intervals/number of monitored days) $\times 100 \%$; (3) pre-visit compliance $=$ (total number of doses taken 7 days before visit 7 ) $\times 100 \%$; (4) post-visit compliance $=($ total number of doses taken 7 days after visit 7 ) $\times 100 \%$; $(5)$ inter-visit compliance $=$ (total number of doses taken during the week exactly between two visits $/ 7) \times 100 \%$.

Two outcome measures were used: (I) the pain experienced during the day, measured on a visual analogue scale (VAS), and (2) the duration of morning stiffness in minutes. Both outcome measures are calculated as the difference between the visit at which the MEMS was given to the patient and the visit at which the MEMS was returned, and calculated so that improvement (less pain, shorter duration of morning stiffness) is positive.

\section{Results}

A total of 14.607 days ( 40.1 patient-years) were monitored for 65 patients (mean \pm s.d. followup: $225 \pm 90$ days, range $55-379$ ). Taking compliance was high: $81 \%$ of all tablets were taken, of which $78 \%$ were as prescribed, whereas on $19 \%$ of the days no medication was taken and on $3.4 \%$ of the days extra medication was taken. The differences in compliance, missed doses and extra doses taken between both treatment groups were small, and not statistically significant (Table 1).

Table 1. Summary of the compliance data

\begin{tabular}{lccc}
\hline Patients & $\begin{array}{c}\text { Piroxicam } \\
(n=34)\end{array}$ & $\begin{array}{c}\text { Tenoxicam } \\
(n=31)\end{array}$ & $\begin{array}{c}\text { Total } \\
(n=65)\end{array}$ \\
\hline $\begin{array}{l}\text { Days monitored } \\
\% \text { days on which at least one dose } \\
\text { taken }\end{array}$ & 7.863 & 6.744 & 14.607 \\
$\begin{array}{l}\% \text { days on which dose taken as } \\
\text { prescribed }\end{array}$ & $83 \%$ & $78 \%$ & $81 \%$ \\
$\%$ days with extra doses & $79 \%$ & $76 \%$ & $78 \%$ \\
$\%$ days with missed doses & $4 \%$ & $3 \%$ & $3 \%$ \\
\hline
\end{tabular}

Percentages relate to the number of days missed. 
Table 2. Days without NSAID intake

Number of consecutive days without drug intake

\begin{tabular}{llllllll}
\hline $\begin{array}{l}\text { Number of } \\
\text { days }\end{array}$ & 1 & $2-3$ & $4-5$ & $6-7$ & $8-9$ & $>10$ & Total \\
\begin{tabular}{l} 
Percentage \\
\hline
\end{tabular} & $67.6 \%$ & $19.6 \%$ & $5.2 \%$ & $3.0 \%$ & $0.8 \%$ & $3.8 \%$ & $100 \%$ \\
\hline
\end{tabular}

Percentage calculated as (total number of days without NSAID intake/total number of days monitored) $\times 100$.

Table 3. Number of days on which more than one tablet was taken

\begin{tabular}{|c|c|c|c|c|c|}
\hline & \multicolumn{5}{|c|}{ Number of extra doses taken } \\
\hline & 1 & $2-3$ & $4-5$ & $6-7$ & Total \\
\hline $\begin{array}{l}\text { Number of } \\
\text { doses }\end{array}$ & 440 & 55 & 2 & 1 & 498 \\
\hline Percentage & $88.4 \%$ & $11.1 \%$ & $0.4 \%$ & $0.2 \%$ & $100 \%$ \\
\hline
\end{tabular}

Percentage calculated as (number of extra doses taken/total number of extra doses) x 100

The interval distribution of the doses taken shows that the majority of the doses $(82 \%)$ were taken at $24 \pm 6 \mathrm{~h}$ intervals. However, $8 \%$ were taken too early $(<18 \mathrm{~h})$ and $11 \%$ were taken too late $(>30 \mathrm{~h})$. Again, there are no statistically significant differences between the treatment groups. Of the missed doses (Table 2), 32.2\% were missed in intervals of 2 days or longer, While $67.8 \%$ of the missed days were followed by a day with a dose taken. Table 3 shows that on the $3.4 \%$ of the total days on which an extra dose was taken, $99.5 \%$ accounted for $1-3$ extra doses taken.

Table 4 shows that there is a slight post-visit rise in compliance at all visits except number 3 , but this was not statistically significant. There was no decline in compliance between visit 1 and visit 5 , but a significant decline $(P=0.04)$ of $6 \%$ between visit 6 and 7 , compared to the pre-visit compliance on visit 6. During the study, the compliance declined from $91 \%$ at visit 1 to $78 \%$ at visit 4 , after which it rose again to $89 \%$ at visit 7 . There were no differences between the two treatment groups.

Table 4. Compliance just before, just after and in between hospital visits

\begin{tabular}{cccccc}
\hline Visit number & $\begin{array}{c}\text { Pre-visit } \\
\text { compliance }\end{array}$ & $\begin{array}{c}\text { Post-visit } \\
\text { compliance }\end{array}$ & $\begin{array}{c}\text { Inter-visit } \\
\text { compliance }\end{array}$ & Pt & Pt \\
\hline 1 & $91 \%$ & $96 \%$ & $97 \%$ & - & - \\
2 & $96 \%$ & $99 \%$ & $93 \%$ & - & - \\
3 & $86 \%$ & $84 \%$ & $85 \%$ & - & - \\
4 & $78 \%$ & $81 \%$ & $80 \%$ & 0.32 & 0.49 \\
5 & $80 \%$ & $82 \%$ & $81 \%$ & 0.70 & 0.95 \\
6 & $89 \%$ & $89 \%$ & $83 \%$ & 1.00 & 0.04 \\
7 & $89 \%$ & - & - & & \\
\hline Mean & $86.6 \%$ & $88.5 \%$ & $86.5 \%$ & & \\
\hline
\end{tabular}

$\because$ Inter-visit compliance at visit 1 is the compliance during the week between visit 1 and 2.

t: Paired Student's t-test for the difference between pre-visit and post-visit compliance.

*: Paired Student's t-test for the difference between pre-visit and inter-visit compliance.

No t-tests were calculated for visits 1 - 3 because the number of patients was $<20$. 
Fig. 1. Distribution of compliance in bands of $10 \%$.

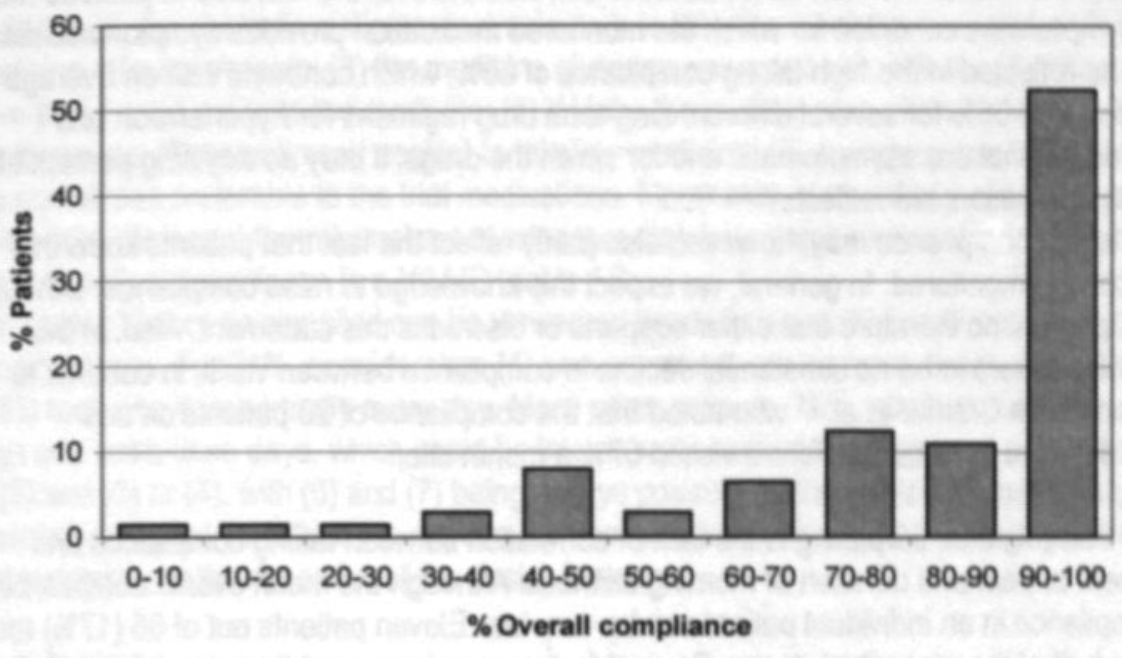

Figure 1 shows the distribution of compliance in bands of $10 \%$, which indicates $>50 \%$ of the patients took $90-100 \%$ of their medication. A substantial number of patients (37\%), however, took $<80 \%$ of the drug. Figures 2 and 3 show the relationship between taking compliance and two main clinical outcome parameters: improvement in patient-reported pain score on a VAS and improvement in duration of morning stiffness during the period that compliance was monitored. There appears to be very little correlation between these outcome variables and compliance: 0.10 and 0.17 (both not significant), respectively.

Fig. 2. Taking compliance with improvement of morning stiffness.

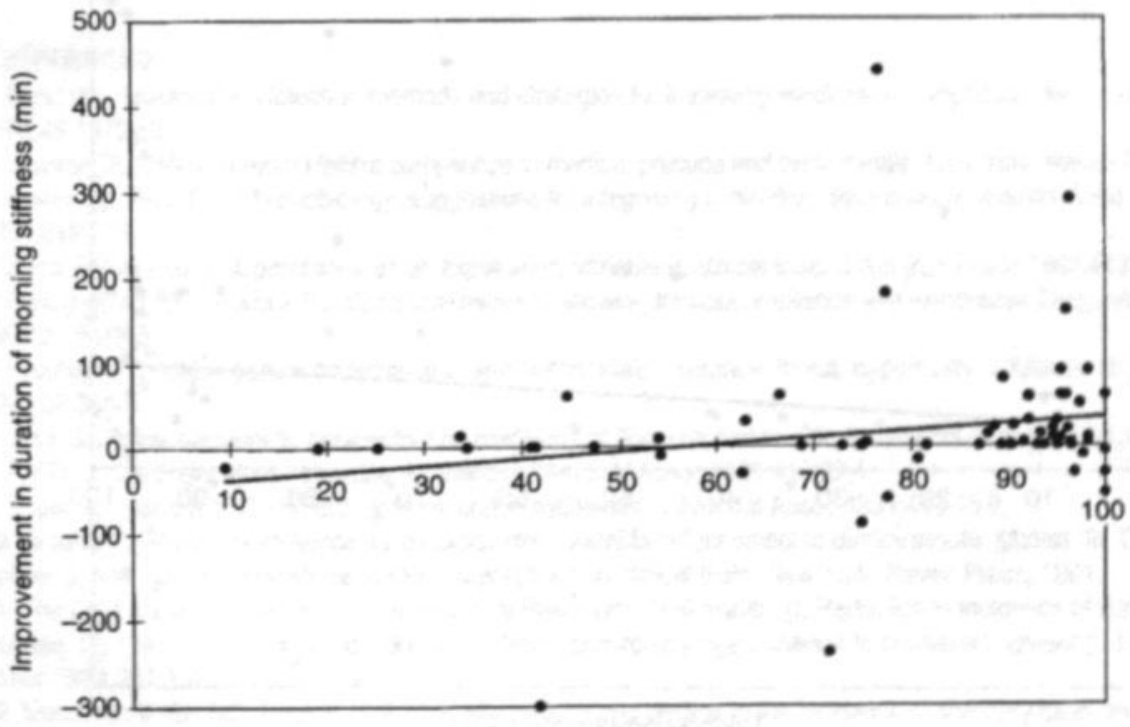

Taking-compliance (\%) 


\section{Discussion}

In this study, the MEMS monitor, as far as we know, was used for the first time in patients with a strongly symptomatic condition for which the monitored medication provides symptomatic relief. This may be reflected in the high taking compliance of $80 \%$, which contrasts with an average compliance of 50-65\% for several different long-term drug regimens for hypertension and hyperlipidaemia that are asymptomatic and for which the drugs, if they do anything perceptible, may create unpleasant side-effects $4,10,23$.

This high taking compliance may, however, also partly reflect the fact that patients knew that compliance was monitored. In general, we expect this knowledge to raise compliance, although there is at present no literature that either supports or discredits this statement. Also, in this study, there appears to be no substantial decline in compliance between visits, in contrast to observations from Cramer et al. ${ }^{21}$ who noted that the compliance of 20 patients on antiepileptics declined from $88 \%$ before a visit to $67 \%$ a month later.

One thing that might be surprising is the lack of correlation between taking compliance and improvement of pain and duration of morning stiffness. Although the mean overall compliance is good, compliance in an individual patient can be very low. Eleven patients out of $65(17 \%)$ took fewer than half of the prescribed doses. Several factors may have contributed to this, including low disease activity, low perceived efficacy or use of non-reported co- medication. The identification of such patients is very easy with MEMS data and could lead to reevaluation of the treatment in a clinical setting, exclusion from a trial if the finding is made in a prerandomization adherence test ${ }^{22}$ or result in stratification by compliance during analyses ${ }^{23}$.

Fig. 3. Taking compliance with improvement in pain score.

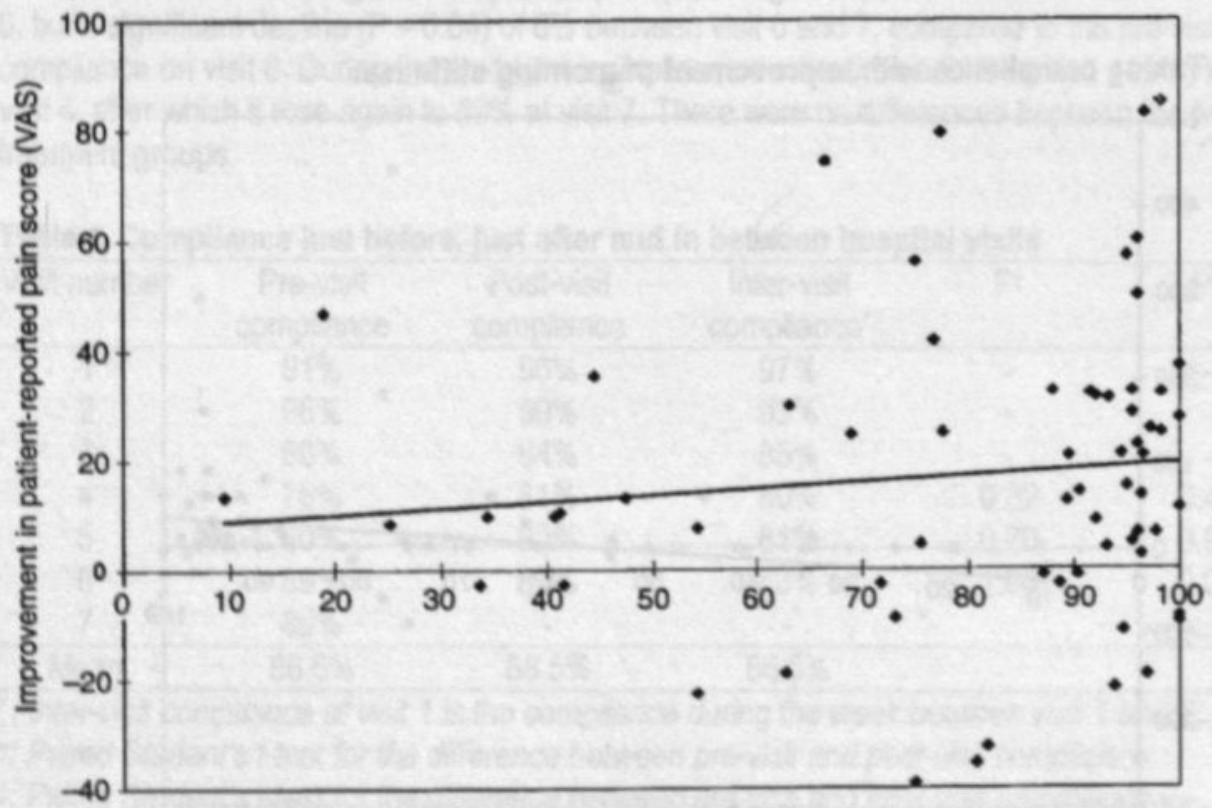

Taking-compliance (\%) 
The dosing history of an individual patient with AS taking NSAIDs can, in our view, be seen as the outcome of at least seven deliberations. For an individual patient enrolled in a study these could be: (1) the doctorlinvestigator instructed me to take the medicine once daily; (2) the medicine relieves my pain; (3) the medicine gives me unwanted side-effects; (4) When I don't have pain I need not take the medicine; (5) if I take the medicine too often it may lose its effectiveness; (6) sometimes I neglect to take my medicine; (7) my other (non-trial) medications are sometimes preferable to the trial medications. More rules can easily be made up, but these seven may represent the minimal set of rules that may have large explanatory power for variable patient compliance in a NSAID trial in AS.

The dosing history as compiled can be viewed as the daily reconciliation of these or other considerations. For $21 \%$, consideration (1) was seemingly pre-eminent; these patients ( 14 out of 65 ) took one dose virtually every day. Many other patients, $79 \%$, alternate between no-dose days and extra-dose days, which could be interpreted as altemating between consideration (2) or (5) and (3) or (4), with (6) and (7) being always possible as the operative dosing rules. Future research designed specifically to explore the implicit rules of dosing may help in gaining more understanding in the dynamics of the dosing history.

\section{Conclusion}

(1) The physician's strict dosing instructions of every day one tablet daily were followed by only $20 \%$ of the patients. Others may follow implicit rules of dosing different from 'do what the doctor says'. (2) 'No-dosing days' are much more common than 'extra-dosing days'. (3) Trying to understand the implicit rules of dosing may help in understanding the dynamics of dosing history.

\section{Acknowledgements}

The authors would like to thank professor J. Urquhart, department of Epidemiology, University of Limburg, for the many cheerful discussions on compliance issues. This study was supported by Roche Nederland and 'Het Nederlands Reumafonds'.

\section{References}

1. Bond WS, Hussar DA. Detection methods and strategies for improving medication complance. Am J Hosp Pharm 1991;48:1978-88.

2. Cramer JA, Spilker B (eds) Patient compliance in medical practice and clinical trials. New York: Raven Press, 1991. 3. Harter JG, Peck CC. Chronobiology. suggestions for integrating it into drug development. Ann NY Acad Sci 1991:618:563-71.

4. Efron B, Feldman D. Compliance as an explanatory variable in clinical trials. J Am Stat Assoc 1991;413:9 17. 5. Goetghebeur EJT, Pocock SJ. Statistical issues in allowing for noncompliance and withdrawal. Drug Informatbn J 1993;27:837-45.

6. Urquhart J. Variable patient compliance in ambulatory trials: nuisance, threat, opportunity. J Antimicrob Chemother 1993:32:643-9.

7. Levy G. A pharmacokinetic perspective on medicament noncompliance. Clin Pharmacol Ther 1993;54:242-4.

8. Rubin D. Comment: dose response estimands. J Am Stat Assoc 1991;413:22-4.

9. Zeger SL, Liang K-Y. Comment: dose response estimands. J Am Stat Assoc 1991;413:18-9.

10. Urquhart J. Patient compliance as an explanatory variable in four selected cardiovascular studies. In: Cramer JA. Spilker B, eds. Patient compliance in medical practice and clinical trials. New York: Raven Press, 1991.

11. The Lipid Research Clinics Coronary Primary Prevention Trial results: (I) Reduction in incidence of coronaryheart disease; (II) The relationship of reduction in incidence of coronary heart disease to cholesterol lowering. J Am Med Assoc 1984;251:351 74.

12. Manninen V, Elo MO, Frick $\mathrm{H}$ et al. Lipid alternations and decline in the incidence of coronary heart dsease in the Helsinki Heart Study. J Am Med Assoc 1988;260: 641-51. 
13. Vander Stichele R. Measurement of patient compliance and the interpretation of randomized clinical trials. Eur J Clin Pharmacol 1991;41:27-35.

14. Kruse W. Patient compliance with drug treatment. new perspectives on an old problem. Clin Invest 1992;70: 1636.

15. Pullar T, Feely M. Problems of compliance with drug treatment: new solutions? Pharm J 1990;245:2135.

16. Cramer JA, Mattson RH, Prevey ML, Scheyer RD, Ouellette VL. How dten is medication taken as pre- scribed? A novel assessment technique. J Am Med Assoc 1989,261:3273-7.

17. Averbuch M, Weintraub M, Pollack DJ. Compliance assessment in clinical trials: the MEMS device. J Clin Res Pharmacoepidemiol 1990;4:199 204.

18. van der Linden S, Valkenburg HA. Evaluation of diagnostic criteria for Ankylosing Spondylitis: A proposal for modification of the New York criteria. Arthritis Rheum 1984;27:361-8.

19. Gonzales JP, Todd PA. Tenoxicam. A preliminary review of its pharmacodynamic and pharmacokinetic properties, and therapeutic efficacy. Drugs 1987;34: 289-310.

20. Todd PA, Clissold SP. Tenoxicam, an update of its pharmacology and therapeutic efficacy in theumatic diseases. Drugs 1991;41:625 46.

21. Cramer JA, Scheyer RD, Mattson RH. Compliance declines between clinic visits. Arch Intern Med 1990;150:1509 10. 22. Probstfield JL. Clinical trial prerandomization compliance (adherence) screen. In: Cramer JA, Spilker B, eds. Patient compliance in medical practice and clinical trials. New York: Raven Press, 1991.

23. Hasford J. Biometric issues in measuring and analyzing partial compliance in clinical trials. In: Cramer JA, Spilker B, eds. Patient compliance in medical practice and clinical trials. New York: Raven Press, 1991. 


\section{Facilitated analysis of data on drug regimen compliance}

\section{Erik de Klerk', Sjef van der Linden', Désireé van der Heijde1, John Urquhart².}

1 Department of Internal Medicine, Division of Rheumatology, University Hospital Maastricht, P.O. Box 5800, 6202 AZ Maastricht, The Netherlands

2 Department of Epidemiology, University of Maastricht, P.O. Box 616, 6200 MD Maastricht, The Netherlands

Manuscript published as: de Klerk E, van der Linden SJ, van der Heijde D, Urquhart J. Facilitated Analysis of Data on Drug Regimen Compliance. Statistics in Medicine 1997;16: $1653-64$

\section{SUMMARY}

Drug actions depend on dose and intervals between doses, in ways that are drug-specific and sometimes complex, complicating the use of drug dosing histories as an explanatory variable in the analysis of clinical trials. We describe a spread-sheet method for conveniently displaying patient's drug dosing histories, to facilitate identification of dosing correlates of clinically important events.

\section{INTRODUCTION}

Drug dosing histories of ambulatory patients can be compiled by the method of electronic medication event monitoring, ${ }^{1-4}$ by which microcircuitry, integrated into various types of packages, detects and records the time and date of actions that signify removal of a dose of drug from the package. Prototype electronic compliance monitors were first made in 1977 , commercialized in $1987^{6}$, and have gradually gained recognition since as the gold standard for assessing drug exposure in ambulatory patients ${ }^{7-10}$. The monitored actions differ according to the type of package: opening and inversion of a liquid container; ${ }^{1}$ opening/closing of a bulk container; ${ }^{2.3}$ ejection of a tablet from a unit-dose 'blister' package; ${ }^{4.11}$ activation of a nebulizer 12.13. Each time-stamped event is interpreted as an administration of the prescribed dose.

The assumptions underlying this interpretation have been discussed by various authorities, with consensus that the record is substantially accurate, and superior to other methods 23,7-9,14.19. In some situations, the method may be inaccurate, ${ }^{20.21}$ but such problems can be minimized by appropriate instruction and questioning of patients, guided by common sense and understanding of the technical specifications and limitations of the method. It is of course possible for a patient to manipulate a monitored package to create a false record of dosing, but doing so requires the concurrence of three things: intention to falsify; know-how, and persistence in maintaining a schedule of package manipulation that conforms credibly enough to the prescribed regimen. Successful falsification leads to the non-complier's misclassification as a drug non-responder. The closest to an absolute standard, against which other compliance measurement methods could be evaluated, is a system of continuous televised observation ${ }^{3}$. 
It is now recognized that electronic monitoring reveals the omission of a much larger proportion of scheduled doses than usually revealed by earlier methods-histories, 1.2.,11,16,17 diaries, 2.8. 11,17 returned tablet counts, $2,8,19$ and measurement of drug concentrations in plasma during scheduled examinations $2,7,22$. Each of these earlier methods affords patients easy ability to censor evidence of omitted doses - prevalent behaviour in a wide range of medical situations $1,2,4,7-9,11-19,23$. Thus, reports of drug trials regularly claim satisfactory drug regimen compliance in over 90 per cent of patients, based, usually, on returned tablet counts. Pullar et al. ${ }^{23}$ devastated such claims, based on careful studies with the phenobarbital marker method in a diversity of trial situations; with this essentially manipulation-proof method, they concluded that returned tablet counts "grossly overestimate" compliance and thus the actual extent of drug exposure in ambulatory trials.

Furthermore, electronic monitoring reveals the temporal patterns of dosing, which the chemical marker methods cannot, ${ }^{14}$ allowing interpretation of the associated clinical data in pharmacokinetic (PK) and pharmacodynamic (PD) terms ${ }^{24.25}$. Whether variable compliance with prescribed dosing regimens is negligent or wilful, and regardless of its motivations, the pharmacologic result is a diversity of temporal patterns of drug exposure that entrain, through PKJPD mechanisms, a corresponding diversity of temporal patterns of drug responses 24,26 .

The development of electronic monitoring had no influence on the 1988 FDA clinical and statistical guidelines, but was an acknowledged stimulus ${ }^{27}$ to the work of Efron and Feldman on compliance as an explanatory variable, which received the JASA Applications Award in 199028. In discussing that paper, Rubin noted 25 that variable compliance represents an observational, non-randomized study of the causal effects of varying dose levels embedded within the randomized experiment of drug versus placebo. In 1991, the FDA's Russell Katz re-iterated the primacy of intention-to-treat analysis, while indicating the desirability of additional analyses that may reveal other aspects of a test drug's dose-dependent actions ${ }^{29}$. This policy is reflected in the FDA-approved relabelling of cholestyramine, based on the Lipid Research Clinics-Coronary Prevention Trial: 30 the intention-to-treat results are supplemented by a table showing reductions in cholesterol levels and coronary risk varying as compliance varied with the recommended dosing regimen ${ }^{31}$. More recently, oral contraceptives have been relabelled in the U.S. and U.K. with recommendations on what to do when scheduled doses have been delayed or omitted, based on results of randomized, controlled omission of doses ${ }^{32}$. To provide such information in labelling is a logical and pragmatic extension of the principle of full-disclosure labeling ${ }^{33}$. Sheiner and Rubin ${ }^{34}$ have challenged the primacy of intention-to treat analysis, given the prevailing levels and patterns of variable compliance. It is a methodologic challenge to extract reliable, useful dose-effect information from an observational study in the face of ambiguity about the origins and concomitants of variable compliance 28,35 . Unambiguous, however, is that varying compliance signifies varying quantities and timing of doses taken, with pharmacologic consequences predictable from pharmacometric models of the drug's actions ${ }^{36}$. Obviously, the state of knowledge of PKJPD mechanisms varies greatly from one drug to another, but development of such information is increasingly an integral part of new drug development, ${ }^{36.37}$ and a natural basis for model-based interpretation of drug exposure data in trials. The "natural experiments" in variable dosing do not permit the certainty of interpretation that can come from randomized, controlled studies, but they challenge clinical pharmacologic understanding by revealing the clinical correlates of a rich diversity of dosing patterns. 
Figure 1. Example of a calendar plot

\begin{tabular}{|c|c|c|c|c|c|c|c|}
\hline Day & Mon & Tue & Wed & Thr & Fri & Sat & Sun \\
\hline Date & & & & & & 0 & 1 \\
\hline 3 & 1 & 1 & 2 & 1 & 0 & 1 & 1 \\
\hline 10 & 1 & 1 & 1 & 1 & 1 & 0 & 0 \\
\hline 17 & 0 & 1 & 1 & 2 & 0 & 2 & 0 \\
\hline 24 & 1 & 1 & 1 & 0 & 1 & 0 & 0 \\
\hline 21 & 1 & & & & & & \\
\hline
\end{tabular}

Some of these dosing patterns would be deemed unethical in controlled experiments, and all are patterns that patients actually execute more or less often in both trials and practice. Thus, their clinical correlates can inform the solutions to, even if they cannot definitively solve, a number of often difficult problems that arise in the development of new drugs: the definition of the optimal dosage regimen; the consequences of following the recommended regimen; the limits of punctuality in dose timing for full benefit; the identification of especially hazardous dosing patterns; pharmaco-economic correlates of common deviations from the recommended regimen, and, of course, comparisons of all these aspects among competing drugs 37,38 . The more compelling correlates will logically suggest designs and prioritization of future randomized, controlled experiments that lie within the scope of ethical possibility, examples of which can be found in contraceptive ${ }^{31}$ and cardiovascular ${ }^{39}$ research.

Used in pursuit of these and other objectives, electronic monitoring of drug exposure creates a large amount of data, and thus a need for methods that facilitate their analysis. Methods that have been used to describe compliance for individual patients are calendar plots, where the number of tablets taken per day are in a calendar-like frame (Figure 1), and chronology plots, where the hour of the tablet taken is depicted over the study period (Figure 2). For groups, data have so far mostly been presented as summary statistics (Table 1). This paper describes a method that provides much detailed data on each patient, while at the same time producing a graph that shows main features of the data.

\section{METHODS}

We used an electronically monitored package (MEMS , APREX Ltd., Zug, Switzerland) to gather data on drug exposure in a three-centre double-blinded randomized comparative phase III trial comparing tenoxicam and piroxicam, two non-steroidal anti-inflammatory drugs (NSAIDs) of the oxicam class, in patients with ankylosing spondylitis (AS). This trial has been reported in detail elsewhere ${ }^{40}$. In brief, 140 AS patients, who fulfilled the modified New York criteria for disease classification, ${ }^{41}$ gave their informed consent to participate in the trial, which was reviewed and approved by the Ethical Committee of the University Hospital Maastricht. Patients were randomly assigned to take $20 \mathrm{mg}$ of either drug, once-daily for 1 year. Clinical status was assessed at baseline and at 1, 2, 4, 6, 8, 10 and 12 months after baseline. Patients were informed that the medication-vent monitors were compiling a record of their dosing, but were not informed about the mechanisms that actuate recording. 
Figure 2. Example of a chronology plot

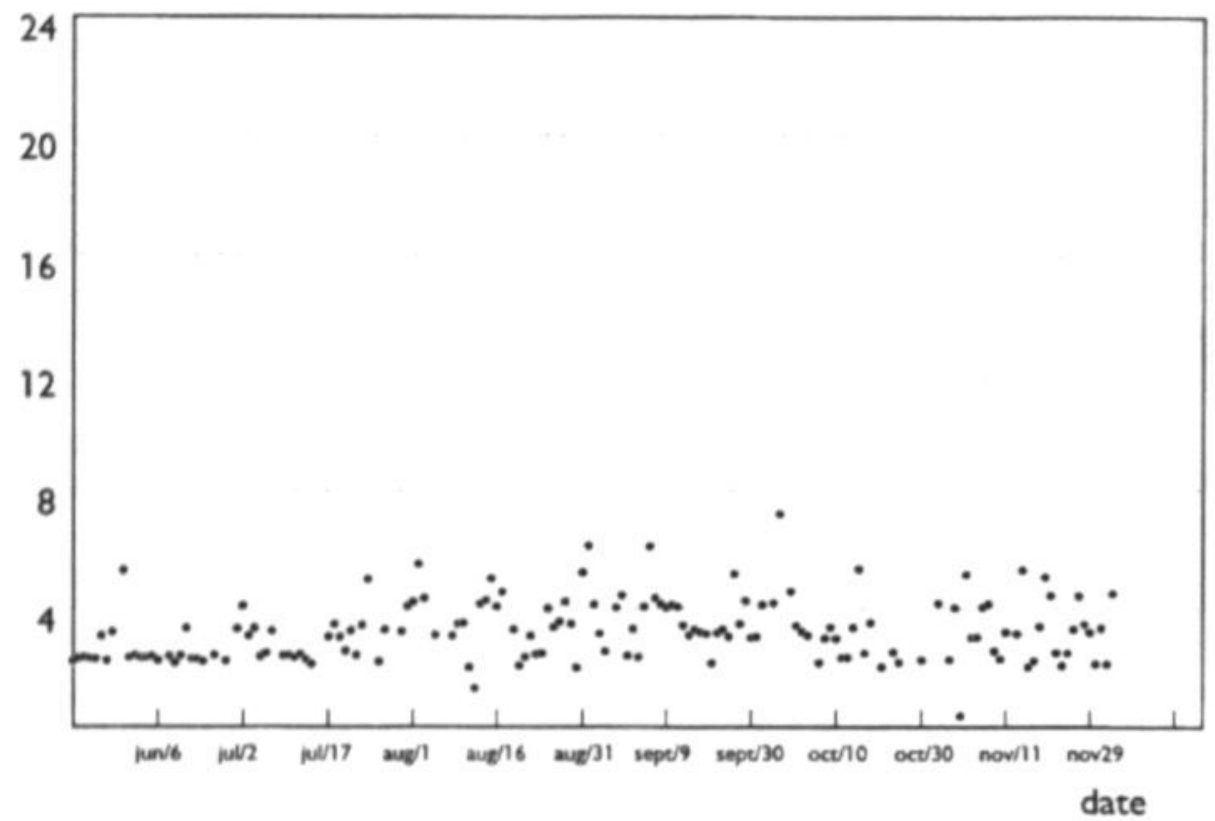

Table 1. Summary of the compliance data

\begin{tabular}{lccc}
\hline Patients & $\begin{array}{c}\text { Piroxicam } \\
(\mathrm{n}=34)\end{array}$ & $\begin{array}{c}\text { Tenoxicam } \\
(\mathrm{n}=31)\end{array}$ & $\begin{array}{c}\text { Total } \\
(\mathrm{n}=65)\end{array}$ \\
\hline Days monitored & & & \\
\% days on which at least 1 dose was taken & $83 \%$ & $78 \%$ & $81 \%$ \\
$\%$ days on which dose was taken as prescribed & $79 \%$ & $76 \%$ & $78 \%$ \\
$\%$ days with extra doses & $4 \%$ & $3 \%$ & $3 \%$ \\
\% days with missed doses & $17 \%$ & $22 \%$ & $19 \%$ \\
\hline
\end{tabular}

Percentages relate to the number of days missed

The 'day' as used in the analyses was defined as beginning at 03:00:00 local time and ending at the following 02:59:59. The 3 hour offset from the usual boundary of midnight was done so that the 'day' changed when dosing was least likely to occur. Doing so, as Norell noted, ${ }^{42}$ minimizes aliasing errors.

\section{RESULTS}

The 1-year trial was completed by 102 patients; 38 dropped out early for a variety of reasons, described in the original report ${ }^{40}$. Because enrolment had already begun before the electronic monitors were available, monitoring was confined to the latter 65 patients enrolled, creating a record of 14,607 monitored days ( 40.1 patient-years), with a mean length of $225 \pm 90$ (SD) days, ranging from 55 to 379 days. Overall, $80 \%$ of doses prescribed for the monitored intervals were recorded as taken; $61 \%$ of doses prescribed for the monitored intervals were recorded as taken within intervals of $24 \pm 6$ hours, that is, in reasonable concordance with once-daily dosing instructions. Extra doses were recorded as taken on $3.4 \%$ of monitored days, whereas no dose 
was recorded as taken on $19 \%$ of monitored days. Differences in compliance, missed doses and extra doses taken between both treatment groups were small, and not statistically significant (data not shown). Therefore the data of the two groups are pooled 40.

\section{Please Note: Table 2 is printed in chapter I, page 2426.}

We organized the data in a spread-sheet (Table 2), in which each row gives one patient's data, and the columns give, reading from left to right, some basic identifiers (including the assigned drug), followed by a variety of dosing errors. The errors include: single days when there was no record of dosing having occurred; sequential days of varying lengths ( 2 up to 9 ) when no record of dosing occurred; and five columns reserved for noting exceptionally long periods ( $>9$ days) of sequential days in which no record of dosing occurred. Continuing rightwards, we present data on the total number of days in which no doses were taken, the length of the monitored interval, and the overall percentage of prescribed doses taken (irrespective of timing) during the monitored interval.

Obviously, the formatting of the table can be adjusted according to the range of dosing errors found in particular studies. One could, for example, include columns for sequential days of extra dosing, and extra columns could be added to tabulate other types of dosing patterns that might arise in another study but were not observed in this study. The objective is to depict all dosing errors deemed, or suspected to be, clinically or pharmacologically salient.

Patients (rows) were rank-ordered by a selected variable, which we chose to be the percentage of days in which the prescribed number of doses were recorded as taken. Patients having identical values were ordered according to the length of the monitored period. Rank-ordering rearranges the data in a useful manner without censoring. The choice of variable to use in rankordering is, of course, arbitrary; the essential point is to rank-order the patients by a parameter that reflects the degree of correspondence with the prescribed regimen. A key consideration in choosing the percentage of days with the prescribed number of doses taken is that, unlike the often-used percentage of prescribed doses taken, it combines both 'taking' and 'timing' aspects of compliance, 40 and, as such, is the more stringent criterion. Rank-ordering can be repeated using other parameters of dosing, as the search for clinical correlates may suggest. If, for example, overdosing, rather than underdosing, were deemed an important issue, one could rank-order by extent of overdosing, for example, the number of days in which $\mathrm{N}$ or more doses were taken, or numbers of sequential days of overdosing.

Rank-ordering facilitates visualization of the range of patients total exposure to drug, as well as the extent and temporal patterning of lapses in dosing. The incidence and range of multiday lapses in dosing (drug 'holidays') is clearly evident, naturally becoming more extensive in the lower part of the table. Only 5 out of 65 patients had no dose-free days at all, while some had one, many had several, and the patients in the lowest portion of the table had so many no-dose days that their exposure to the drug was episodic, far from the continuity called for by the protocol.

The table provides much detailed data on each patient, and can be used as such, but when it is viewed from some distance, it presents a graphical quality that shows main features of the data. At the top of the table one sees patients who have no entries to the right of the identifiers, 
because their dosing histories were in close conformity to the prescribed regimen, with uninterrupted continuity of drug exposure.

Moving downwards, one sees progressively more entries to the right of the identifiers, representing more and bigger deviations from the regimen, in various patterns, with growing divergence between actual and prescribed amounts of drug taken. Drug exposure, as one moves downward in the table, becomes progressively more episodic.

\section{DISCUSSION}

Table 2's graphical feature highlights the large magnitude of inter-patient differences in drug exposure. By ignoring these differences, as the intention-to-treat policy for trials analysis requires, one may end up with averages that hardly reflect dose-dependent treatment responses of the majority of patients. While the range of drug exposure may or may not be similar in both trial and practice settings, it is so wide, so skewed in the direction of underdosing, and so qualitatively different at the extremes, that the all-patient average is not informative of the numerical majority of patients whose drug exposure, though not perfectly in conformity with the prescribed regimen, is nearly so. Even if one had a very large data set, the graphical feature allows fast identification of a group of patients in which compliance appears to be more prevalent then desirable, and a closer look would quickly reveal the detailed information of that particular subset.

The contrast is stark between the continuity of drug exposure among the most versus the least compliant patients. Considering the painful nature of ankylosing spondylitis, it is surprising to see the sparing use by some patients of drugs that have wellestablished and consistent analgesic effects. As previously discussed, 40 there was no evident correlation between clinical parameters of disease severity and dosing histories. Thus, the results were also challenging to the present clinical understanding of the dynamics of action of NSAIDs in this disease.

Another notable and surprising result is that the range of compliance in this study was similar to What has been found with electronic monitoring in a wide range of diseases, severity of disease, and prognosis ${ }^{10,26}$. It seems that the range of compliance is rather consistent with chronic-use agents by patients not especially selected for compliance behaviour. Patient selection that is based, explicitly or implicitly, on responses to previously prescribed drug regimens may, of course, tend to select for particular degrees of compliance, for example persistent nonresponse is likely to have its origins in persistently poor compliance. On the other hand, Petri has provided a presumptive example of selection for especially good compliance ${ }^{43}$. Our study appears not to have engaged either type of selection mechanism, and so is presumably reflective of the range of compliance one might expect to find in clinical trials. It also demonstrates again that a once-daily dosing regimen does not, per se, ensure good compliance.

\section{Drug Holidays}

Table 2 also emphasizes the relatively high incidence of drug 'holidays' - usually defined as three sequential days without dosing. With a once-daily dosing regimen, as in the present study, holidays usually begin with a sudden transition from a period of correct dosing to a period with no dosing - in effect, a sudden halt in dosing. Some days later, dosing resumes. One naturally wonders whether these sudden transitions have any special consequences. Surveying the literature for information on this point, one is struck by a structural bias within clinical 
pharmacology toward studying the onset of drug action, as dosing begins, ignoring what occurs when dosing suddenly stops 26 . Thus, the extent to which 'rebound' effects may occur is relatively obscure; known examples involve routinely measured variables, for example, heart rate, or are vivid enough to have been detected observationally.

Drug holidays have an end as well as a beginning, and the ending is usually no less abrupt than the beginning. Thus, the table also highlights a further issue, arising with drugs that have a substantial 'first dose effect'. This term refers to the situation in which patients often cannot tolerate the full, therapeutic dose from the outset of treatment, and so require that dosing begin with careful, stepwise increases in quantity administered. Examples of drugs in which a first dose effect is especially prominent are prazosin ${ }^{44}$ and flecainide ${ }^{45}$. Each involves rather vivid effects, with variable potential for hazard. However, first-dose effects probably vary in degree, with some probably being not so severe as to force gradual titration, but still having a certain potential for mischief.

One consequence of the discovery of drug holidays is the recognition that first-dose effects are often far from a one-time affair, but may be repeated again and again in the same patient, depending on the pattern and length of holidays needed to restore conditions for a first-dose effect. Clinical pharmacologists are gradually recognizing the need to pay more attention to the 'off' side of the frequent on and off transitions in dosing. The table is a useful way to identify patients whose holiday dosing patterns conform to certain criteria of prior drug exposure, suddenness of transition, length of dose-free interval, and so forth.

\section{Dosing intervals}

We opted not to include information on intervals between doses, per se, though the data are available. One could, for example, ignore the formalism of the 'day', and focus instead on ranges of intervals between doses. That might be useful in the case of an agent whose duration of action was in the vicinity of 24 hours, such that a few hours difference in dosing interval might have a strong influence on the expression of drug action. Such instances have been reported with atenolol, ${ }^{39}$ the combined oral contraceptives, ${ }^{32}$ and the progestin-only oral contraceptive 46. One could also classify doses by when they occurred within the 24 hour cycle, if, for example, chronopharmacologic effects were of interest. Colour-coding or otherwise marking rows according to the occurrence/non-occurrence of various types of clinical events may facilitate recognition of the dosing correlates of those events.

\section{Overview}

Formatting the data in the manner of the table brings to the fore many questions - most notably, perhaps, about the genesis of the wide range in dosing and the impact that it has on conventional means of analysis. One is led to consider possible experimental designs that can avoid limitations of present means of analysing data from drug trials:

- What is the impact of the wide range of drug exposure on the results of intention-totreat analysis?

- What are the reasons for such a wide range in dosing?

- Is it possible to identify in a qualification period 47 the patients destined to occupy the lower part of the table, in order to drive drug exposure into closer correspondence with the prescribed regimen, or to be able to perform a balanced randomization of patients 
by compliance to ensure more nearly comparable degrees of variable drug-exposure between treatment arms than might arise from simple randomization?

In respect to the first question, we have included a specially marked row with the averaged values for all recipients of the drugs, showing the wide range of drug exposure above and below the average. Levy has given an illuminating discussion of the various factors that may render the actions of a particular drug either highly dependent on, or relatively independent of, such variations in drug exposure ${ }^{48}$. The second and third questions are challenging, but beyond the scope of this paper.

\section{CONCLUSIONS}

It is useful to present data on patient compliance with protocolspecified drug regimens in a spread-sheet form in which each row represents an individual patient's data, and columns indicate the incidence of various patterns of non-compliant dosing. The rows are rank-ordered by a parameter that reflects differential degrees of drug exposure; we used the percentage of treatment days with correct dosing, which integrates both dose-taking and dose-timing aspects of compliance. The resulting table, which reduces a large amount of raw data on times/dates of individual doses, thus has the attributes of a graph as well. Understanding the clinical correlates of variable drug exposure may be facilitated by colour-coding, or otherwise marking, individual rows according to the occurrence of certain clinical or other events or outcomes. If a particular pattern of dosing appears to have important consequences, its incidence may be a useful aiternative rank-oratening parameter.

\section{REFERENCES}

1. Kass, M. A., Gordon, M., Morley, R. E., Meltzer, D. W. and Goldberg, J. J. Compliance with topical timolol treatment, American Joumal of Ophthalmology, 103, 188-193 (1987).

2. Cramer, J. A., Mattson, R. H., Prevey, M. L., Scheyer, R. D. and Ouellette, V. L. How often is medication taken as prescribed? A novel assessment technique, Joumal of the American Medical Association, 261, 32733277 (1989).

3. Averbuch, M., Weintraub, M. and Pollack, D. J. Compliance assessment in clinical trials: the MEMS device, Journal of Clinical Research in Pharmacoepidemiology, 4, 199-204 (1990).

4. Eisen, S. A., Woodward, R. S., Miller, D., Spitznagel, E. and Windham, C. A. The art of medication compliance on the control of hypertension, Joumal of General Internal Medicine, 2, 298-305 (1987).

5. Kass, M. A., Zimmerman, T., Yablonski, M. and Becker, B. Compliance to pilocarpine therapy, Investigations in Ophthalmology, (ARVO abstracts supplement), 108, abstract 2 (1977).

6. Urquhart, J. Patient compliance with prescribed drug regimens: overview of the past 30 years of research, in Nimmo, W. S. and Tucker, C. T. (eds), Clinical Measurement in Drug Evaluation, Wiley, Chichester, 1995, pp. 213 227.

7. Feinstein, A. R. On white-coat effects and the electronic monitoring of compliance, Archives of Internal Medicine, $150,1377-1378(1990)$.

8. Bond, W. S. and Hussar, D. A. Detection methods and strategies for improving medication compliance, American Joumal of Hospital Pharmacy, 48, 1978-1988 (1991).

9. Kruse, W. Patient compliance with drug treatment - new perspectives on an old problem, Clinical Investigations, 70, 163-166 (1992).

10. Cramer, J. A. Microelectronic systems for monitoring and enhancing patient compliance with medication regimens, Drugs, 49, 321-327 (1995).

11. Potter, L. S. Oral contraceptive compliance and its role in the effectiveness of the method, in Cramer, J. A. and Spilker, B. (eds), Compliance in Medical Practice and Clinical Trials, Raven Press, New York, 1991, pp. 195-207. 12. Tashikin, D. P., Rand, C., Nides, M., Simmons, M., Wise, R., Coulson, A. H., Li, V. and Gong. H. Jr. A nebulizer chronolog to monitor compliance with inhaler use, AJM, 91, (suppl 4A), 33S-36S (1991).

13. Mawhinney, H., Spector, S. L., Kinsman, R. A., Siegel, S. C., Rachelefsky, G. S., Katz, R. M. and Rohr, A. S. Compliance in clinical trials of two nonbronchodilator, antiasthma medications, Ann All, 66, 294299 (1991). 
14. Pullar, T. and Feely, M. Problems of compliance with drug treatment: new solutions?, Pharm J, 245, 213215 (1990).

15. Vander Stichele, R. Measurement of patient compliance and the interpretation of randomized clinical trials, European Joumal for Clinical Pharmacology, 41, 27-35 (1991).

16. Rudd, P. Compliance with antihypertensive therapy, a shifting paradigm, Card Rev, 2, 230-240 (1994).

17. Waterhouse, D. M., Calzone, K. A., Mele, C. and Brenner, D. E. Adherence to oral tamoxifen: a comparison of patient sellf-report, pill counts, and microelectronic monitoring, Journal of Clinical Oncology, 11, 11891197 (1993).

18. Matsui, D., Hermann, C., Braudo, M., Ho, S., Olvieri, N. and Koren, G. Clinical use of the Medication Event Monitoring System: a new window into pediatric compliance, Clinical Pharmacology and Therapeutics, 52, 102103 (1992).

19. Guerrero, D., Rudd, P., Bryant-Kosling, C. and Middleton, B. F. Antihypertensive medicationtaking. Investigation of a simple regimen, American Joumal of Hypertension, 6, 586-592 (1993).

20. Matsui, M., Hermann, C., Klein, J., Berkowitch, M., Olivieri, N. and Koren, G. Critical comparison of novel and existing methods of compliance assessment during a clinical trial of an oral iron chelator, Joumal of Clnical Pharmacology, 34, $944-949$ (1994).

21. Kalvik, A., Kwok, M., Tseng, A., Currie, N., Busto, U. E. and Naranjo, C. A. Variations in medication management systems (MEMS) performance, Clinical Pharmacology and Therapeutics, 55, 157 (1994).

22. Cramer, J. A., Scheyer, R. D. and Mattson, R. H. Compliance declines between clinic visits, Archives of Intemal Medicine, 150, 1509-1510 (1990).

23. Pullar, T., Kumar, S., Tindall, H. and Feely, M. Time to stop counting the tablets?, Clinical Pharmacology and Therapeutics, 46, 163-168 (1989).

24. Rubio, A., Cox, C. and Weintraub, M. Prediction of diltiazem plasma concentration curves from limited measurements using compliance data, Clinical Pharmacokinetics, 22, 238-246 (1992).

25. Rubin, D. Comment: dose-response estimands, Joumal of the American Statistical Association, 86(413), $22-24$ (1991).

26. Urquhart, J. Role of patient compliance in clinical pharmacokinetics: review of recent research, Clinical Pharmacokinetics, 27, 202-215 (1994).

27. Efron, B. and Feldman, D. Rejoinder, Joumal of the American Statistical Association, 86(413), 25-26, (1991).

28. Efron, B. and Feldman, D. Compliance as an explanatory variable in clinical trials, Joumal of the American Statistical Association, 86(413), 9-17 (1991).

29. Katz, R. Regulatory view. use of subgroup data for determination of efficacy, in Cramer, J. A. and Spilker, B. (eds), Compliance in Medical Practice and Clinical 'rials, Raven Press, New York, 1991, pp. 251-264.

30. The Lipid Research Clinics Coronary Primary Prevention Trial results: (I) Reduction in incidence of coronary heart disease; (II) The relationship of reduction in incidence of coronary heart disease to cholesterol lowering, Journal of the American Medical Association, 251, $351-374$ (1984).

31. QUESTRAN (cholestyramine). Physicians Desk Reference, 49th edn. Medical Economics Press, Oradell, NJ, 1995, pp. 736-738.

32. Guillebaud, J. Any questions, British Medical Journal, 307, 617 (1993).

33. Lasagna, L. and Hutt, P. B. Health care, research, and regulatory impact of noncompliance, in Cramer, J. A. and Spilker, B. (eds), Compliance in Medical Practice and Clinical Trials, Raven Press, New York, 1991, pp. 393403. 34. Sheiner, L. B. and Rubin, D. B. Intention to treat analysis and the goals of clinical trials, Clinical Pharmacology and therapeutics, 57, 6-15 (1995).

35. Urquhart, J. Patient compliance as an explanatory variable in four selected cardiovascular studies, in Cramer, J. A. and Spilker, B. (eds), Compliance in Medical Practice and Clinical Trials, Raven Press, New York, 1991, pp. 301-322.

36. Peck, C. C., Barr, W. H., Benet, L. Z., Collins, K, Desjardins, R. E., Furst, D. E., Harter, J. G., Levy, G, Ludden, T., Rodman, J. H., Sanathanan, L., Schentag, J. J., Shah, V. P., Sheiner, L B., Skelly, J. P., Stanski, D. R., Temple, R. J., Viswanathan, C. T., Weissinger, J. and Yacobi, A. Opportunities for integration of pharmacokinetics,

pharmacodynamics, and toxicokinetics in rational drug development, Clinical Pharmacology and Therapeutics, 51, 465-473 (1992).

37. Peck, C. C. Clinical new drug development: How golden are the eggs? Inaugural professional lecture, University of Leiden, the Netherlands, 29 March 1994. Privately printed.

38. Urquhart, J. Correlates of variable patient complance in drug trials: relevance in the new health care environment, in. Testa, B. and Meyer, U. A. (eds), Advances in Drug Research, Academic Press, London, 1995, pp. 237-257.

39. Johnson, B. F. and Whelton, A. A study design for comparing the effects of missing daily doses of antihypertensive drugs, American Journal of Therapeutics, 1, 260-267 (1994).

40. de Klerk, E. and van der Linden, S. Compliance monitoring of NSAID drugtherapy in ankylosing spondylitis, experiences with an electronic monitoring device, British Journal of Rheumatology, 35, 60-65 (1996).

41. van der Linden, S., Valkenburg, H. A. and Cats, A. Evaluation of diagnostic criteria for ankylosing spondyilitis: a proposal for modification of the New York criteria, Arthritis and Rheumatism, Z, 361-368 (1984). 
42. Norell, S. E., Granstrom, P. A. and Wassen, R. A medication monitor and fluorescein technique designed to study medication behaviour, Acta Ophthaimology, 58, 459 (1980).

43. Petri, H. and Urquhart, J. Patient compliance with betablocker medication in general practice, Pharmacoepidemiology and Drug Safety, 3, 251-256 (1994).

44. Prazosin hydrochloride. Physicians Desk Reference, 49th edn, Medical Economics Press, Oradell, NJ, 1995, pp. 1873-1874.

45. Flecainide acetate. Physicians Desk Reference, 49th edn, Medical Economics Press, Oradell, NJ, 1995, pp. 13871390.

46. McCann, M. F. and Potter, L. S. Progestin-only oral contraception: a comprehensive review, Contraception, $\mathbf{5 0 ,}$ (suppl 1), S9-S195 (1994).

47. Knipschild, P., Leffers, P. and Feinstein, A. R. The qualification period, Joumal of Clinical Epidemiology, 44, 461 464 (1991).

48. Levy, G. A pharmacokinetic perspective on medicament noncompliance, Clinical Pharmacology and Therapeutics, 54, 242-244 (1993). 


\title{
Development of a questionnaire to explore the likelihood and underlying factors for variable patient compliance on anti- rheumatic drug therapy.
}

\section{Erik de Klerk ${ }^{1}$, Désirée van der Heijde ${ }^{1}$, Hille van der Tempel ${ }^{2}$, Sjef van der Linden 1.}

1: Department of Rheumatology, Universtiy Hospital Maastricht, PO Box 5800, 6202 AZ Maastricht.

2: Department of Rheumatology, Maasland Hospital Sittard, PO Box 5500, 6130 MB Sittard.

Manuscript published as: de Klerk E, van der Heijde $D$, van der Tempel $H$, van der Linden $S$. Development of a questionnaire to explore the likelihood and underlying factors for variable patient compliance on anti-rheumatic drug therapy. Joumal of Rheumatology 1999;26(12): $2635-41$

\begin{abstract}
Objective: to develop a rheumatology oriented questionnaire that measures compliance to drug regimen and identifies factors that contribute to sub-optimal patient compliance in patients with rheumatoid arthritis (RA), polymyalgia rheumatica (PMR) and gout.

Methods: 32 patients (16 RA, 8 PMR, 8 gout) participated in semi-standardized home interviews about their attitude toward their anti-rheumatic medication, actual drug intake and reasons for not taking medication. A focusgroup-interview with 7 patients ( 3 RA, 2 PMR, 2 gout) was held. Following an advertisement in the rheumatology patient-organization magazine $(>8,000$ patients) 14 patients (9 RA, 5 PMR) called and explained their reasons for noncompliance. All interviews were recorded on tape, transcribed, and independently reviewed by 2 investigators. Thirty-one statements were selected. After a field test, the phrasing of some items was revised. The questionnaire was then sent by mail to 117 consecutive outpatients (58 RA, 30 PMR, 29 gout).

Results: 12 items were excluded because of low or high corrected item-total correlation or skew distribution of the answers. Internal consistency of the remaining 19 items was intermediate (0.71). Discriminant analyses with an overall patient self-report compliance measure showed a sensitivity of $98 \%$, a specificity of $67 \%$ and a Cohen's Kappa of 0.71 . Stepwise discriminant analyses revealed that 3 items classified $84 \%$ of all cases correct with a sensitivity of $99 \%$, a specificity of $80 \%$ and a Kappa of 0.78 .

Conclusion: The 19-item measure was well accepted. It is useful to detect possible barriers for optimal compliance and predicting patient compliance to drug regimen.
\end{abstract}

\section{Support}

This project was supported by grant NR 831 from the Dutch League against Rheumatism ('Nederlands Reumafonds'). 


\section{Introduction}

Given a good indication for drug-therapy, patient compliance to the prescribed drug-regimen is a prerequisite for adequate therapeutic response. However, it is widely known that not all drugs prescribed for ineumatic conditions are taken as advised. Estimates for the percentage of prescribed anti-rheumatic drugs actually taken range between 30 and $80 \%{ }^{1-4}$. These figures, though partly obtained with compliance measurement instruments now regarded as inadequate such as pill-counts and physician estimates, emphasize the importance of exploring patient compliance in greater detail 5 .

Electronic monitoring (EM) systems that record time and date on every occasion that the medication package is opened provide very detailed and precise dosing histories assuming that opening the cap represents drug intake. These systems are currently regarded as the gold standard for compliance measurement 5,6 . Although it is possible to employ the system in everyday clinical practice its use has been as a clinical research tool mainly.

Measurement of chemical substances in body fluids (such as active drugs, metabolites or markers in plasma, urine, saliva, hair or exhaled air provide prove of ingestion of the drug, but usually suffer from sampling restrictions: the observed concentrations only reflect intake over a relatively short period of time prior to ingestion 7-21. Most of these methods are invasive, require explicit patient consent, special laboratory equipment and personnel and are limited by large inter- and intra-patient variations 22 . Therefore, these methods have been used only sparsely in assessing compliance and are not suitable for use in clinical practice.

Patient administered questionnaires are easy-to-use and widely accepted measurement instruments ${ }^{23}$. A questionnaire can serve as an accurate measurement instrument as well as a platform to explore various related issues, an obvious advantage above technical devices such as electronic monitoring and determination of chemical substances. It also has advantages above interview techniques: questionnaires provide standardized answer categories that make it much easier to interpret and process the data ${ }^{23}$, and has a great advantage in feasibility (e.g. cheaper, no trained interviewers needed). However, only a few compliance questionnaires are available 2428 , none of which has been validated in rheumatic diseases.

Therefore, we set out to develop a iheumatology oriented questionnaire that measures compliance to drug regimen, identifies factors that contribute to sub-optimal patient compliance and possibly, can be used to predict future compliance in patients with rheumatoid arthritis (RA), polymyalgia theumatica (PMR) and gout. RA was chosen because of its high relevance to rheumatology and especially because of the relevance of compliance with the so-called disease modifying anti-iheumatic drugs ${ }^{29}$. PMR is of interest because of the high efficacy of prednisone/prednisolone treatment and the possible rebound effects following interruption of drug-therapy. Gout was thought to be of interest because of our clinical impression that variable compliance is not infrequent in this patient group.

\section{Methods}

The development procedure comprised a 4-step process: 1. a patient-based collection of all possible items that could be applicable to the question under scrutiny, 2 . selection of relevant items from this pool and construction of a scale; 3 . field test to evaluate the preliminary questionnaire on practical issues like the acceptance by patients, the accuracy and lucidity of 
the questions and the time required to complete; and 4. mailing of the questionnaire to test internal consistency, test-retest-reliability, criterium- and convergent/divergent validity.

All patients were recruited from the outpatient clinic of the University Hospital Maastricht. This hospital serves as a secondary / tertiary referral center for the southernmost province of the Netherlands. Approval for all stages was obtained from the medical ethical committee from the University Hospital Maastricht.

We compared the performance of our questionnaire with the Long Term Medication Behavior Scale (LTMBS), a 26-item measure developed and tested in transplant patient groups 24,26 . This questionnaire was available in Dutch, has been welltested, and has proven to be of value in the field of measurement of compliance in transplant patients.

In addition, we devised 6 descriptions of patients and their compliance based on our subjective impression of patient compliance patterns (table 1). These patterns can be summarized as follows: 1. perfect complier, 2. very good complier, 3. good compliance with infrequent omissions, 4 . intermediate compliance with frequent omissions, 5. low compliance, 6 . denial of disease and not compliant. Patients are asked which description they believe describes themselves best. This measure is used as a surrogate gold standard for patient compliance.

\section{Item collection.}

First, a question-route ${ }^{30}$ was devised from concepts related to patient compliance found in the scientific literature and from the experience of participating theumatologists and investigators. It included questions on patients' knowledge of their disease and drug-therapy, attitude toward their anti-rheumatic medication, actual drug-intake and reasons for not taking the medication or taking more than prescribed, as well as previous experience with drug-regimen, support from the partner and difficulties in the every-day execution of the regimen. Feasibility of the questionroute was tested in 5 pilot interviews with RA patients.

Thirty-two consecutive outpatients (16 RA, 8 PMR, 8 gout) who were willing to participate were visited in their home by one investigator $(E d K)$ for a semi-standardized interview. Patients were encouraged to openly discuss any subject related to drug-intake they wanted to; the questionroute served merely as a guidance to ensure that all relevant topics were addressed.

Furthermore, a focus group interview (FGI) with 7 consecutive outpatients (3 RA, 2 PMR, 2 gout) was held.

FGI can be used to explore patients' opinions to a deeper extent by taking advantage of group discussion and subsequent clarification of patients' views and ideas 30,31 . In addition, to allow for input from outside our region we placed an advertisement in the Dutch rheumatology patient organization magazine "In Beweging" (over 8,000 patients are subscribed) which asked patients to call the investigator (anonymously) if they had ever deviated from the drug regimen prescribed by their rheumatologist, to explain their reasons for doing so. Fourteen patients ( 9 RA and 5 PMR) called the investigator and openly discussed their reasons for deviations from the prescribed drug-regimen. All home-interviews and focus-group interview were recorded on tape and transcribed. Careful notes were taken from the telephone-interviews. 
Table 1: Patient descriptions:

Instruction:

Below you find 6 descriptions of 6 different patients. Try to indicate which of the descriptions describes yourself best. It is possible that only part of the description describes you. In that case, try to select the description that is most appropriate for you situation. Where the description says 'he' you can of course also read 'she'.

\section{Patient 1:}

Patient 1 is very punctual, in everything he does. He gets up every day at the same moment, eats at the same moment, and takes his drugs at the same moment. There is never more then 15 minutes difference in the moment of taking the drug. Forgetting to take the medicines occurs never.

\section{Patient 2:}

Patient 2 is also very punctual, but somewhat less so then patient 1. Every now and then he deviates a little from the daily routines. He takes essentially all medicines, but the timing with which he takes them may vary a little. Very infrequently, like 2 times per month, he forgets to take his anti-meumatic medicines.

\section{Patient 3:}

Patient 3 is less punctual. He likes change. He also does not want to have his life dictated by his disease or medicines. He is also less punctual in taking his medicines. He takes most of the prescribed tablets, but the timing varies and it happens every now and then, conscious or unconsciously, skips a scheduled dose, approximately 6 times per month.

\section{Patient 4:}

Patient 4 does not care very much about the medicines. There may be many causes for this, like inactive disease or other things that require attention. Therefore there is not much regularity in taking the drugs and it happens often that he doesn't take the medicines,approximately 15 times per month.

\section{Patient 5:}

Patient 5 does almost not take any of the medicines from his meumatologist. Sometimes there is a period in which he takes a couple of tablets, but overall there are more days that he does not take any drugs then that he does.

\section{Patient 6:}

Patient 6 denies being ill. The theumatologist may say that there is something wrong, but he does not agree with that at all. Of course this has consequences for taking the drugs, these are almost never taken.

\section{Item selection and scale construction.}

Two investigators (EdK and DvdH) independently reviewed all interviews for patients' remarks relating explicitly to their compliance to drug regimen. All unique remarks were listed. This resulted in an initial list of 96 statements. Categorization of these 96 items and selection of the best representative of such a category resulted in 31 items. For example: several items related to 'trust in the rheumatologist' as an important factor for compliance with the drug regimen, but all in different wordings. We chose the item which represented the issue 'trust in rheumatologist' best.

As answering scale, we chose a 4 point Likert scale with anchors 'don't agree at all, 'don't agree', 'agree', and 'agree very much'. 


\section{Field test}

Twelve patients (6 RA, 3 PMR and 3 gout) completed the questionnaire in presence of the investigator (EdK). The questionnaire was well accepted, none of the patients had any problems completing the questionnaire. However, the phrasing of several items was revised according to patients' comments and the layout was altered to enhance clarity and ease of completion. The average time needed for completion was approximately 12 minutes.

\section{Mailing}

Thereafter the resulting questionnaire, named CQR (Compliance Questionnaire Rheumatology) was sent by mail to 117 consecutive patients ( 58 RA, 30 PMR, 29 gout). We included the LTMBS as a comparator. If no response was available after 2 weeks, a postal reminder was sent. One month after the questionnaire was received, an identical second set of the 2 questionnaires was sent to all responders to assess test-retest reliability. Again, if no answer was received after 2 weeks a postal reminder was sent to the patients.

\section{Statistical analyses}

The CQR and LTMBS were analyzed in parallel to ensure equal opportunities for both questionnaires to prove their value in a meumatic population. Some of the items in the CQR ask for a negative response (example: I don't like to take medicines. If I can do without them I will). To obtain a useful total score several items were recoded (score $1 \rightarrow 4,2 \rightarrow 3,3 \rightarrow 2,4 \rightarrow 1$ ), denoted in Appendix 1. This results in a total score where higher scores should be related to higher compliance. Throughout the analyses, the patient descriptions (table 1) served as surrogate gold standard.

The item reduction procedure utilized 1. skewness of answer distribution ( $>90 \%$ of all responses in one category), 2. very low $(<0.20)$ or very high $(>0.80)$ corrected item-total correlation, and 3. internal consistency as estimated by Cronbach's alpha (32), with recalculation of alpha after removal of each of the individual items. Test-retest reliability was assessed by calculating Intra Class Correlation Coefficients (ICC), a measure of concordance that corrects for systematic errors (33).

To deal efficiently with missing values, for the CQR we ruled out patients with 4 or more missing items out of the analyses and substituted missing values for patients with 3 or less missing values with the patients average on all non-missing items.

Discriminant analyses, forward stepwise discriminant analyses and factor analyses were used to analyze the value of the questionnaire against the surrogate gold standard. Sensitivity, specificity and the agreement beyond chance (expressed as Cohen's Kappa) were used to summarize the concordance between the questionnaire results and the surrogate gold standard. All analyses were conducted on an IBM compatible personal computer in SPSS for Windows 95 version 7.0 . 
Table 2: Demographic data of the patients who retumed the first mailing.

\begin{tabular}{lcccc}
\hline & \multicolumn{3}{c}{ Gender } & \multicolumn{2}{c}{ Male } \\
\cline { 2 - 5 } & Count & Age (st.dev.) & Count & Age (st.dev.) \\
\cline { 2 - 5 } $\begin{array}{l}\text { Rheumatoid } \\
\text { Arthritis }\end{array}$ & 34 & $61(14)$ & 18 & $67(20)$ \\
$\begin{array}{l}\text { Polymyalgia } \\
\text { Rheumatica }\end{array}$ & 16 & $71(12)$ & 2 & $73(4.1)$ \\
Gout & 2 & $77(4.6)$ & 15 & $60(12)$ \\
\hline Total & 52 & $64(14)$ & 35 & $64(16)$ \\
\hline
\end{tabular}

\section{Results}

Table 2 shows some demographic data. The postal survey had a response rate of $75 \%$ after one reminder. The age distribution between the responders and non-responders was not significantly different. Only $58 \%$ of all LTMBS questionnaires were returned without any missing data, contrasted with $95 \%$ of all CQR questionnaires. There were no missing data for the patient descriptions.

Figure 1 shows the self-categorization of patients in several categories of compliance.

Descriptions $1-3$ were used by the great majority of the patients, reflecting a very high self perceived compliance rate.

Figure 1: Self categorization of patients into categories of compliance.

\section{Percentages of Self-Reported Drug Intake}

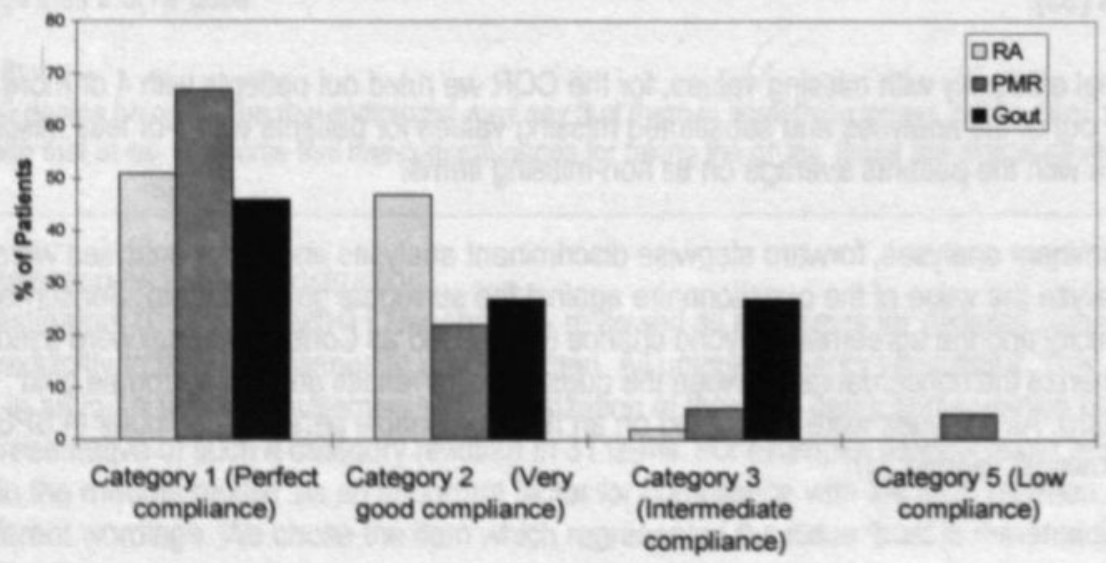

Self-Reported Drug Intake

To determine the relative value of the individual items we performed various tests. First, the consistency of responses was assessed by calculating the percentage response in one answer 
category (e.g. "completely agree"). ltems were deleted when $>90 \%$ of all answers were in one category, indicating questions that don't differentiate between patients. This resulted in the deletion of 1 item from the CQR and 7 items from the LTMBS. Second, items were checked for the corrected-item total correlation (cITC) and deleted if cITC $<0.20$ (reflecting items lacking correlation with the overall concept of the measure, being patient compliance) and deleted if cITC $>0.80$ (reflecting items that do not contribute to the diversity of reasons for the overall concept) ${ }^{34}$. This resulted in the removal of 11 CQR items and 6 LTMBS items. Finally, a check was performed whether the internal consistency (as indicated by Cronbachs' Alpha) rose importantly $(>0.05)$ upon removal of any of the resulting items 23 . This was not the case, indicating heterogeneity of the remaining items.

Therefore, we proceeded with the CQR with 19 questions (Appendix 1) and the LTMBS with 15 questions (Appendix 2).

Reliability was assessed by the one-month test-retest study. The response rate (again after one reminder) was $80 \%$, equal to $60 \%$ of the originally sent questionnaires. For the CQR test-retest reliability was satisfactory: there was no statistically significant difference in CQR-total score between the 2 measurements. Average score $+1-$ standard deviation was $62+1-7$ on the first measurement and $62+1-7$ after one month, whereas the intra-class correlation coefficient (ICC) was intermediate: 0.73 . The LTMBS was more variable: the overall score rose within 1 month from $75+1-21$ to $83+1-27(p=0.006)$ and the ICC was 0.31 , reflecting instability of the measurement.

Table 3: Performance of CQR and LTMBS.

\begin{tabular}{lcc}
\hline & CQR & LTMBS \\
\hline $\begin{array}{l}\text { Internal Consistency } \\
\text { (Cronbachs Alpha) }\end{array}$ & 0.71 & 0.82 \\
& & \\
Discriminant Analyses & & \\
- sensitivity & $98 \%$ & $88 \%$ \\
- specificity & $67 \%$ & $96 \%$ \\
- Kappa & 0.71 & $75 \%$ \\
& & 0.64 \\
Stepwise discriminant & 3 items qualified & 0 items qualified \\
analyses & & \\
- sensitivity & $99 \%$ & \\
- specificity & $80 \%$ & \\
- kappa & 0.78 & \\
& & \\
\hline
\end{tabular}

1:CQR: 3 items qualified for stepwise discriminant analyses:

- I take my medicines because I have complete confidence in my rheumatologist.

- If I don't take my anti-rheumatic medicines regularly, the inflammation returns.

- It happens every now and then, that we go out for the weekend and then I don't take my medicines.

Table 3 shows the performance of the 2 questionnaires. Internal consistency as measured by Cronbachs' Alpha was 0.71 for the CQR and 0.82 for the LTMBS. Discriminant analyses, the derivation of a mathematical equation from all 19 items in the CQR to classify patients in 2 
groups, compliers (defined as self-categorization as patients 1 or 2 on the patient descriptions) and noncompliers (defined as self-categorization as patients $3-6$ on the patient descriptions), classified $88 \%$ of all patients correctly. Sensitivity of the CQR and LTMBS to detect noncompliance were $98 \%$ and $96 \%$ respectively, and specificity of the CQR and LTMBS to detect noncompliance were $67 \%$ and $75 \%$, respectively. Cohens' Kappa, a measure for the correct classification beyond chance, was good with 0.71 and 0.64 for CQR and LTMBS, respectively.

Thereafter, forward stepwise discriminant analyses, an attempt to build an equation that classifies as many patients correctly with as little items as possible showed that only 3 CQR items are needed to reach a sensitivity of $99 \%$, a specificity of $80 \%$, and a Kappa of 0.78 . There was no such simplification possible of the equation of the LTMBS.

Sub-group analyses using analyses of variance (ANOVA) did not show significant differences between the 3 diseases on CQR and LTMBS total scores.

Convergent/divergent validity.

Comparison of the 2 measures showed high divergent validity: the average inter-item correlation was 0.03 , correlation of the CQR-total score and the LTMBS-total score was 0.0623 . This indicates that although both measures seem to measure the same concept, they seem to do so in unrelated ways.

\section{Discussion}

This study shows that it is possible to develop a patient-oriented questionnaire that can classify patients with high accuracy into several classes of self-reported compliance. The CQR showed high sensitivity and satisfactorily specificity to detect sub-optimal compliance. It was received well by patients, is relatively short of length ( 19 items) and provides a stable measurement over time.

The selection of the 3 different disease groups (RA, PMR and gout) who participated in the development procedure deserves closer attention. Together, the 3 diseases represent an important part of all patients seen at the rheumatology outpatient clinic. More importantly, they represent examples of diseases where one could expect compliance patterns to be different due to the various degree of symptom relief ${ }^{35}$. In PMR, symptom relief is usually good and fast after prednisone administration, while in RA symptom relief is variable and at times seemingly independent of adequate drug intake. Gout represents a disease where compliance may vary with the frequency and severity of gout attacks, but where long-term compliance to drug therapy may be required even in the absence of symptoms. The current questionnaire was developed to reflect all these situations, even though it may be possible in the future to modify this instrument to make it more versatile in either of these directions.

The patients who participated in the item-collection procedure were all consecutively seen at our rheumatology outpatient clinic and thus may be seen as representatives of a larger group. Since compliance distributions are usually skewed ${ }^{36}$, we increased the chances of finding all reasons for low compliance by specifically inviting low-compliers to call the investigator by an advertisement in the Dutch Rheumatology organization magazine. 
The response at the mailing of $75 \%$ may have resulted in some selection toward a more compliant group of patients. The comparison of age between the responders and nonrepsponders showed no differences, but age is in general not well associated with compliance.

For the purpose of the development of the questionnaire and the first series of tests we deemed it possible to compare the overall score against a self-developed, surrogate gold standard: 6 patient descriptions. The descriptions were based on our experience of approximately 40 patient interviews, our understanding of the scientific literature and analyses of varbus compliance datasets. However, it has been shown that self-report instruments usually overestimate true compliance rates 6.37 . The fact that the total-score of the CQR was able to classify patients with high accuracy does therefore not automatically mean that it will also be able to classify patients with similar accuracy when compliance is measured with more advanced measurement instruments. To assess its final properties, one has to conduct a study where the CQR is compared against an electronic monitoring instrument as gold standard.

Since the LTMBS was developed primarily for transplant recipients, one might expect that the CQR would have performed better in a population of patients with rheumatic diseases. Therefore it is somewhat surprising that the CQR and LTMBS showed similar results in these 3 patient groups.

Although the reason for this similarity is not clear, one could hypothesize that the explanation for the similar results obtained by the 2 measures should be sought in the concepts underlying the cause of variable compliance. Looking closely at the 3 factors found by the stepwise discriminant analyses one can see that the greatest weight is given to 1 . confidence in the physician; 2 . previous bad experience from skipping doses; and 3. irregularity in daily life. These are hardly rheumatology specific factors, and are easily applicable to other fields of medicine as well. In fact, it has been shown that compliance can show remarkable similar patterns between different diseases and drugs ${ }^{36}$.

Furthermore, both measures arrive at the conclusion in different ways. The LTMBS asks whether patients judge themselves to be able to take their drugs under a variety of circumstances while the CQR asks how far patients agree with statements from other patients. There is a difference between providing an estimate of one's own behavior (which in general is difficult) and providing an opinion on what other people say or think (which is in general more easy).

In addition, the virtually absent correlation between the CQR-total score and LTMBS-total score $(0.06)$ provides further evidence that both measures arrive at the same conclusion in different ways. The low test-retest reliability of the LTMBS impedes its use in this patient population. Finally, some of the questions in the LTMBS are not relevant to rheumatology patients (e.g. taking my medication even though it causes spots on my face and excessive hairgrowth) and it is lacking the probably important concept of pain as compliance modifier.

Therefore, we feel that the CQR, though the analyses show similar results, has advantages above the use of the LTMBS in a rheumatology patient population.

Devising an instrument of which the total score of 19 items closely reflects self-categorization into categories that can be asked in one question by itself would hardly contribute to the 
compliance measurement field. The real added value of the CQR lies in the fact that it provides patient-specific information that points to sources of sub-optimal compliance, thus perhaps providing means to improve compliance. This property makes it potentially a useful addition or perhaps even an alternative for more advanced measurement methods such as electronic monitoring or the use of chemical markers.

The CQR can be used to explore patient compliance in a variety of settings. One example would be clinical trials where optimal compliance is of great importance to arrive at scientific sound conclusions. The overall score would give the investigator an estimate of the number of drugs taken, while the answers themselves would provide means to discuss these issues with the patient and in this way might improve compliance. Another example in the field of pre marketing randomized controlled trials is using measures like the CQR in a pre-trial, prerandomization run-in period to select patients for good compliance 38,39 .

In every-day clinical practice the CQR can be applied by asking patients who do not respond properly to adequate anti-rheumatic therapy to complete the questionnaire. This would provide the possibility to assess whether the patient is likely to be a non-responder or a non-complier, and provides insight into reasons for such behavior. Unnecessary dose-alterations or the addition of second or third drugs in patients could then perhaps be avoided.

\section{Conclusion}

The CQR is a newly developed 19 item, rheumatology specific, self-administered and welfaccepted patient questionnaire to measure and explore patient compliance on drug regimen. It seems useful in diagnosing reduced patient compliance, as indicated by a high sensitivity and good specificity. It has good test-retest reliability, analyses show good predictive potential and the questionnaire allows for the identification of important compliance-related factors. It can be used both in every-day clinical practice and research to identify non-compliant patients among those who are considered non-responders on anti-rheumatic drug therapy. At the same time the CQR offers tools to discuss and perhaps improve patient compliance. We feel that the CQR might be a useful addition to the diagnostic questionnaires currently available in rheumatology.

\section{Acknowledgements.}

We would like to acknowledge the help and support of J. Urquhart with this project, and his useful suggestions and comments on this manuscript. We also would like to thank M. Boers, M. van Santen-Hoeufft, A. Boonen, P. Dubbeld, C. Langenaken, A. Spoorenberg, and L. Heuft Dorenbosch for their help with finding the patients for this project, and of course all participating patients for kindly participating with this series of investigations. Finally we would like to acknowledge the help of $\mathrm{L}$. Haller for translating the CQR-items.

\section{Literature.}

1. Sackett DL. Haynes RB. Compliance with therapeutic regimens. Baltimore and London: Johns Hopkins University Press, 1976.

2. Geertsen HR, Gray RM, Ward JR. Patient non-compliance within the context of seeking medical care for arthritis. J Chronic Dis 1973; 26: 689-98.

3. Gotzsche PC. Methodology and overt and hidden bias in reports of 196 double-blind trials of nonsteroidal antinflammatory drugs in rheumatoid arthritis Controlled Clin Trials 1989; 10: 31-56.

4. de Klerk E, van der Linden SJ. Compliance monitoring of NSAID drug therapy in ankylosing spondylitis, experiences with an electronic monitoring device. Br J Rheumatol 1996; 35: 60-5. 
5. Urquhart J. The electronic medication event monitor - lessons for pharmacotherapy. Clin Pharmacokinet 1997; 32 : 345-56.

6. Bond WS, Hussar DA. Detection methods and strategies for improving medication compliance. Am J Hosp Pharm 1991; 48: $1978-88$.

7. Jundt JW, Browne BA, Fiocco GP, Steele AD, Mock D. A comparison of low dose methotrexate bioavailability, oral solution, oral tablet, subcutaneous and intramuscular dosing. J Rheumatol 1993; 20: 1845-9.

8. Pullar T, Peaker S, Martin MF, Bird HA, Feely MP. The use of a pharmacological indicator to investigate compliance in patients with a poor response to antirheumatic therapy. Br J Rheumatol 1988; $27: 381-4$.

9. Fischer B, Lehr S, Schnaiter A, et al. Compliance testing by measurement of piracetam in urine-a possible method of compliance control for piracetam intakers. An empirical investigation. Neuropsychobiology 1983; 10: 1922. 10. Yoder LJ, Guitrau M, Jacobson R. Comparison of a urine spot test and blood tests as indicators of patient compliance. Indian J Lepr 1991; 63: 195-202.

11. Vasses PH, Hockensmith JW, Gennaro AR, Amadio P. Jr. Urine test as a potential aid in testing for patient compliance with methyldopa therapy. Am J Hosp Pharm 1979; 36: 1046-50.

12. Fuller RK, Neiderhiser DH. Evaluation and application of a urinary diethylamine method to measure compliance with disulfiram therapy. J Stud Alcohol 1981; 42: 202-7.

13. Lowenthal DT, Briggs WA, Mutterperl R, Adelman B, Creditor MA. Patient compliance for antihypertensive medication: the usefulness of urine assays. Curr Ther Res Clin Exp 1976; 19:4059.

14. Huikeshoven H. A simple urine spot test for monitoring dapsone selfadministration in leprosy treatment. Bull World Health Organ 1986; 64: 279-81.

15. Boner AL, Valletta EA, Plebani M, Biancotto R, Bellanti JA. Reliability of salivary theophylline concentration monitoring in children with bronchial asthma following the administration of different drug formulations. Allergol Immunopathol Madr 1985; 13: 393-8.

16. El Guebaly N, Davidson WJ, Sures HA, Griffin W. The monitoring of saliva drug levels: psychiatric applications. Can J Psychiatry 1981; 26: 43-8.

17. Jaber M, Schneider AT, Goldstein S, Sergiou H, Bjornson L, Chiaramonte LT. Reliability and predictive value of salivary theophylline levels. Ann Allergy 1987; 58: 105-8.

18. Zysset T, Rudeberg A, Vassella F, Kupfer A, Bircher J. Phenytoin therapy for epileptic children: evaluation of salivary and plasma concentrations and of methods of assessing compliance. Dev Med Child Neurol 1981; 23: 66-75. 19. Tracqui A, Kintz P, Mangin P. Hair analysis: a worthless tool for therapeutic compliance monitoring. Forensic Sci Int 1995; 70: 183-9.

20. Paulson SM, Krause S, Iber FL. Development and evaluation of a compliance test for patients taking disulfiram. Johns Hopkins Med J 1977; 141: 119-25.

21. Rychtarik RG, Smith PO, Jones SL, Doerfler L, Hale R, Prue DM. Assessing disulfiram compliance: validational study of an abbreviated breath test procedure. Addict Behav 1983; 8: 361-8.

22. de Klerk E. Measurement of Patient Compliance on Drug Therapy. In: Vingerhoets A, ed. Advances in Behavioral Medicine Asessment, 1999.

23. Streiner DL, Norman GR. Health Measurement Scales. Oxford: Oxford Uriversity Press, 1989: p 175.

24. De Geest S, Abraham I, Gemoets H, Evers G. Development of the long-term medication behaviour self-efficacy scale: qualitative study for item development. J Adv Nurs 1994; 19: $233-8$.

25. De Geest S, Abraham I, Dunbar Jacob J. Measuring transplant patients' compliance with immunosuppressive therapy. West J Nurs Res 1996; 18: 595-605.

26. de Geest S, Borgermans L, Gemoets $\mathrm{H}$, et al. Incidence, determinants, and consequences of subclinical noncompliance with immunosuppressive herapy in renal transplant recipients. Transplantation 1995; 59: 340.7

27. Beck NC, Parker JC, Frank RG, et al. Patients with rheumatoid arthritis at high risk for noncompliance with salicylate treatment regimens. J Rheumatol 1988; 15: 1081-4.

28. Svarstad BL, Braun-Curtin R, Andress D. Assessing barriers to patient adherance with difficult drug regimens: a new screening technique. Abstract for Scientific Meeting on Social Pharmacy and Patient Compliance, Wisconsin University, august $21 \pm 1,1996$.

29. Rooney PJ, Bellamy N. Do meumatic patients comply ?. Eur J Rheumatol Inflamm 1984; 7: $25-7$.

30. Kitzinger J. Qualitative research. Introducing focus groups. BMJ 1995; 311: 299-302.

31. Basch CE. Focus group interview. an underutilized research technique for improving theory and practice in health education. Health Educ Q 1987; 14: 411-48.

32. Norusis MJ. SPSS/PC+ Statistics 4.0 for the IBM PC/XT/AT and PS/2. Chicago: SPSS International Lid. 1990.

33. Fleiss JL. The design and analysis of clinical experiments John Wiley and Sons, 1986: 448.

34. de Jong Z, van der Heijde D, McKenna S, Whalley D. The reliability and construct validity of the RACol: a ineumatoid arthritis-specific quality of life instrument. British Joumal of Rheumatology $199736(8): 878-83$.

35. Rooney PJ, Buchanan WW. In rheumatoid arthritis is compliance in physicians more of a problem than compliance in patients. Clinical Rheumatology 1999 9:315-8. 
36. Urquhart J, De Klerk E. Contending paradigms for the interpretation of data on patient ๓mpliance with therapeutic drug regimens. Stat Med; 1998 17: 251-67.

37. Dunbar J, Dunning EJ, Dwyer K. Compliance measurement with arthritis regimen. Arthritis Care Res 1989; 2:S\& 16.

38. Probstfield JL. Clinical trial prerandomization compliance (adherence) screen. In: Cramer JA, Spilker B, eds. Patient compliance in medical practice and clinical trials. New York: Raven Press, 1991: 323334.

39. Knipschild P, Leffers P, Feinstein AR. The qualification period. J Clin Epidemiol 1991; 44: 461-4.

\section{Appendix 1: CQR-19 1.}

\section{Compliance Questionnaire Rheumatology:}

Instructions to the patient:

On the next pages you will find a number of statements made by patients with a rheumatic disease. Please indicate for each statement how far you agree, by placing a cricle around the number that reflects your opinion best.

1. If the rheumatologist tells me to take the medicines, I do so.

2. I take my anti-rheumatic medicines because I then have fewer problems.

3. I definitely don't dare to miss my anti-rheumatic medications.

4. If I can help myself with alternative therapies, I prefer that to what my rheumatologist prescribes ${ }^{2}$.

5. My medicines are always stored in the same place, and that's why I don't forget them.

6. I take my medicines because I have complete confidence in my rheumatologist.

7. The most important reason to take my anti-rheumatic medicines is that I can still do what I want to do.

8. I don't like to take medicines. If I can do without them, I will 2.

9. When I am on vacation, it sometimes happens that I don't take my medicines?

10. I take my anti-rheumatic drugs, for otherwise you don't have to go

to your ineumatologist.

11. I don't expect miracles from my anti-rheumatic medicines?

12. If you can't stand the medicines you might say: 'throw it away, no matter what' 2 .

13. If I don't take my anti-rheumatic medicines regularly, the inflammation retums.

14. If I don't take my anti-rheumatic medicines, my body warns me.

15. My health goes above everything else and if I have to take medicines to keep, I will.

16. I use a dose organizer for my medications.

17. What the doctor tells me, I hang on to.

18. If I don't take my anti-ineumatic medicines, I have more complaints.

19. It happens every now and then, I go out for the weekend and then I don't take my medicines 2.

1: for gout patients, the word anti-rheumatic was changed to anti-gout.

2: these items were recoded to compute the total score, as indicated in the 'methods section'. 


\section{Appendix 2: LTMBS (15 qualified items).}

Instructions for the patient:

There are situations in which it is more difficult to take your medicines correctly then others. In the questions below you will find a number of such situations. Please read each of the situations carefully. Self-reflect how well you are able to take your medicines correctly in that specific situation.

Taking my medication....

1 .... When it may render me impotent.

2. ... event though it causes spots on my face and excessive hair growth.

3. .. When the time of intake does not coincide with my meal times.

4. ... When I am in the middle of a project at home.

5. ... When nobody reminds me about the time at which I should take the medication.

6. ... after I have gotten very angry at a friend.

7. ... while watching an exciting program on TV.

8. ... when I feel very ill.

9. ... When I feel very sad.

10... while unknown people are watching me.

11 ... when I feel sick in my stomach.

12. when I am having an argument with my partner.

13. . When I am at a party.

$14 . .$. while taking a long walk.

$15 . .$. on an evening out. 



\title{
The compliance questionnaire rheumatology (CQR) compared with electronic medication event monitoring: a validation study.
}

\author{
Erik de Klerk', Désireé van der Heijde 1,2, Robert Landewé', Hille van der Tempel⿳3, \\ Sjef van der Linden'1.
}

1: Department of Internal Medicine, division of Rheumatology, University Hospital Maastricht. 2: Limburg University Center, Diepenbeek, Belgium. 3: Department of Rheumatology, Maasland Hospital Sittard,

\section{Manuscript submitted to the Joumal of Rheumatology}

\section{Abstract}

Objective: to validate the 19-item Compliance Questionnaire Rheumatology (CQR) against the 'gold standard' in compliance measurement, electronic medication event monitoring.

Methods: 127 patients, 81 with RA taking NSAIDS ( 13 diclofenac and 20 naproxen) or DMARDs ( 25 sulfasalazine and 23 methotrexate), 17 patients with polymyalgia rheumatica (PMR) taking prednisone, and 29 patients with gout taking daily prophylactic colchicine (12) or the uric acid lowering drugs allopurinol (10) or benzbromaron (7), used their medication from a regular medication bottle fitted with a special cap containing micro-electronics capable of recording time and date of opening and closing, defined as a 'medication event'. Data were processed to reflect the following: 1 . the percentage of prescribed medication events during the study period (taking compliance) and 2. the proportion of days with the prescribed number of medication events (i.e.,correct dosing). Satisfactory compliance was defined as taking compliance or correct dosing $>80 \%$, while unsatisfactory compliance was defined as taking compliance or correct dosing $\leq 80 \%$. All patients were informed about the monitoring, and were followed for 6 months (gout: 1 year). At baseline patients completed a set of questionnaires including the 19 item CQR.

Results: 85 patients had complete questionnaire and electronic monitoring data. Multiple linear regression analyses showed that the total, weighted CQR score significantly and adequate predicts taking compliance $\left(p=0.001, R^{2}=0.46\right)$ and correct dosing $\left(p=0.004, R^{2}=0.42\right)$. Discriminant analyses showed that specificity and sensitivity to detect good taking compliance were $95 \%$ and $62 \%$, respectively. The predictive value to detect unsatisfactory taking compliance was $86 \%$, to detect good taking compliance was $83 \%$. The likelihood ratio of the CQR-19 to detect low taking compliance was 11.6. Four items were especially predictive: (a). fear of forgetting to take the drug, (b) being able to function well, (c) routines in daily life and (d) side-effects (combined R2: 0.35).

Conclusion: These results support the validity of the Compliance Questionnaire Rheumatology.

\section{Support}

This project was supported by grant NR 831 from the Dutch Arthritis Association ('Nederlands Reumafonds'). 


\section{Introduction}

Previously we have reported on the development of the Compliance Questionnaire Rheumatology (CQR), a meumatology-specific questionnaire that measures patient compliance to drug regimens, identifies factors that contribute to suboptimal patient compliance and, possibly, can be used to predict future compliance in patients with rheumatoid arthritis (RA), polymyalgia rheumatica (PMR) and gout 1 .

The 19-item instrument had encouraging psychometric properties: a good testretest reliability, a moderate internal consistency, and validation using discriminant analyses against an overall patient self-report compliance measure showed a sensitivity of $98 \%$, a specificity of $67 \%$ and an estimated Kappa of 0.78 to detect low compliance. We concluded that the CQR was well accepted, and that it was useful to detect possible barriers for optimal compliance and predicting patient compliance to a drug regimen, based on the comparison with the selfreport of patient compliance as a surrogate gold standard.

Even though psychometric properties of the instrument were encouraging, the development procedure lacked a formal validation of the instrument against a gold standard. An ideal compliance measurement instrument to validate the CQR against should be simultaneously unobtrusive (to avoid patient sensitization and maximize cooperation), objective (to produce discrete and reproducible data for each subject), and practical (to maximize portability and minimize $\cos t)^{2}$. Unfortunately, such an instrument does not exist ${ }^{3-5}$.

The compliance measurement instrument that is closest to the requirements of a gold standard is electronic medication event monitoring. This method records time and date of opening and closing of the drug medication package via special micro-electronic circuitry integrated in the cap of a pill-bottle (AARDEX Ltd, Zug, Switzerland) and is known as Medication Event Monitoring System (MEMS $\left.{ }^{\circledast}\right)^{6,7}$. With this method, a history of medication events, assumed to indicate dosing times, is created which can be compared to the prescribed dosing regimen. The method conforms to the definition of patient compliance: "the extent to which the actual dosing history conforms to the prescribed dosing regimen" 8 . The advantages of electronic medication event monitoring are that it can provide accurate times of drug intake over a long period (up to 3 years), it is not invasive, and it does not require laboratory analyses. It is also not sensitive to 'white-coat compliance', the phenomenon wherein ordinarily poorly compliant patients dose correctly just before a clinical visit. The disadvantage of the instrument is of course that it is an indirect method, in that it does not prove drug intake, and it requires the assumption that with every cycle of opening/closing of the pill-bottle signifies that the prescribed dose was actually taken.

The assumption that each opening of the bottle truthfully reflects the taking of the pill has been discussed among authorities in the field of patient compliance research, with the conclusion that the assumption is likely to hold since it would require a very strong routine, combined with sustained malfeasance, for a patient to open the bottle at each scheduled dosing time for a long period of time without taking the tablet. At the same time all other methods to measure patient compliance are easily vulnerable to patient-initiated data-tailoring $5,9-13$. Therefore we decided to validate the $C Q R$ against electronic medication event monitoring. 


\section{Methods}

The development of the CQR has been described in detail before 1. It consists of 19 items, which were derived from a series of patient-interviews and a focus group interview, and reflect statements that were made by individual patients regarding their drug-taking behavior (appendix 1). Patients are asked to indicate how much they agree with each statement on a 4 point Likert scale, with anchors 'don't agree at all' (scored as 1), 'don't agree' (scored as 2), 'agree' (scored as 3), and 'agree very. Six items are negatively stated (numbers 4, 8, 9, 11, 12 and 19), and are therefore recoded $(4=1,3=2,2=3,1=4)$ to reflect a positive score. The CQR total score is calculated by summing up the items, subtracting 19 and dividing by 0.57 . This ensures that the CQR total score can vary from 0 (complete noncompliance) to 100 (perfect compliance).

For this validation study, prior permission was obtained from the Medical Ethical Committees of all 3 participating hospitals. We included all consenting consecutive outpatients at the outpatient wards of rheumatology of the University Hospital Maastricht, Atrium Hospital Heerlen, and Maasland Hospital Sittard, respectively a primary-secondary and 2 primary referral centers for theumatology.

Patients fulfilled the following inclusion criteria: a diagnosis by a rheumatologist of meumatoid arthritis (RA), polymyalgia rheumatica (PMR) or gout. The following medications were included: for RA patients, sulfasalazine (prescribed twice daily after up-titration), methotrexate (prescribed once-weekly), diclofenac (prescribed twice or thrice daily, combination with misoprostol was allowed), or naproxen (twice daily). For PMR patients, prednisone or prednisolone (in the analyses patients on prednisone and prednisolone were combined) were included. Gout patients were included if they were started on prophylactic daily colchicine, or on allopurinol or benzbromaron (in the analyses patients on allopurinol or benzbromaron were combined and categorized under 'uric acid lowering agents'). For all groups prescriptions had to be first prescriptions (note that this is not the same as new diagnoses) and had to be 'taken as directed' (not: 'on demand'). In a case where 2 drugs were started at the same time (mostly gout) the drug to monitor was chosen to be the drug group where the least number of patients were enrolled. Patients were to be responsible for taking their own medication and were therefore not included if a care-giver was involved in the patients' medication taking (e.g. in the case of a nursing home, or hospitalized patients).

During the visit at the outpatient ward of rheumatology, patients were informed by their meumatologist about the purpose and requirements of the project and the nature of the MEMS system, so that patients were aware of the monitoring nature of the drug-package, and signed the informed consent document. Each patient received a MEMS cap and pillbottle, and his/her pharmacist was notified by fax that the patient was in a clinical study and was asked to transfer the prescribed medication to the pill-bottle. Patients also received the CQR, which they were asked to complete in the first week after start of the medication. All patients received a follow-up phone-call by the investigator (EdK) approximately 3 days after the visit to the rheumatologist to answer further questions, and to ensure that the medication was indeed transferred to the MEMS bottle. No patients reported problems with transferring the medication to the MEMS bottle.

Six months (gout patients: 12 months) after start of drug therapy, or sooner if withdrawal was deemed necessary because of lack of efficacy or sideeffects, patients were asked to complete 
the identical set of questionnaires again and to return the electronically monitored pillbottle to the rheumatologist or investigator. In addition, patients were asked to request a medication history from their pharmacy. This is a computerized list containing all drugs and the date at Which they were dispensed at the pharmacy. In the Netherlands the majority of patients are required by their health insurer to subscribe to one pharmacy, ensuring that virtually all dates of medication dispensing (and therefore extra openings to fill the bottles) were recorded.

The data of the MEMS system were downloaded via a communicator to a personal computer, and analyzed by a special software package designed to analyze dosing histories (CSS version 2.1, AARDEX Lid, Switzerland). If necessary days of special openings of the pill-bottle (such as pharmacy-visits or if the patient had recorded unnecessary openings) were marked as 'nonmonitored period'. These days were subsequently not used in the analyses. For example: a patient with 100 monitored days with 4 refill-visits at the pharmacy would be analyzed with 96 monitored days.

Patient compliance was calculated as both taking compliance and correct dosing:

Taking compliance: the percentage of prescribed doses taken, calculated as: (total number of openings / total number of prescribed doses) * $100 \%$ Example: a patient opened the MEMS cap 170 times while on twice-daily sulfasalazine for a monitored period of 100 days, so taking compliance $=(170 / 200) *{ }^{*} 100 \%=85 \%$

Correct dosing: the percentage of days on which the correct number of doses was taken, calculated as; (the total number of days with openings as prescribed / total number of monitored days) * $100 \%$

Example: a patient opened the MEMS cap 170 times while on twice-daily sulfasalazine for a monitored period of 100 days, but only on 58 days there were 2 openings, during a monitored period of 100 days, so correct dosing $=(58 / 100)^{*} 100 \%=58 \%$.

Satisfactory compliance was arbitrarily defined as taking compliance or correct dosing $>80 \%$. Unsatisfactory compliance was arbitrarily defined as taking compliance or correct dosing $\leq 80 \%$.

Analyses consisted of descriptive statistics, Pearson's correlation coefficients, multiple regression analyses, oneway analysis of variance and (stepwise) discriminant analyses. Weights of the discriminant function were determined with prior probabilities computed from group sizes, and computed using the separate group covariance matrix. The classification results of the discriminant analyses were computed into sensitivity, specificity, and likelihood ratios. All analyses were performed on a Personal Computer using SPSS version 10.0.7 for Windows.

\section{Results}

One-hundred twenty-seven consenting, consecutive patients of the outpatient ward were included. They consisted of 81 patients with RA using NSAIDs ( 13 diclofenac and 20 naproxen) or DMARDs (25 sulfasalazine and 23 methotrexate), 17 patients with polymyalgia rheumatica taking prednisone or prednisolone and 29 patients with gout taking colchicine (12) or allopurinol (10) or benzbromaron (7). Some basic descriptive demographic variables are shown in table 1. 
Twenty-three patients did not complete the CQR within 2 weeks after initiation of the new prescription. These patients were therefore excluded from the analysis. Of the remaining 104 patients, there were 85 patients who completed all 19 questions, and 19 patients had a missing value for at least one of the 19 items. Questions 9 and 19 were missed most often. A comparison of compliance between the groups with 104 patients (all patients with an available CQR) and 85 patients (the group who completed the CQR without any missing values) showed no significant differences between taking compliance and correct dosing (table 3). Since the development procedure of the CQR ${ }^{1}$ showed that there is no statistical justification to reduce the number of items below 19 , and to ensure that the instrument was analyzed as designed we used the dataset with all 85 patients who had a complete set of CQR data and MEMS data to analyze the validity of the CQR.

\section{Table 1: Demographical data}

\begin{tabular}{lccc}
\hline & RA & PMR & Gout \\
& $\mathrm{n}=81$ & $\mathrm{n}=17$ & $\mathrm{n}=29$ \\
\hline Age: mean (sd) & $60(14)$ & $72(7)$ & $58(12)$ \\
Gender (\% female) & $66 \%$ & $76 \%$ & $20 \%$ \\
Social support & & & \\
$\quad$ Single & $29 \%$ & $24 \%$ & $17 \%$ \\
$\quad$ Married / living & $64 \%$ & $70 \%$ & $80 \%$ \\
$\quad$ together without & & & \\
$\quad$ children & & $6 \%$ & $3 \%$ \\
$\quad$ Married / living & $7 \%$ & & \\
$\quad$ together with & & & \\
$\quad$ children & & $24 \%$ & $17 \%$ \\
Education & & $71 \%$ & $80 \%$ \\
$\quad$ Low & $28 \%$ & $6 \%$ & $3 \%$ \\
$\quad$ Intermediate & $64 \%$ & $12 \%$ & $54 \%$ \\
$\quad$ High & $7 \%$ & & \\
Work & $26 \%$ & & \\
$\quad$ \% working & & & \\
\hline
\end{tabular}

The mean CQR score was 76.6 (standard deviation: 12.8). One-way analyses of variance showed that there were no statistical differences between the various treatment groups ( $F$ : $0.329, \mathrm{df}=107, \mathrm{p}=0.92$ ). Compliance as measured by the MEMS system is summarized in table 2. These data are reported in more detail elsewhere ${ }^{14}$.

The total CQR score, which essentially sums the individual items unweighted, did not show any correlation with taking compliance or correct dosing ( $R^{2}=0.07$ and 0.03 , respectively). However, multiple regression analyses with compliance variables as independent variables and all 19 CQR items as dependent variables showed that the CQR items significantly and accurately predict taking compliance $\left(F=2.91, d f=84, p=0.001, R^{2}=0.46\right)$ and correct dosing $(F=2.46$, $p=0.004, R^{2}=0.42$ ). This indicates that the weighting scores assigned to the individual items in the multiple regression analyses are an important factor in the explanation of taking compliance and correct dosing. 
Table 2: summary of compliance data.

\section{Mean Taking Compliance \pm Mean Correct Dosing \pm \\ Std. Deviation \\ (95\% confidence interval)}

(\%)

\begin{tabular}{cccc}
\hline Naproxen & $82 \pm 16$ & $68 \pm 25$ & 20 \\
& $(75-90)$ & $(57-80)$ & \\
Diclofenac & $77 \pm 27$ & $67 \pm 33$ & 13 \\
& $(61-93)$ & $(47-87)$ & \\
Sulfasalazine & $72 \pm 29$ & $55 \pm 28$ & 25 \\
& $(60-83)$ & $(44-67)$ & \\
Methotrexate & $107 \pm 22$ & $81 \pm 15$ & 23 \\
& $(98-117)$ & $(75-87)$ & \\
Prednisone & $96 \pm 12$ & $88 \pm 9$ & 17 \\
& $(89-102)$ & $(83-92)$ & \\
Colchicine & $65 \pm 27$ & $44 \pm 29$ & 12 \\
& $(48-81)$ & $(26-62)$ & \\
Uric acid lowering & $84 \pm 15$ & $74 \pm 21$ & 17 \\
drugs & $(76-92)$ & $(63-85)$ & \\
& & & 127 \\
\hline Total & $85 \pm 26$ & $69 \pm 26$ & \\
& $(80-89)$ & $(64-74)$ & \\
\hline
\end{tabular}

Table 3: $2 \times 2$ table with classification results of the discriminant analyses

\begin{tabular}{|c|c|c|c|}
\hline & \multicolumn{2}{|c|}{ Taking compliance (MEMS) } \\
\hline & & unsatisfactory & good \\
\hline \multirow{2}{*}{$\begin{array}{r}\mathrm{CQR} \\
\text { prediction } \\
\text { function }\end{array}$} & unsatisfactory & 18 & 3 \\
\hline & good & 11 & 53 \\
\hline
\end{tabular}

A discriminant analysis was performed to test the predictive value of the CQR. The classification table of the calculated discriminant function (see appendix for the individual weights of the items, the critical cutting score and an explanation) of the CQR versus MEMS data to detect taking compliance $\leq 80 \%$ (table 3 ) shows a sensitivity and specificity of $62 \%$ ( $95 \%$ confidence interval: $56.8-67.3 \%)$, and $95 \%$ (92.2-97.1\%), respectively. The Likelihood ratio for a positive test result (e.g., to detect taking compliance $\leq 80 \%)=11.6$.

Sensitivity and specificity to detect unsatisfactory correct dosing ( $\$ 80 \%)$ were $89 \%(95 \% \mathrm{Cl}$ : $85.0-91.9 \%)$ and $70 \%$ (64.7-74.7\%), respectively. The corresponding likelihood ratio to detect correct dosing $\leq 80 \%$ is therefore 2.9 .

The same analyses were performed to see how well the CQR was able to detect taking compliance and correct dosing $\leq 50 \%$. The sensitivities were $63 \%$ (95\% Cl: $57.2-67.8 \%$ ) and 
$62 \%(56.6-67.2 \%)$, the specificities were $97 \%$ (95\% Cl: $95.7-99.1 \%)$ and $93.8 \%(91.1-96.4 \%)$, respectively. The corresponding likelihood ratio to detect taking compliance $\leq 50 \%$ is 24.1 , to detect correct dosing $\leq 50 \%$ of 9.9 .

The choices for compliance $\leq 80 \%$ and $\leq 50 \%$ are arbitrary and are based on our clinical judgment solely. We have summarized the performance for other detection levels of the CQR in terms of likelihood to detect low compliance in figure 1. It is clear that the likelihood ratio rises with lower detection levels.

Figure 1: Relationship between cut-off point and Likelihood ratio to detect patient compliance < cut-off point.
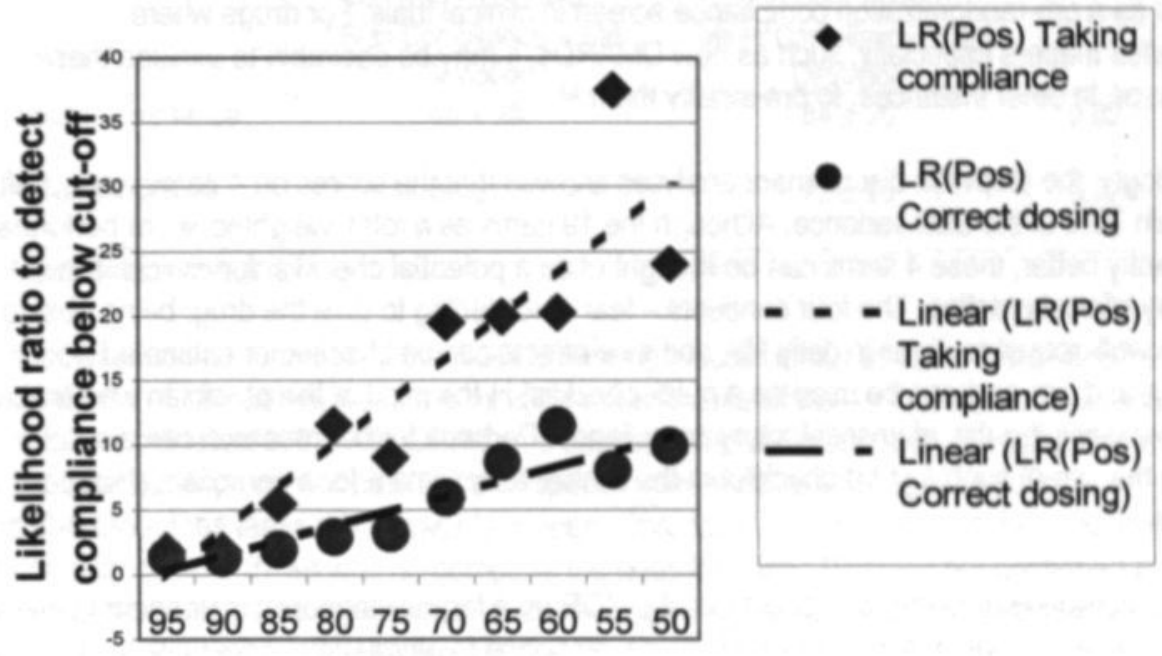

Cut-off point

Lines represent linear regression functions. For:

Taking compliance: Likelihood ratio $=-3.5298+3.39^{*}$ cut-off point $\left(r^{2}=0.83\right)$

Correct dosing: Likelihood ratio $=-0.9099+1.16^{*}$ cut-off point $\left(r^{2}=0.85\right)$

Four items were especially predictive for taking compliance, comprising of the concepts 1 . fear of forgetting to take the drug, 2 . being able to function well, 3 . routines in daily life and 4 . sideeffects (combined $R^{2}: 0.35$ ). This means that with only these 4 items it is possible to explain $35 \%$ of the variance in taking compliance.

\section{Discussion}

The CQR is a patient oriented questionnaire that was designed to explore concepts related to patient compliance on anti-rheumatic drug regimens. It has several attractive properties: with 19 items it is a relative short measure, and since it is heavily based on patients input during the development phase the items are easy to read, understand and answer. Patients can complete the questionnaire in their own environment, a personal interviewer is not required. Average time to complete was approximately 12 minutes. It has good psychometric properties, as reported elsewhere 1. 
In this validation study the performance of the CQR was compared against electronically measured taking compliance and correct dosing. The total CQR score did not correlate with either taking compliance or correct dosing. However, the discriminant analyses showed that it is possible to assign individual weights to each item that allow the investigator to discriminate patients with relatively good 'taking compliance' and 'correct dosing' from those who do not comply very well.

To facilitate future use of the CQR in scientific research, we have included 4 discriminant formulas, optimized to detect taking compliance $\leq 80 \%, \leq 50 \%$, and correct dosing $\leq 80 \%$ and $\leq 50 \%$ (appendix 1). These discriminant formulas can be used in several ways: e.g. When screening for patients who are likely to comply suboptimally to antirheumatic drug therapy, perhaps as a pre-randomization compliance screen in clinical trials. For drugs where compliance matters especially, such as new DMARDs, it may be desirable to exclude these patients, or, in other instances, to pre-stratify them ${ }^{12}$.

Interestingly, the stepwise discriminant analyses showed that the scores on 4 items were useful to explain $35 \%$ of the total variance. Although the 19 items as a total, weighted score performed significantly better, these 4 items can be thought of as a potential checklist for clinicians in everyday clinical practice. The four concepts - fear of forgetting to take the drug, being able to function well, robust routines in daily life, and side effects can be checked or estimated clinically, and can perhaps be used as a quick checklist in the mind of the physician who is trying to assess the risk of unsatisfactory compliance. Perhaps further research can also validate the use of such a short checklist in the clinical assessment for a compliance support program.

If more precision is required, one could use the CQR as a formal diagnostic instrument in everyday clinical care in patients with a lack of clinical response to antirheumatic therapy, to distinguish between inadequate compliance and pharmacologic non-response. Doing so may prevent needless escalation of the dose or change of drug. The specific answers to the questions may provide clues to overcome the compliance problem.

Furthermore, the CQR could have a place in compliance-intervention strategies such as measurement-guided intervention $15,16,17$, where it can provide useful insights into the reasons and factors underlying patient compliance/noncompliance (which the electronic monitors cannot). This approach, when carefully applied to patients who have a problem in complying satisfactorily with prescribed drug regimens, has shown promising results in other fields of medicine but to our knowledge has not been tested yet in rheumatology. Currently we are investigating this application of the CQR in a project evaluating a compliance enhancing intervention in RA patients.

A final use of the CQR could be to employ electronic medication event monitoring more costeffectively in routine clinical practice. The monitors have so far mostly been used in clinical trials, but could be valuable in routine daily practice as a diagnostic instrument to detect whether non-response is due to noncompliance or pharmacologic nonresponse, and as a tool to improve compliance by giving patient and healthcare provider insight in the dosing history. It seems logical (but is so far not proven) that a compliance intervention is most useful in patients who have low compliance to start with. The CQR could be used to pre-screen these patients, 
thus minimizing the use of monitors in patients who are good compliers from the outset of heir treatment.

Some may find it cumbersome to use a discriminant function, which requires incorporating the weights for the 19 items and a critical cutting score. We have therefore created a Microsoft Excel spreadsheet, where all weights and critical cutting scores for a variety of scenarios are pre-calculated. The spreadsheet is easy to use, and freely available via the first author or via the World Wide Web (appendix 2).

Table 4: difference between the 2 groups

\begin{tabular}{cccc}
\hline & $\begin{array}{c}\text { Patients with no missing } \\
\text { items on CQR }(n=85) \\
\text { Mean Compliance } \pm \text { Std. } \\
\text { Deviation }\end{array}$ & $\begin{array}{c}\text { Patients with missing items } \\
\text { on CQR }(n=42) \\
\text { Mean Compliance } \pm \text { Std. } \\
\text { Deviation }\end{array}$ & $\begin{array}{c}P^{\prime} \\
\text { Taking compliance }\end{array}$ \\
\hline Correct Dosing & $65 \pm 28$ & $84 \pm 20$ & 0.82 \\
\hline
\end{tabular}

\section{1: Mann-Whitney test}

A special concem in the use of the CQR is missing values. In our sample, there were 19 patients out of 104 with at least one missing value for one of the 19 CQR questions (18\%). One possible explanation is that the CQR items that were missed most often, question 9 and 19 (appendix 1), which ask for holidays and special weekends, are not applicable to some patients and therefore they leave the answer box open. One could hypothesize that these patients differ in compliance from those who do complete the questionnaire. This was not confirmed by analysis, however (table 4). It is clear that when applying the CQR, the importance of completing all 19 items must be stressed.

\section{Conclusion}

These results support the validity of the CQR. The high predictive values of the CQR suggest that it might be useful as a screening instrument.

\section{Acknowledgements.}

We would like to thank the participating rheumatologists for kindly including patients in the study: Maarten Boers, Marijke van Santen, Henk Goei-The, Harry Houben, Robert Landewé, Anneke Spoorenberg, Liesbeth Heuft-Doorenbosch, Peter Dubbeld, Mike de Jager, Wilfred van der Weele, Hans Groenendael, Christine Langenaken. Also, we would like to thank John Urquhart for his contributions and support to this study, as well as for reviewing this manuscript. 


\section{References}

1. de Klerk $E$, van der Heijde $D$, van der Tempel $H$, van der Linden $S$. Development of a questionnaire to investigate patient compliance with antirheumatic drug therapy. The Joumal of Rheumatology 1999; 26:2635-41.

2. Rudd P. In search of the gold standard for compliance measurement . Archives of Internal Medicine 1979; 139:6278.

3. Dunbar J. Adherence measures and their utility. Controlled Clinical Trials 1984; 5:515-21 (Suppl 4).

4. Bond WS, Hussar DA. Detection methods and strategies for improving medication compliance. American Joumal for Hospital Pharmacy 1991; 48:1978-88.

5. de Klerk E. Measurement of Patient Compliance on Drug Therapy. In: Vingerhoets A, ed. Advances in Behavioral Medicine Asessment, Advances in Behavioral Medicine Asessment, 2002, Harwood Academic Publishers, ISBN 158391-226-6.

6. Kruse W, Weber E. Dynamics of drug regimen compliance-its assessment by microprocessor-based monitoring. European Joumal of Clinical Pharmacology 1990; 38:561-5.

7. Cramer JA, Mattson RH, Prevey ML, Scheyer RD, Ouellette VL. How often is medication taken as prescribed? A novel assessment technique. Journal of the American Medical Association 1989; 261:32737.

8. Urquhart J, Chevalley C. Impact of unrecognized dosing errors on the cost and effectiveness of pharmaceuticals. Drug information Journal 1988; 22:363-378.

9. Feinstein AR. On white-coat effects and the electronic monitoring of compliance. Archives of Internal Medicine $1990 ; 150: 1377-8$.

10. Urquhart J, de Klerk E. Contending Paradigms for the interpretation of data on patient compliance with therapeutic drug regimens. Statistics in Medicine; 17(3): 251-67.

11. Urquhart J. Patient compliance with prescribed drug regimens: overview of the past 30 years of research. In: Nimmo W.S. T, G.T., ed. Clinical Measurement in Drug Evaluation: John Wiley \& Sons, 1995:213227.

12. Cramer JA, Spilker B, editors. Patient compliance in medical practice and clinical trial. New York: Raven Press, 1991.

13. Metry J, Meyer U. Drug regimen compliance: issues in clinical trials and patient management. Chichester. John Wiley and Sons Ltd, 1999.

14. de Klerk E, van der Heijde D, Landewé R, van der Tempel $H$, van der Linden S. Patient compliance in rheumatoid arthritis, polymyalgia and gout. (submitted Joumal of Rheumatology).

15. Peveler R, George C, Kinmonth AL, Campbell M, Thompson C. Effect of antidepressant drug counselling and information leaflets on adherence to drug treatment in primary care: randomised controlled trial. British Medical Joumal 319:612-5, 1999.

16. Cramer JA, Rosenheck R. Enhancing medication compliance for people with serious mental disease. Joumal of Nervous and Mental Disease 187: 53-4, 1999.

17. Bumier M, Schneider MP, Chiolero A, Fallab CL, Brunner HR. Objective moritoring of drug compliance: an important step in the management of hypertension resistant to drug therapy. American Joumal of Hypertension 12: 129A (abstract D075), 1999. 
Appendix 1: the Compliance Questionnaire Rheumatology.

\section{Instructions to the patient.}

On the next pages you will find a number of statements made by patients with a rheumatic disease. Please indicate for each statement how far you agree, by placing a circle around the number that reflects your opinion best.

1. If the rheumatologist tells me to take the medicines, I do so.

2. I take my anti-rheumatic medicines because I then have fewer problems.

3. I definitely don't dare to miss my anti-rheumatic medications.

4. If I can help myself with alternative therapies, I prefer that to what my rheumatologist prescribes ${ }^{2}$.

5. My medicines are always stored in the same place, and that's why I don't forget them.

6. I take my medicines because I have complete confidence in my rheumatologist.

7. The most important reason to take my anti-rheumatic medicines is that I can still do what I want to do.

8. I don't like to take medicines. If I can do without them, I will'2.

9. When I am on vacation, it sometimes happens that I don't take my medicines?

10. I take my anti-rheumatic drugs, for otherwise you don't have to go

to your rheumatologist.

11. I don't expect miracles from my anti-rheumatic medicines?

12. If you can't stand the medicines you might say: "throw it away, no matter what' ' .

13. If I don't take my anti-rheumatic medicines regularly, the inflammation returns.

14. If I don't take my anti-rheumatic medicines, my body warns me.

15. My health goes above everything else and if I have to take medicines to keep, I will.

16. I use a dose organizer for my medications.

17. What the doctor tells me, I hang on to.

18. If I don't take my anti-rheumatic medicines, I have more complaints.

19. It happens every now and then, I go out for the weekend and then I don't take my medicines 2.

The answers are scored on a four-point Likert scale with anchors: 1. don't agree at all; 2. don't agree; 3 . agree; 4 . agree very much.

$1:$ for gout patients, the word anti-rheumatic was changed to anti-gout.

2: these items were recoded to compute a total score, as indicated in the 'methods section'. 


\section{Appendix 2: Clarification of discriminant function}

The CQR consists of 19 individual items. The variable to test against is taking compliance, defined in a binary form as taking compliance $s x \mathrm{x}$ (reflecting insufficient compliance) and taking compliance $>x x \%$ (reflecting good taking compliance), where $x x$ can be any value between 0 and 100 .

The discriminant analyses involves deriving an equation of the following form:

$Z_{k}=a+W_{1} X_{1 k}+W_{2} X_{2 k}+\ldots+W_{19} X_{19 k}$

\section{Where}

$\mathrm{Z}_{\mathrm{k}}=$ discriminant $\mathrm{Z}$ score for patient $\mathrm{k}$,

$\mathrm{a}=$ intercept,

$W_{i}=$ discriminant weight,

$X_{1 k}=$ CQR-score for item 1 and patient $k$.

The discriminant function for the CQR against taking compliance $\leq 80 \%$ and taking compliance $>80 \%$ was determined to be:

$Z_{k}=-3.478-\left(0.445^{*}\right.$ item01) $-\left(0.952^{*}\right.$ item02 $)+\left(1.676^{*}\right.$ item03) $-\left(0.210^{*}\right.$ item04 $)+$ $\left(0.024^{*}\right.$ item05) $-\left(0.535^{*}\right.$ item06 $)+\left(0.003^{*}\right.$ item07) $+\left(0.014^{*}\right.$ item08) $-\left(0.011^{*}\right.$ item09) $\left(0.255^{*}\right.$ item 10$)+\left(0.102^{*}\right.$ item11 $)+\left(0.115^{*}\right.$ item12 $)+\left(0.025^{*}\right.$ item 13$)+\left(0.109^{*}\right.$ item14 $)+$ $\left(0.447^{*}\right.$ item15) $+\left(0.228^{*}\right.$ item16) $+\left(0.535^{*}\right.$ item17) $-\left(0.419^{*}\right.$ item18 $)+\left(0.683^{*}\right.$ item19)

The value of the optimal cutting score for the discrimination function was calculated using

$Z_{C U}=\left(N_{a} Z_{b}+N_{b} Z_{a}\right) /\left(N_{a}+N_{b}\right)$

Where

$\mathrm{Z}_{\mathrm{CU}}=$ critical cutting score value for unequal groups,

$\mathrm{N}_{\mathrm{a}}=$ number of observations in group a (patients with taking compliance $\leq 80 \%$ ),

$\mathrm{N}_{\mathrm{b}}=$ number of observations in group b (patients with taking compliance $>80 \%$ ),

$\mathrm{Z}_{\mathrm{a}}=$ centroid for group $\mathrm{a}$

$\mathrm{Z}_{\mathrm{b}}=$ centroid for group $\mathrm{b}$

Resulting in the optimal cutting score of $\left(\left(29^{*} 0.628\right)+\left(56^{*}-1.213\right)\right) /(29+56)$ $=-0.58489$

So, if for an individual patient $k$ the values of $X_{1}, X_{2}, X_{3}$ etc were replaced by his/her CQR scores, a score $\mathrm{Z}_{k}$ is obtained. If $\mathrm{Z}_{\mathrm{k}}$ is below the $\mathrm{Z}_{\mathrm{Cu}}$ of -0.58489 the patient is predicted to be in the group of taking compliance $\leq 80 \%$, if $\mathrm{Z}_{k}$ is higher then $\mathrm{Z}_{\mathrm{cu}}$ the patient is predicted to be in the group of taking compliance $>80 \%$. 
Using the discriminant function, a $2 \times 2$ table can be computed (table 1).

Table 1: $2 \times 2$ table of classification according to discriminant function versus classification against gold standard (MEMS).

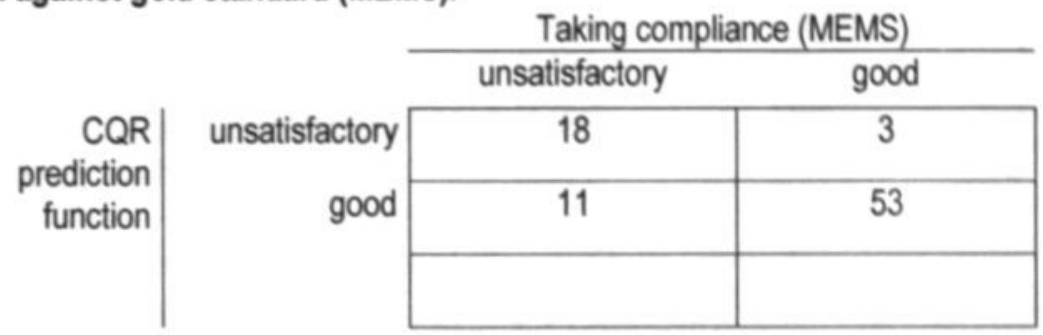

Since the CQR is designed to detect low compliance, the desired test result is to detect taking compliance $\leq 80 \%$. Sensitivity to detect taking compliance $\leq 80 \%$ can be calculated as:

$18 /(18+11) * 100 \%=62.1 \%$. Specificity to detect taking compliance $\leq 80 \%$ can be calculated as: $53 /(53+3) * 100 \%=94.6 \%$.

The predictive value to detect low taking compliance $(\leq 80 \%)$ is calculated as: $18 /(18+3)$ * $100 \%=85.7 \%$. Similarly, predictive value to detect good taking compliance $(>80 \%)$ is calculated as: $53 /(53+11) * 100 \%=82.8 \%$. The likelihood ratio to detect low taking compliance is represented by (sensitivity) $/(100$-specificity) $=62.1 / 5.4=11.4$

To help the reader to use the classification results of the CQR in a variety of situations, the discriminant weights for the individual CQR items to detect taking compliance $\leq 80 \%$, correct dosing $\leq 80 \%$, taking compliance $\leq 50 \%$ and correct dosing $\leq 50 \%$, as well as the critical cutting scores are given in table 2.

Table 2: discriminant weights for 4 CQR prediction functions.

\begin{tabular}{ccccc}
\hline CQR item & $\begin{array}{c}\text { Taking Compliance } \\
\leq 80\end{array}$ & $\begin{array}{c}\text { Taking } \\
\text { Compliance } 5 \text { 50 }\end{array}$ & $\begin{array}{c}\text { Correct Dosing } \\
\leq 80\end{array}$ & $\begin{array}{c}\text { Correct Dosing } \\
\leq 50\end{array}$ \\
\hline (Constant) & -3.4777 & -0.0294 & -5.0388 & -2.6171 \\
1 & -0.4448 & -0.1530 & -1.2897 & -0.4475 \\
2 & -0.9517 & -1.1213 & -0.1453 & -0.3557 \\
3 & 1.6758 & 1.1975 & 1.2362 & 1.8116 \\
4 & -0.2101 & -0.4300 & 0.3197 & -0.0317 \\
5 & 0.0244 & -0.1251 & 0.7938 & 0.1827 \\
6 & -0.5353 & -1.0975 & -0.0142 & -0.9797 \\
7 & 0.0030 & 0.5287 & 0.1136 & -0.2690 \\
8 & 0.0135 & 0.0389 & 0.1321 & -0.2455 \\
9 & -0.0106 & -0.0301 & -0.0999 & 0.0399 \\
10 & -0.2546 & -0.0048 & -0.0640 & -0.1436 \\
11 & 0.1023 & 0.0344 & 0.2135 & 0.1329 \\
12 & 0.1155 & 0.1613 & 0.1795 & 0.0738 \\
13 & 0.0248 & -0.0413 & 0.1246 & -0.3445
\end{tabular}




\begin{tabular}{ccccc}
\hline 14 & 0.1091 & -0.1884 & 0.2075 & 0.1946 \\
15 & 0.4475 & 0.0900 & -0.1535 & 0.2179 \\
16 & 0.2284 & 0.1318 & -0.0269 & 0.1442 \\
17 & 0.5350 & 0.4040 & 0.3362 & 0.3698 \\
18 & -0.4191 & 0.0529 & -0.6158 & -0.4663 \\
19 & 0.6829 & 0.6527 & 0.4234 & 0.9168 \\
\hline Critical & & & & -0.9890 \\
\hline Cutting Score & -0.5849 & 0.3490 & -2.0046 & \\
\hline
\end{tabular}

In addition, we have created a Microsoft Excel spreadsheet that is designed to help the user calculate the discriminant function from the raw CQR scores for taking compliance and correct dosing cut-off values between $95 \%$ and $50 \%$. It is freely available via the first author (erik@project.demon.nl) and can also be downloaded from the world wide web (www.project.demon.nV/CQR). 


\section{Patient compliance in rheumatoid arthritis, polymyalgia rheumatica and gout.}

\section{Erik de Klerk', Désirée van der Heijde1, ${ }^{1,2}$, Robert Landewé1, Hille van der Tempel', John Urquhart ${ }^{4}$, Sjef van der Linden'1.}

1: Department of Internal Medicine, division of Rheumatology, University Hospital Maastricht. 2: Limburg University Center, Diepenbeek, Belgium. ${ }^{3}$ : Department of Rheumatology, Maasland Hospital Sittard. ${ }^{4}$. Department of Epidemiology, Maastricht University.

\section{Manuscript accepted by the Joumal of Rheumatology}

\section{Abstract}

Objective: To explore patient compliance with prescribed drug regimens in the setting of usual care for outpatients with RA, gout, and PMRby utilizing electronic medication event monitors (MEMS) to register openings of the medication package. To examine the influence of disease, frequency of intake of the drug, and class of drug on compliance. Further to explore the influence of demographic factors, quality of life measures, coping, health status, and functional ability as potential predictors of patient compliance.

Methods: 127 consenting consecutive patients were enrolled, of which 81 RA patients, 33 taking NSAIDS ( 13 diclophenac TID and 20 naproxen BID) and 48 taking DMARDs ( 25 sulfasalazine [SSZ] BID and 23 methotrexate [MTX] once-weekly), 17 PMR patients starting with prednisolone QD and 29 patients with gout starting with colchicine (12, QD) or starting with uric acid lowering agents (17, QD). All patients received first prescriptions and were instructed to take the medication as prescribed. Follow-up was 6 months (gout: 12 months). All patients were aware of the monitoring nature of the package. At baseline a series of questionnaires was completed. We summarized the dosing histories as taking compliance (\% of total prescribed doses taken), correct dosing ( $\%$ of doses taken as prescribed) and timing compliance (\% of doses taken within + or $-25 \%$ of prescribed interdose intervals).

Results: A total of 26,685 days (> 73 patient-years) were monitored. Compliance expressed as taking compliance: mean $(95 \% \mathrm{Cl})$, correct dosing mean $(95 \% \mathrm{Cl})$ and timing compliance mean (95\% Cl) are: naproxen: $82 \%(75-90), 68 \%(57-80), 48 \%$ (34-61), diclophenac: $77 \%(61-93)$, $67 \%$ (47-87), 39\% (21-57), MTX: 107\% (98-117), 81\% (75-87), 83\% (76-90), SSZ: 72\% (60-84), $55 \%$ (44-67), $25 \%$ (18-33), prednisolone: $96 \%$ (89-102), 88\% (83-92), 82\% (74-89), colchicine: $65 \%$ (48-81), 44\% (26-62), 32\% (18-46), uric acid lowering agents: 84\% (76-92), 74\% (63-85), $65 \%$ (52-79). Missed doses occurred more frequently than taking of extra doses: in RA, on $10 \%$ of all monitored days there was no evidence of dosing, while on $3 \%$ of all monitored days extra doses were taken. In PMR and gout these numbers are $10 \%$ and $4 \%$, and $15 \%$ and $7 \%$, respectively. We observed a decline of compliance over time in all study medication groups. Multiple regression analyses showed that the class of medication (symptom modifying or disease controlling), the dosing frequency, the gender, coping pattern (avoidance, passive reaction pattern and expression of emotions), and the overall health (total NHP score) together explained $67 \%$ of the variance in taking compliance (adjusted $\left.R^{2}\right)(p=0.002)$. 
Conclusion: studying patient compliance with prescribed drug regimen utilizing state-of-the art electronic medication event monitors in RA, gout and PMR showed that large differences exist in compliance between the various medication groups. Compliance declines over time. A regression model shows that it is possible to relate differences in patient compliance to a number of medication and patient related factors.

\section{Support}

This project was supported by grant NR 831 from the Dutch Arthritis Association ('Nederlands Reumafonds').

\section{Introduction}

Compliance with treatment guidelines or standards by health professionals and compliance with prescribed drug regimens by patients are major determinants of outcome ${ }^{1,2}$. In daily practice reduced compliance is a well-known but poorly understood phenomenon. Data on drug regimen compliance by patients in rheumatology are scarce. A study among patients with ankylosing spondylitis revealed that deviations from the prescribed once-daily regimen of a NSAID occurred frequently, even in the setting of a randomized clinical trial ${ }^{3}$.

In this article we explore patient compliance with prescribed drug regimens in the setting of usual care for outpatients with one of three rheumatological diseases: rheumatoid arthritis (RA), gout, or polymyalgia rheumatica (PMR). The dosing frequency called for by the drug regimens varied between "three times daily" and "once-weekly". The drugs prescribed differ in their actions. Some have "direct symptom-modifying effects", others are intended for use as "lateonset disease-controlling therapy' or 'preventive therapy'. Prednisolone was used as drug that has both symptom-modifying as well as disease-controlling effects.

We used electronic medication event monitoring devices to document patient compliance with drug therapy, because this method addresses several aspects of patient compliance 4,5. This method is widely considered to be the gold standard for compiling drug dosing histories of ambulatory patients $6-8$.

We describe compliance with naproxen, diclofenac, sulfasalazine and methotrexate in RA, prednisone in PMR, and colchicine, allopurinol and uricosurica in gout. We examine the influence of disease, frequency of intake of the drug, and indication (direct effects versus late onset of effectiveness) on patient compliance. In addition we explore the influence of a number of demographic factors, quality of life measures, coping, health status, and functional ability as potential predictors of patient compliance.

\section{Methods}

The study was conducted as a series of cohort studies. We included all consecutive consenting outpatients with a diagnosis by a rheumatologist of RA, PMR or gout at the outpatient clinics of meumatology of the University Hospital Maastricht, Atrium Hospital Heerlen and Maasland Hospital Sittard, respectively a secondary/tertiary and 2 secondary referral centers for theumatology. For all studies, prior approval from the Medical Ethical Committee of all 3 hospitals was obtained. 
Patients with RA were to be included when the rheumatologist prescribed sulfasalazine (BID, after up-titration) or oral methotrexate (once-weekly), or if the rheumatologist prescribed either diclofenac (TID or combined with misoprostol BID, or naproxen (BID). Patients with a diagnosis of PMR were to be included if they received prednisone or prednisolone QD. In the analyses, patients on prednisone and prednisolone were combined and in this manuscript we will continue to use the term prednisolone for this group. Patients with a diagnosis of gout were to be included if the ineumatologist prescribed long-term prophylactic maintenance therapy with colchicines (QD), or uric acid lowering agents such as allopurinol or benzbromaron (QD). In the analyses, patients on allopurinol or benzbromaron were combined in a single group, called uric acid lowering agents.

All prescriptions in all diagnoses had to be first prescriptions (which did not necessarily mean a newly-made diagnosis) and had to be written 'to be taken as directed' (not: 'on demand'). We further required that the treating ineumatologist expected that drug-treatment would continue for at least 6 months.

To measure patient compliance we used the Medication Event Monitoring System (MEMS`, Aardex, Zug, Switzerland). It consists of a cup-type medication container, with a threaded, screw-cap closure. Within the closure is micro-electronic circuitry to record time and date of each opening and closing of the medication package. The method, with its advantages and disadvantages, has been discussed in detail elsewhere ${ }^{6-12}$.

The rheumatologist informed eligible patients about the purpose of the project and the nature of the MEMS system. A demonstration was given with a demo unit of how the system worked. Patients were then asked to sign the informed consent document. Each patient then received a MEMS system, and the patient's pharmacist was notified by fax that the patient was entered in a research project and asked to transfer the prescribed medication to the MEMS container. Patients also received a set of questionnaires (see below), which they were asked to complete in the first week after start of the medication. All patients received a follow-up phone-call by the investigator ( $E d K)$ approximately 3 days after the visit to the rheumatologist to answer questions, and to ensure that the medication was indeed transferred to the MEMS container.

Six months after start of drug therapy, (12 months in the case of gout patients) or sooner if patient or rheumatologist stopped medication, patients were asked to complete a second set of questionnaires, identical to the first set, and to return the MEMS container to the meumatologist or investigator. In addition, patients were asked to provide a prescription drug history, which they obtained from their pharmacy. This is a computerized list containing all dates and drugs which were dispensed at the patient's pharmacy. In the Netherlands the majority of patients are required to subscribe to one pharmacy, ensuring that most if not all dates of medication dispensing (and therefore extra openings) were recorded ${ }^{13}$. The data of the MEMS system were downloaded via a MEMS-communicator to a Windows ${ }^{\bullet}$-based personal computer, and analyzed by special software designed to analyze dosing histories (CSS version 2.1, Aardex, Zug, Switzerland).

Each patients' data were compared with the prescription drug history and, if available, remarks of the patient and, and, if necessary, days of special openings (such as pharmacy-visits or if the patient had recorded treatment-unrelated openings). These extra openings were marked as a 
'non-monitored period'. This procedure ensures that the calculation of the compliance summary variables (see below) is as free as possible of artifacts unrelated to actual medication taking.

\section{The dosing histories were transformed to}

\section{Taking compliance:}

The percentage of prescribed doses taken, calculated as:

(total number of recorded medication events / total number of prescribed doses) $\times 100 \%$ Example: a patient opened and closed the MEMS container 170 times while prescribed sulfasalazine BID for a monitored period of 100 days, so taking compliance $=(170 / 200) \times$ $100 \%=85 \%$.

Taking compliance is useful as an overall compliance variable. However, it is rather crude, as no information on the timing of doses is incorporated, and omitted doses occurring at one time can be obscured by extra doses taken at another time.

\section{Correct dosing}

The percentage of days within which the correct number of doses were taken, calculated as: (the total number of days with recorded medication events as prescribed / total number of monitored days) $\times 100 \%$

Example: a patient who had been prescribed sulfasalazine BID has a dosing history, compiled by the MEMS system, that showed 170 medication events during a monitored period of 100 days, but only 58 of the monitored days showed 2 medication events. Thus, correct dosing = $(58 / 100) \times 100 \%=58 \%$.

Correct dosing is a useful variable to look at actual day-by-day drug use. It incorporates day-byday variability in dosing, and is not influenced by 'catch-up dosing'. It is stricter than taking compliance.

\section{Timining compliänce}

We allowed the patients to vary the interdose-intervals within an arbitrarily chosen plus or minus $25 \%$. Thus, for a QD regimen, the prescribed interval is 24 hours, but we allowed intervals of 18-30 hours. Similarly, for a BID regimen we allowed intervals of $9-15$ hours, for a TID regimen we allowed intervals of 6-10 hours and for a once-weekly regimen we allowed intervals of 126210 hours.

Timing compliance was then calculated as: (the number of interdose-intervals of allowed duration / number of prescribed interdose-intervals) $\times 100 \%$.

Note that if there are missed doses, the number of interdose intervals is by definition lower than the number of prescribed interdose-intervals, so timing compliance does not necessarily add up to $100 \%$.

Example: a patient who had been prescribed sulfasalazine BID has a dosing history, compiled by the MEMS system, of 170 medication events during a monitored period of 100 days, but only 45 of all interdose intervals were between 18 and 30 hours duration. Timing compliance is: (45I 199) $\times 100 \%=22.6 \%$.

Timing compliance looks at interdose-intervals, which, when excessively long, may indicate periods of time when drug action was subtherapeutic or absent. It is a stricter measure of compliance with the prescribed drug regimen than correct dosing, 


\section{Questionnaires}

The questionnaires consisted of some demographic questions: age, gender, education (low = primary school, intermediate= secondary school, high=further education), profession (employed or not) and social support (living alone, with partner or with partner and children). We also asked the patients to complete the Health Assessment Questionnaire (HAQ) ${ }^{14}$, Nottingham Health Profile (NHP) ${ }^{15}$, Utrecht Coping List (UCL) ${ }^{16}$, European Quality of Life measure (EuroQol) ${ }^{17}$, Long Term Medication Behavior Self-Efficacy Scale (LTMBS) ${ }^{18}$, a self-composed list of 40 frequent side-effects, and for RA patients only, the Rheumatoid Arthritis Quality of Life measure (RAQOl) 1921.

$\mathrm{HAQ}$ scores range from 0 (minimum) to 3 (maximum) ${ }^{14}$. The NHP scores were summed and computed into 6 subscales: energy, pain, emotional reactions, sleep, social isolation and physical mobility ${ }^{15}$. For the UCL, seven subscales were computed: active attitude, palliative reaction, avoidance, seeking social support, passive reaction pattern, expression of emotions, comforting thoughts ${ }^{16}$. The EuroQol describes health status in 3 levels: 1-no problem, 2-some problems, 3-extreme problems. It also includes a self-rated thermometer, indicating the patients' own assessment of their health state ${ }^{17}$. The LTMBS is a 26-item questionnaire designed to measure self-efficacy for patients on chronic drug therapy. The results were summed and calculated to a scale ranging from 0 (lowest possible self-efficacy) to 100 (highest possible selfefficacy) ${ }^{18,22}$. The RAQol ranges from 0 (worst possible quality of life) to 30 (perfect quality of life) 1921 .

As no standard instrument was available at the time of the start of the study to document side effects of drug treatment in meumatology, we devised a measure with 40 questions for the most common side-effects associated with naproxen, diclofenac, sulfasalazine, methotrexate, prednisone, colchicine, allopurinol and benzbromaron. The frequencies of side-effects were based on US FDA-approved labeling for each of these products, as compiled in the Physicians Desk Reference (PDR) ${ }^{23}$. Each question consisted of 2 parts: occurrence (never $=0$, sometimes $=1$, frequently $=2$, often $=3$, always $=4$ ) and, if the answer was anything other then 'never', patients were asked to rate the severity on a range from 1 (not disturbing at all) to 5 (very disturbing). A frequency-of-side-effects score was computed by summing the 40 items of occurrence into one variable (range: $0=$ no side effects at all, $160=$ maximum frequency of side effects score). In addition, a total side-effects score was calculated as (occurrence $\mathrm{x}$ frequency), ranging from 0 (no side effects at all) to a maximum of 800 (maximum occurrence and severity of side-effects).

\section{Statistics}

Analyses consisted of descriptive statistics (means, standard deviations and $95 \%$ confidence intervals), Pearson's correlation coefficients, (stepwise) multiple regression analyses with adjustment for multiple variable testing, one-way analysis of variance with the Scheffe multiple comparison test for post-hoc analysis, and, where appropriate, non-parametric alternatives. All analyses were performed using SPSS version 10.0.7 for Windows. 


\section{Results}

Figure 1: Example of a calendar plot.

August 1998

\begin{tabular}{l|c|c|c|c|c|c|c}
\hline & Mon & Tue & Wed & Thr & Fri & Sat & Sun \\
\cline { 2 - 8 } & & & & & & 0 & 1 \\
\cline { 2 - 8 } 3 & 1 & 1 & 1 & 1 & 0 & 0 & 1 \\
\cline { 2 - 8 } 10 & 1 & 1 & 1 & 1 & 1 & 1 & 1 \\
\cline { 2 - 7 } 17 & 1 & 1 & 1 & 1 & 1 & 1 & 1 \\
\cline { 2 - 7 } 24 & 1 & 0 & 1 & 1 & 1 & 0 & 1 \\
\cline { 2 - 7 } 31 & 1 & & & & & &
\end{tabular}

This gout patient, prescribed allopurinol QD, told us that he likes to go out on the weekends, and thought that allopurinol and alcohol did not go together well. Hence he wouldn't take it on most saturdays. See also figure 2 for the chronology plot (patient 2046).

\section{Compliance on the individual level}

It is often useful to convert the dosing histories from the electronic monitors to calendar and chronology plots for a quick overview of the patient's dosing history. The calendar plot (an example is shown in figure 1) shows the number of recorded doses on each day of the study period. It is helpful to identify periods in which dosing was not optimal, and to correlate clinical events (such as the occurrence of flares, gout attacks, or specific adverse drug reactions) to specific dates. However, the calendar plot does not give details on within-day timing of drug intake, and only roughly shows changes in the patient's dosing pattern over time. Such information is shown by the chronology plot ( 4 examples are shown in figure 2). From these plots it becomes apparent that patient compliance on drug therapy is a day-by-day phenomenon, which, in some instances, is difficult to grasp in a single summary variable.

Figure 2: Example of 4 chronology plots.

\section{Patient 1089}

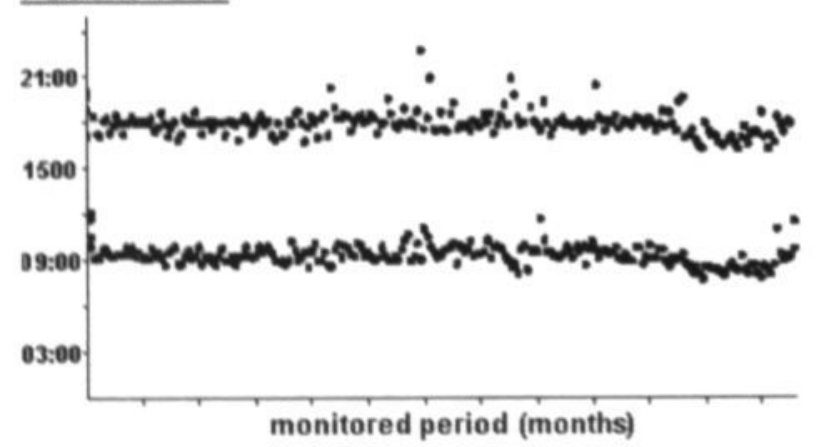




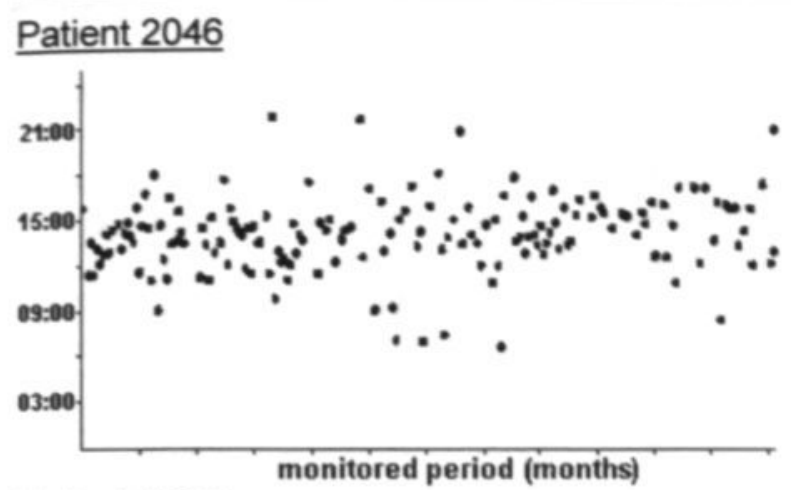

Patient 1005

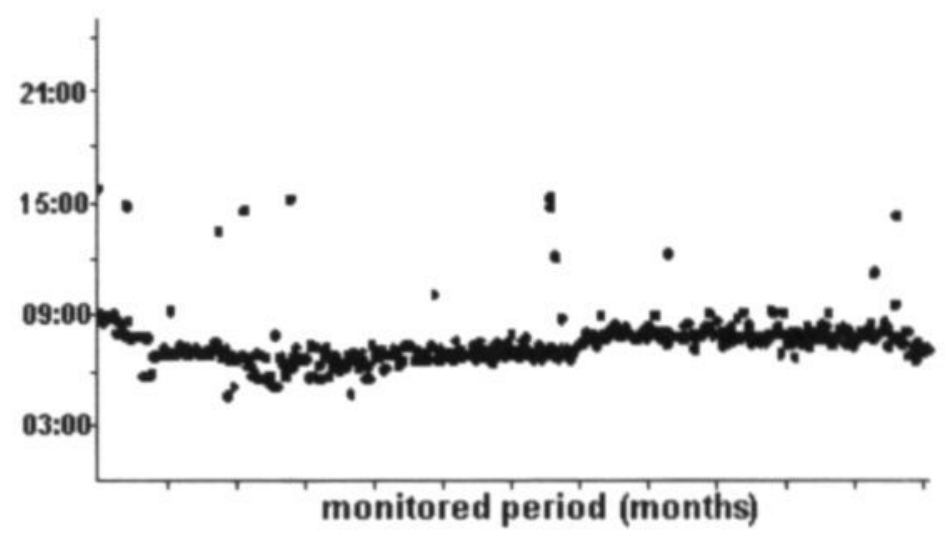

Patient 1029

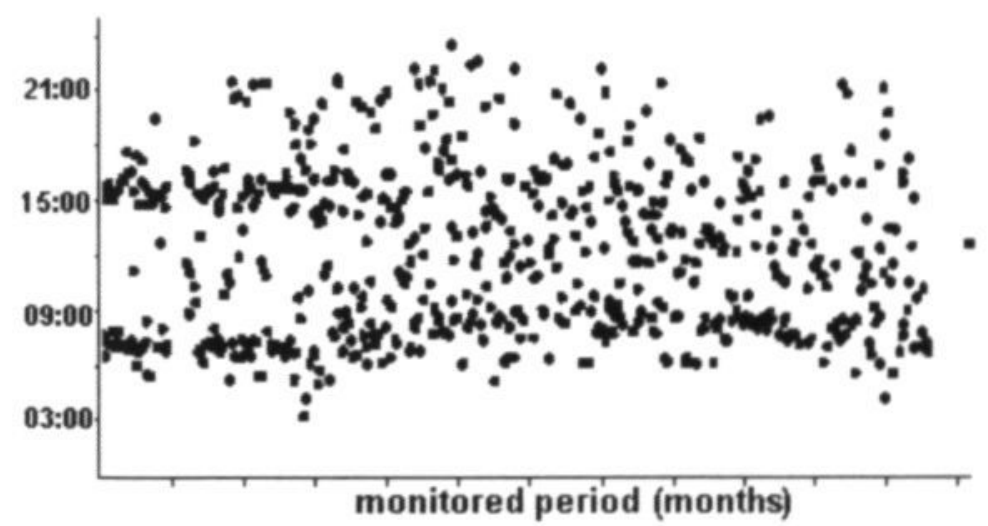

Patient 1089 is a RA patient on BID sulfasalazine. She is taking almost $100 \%$ of the drugs, but is taking the doses in relatively short intervals, resulting in a lower timing compliance (25\%). Patient 2046 is a gout patient on QD allopurinol (see also figure 1 for the calendar plot), frequently missing doses on weekend days. Patient 1005 is a PMR patient prescribed QD prednison. She frequently takes extra doses, but hardly ever misses a dose. Lastly, patient 1029 is a gout patient on BID maintenance therapy with colchicine. Even though taking compliance is good at $84 \%$, he is taking the correct number of doses on $60 \%$ of the days, and only $20 \%$ of all doses are within the prescribed interdose-interval. 


\section{Overall compliance results}

One-hundred twenty-seven consenting, consecutive patients of the outpatient clinic were included. They consisted of 81 patients with RA using NSAIDs ( 13 dicbfenac and 20 naproxen) or DMARDs ( 25 sulfasalazine and 23 methotrexate), 17 patients with polymyalgia rheumatica taking prednison and 29 patients with gout taking colchicine (12) or allopurinol (10) or benzbromaron (7). A total number of 26.685 days were monitored ( $>73$ patient years). The mean follow-up was 210 days. Table 1 summarizes the demographic data.

\section{Table 1: Demographical data}

\begin{tabular}{lccc}
\hline & $\begin{array}{c}\text { RA } \\
\text { N=81 }\end{array}$ & $\begin{array}{c}\text { PMR } \\
\mathbf{N}=17\end{array}$ & $\begin{array}{c}\text { Gout } \\
\mathbf{N}=29\end{array}$ \\
\hline $\begin{array}{l}\text { Age: mean (sd) } \\
\text { Gender (\% female) }\end{array}$ & $60(14)$ & $72(7)$ & $58(12)$ \\
$\begin{array}{l}\text { Social support } \\
\text { single }\end{array}$ & $66 \%$ & $76 \%$ & $20 \%$ \\
$\begin{array}{l}\text { married / living together } \\
\text { without children }\end{array}$ & $29 \%$ & $24 \%$ & $17 \%$ \\
$\begin{array}{l}\text { married / living together } \\
\text { with children }\end{array}$ & $64 \%$ & $70 \%$ & $80 \%$ \\
$\begin{array}{l}\text { Education } \\
\text { Low }\end{array}$ & $7 \%$ & $6 \%$ & $3 \%$ \\
$\begin{array}{l}\text { Intermedidate } \\
\text { High }\end{array}$ & $28 \%$ & $24 \%$ & $17 \%$ \\
Work \\
\% working
\end{tabular}

Figure 3a: Taking compliance

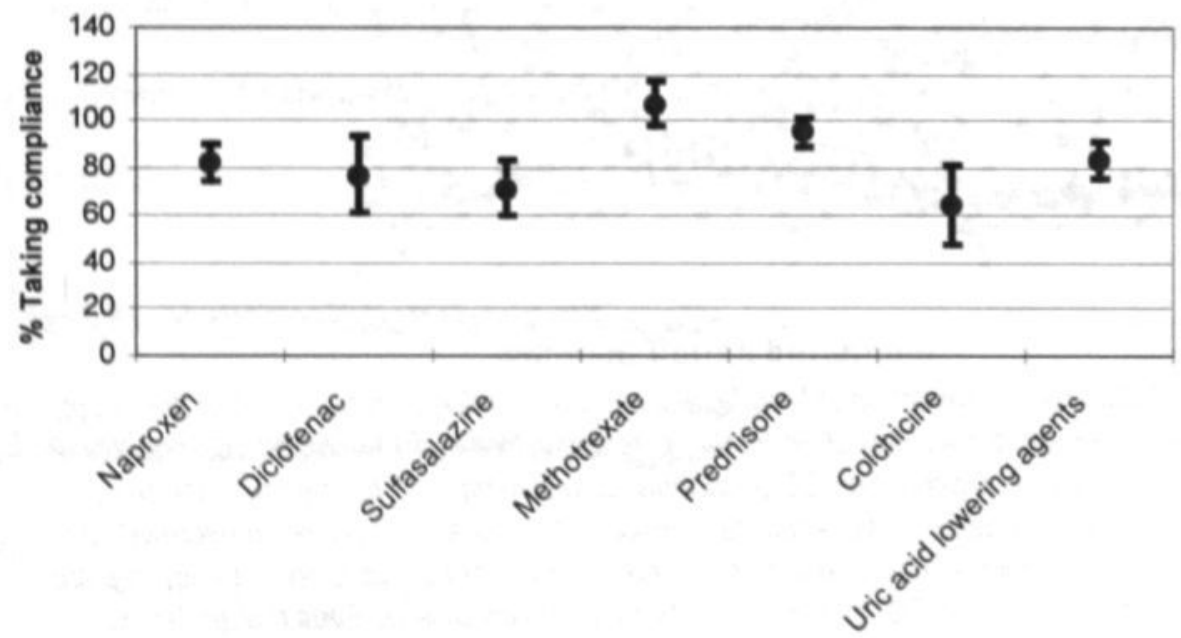


Figure 3b: Correct Dosing

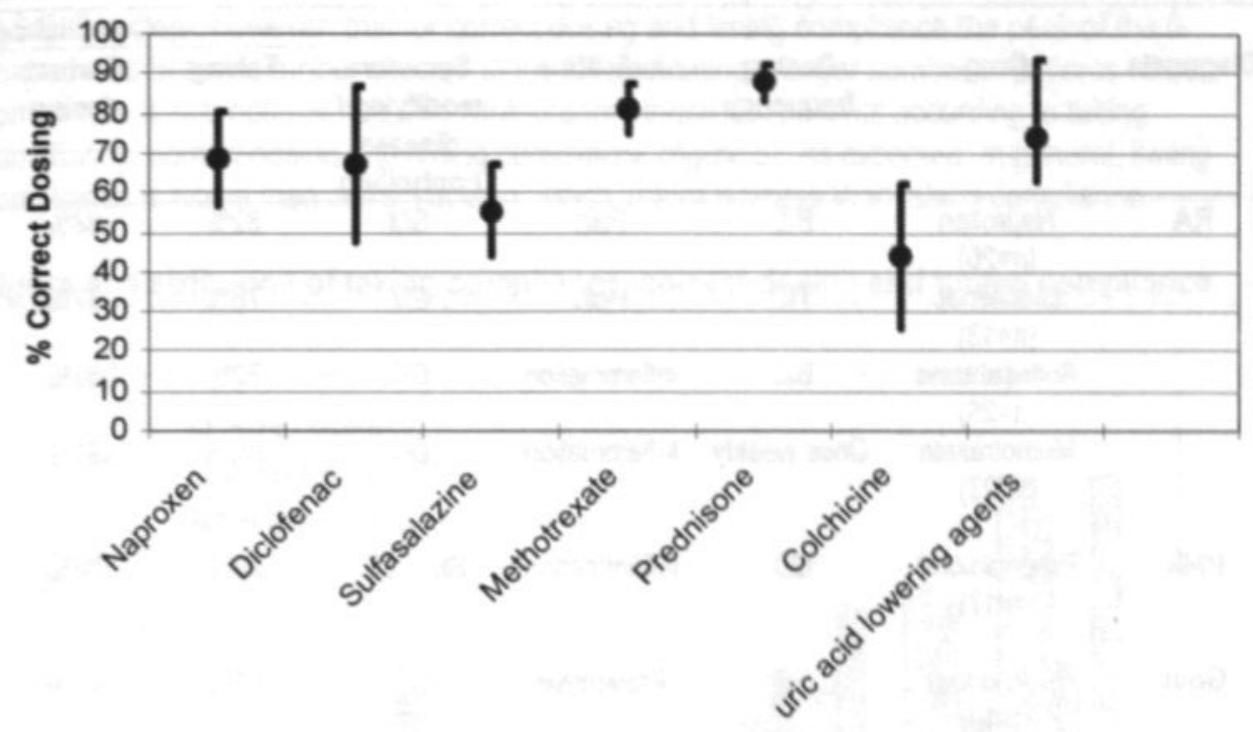

Figure 3c: Timing compliance

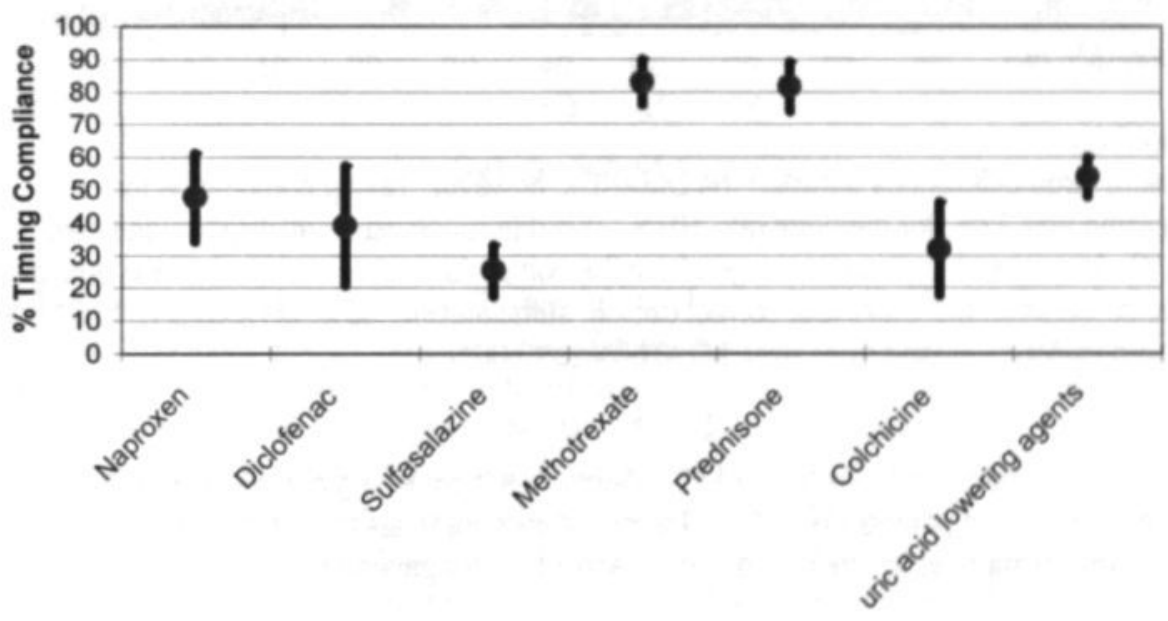

RA; NSAIDS

Figures 3 a-c depict the taking compliance, correct dosing, and timing compliance of the various drugs between the three diagnoses, along with the corresponding $95 \%$ confidence intervals. There are clear and statistically significant differences between the drugs (table 2). Compliance with naproxen and diclofenac were comparable, with a taking compliance of $82 \%$ and $76 \%$, correct dosing of $68 \%$ and $67 \%$ and timing compliance of $48 \%$ and $39 \%$ respectively. 
Table 2. Diagnosis, patient compliance and drug regimen.

\begin{tabular}{|c|c|c|c|c|c|c|c|}
\hline \multirow[b]{2}{*}{ Diagnosis } & \multirow[b]{2}{*}{ Drug } & \multirow[b]{2}{*}{$\begin{array}{l}\text { Dosing } \\
\text { frequency }\end{array}$} & \multirow[b]{2}{*}{ Indication } & \multirow[b]{2}{*}{$\begin{array}{l}\text { Symptom } \\
\text { modifying I } \\
\text { disease } \\
\text { controlling }\end{array}$} & \multicolumn{3}{|c|}{ Compliance } \\
\hline & & & & & Taking & $\begin{array}{l}\text { Correct } \\
\text { dosing }\end{array}$ & Timing \\
\hline \multirow[t]{4}{*}{ RA } & $\begin{array}{c}\text { Naproxen } \\
(n=20)\end{array}$ & BID & Pain & SM & $82 \%$ & $68 \%$ & $48 \%$ \\
\hline & $\begin{array}{c}\text { Diclofenac } \\
(n=13)\end{array}$ & TID & Pain & SM & $76 \%$ & $67 \%$ & $39 \%$ \\
\hline & $\begin{array}{l}\text { Sulfasalazine } \\
\qquad(n=25)\end{array}$ & BID & Inflammation & DC & $72 \%$ & $55 \%$ & $25 \%$ \\
\hline & $\begin{array}{l}\text { Methotrexate } \\
\quad(n=23)\end{array}$ & Once weekly & Inflammation & DC & $107 \%$ & $81 \%$ & $83 \%$ \\
\hline PMR & $\begin{array}{l}\text { Prednisolone } \\
\quad(n=17)\end{array}$ & $Q D$ & Inflammation & $S M+D C$ & $96 \%$ & $88 \%$ & $82 \%$ \\
\hline \multirow[t]{3}{*}{ Gout } & $\begin{array}{c}\text { Colchicine } \\
(n=12)\end{array}$ & $\mathrm{QD}$ & Preventive & $\mathrm{DC}$ & $65 \%$ & $44 \%$ & $32 \%$ \\
\hline & $\begin{array}{l}\text { allopurinol I } \\
\text { benzbromaron } \\
(n=17)\end{array}$ & QD & Lower urate & DC & $84 \%$ & $74 \%$ & $62 \%$ \\
\hline & & & & & $\begin{array}{c}F=7.13, \\
p<0.001^{1}\end{array}$ & $\begin{array}{c}F=5.98, \\
P<0.001^{1}\end{array}$ & $\begin{aligned} F & =19.1 \\
P & <0.001\end{aligned}$ \\
\hline
\end{tabular}

1 One way ANOVA

RA; DMARDS

There were large differences between the DMARDs, however. Taking compliance for sulfasalazine was $72 \%$, for methotrexate $107 \%$. This difference was statistically significant $(p<0.001)$. A comparable picture emerges from the comparison of correct dosing and timing compliance between the DMARDs: correct dosing: sulfasalazine: $55 \%$, MTX $81 \%(p<0.001)$ and timing compliance: sulfasalazine: $25 \%$, MTX: $83 \%$ ( $p<0.001)$.

\section{PMR}

Compliance with prednisolone among PMR patients was high: taking compliance: $96 \%$, correct dosing: $88 \%$ and timing compliance $82 \%$. The confidence intervals around the mean were relatively small compared to other drugs, indicating little inter-patient variability.

\section{Gout}

The compliance of PMR patients prescribed systemic steroids contrasted quite sharply with the compliance of the gout patients. Especially compliance on maintenance colchicine therapy was strikingly low: taking compliance $65 \%$, correct dosing $44 \%$ and timing compliance $32 \%$. Compliance with the combined uric acid lowering agents was better: taking compliance $84 \%$, correct dosing $74 \%$ and timing compliance $54 \%$. 
Figure 4 shows the distribution of taking compliance, correct dosing and timing compliance, when the proportion of patients is plotted against compliance categorized in categories of $10 \%$ each. The distribution follows the previously described 'typical J-shaped compliance distribution' $(4,24)$. It is clear, however, that for correct dosing and timing compliance the peak of the $\mathrm{J}$ shaped distribution is further skewed to the left, indicating a larger number of patients whose compliance is sub-optimal. We also rank-ordered individual patients according to taking compliance, correct dosing and timing compliance (figure 5). As expected, in general, timing compliance is worse than correct dosing, which in turn is worse then taking compliance.

Figure 4: distribution of taking compliance, correct dosing and timing compliance.

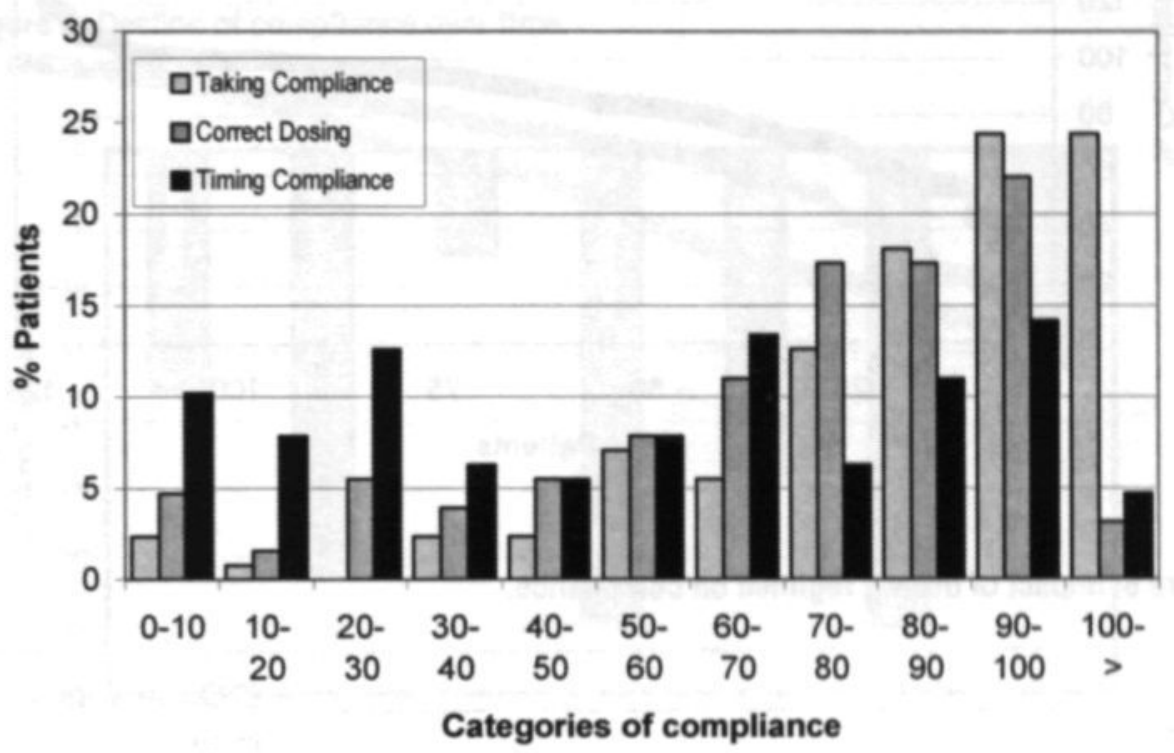

Missed doses occurred more frequently than taking of extra doses: in RA, on $10 \%$ of all monitored days there was no evidence of dosing, while on $3 \%$ of all monitored days extra doses were taken. In PMR, missed and extra doses were $10 \%$ and $4 \%$ of all monitored days, and in gout they were $15 \%$ and $7 \%$, respectively. We further divided missed doses in 'occasionally missed' (periods of 1 or at most 2 consecutive days without dosing) and 'drug holidays' (periods of 3 or more consecutive days without dosing) $(25,26)$. Drug holidays were not computed for the patients on methotrexate, because of the weekly dosing regimen. There were a total of 192 drug-holidays. Patients on sulfasalazine, colchicine and uric acid lowering agents had the highest frequency of drug holidays (2.4-2.5 per patient), while all other groups had approximately 1-1.2 drug holidays per patient. 
Figure 5: Patients rank-ordered by taking compliance, correct dosing and timing compliance.

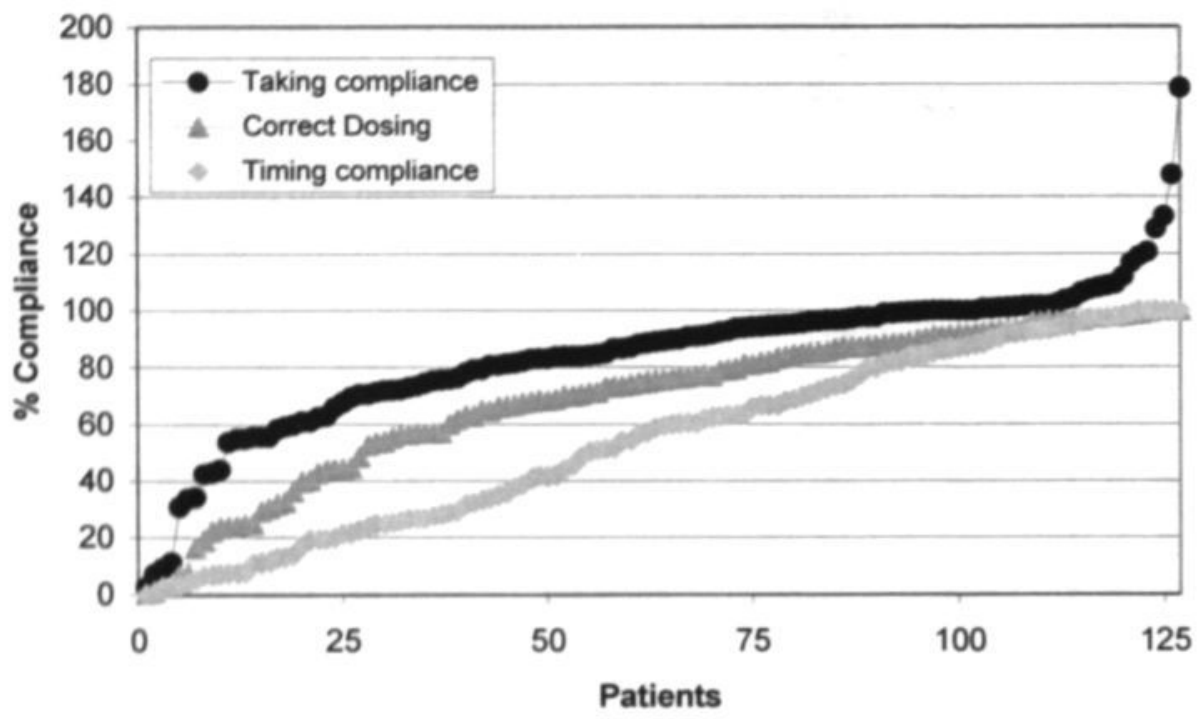

Figure 6: Impact of dosing regimen on compliance.

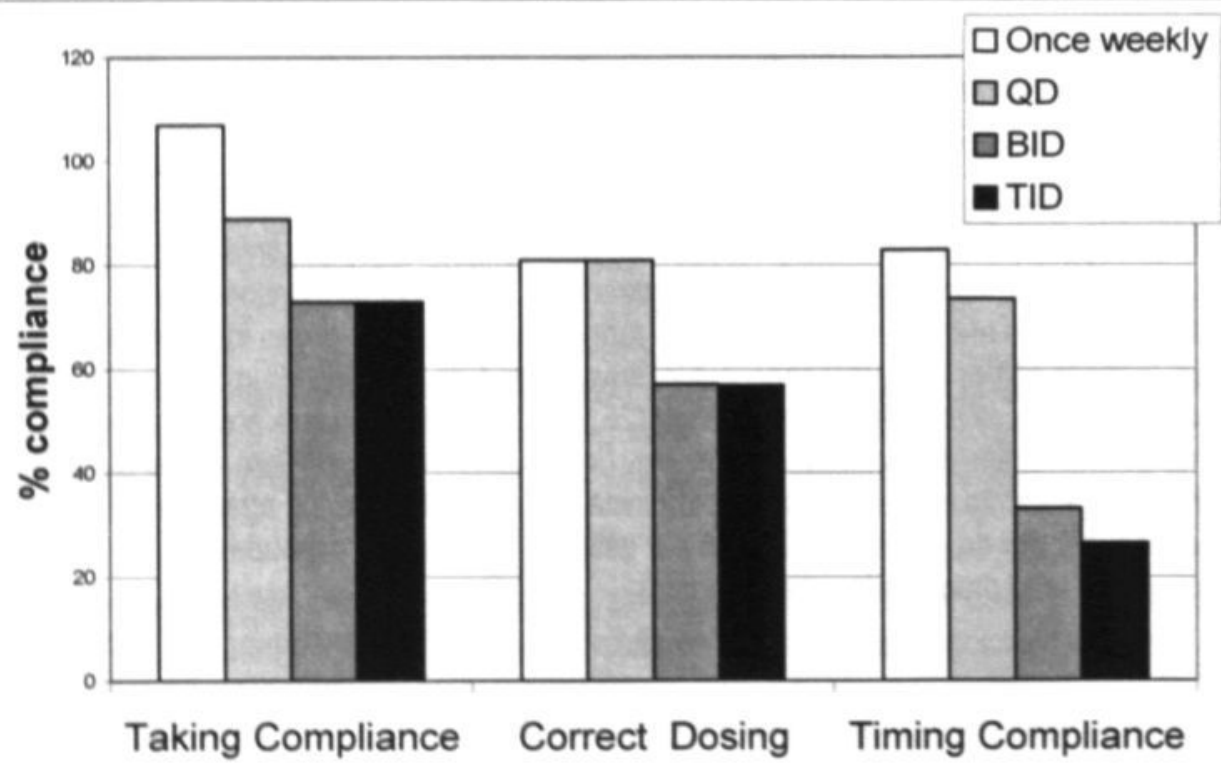

QD: Once-daily, BID: twice-daily, TID: three times daily 
There were clear and statistically significant differences in compliance between the 4 dosing regimens (figure 6). Compliance with once weekly (all RA patients on MTX) was the best, followed by QD, then BID and TID, for taking compliance, correct dosing and timing compliance. Three separate ANOVA's showed that these differences were statistically significant (all p values $<0.001$ ).

All groups showed a gradual and large decline of compliance over time. Comparison of compliance in the first month versus compliance in the $\sigma^{\text {th }}$ month showed an overall decline of $22 \%$ (figure 7). Although the between-drugs differences were large, none reached statistical significance.

Figure 7: Decline of compliance over time.

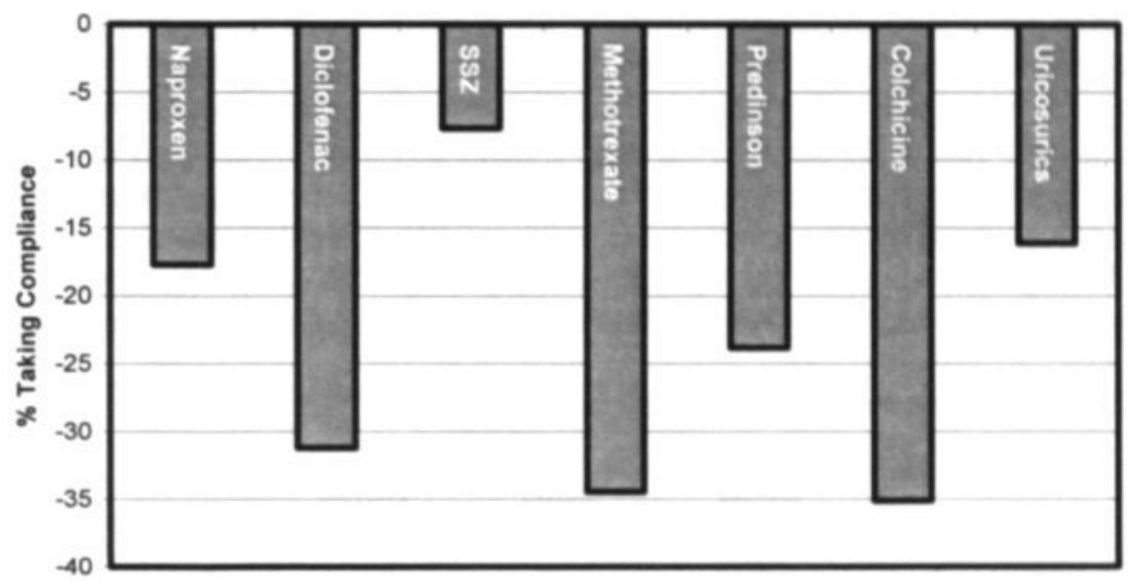

\section{Determinants of compliance}

\section{Functional capacity}

$\mathrm{HAQ}$-total score was $0.75 \pm 0.68$. There were statistically significant differences in $\mathrm{HAQ}$ scores between the three diseases: RA patients had the highest scores $(0.87 \pm 0.72)$, PMR patients were in-between $(0.68 \pm 0.67)$ and gout patients showed the lowest scores $(0.44 \pm 0.44)$. These differences were statistically significant $\left(\chi^{2}=8.24, p=0.02\right)$. There was no correlation of HAQ-scores, nor of HAQ-category scores (data not shown) with taking complianœ, correct dosing, or timing compliance. This was also true within each of the three diseases. In addition, a one-way ANOVA with the HAQ-total score with taking compliance, correct dosing and timing compliance as separate independent variables, did not show any statistically significant differences. These results indicate that functional capacity, as measured by HAQ-total score, seem not to be associated with patient compliance.

\section{Overall health profile}

The NHP total score at baseline was $11.6 \pm 7.8$. There were no differences between the drugs or the diseases. The NHP baseline subscores were as follows: energy: $0.03 \pm 0.03 ;$ pain: 0.30 \pm 0.20 ; emotional reactions: $0.16 \pm 0.21$; social isolation: $0.02 \pm 0.04$; sleep: $0.09 \pm 0.08$; 
physical mobility: $0.23 \pm 0.18$. Neither taking compliance, correct dosing nor timing compliance were associated with the total score, although the subcategories were statistically significantly associated with taking compliance ( $F=2.50, p=0.03)$, correct dosing $(F=2.30, p=0.04)$ and timing compliance $(\mathrm{F}=2.08, \mathrm{p}=0.06)$. These findings suggest that some NHP baseline sub-scores are predictive of compliance during the study period.

\section{Coping}

The UCL subscores were (mean \pm sd): active attitude, $17.5 \pm 5.6$; palliative reaction, $18.5 \pm$ 5.4 ; avoidance, $17.1 \pm 5.4$; seeking social support, $12.7 \pm 4.4$; passive reaction pattern, $11.3 \pm$ 3.9 ; expression of emotions, $5.5 \pm 2.3$; comforting thoughts, $13.1 \pm 3.2$. There were no differences between UCL subscores within the drugs, diseases studied, or categories of compliance.

\section{Perceived health status}

There were no between-disease differences in baseline overall health status as measured by the EuroQol VAS. Compliance scores between patients who rated their health status as worse during the pre-study period were statistically significantly higher when compared with those of patients who rated their health-status as the same or better during the pre-study period (table 3). In addition, the visual analogue scale that is part of the EuroQOI showed a statistically significant association with taking compliance $(F=4.32, p=0.04)$. The association was negative, meaning that the better the perceived health state at beginning of the study, the lower was compliance during the study. The strength of the association was negligible, however $\left(R^{2}=0.04\right)$.

\section{Table 3: EuroQol health status at baseline.}

\begin{tabular}{cccc}
\hline & $\begin{array}{c}\text { Better } \\
(n=20)\end{array}$ & $\begin{array}{c}\text { Same } \\
(n=62)\end{array}$ & $\begin{array}{c}\text { Worse } \\
(n=61)\end{array}$ \\
\hline Taking compliance & $81 \%$ & $78 \%$ & $95 \%$ \\
Correct dosing & $69 \%$ & $61 \%$ & $79 \%^{2}$ \\
Timing compliance & $43 \%$ & $46 \%$ & $66 \%^{3}$ \\
\hline
\end{tabular}

1: differences were statistically significant: $F=5.42, p<0.01$

2: differences were statistically significant: $F=6.00, p<0.01$

3: differences were statistically significant: $F=5.25, p<0.01$

\section{Self-efficacy}

The average LTMBS-total score was 89.5 (std.dev. 9.13), indicating high levels of self-efficacy. There were statistically significant between-disease differences in self-efficacy $\left(\chi^{2}=7.96\right.$, $p=0.02$ ): patients with PMR had higher levels of self-efficacy (mean: $96 \pm 5$ ), whereas gout patients had lower levels of self-efficacy $(86 \pm 11)$. Total self-efficacy was statistically significantly associated with taking compliance ( $F=5.9, p=0.02)$, but not with correct dosing or timing compliance. In addition, the explained variance of total selfefficacy score on taking compliance was low $\left(R^{2}=0.07\right)$. Furthermore, the association of individual LTMBS items with taking compliance, correct dosing and timing compliance were not statistically significant.

\section{Drug related side-effects}

From the self-devised questionnaire for side-effects, we noted 107 patients (84\%) reporting at least one side effect. The average was 3.3 side effects (sd: 5.0 ), with a minimum of 0 and a 
maximum of one patient who reported 25 side effects. The severity was 16.5 (sd 20.7), while the frequency $x$ severity of side effects was 6.4 (sd 11.0). There was no association between frequency, severity, or the combination of both, with taking compliance, correct dosing, or timing compliance. In addition, no individual items on the side-effects measure were associated with any compliance summary variable.

\section{RA Quality of life}

Within RA patients, there were no differences in RAQol total score between the 4 drugs, nor between the 2 drug-groups (symptom modifying and disease controlling). The RAQottotal score and its individual items did not show any association with taking compliance ( $F=0.21, p=0.65$ and $F=1.0, p=0.50$, respectively), correct dosing $(F=0.34$ with $p=0.56$ and $F=0.86$ with $p=0.66$ ) or timing compliance $(F=0.05$ with $p=0.94$ and $F=0.86$ with $p=0.66)$. We therefore conclude that RAQol total score is not associated with compliance.

Table 4. Predictors of Taking compliance: a multiple regression model with backward removal of variables.

\begin{tabular}{|c|c|c|}
\hline Variable in the regression equation & Standardized $\beta$ & Unstandardized $\beta$ \\
\hline constant & & 65.4 \\
\hline $\begin{array}{l}\text { Class of medication } 1 \\
\text { (symptom modifying or disease controlling) }\end{array}$ & -0.66 & -23.3 \\
\hline Dosing frequency & 1.16 & 8.2 \\
\hline Gender & 0.38 & 13.5 \\
\hline Partial R2 & 0.31 & \\
\hline Avoidance & -0.41 & -2.2 \\
\hline Passive reaction pattern & 0.79 & 5.0 \\
\hline Expression of emotions & 0.40 & 3.5 \\
\hline NHP & -0.62 & -1.7 \\
\hline $\begin{array}{r}\text { Partial R2 } \\
\text { Total R2 }\end{array}$ & $\begin{array}{l}0.36 \\
0.67\end{array}$ & \\
\hline
\end{tabular}

All $\beta$ s: $p<0.05$

Independent variable: Taking Compliance

1: class of medication: $1=$ symptom modifying, $2=$ disease controlling, $3=$ both

2: dosing frequency: $1=0$ once daily, $2=t w i c e$ daily, $3=$ thrice daily, $7=$ once-weekly

3: gender: $0=$ female, 1 = male

4 : coping: avoidance ( $7=$ lowest, 56 =highest), passive reaction pattem (7=lowest, 32=highest), expression of emotions ( $3=$ lowest, 19=highest).

5: NHP: $0=$ lowest, 34=highest.

A multiple regression model with taking compliance as dependent variable and backward elimination of the demographic and questionnaire variables showed that the class of medication (symptom modifying or disease controlling), the dosing frequency (once weekly, QD, BID or TID), the gender, coping (avoidance, passive reaction pattern and expression of emotions), and the overall health (total NHP score) together explained $66.6 \%$ of the variance in taking compliance (adjusted $R^{2}$ ) ( $p=0.002$, table 4$)$. In this regression model there was little co-linearity between the variables, and the residual error was randomly distributed, indicating good fit of the 
model. The result for correct dosing was approximately equal (adjusted $R^{2}=52 \%, p=0.014$, with the standardized B-coefficient for gender being statistically not significant. For timing compliance the model did not converge, probably due to the strongly skewed distribution of the timing compliance variable as shown in figure 4 .

\section{Discussion}

The use of electronic monitors to investigate patient compliance is relatively new in rheumatology. While the method is indirect, in that it does not prove ingestion, it nevertheless captures, with indelible time stamping, the occurrence of the maneuvers needed to remove a dose of drug from the monitored drug-package. In this respect electronic medication event monitoring differs sharply with other methods for estimating patient compliance, such as returned pill-counts, patient reports, questionnaires, diaries and physician estimates, each of which can be altered at any time by one or a few simple acts (such as emptying the pillbox, or exaggerating compliance on a questionnaire, or a 'little white lie' when asked for the number of tablets taken) ${ }^{27}$. With electronic monitoring, the clock cannot be reset, so that a dose not taken indelibly remains a dose not recorded. In addition, electronic monitoring is automatic, does not rely on memory, and is non-invasive. All of this means that the use of electronic monitoring offers several advantages in both accuracy and precision of measurement, thus providing better data then the more traditional methods.

The patients were aware of how the monitoring took place. A few patients complained at the end of the study that they had felt like they were being watched, which in turn had increased their compliance. There were no instances in which patients reported having taken less medicine because of the monitors. In fact, there were a number of patients who had forgotten about the monitoring nature of the package when they were contacted to return the monitor.

This study reports the first data on electronically compiled dosing histories in a diverse population of patients with rheumatic conditions. Thus, it provides an unprecedented look into patients' compliance behavior, revealing some very clear and relevant differences betweendiseases, between drugs, and, most of all, between-patients.

Compliance with DMARDs and prednisone was in general much better then compliance with NSAIDs and anti-gout therapy. However, compliance with sulfasalazine, prescribed BID, appeared to be substantially and significantly lower then compliance with once-weekly methotrexate. Compliance with prednisolone in PMR was very good, with very little inter-patient variability, meaning that not just the average was high, but that indeed almost all patients prescribed prednisone were taking the medication in very close correspondence to the prescribed regimen. Compliance with NSAIDs in RA and uric acid lowering agents in gout were clearly low, even though the medication was prescribed to be taken daily, not 'on demand', although the latter more closely resembles the way that most of the patients actually took these agents. The level of compliance with NSAIDs that we have observed in this study was strikingly similar to the compliance with once daily prescribed piroxicam and tenoxicam that we previously reported, using the same method, for patients with ankylosing spondylitis ${ }^{3}$. Compliance on colchicine maintenance therapy was, perhaps not unexpected, lowest of all.

Transformation of the dosing histories to a summary variable is an important issue, because summarization of temporal patterns inevitably results in loss of precision ${ }^{28}$. The dosing histories 
per se, as depicted in figure 2, cannot be analyzed without some sort of summarization. We choose to report three different compliance variables: taking compliance, correct dosing, and timing compliance. Each represents different aspects of dose taking. Taking compliance provides a gross estimate of all doses taken over a long period. This variable is insensitive to dosing errors (such as taking a dose late, or catch-up dosing where a missed dose is followed by a day with e.g. 2 doses). It thus provides mainly insight in overall drug exposure over the monitored period. It resembles the traditional pill-count, but with the difference that for each 'pill' to be counted, the monitor has to be opened and closed, and with automatic time stamping.

Correct dosing, where the percentage of days with the correct number of doses is summarized, reflects more the intention of the patient to take the medication as prescribed. It does not correct for catch-up dosing, but variations within inter-dose intervals are allowed. Timing compliance focuses on these inter-dose intervals, and is the strictest of the three. The differences in length of interdose-intervals ( 8 hours for TID and 168 hours for once-weekly) were corrected for by giving a relative leeway of $\pm 25 \%$ of the interdose intervals rather then absolutely defined intervals.

We clearly see differences in taking compliance, which in general is highest, correct dosing, and timing compliance, which is lowest. In fact, as can be seen in figure $3 \mathrm{c}$, timing compliance is very low for most drugs except methotrexate in RA and prednisolone in PMR, perhaps providing insight into tactics to follow in compliance interventions.

Less frequent dosing was strongly related to better compliance. This relationship has been observed with electronic medication event monitoring before in other fields of medicine (29). Interestingly, once-weekly dosing is associated with better compliance than more frequent dosed sulfasalazine. Recently, four other studies, utilizing electronic monitoring with once weekly-prescribed drugs, showed the same superior compliance (30-33). As once weekly MTX is readily available in theumatology, we regard this as a very interesting finding which warrants further research.

The relationship between the individual demographic and questionnaire variables and compliance was weak. Especially the lack of a relationship between compliance and side effects may come as a surprise. However, it is clear that such a relationship is by no means simple. Early onset, severe side effects may result in discontinuation of the drug, while less severe, noticeable side-effects may actually be perceived as 'the drug is working'. Another interpretation of the lack of the relationship may be that the questionnaire to capture information about side-effects in this study systematically, is not the optimal way to do so. Especially the way the data from the questionnaire are transformed to a variable that is related to compliance may not be optimal. Due to the heterogeneity of the patient sample and the lack of a gold standard for side-effects the lack of relationship between compliance and side-effects need to be interpreted with caution.

However, combining the variables in a multiple regression analysis showed that a combination of a few variables predict taking compliance and correct dosing to a substantial degree. The key variables are: the nature of the drug (symptom-modifying associated with lower compliance than disease-controlling, while systemic steroids, dual properties, are associated with the highest compliance), the dosing regimen (less frequent dosing results in higher compliance), gender (females show higher compliance), coping (avoidance is related with lower compliance, 
expression of emotions and passive reaction pattern are related with higher compliance) and overall perceived health (where a higher perceived health is related with lower compliance). The overall correlation of this multiple regression correlation with taking compliance, adjusted for multiple variables in the equation was high, adjusted $R^{2}=0.67$. Closer examination of the model shows that the variables that are fixed (nature of drug, dosing regimen and gender) explain a total of $45.8 \%$ of the explained variance while the other variables (the three coping variables avoidance, passive reaction pattern and expression of emotions, and the overall perceived health) explain a total of $54.2 \%$ of the explained variance. Given the relatively small size of the study and the very heterogeneous study population we await for confirmation of the model in other studies, however, if these variables do appear to be statistically significantly related to taking compliance and correct dosing they might provide an important clinical tool for compliance awareness and, perhaps, compliance intervention.

\section{Conclusion}

Studying patient compliance with prescribed drug regimen utilizing electronic medication event monitors in RA, gout and PMR showed that large differences exist in compliance between the various medication groups. Compliance declines over time. A regression model shows that it is possible to relate differences in patient compliance to a number of medication and patient related factors.

\section{Acknowledgement}

We would like to acknowledge the help of the AV dienst of the Maastricht Univerisity Hospital who kindly helped with the inclusion of patients in this study.

\section{References}

1. Hasford J. Biometric issues in measuring and analyzing partical compliance in clinical trials. In: Cramer JA, Spilker B, eds. Patient compliance in medical practice and clinical trials. New York: Raven Press, 1991:265-82.

2. Urquhart. Patient compliance with prescribed drug regimens: overview of the past 30 years of research. In: Nimmo W.S. T. G.T., ed. Clinical Measurement in Drug Evaluation: John Wiley \& Sons, 1995:213-27.

3. de Klerk E, van der Linden SJ. Compliance monitoring of NSAID drug therapy in ankylosing spondylitis, experiences with an electronic monitoring device. Br J Rheumatol 1996; 35:60-5

4. Urquhart J, De Klerk E. Contending paradigms for the interpretation of data on pafent compliance with therapeutic drug regimens. Stat Med 1998; 17:251-67.

5. de Klerk E. Measurement of Patient Compliance on Drug Therapy. In: Vingerhoets A, ed. Advances in Behavioral Medicine Asessment"Advances in Behavioral Medicine Asessment, 1998.

6. Cramer JA. Microelectronic systems for monitoring and enhancing patient compliance with medication regimens. Drugs 1995; 49:321-7

7. Kastrissios H, Blaschke TF. Medication compliance as a feature in drug development. Annu Rev Pharmacol Toxicol; $37: 451-75$

8. Urquhart J. The electronic medication event monitor - lessons for pharmacotherapy. Clin Pharmacokinet 1997; 32:345-56.

9. Farmer K. Methods for measuring and monitoring medication regimen adherence in clinical trials and clinical practice. Clin Ther 1999; 21:107490.

10. Amet I, Haefeli W. Overconsumption detected by electronic drug monitoring requires subtle interpretation. Clin Pharmacol Ther 2000; 67:447.

11. George C, Peveler R. Compliance with tricyclic antidepressants. British Joumal of Clinical Pharmacology 2000; 50:166-71.

12. Liu H, Golin C, Miller L, et al. A comparison study of multiple measures of adherence to HIV protease inhibitors. Annals of Internal Medicine 2001; 134:968-77.

13. Strom B. Pharmacoepidemiology. Wley, Chichester, $1994: 741$.

14. van der Heijde D, van Riel P, van de Putte L. Sensitivity of a Dutch Health Assessment Questionnaire in a trial comparing hydroxycholoquine vs sulphasalazine. Scandinavian Joumal of Rheumatology 1990; 19:407-12. 
15. Hunt SM, McE wen J, SP. M. Measuring health status: a new tool for clinicians and epidemiologists. J Royal Coll Gen Practit 1985; 35:185-88.

16. Schreurs PJG, van de Willige G, Brosschot JF, Tellegen B, Graus GMH. De Utrechts coping list: UCL, herziene handleiding. Utrecht: Vakgroep Kinische Psychologie en Gezondheidswetenschappen, 1993.

17. Brooks R. EuroDol: the current state of play. Health Policy 1996; 37:5372.

18. De Geest S, Abraham I, Gemoets H, Evers G. Development of the long-term medication behaviour selfefficacy scale: qualitative study for item development. J Adv Nurs 1994; 19:233-8

19. Tihuis G, de Jong Z, Zwinderman A, et al. The validity of the Rheumatoid Arthritis Quality of Life (RAQol) questionnaire. Rheumatology 2001; 40:1112-9.

20. de Jong Z, van der Heijde D, McKenna SP, Whalley D. The reliability and construct validity of the RAQol: a meumatoid arthritis-specific quality of life instrument. British Joumal of Rheumatology 1997; 36:878:83.

21. Whalley D, McKenna SP, de Jong Z, van der Heijde D. Quality of life in ineumatoid arthritis. British Joumal of Rheumatology 1997; $36: 8848$.

22. de Geest S, Borgermans L, Gemoets $\mathrm{H}$, et al. Incidence, determinants, and consequences of subclinical noncompliance with immunosuppressive therapy in renal transplant recipients. Tansplantation 1995; 59:340-7.

23. Physicians Desk Reference. Montval (NJ): Medical Economics Co, 1997.

24. Lesaffre $E$, de Klerk E. Estimating the power of complianceimproving methods. Controlled Clinical Trials 2000; 21:540-51.

25. Urquhart J, Chevalley C. Impact of unrecognized dosing errors on the cost and effectiveness of pharmaceuticals. Drug Information Journal 1988; 22:363-78.

26. de Klerk E, van der Linden S, van der Heijde D, Urquhart J. Facilitated analysis of data on drug regimen compliance. Statistics in Medicine 1997; 16:1653-64.

27. de Klerk E. Measurement of patient compliance with drug therapy. In: Vingerhoets A, ed. Assessment in Behavioral Medicine: Brunner-Routledge, 2001:215-43.

28. Vrijens B, Goetghebeur $\mathrm{E}$. Comparing compliance patterns between randomized treatments. Controlled Clinical Trials 1997; 18:187-203.

29. Claxton A, Cramer J, Pierce C. Medication compliance: the importance of the dosing regimen. Clinical Therapeutics 2001; 23:1296-1310.

30. Ridwan E, Schultnik W, Dillon D, Gross R. Effects of weekly iron supplementation on pregnant Indonesian woman are similar to those of daily supplementation. Am J Clin Nutr 1996; 63:88490.

31. Galloway R, McGuire J. Daily versus weekly. how many pills dos pregnant woman need ? Nutr. Rev. 1996; 54:318-23.

32. Iorillo D, Landry P. Darioli R. Electronic monitoring of travellers' adherence to mefloquine malaria chemoprophylaxis, Poster presented at 6 th Conference of th International Society for Travel Medicine, Montreal, Quebec, 1999.

33. Claxton A, de Klerk E, Parry M, Robinson J, Schmidt M. Patient compliance to a new enteriocoated weekly formulation of fluoxetine during continuation treatment of major depressive disorder. J Clin Psychiatry 2000; 61: 928 932. 


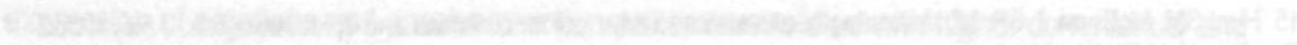
Q

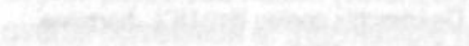

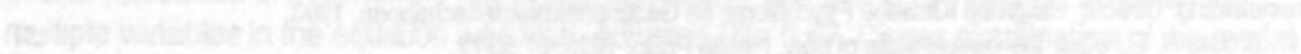

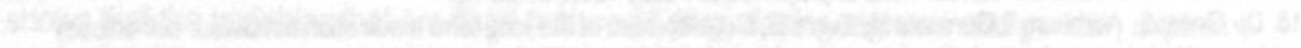

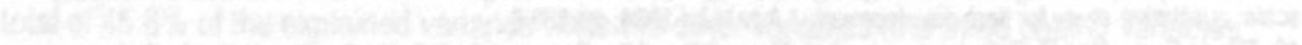

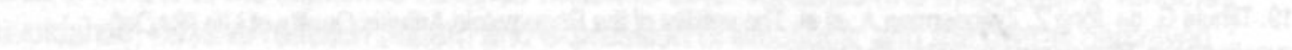

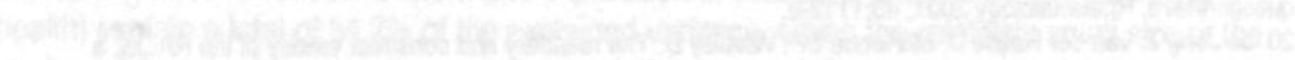

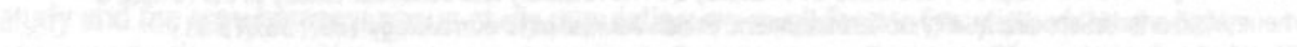

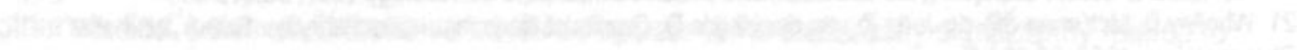

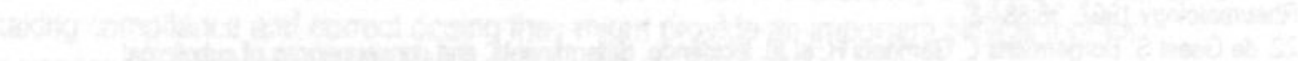
10:

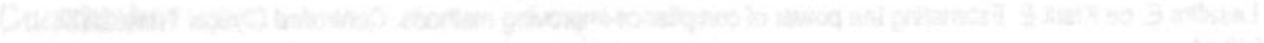

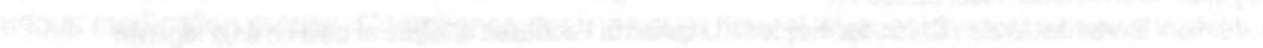

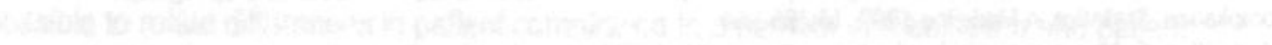

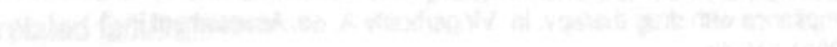




\section{Compliance to an oral bisphosphonate therapy in women with early postmenopausal bone loss}

\section{Geraline L. Leusink', Erik de Klerk², Victor J.M. Pop ${ }^{3}$, Désireé M.F.H. van der Heijde $^{2}$, Socrates E. Papapoulos ${ }^{5}$, Huib A.P. Pols ${ }^{6}$ and Andre Knottnerus ${ }^{4}$}

' Diagnostic Centre Eindhoven; ${ }^{2}$ Department of Rheumatology, University Hospital Maastricht; ${ }^{3}$ Department of Social and Behavioral Science, University of Tilburg; ${ }^{4}$ Department of Family Medicine, University of Maastricht; ${ }^{5}$ Department of Endocrinology and Metabolic Diseases, Leiden University Medical Centre; ${ }^{6}$ Department of Internal Medicine, Erasmus University Rotterdam; the Netherlands

Manuscript: Published as G. Leusink. E. de Klerk, H.A. Pols, C. Pop, D. van der Heijde, S. Papapoulos, H. Pols, A. Knottnerus. Patient compliance to an oral bisphosphonate therapy in women with early postmenopausal bone loss. In: Leusink, Osteoporosis around the menopause: occurrence, determinants and preventive drug treatment. Datawyse, Universitaire Pers, Maastricht, ISBN 905278 2047.

\section{Abstract}

In order to achieve optimal benefit from the treatment of postmenopausal bone loss, strict compliance with bisphosphonate ingestion instructions is required. Low absorption $(<2 \%)$ and significant food-drug interaction make it necessary for the drug to be ingested at least 30 minutes before a meal.

We examined the compliance of a cohort of early postmenopausal women to oral pamidronate (Aminomux $\%$, prescribed for the prevention of bone loss. Patient compliance was measured using: MEMS (Medication Event Monitoring System, AARDEX Ltd., Switzerland). This consists of a special, microprocessor-equipped pill-phialcap that records the time and date of opening the cap. The women were instructed to take the pamidronate half an hour before breakfast or dinner. Eighty-six women were followed for a mean duration of 38,268 days (104 patient years). Overall, compliance was high: $90 \pm 13 \%$ (range, 20-101) of all tablets were ingested. Seventyeight percent of patients took the capsules within a $25 \%$ time window around the prescribed dosing intervals (timing compliance). There were 133 periods of three or more days without drug intake (drug holidays), with large inter-individual variation. Overall compliance for the time of day was consistent: $33.1 \%$ of the women took the pamidronate capsule in the morning and $58.4 \%$ took it in the evening. However, $50 \%$ of all patients showed a significant variation in the time of ingestion of capsules (standard deviation for time of ingestion $>2$ hour), making it probable that food-drug interaction could have occurred. No relationship between the time of capsule ingestion and changes in lumbar spine bone mineral density (BMD) was observed. Overall, taking and timing compliance was high. This was surprising because of the asymptomatic nature of low BMD. No difference was found in BMD response between women who took pamidronate in the mornings and those who took it in the evenings. 


\section{Introduction}

Osteoporosis is a common and important cause of morbidity and mortality among postmenopausal women. It arises as a consequence of progressive loss of bone, and results in an increased risk of fractures. Four in about ten white women currently at the age of 50 years will sustain one or more osteoporotic fractures in their remaining lifetime ${ }^{1-6}$. As the elderly population grows, the worldwide annual incidence of hip fractures is projected to increase from 1.7 million in 1990 to 6.3 million by 2050 , obviously placing great economic strain on health care systems ${ }^{7}$.

There are several strategies to reduce the incidence of fractures in postmenopausal women. Among these, bisphosphonates which can reduce the incidence of osteoporotic fractures by about $50 \%$ are used in the prevention and treatment of osteoporosiso-12. Specific pharmacological properties of bisphosphonates include very low intestinal absorption and significant drug-food interactions, most notably with calcium ${ }^{13}$. These properties necessitate specific instructions about the timing and conditions of the administration of these drugs. For example, for alendronate, the manufacturer recommends taking the bisphosphonates in the morning 30 to 60 minutes before breakfast with water only ${ }^{14}$. If such instructions are not carefully followed, it is assumed that the full efficacy of treatment will not be achieved. In addition, such strict instructions may reduce patient compliance over longer periods.

Patient compliance to a prescribed drug regimen can be accurately measured using electronic monitoring of the opening of medication phials. Although an indirect measurement, as there is no proof of drug intake, this method has many advantages over other techniques for measuring compliance and is currently considered the gold standard. ${ }^{19}$ The advantages and disadvantages of other methods of measuring compliance have been described in detail elsewhere ${ }^{17,18}$.

Surprisingly, data on patient compliance with bisphosphonates are not available. In the present study, we examined the compliance to once daily administration of the aminobisphosphonate pamidronate in asymptomatic early postmenopausal women with low bone mineral density (BMD), selected from a population-based cohort, who participated in a trial of the effects of various interventions for the prevention of bone loss. For this, electronic monitoring instruments capable of recording the time and date of removing tablets from a container were used.

The objectives of the study were, firstly, assessment of the overall compliance rate to treatment and to specific instructions about the timing of drug intake and, secondly, the relationship between compliance to these instructions and changes in BMD after two years.

\section{Methods}

In a population-based cohort of 8.503 women aged from $47-54$ years, 15.649 fulfilled the following criteria: menopause for up to three years and BMD of the lumbar spine in the lower tertile of premenopausal women $<0.998 \mathrm{~g} / \mathrm{cm} 2$ (DXA Hologic). All patients were given calcium carbonate $1000 \mathrm{mg}$ (Davitamon), which consists of $400 \mathrm{mg}$ elementary calcium. Of these, 392 women were randomized to the following groups: the first group $(n=129)$ received no additional treatment; the second group ( $n=133$ ) received oestradiol $2 \mathrm{mg}$ continuously combined with dydrogesterone $10 \mathrm{mg}$ in the second half of the cycle (Femoston $\mathrm{n}^{\circ}$ ); and the third group ( $\mathrm{n}=130$ ) 
received oral pamidronate (APD) $100 \mathrm{mg} /$ day, (Aminomux ${ }^{\circ}$, Gador, Argentina). The duration of treatment was two years. BMD was assessed at baseline, and after one and two years.

In the group receiving pamidronate, compliance was measured using the Medication Event Monitoring System (MEMS, Aardex Ltd., Switzerland). This system consists of a normal pill container with a special cap that contains electronic microcircuitry to record the time and date of every opening. Throughout the analysis, we assumed that with every opening a tablet was actually taken. The data from the monitors were downloaded to an IBM compatible personal computer, using a dedicated modem and CSS software version 2.1 (AARDEX Ltd, Switzerland), which was also used for the calculation of the compliance variables.

Patients were instructed to take the pamidronate capsule 30-60 minutes before breakfast or dinner, with two glasses of water, and not together with food or calcium tablets. All patients had given their written informed consent and were told that the cap was capable of 'counting pills'. We did not use electronic monitoring in the calcium and hormone replacement therapy (HRT) group, because the calcium tablets did not fit into the special boxes and HRT is accompanied by special dose-organizers with instructions to take the dydrogesterone in the second half of the cycle.

In addition to the electronic data in the pamidronate group, we counted the number of returned tablets in all three groups. Monitoring was applied for at least six months after the initiation of treatment, and patients were followed until two years after baseline.

Compliance was calculated as:

1. Taking compliance $=($ total number of doses taken/number of days monitored $) \times 100 \%$

2. Timing compliance $=$ (number of doses taken at $24 \pm 6$ hourly intervals/number of days monitored) $\times 100 \%$

The response to treatment was assessed by the changes of the BMD in the lumbar spine, measured by dual energy X-ray absorptiometry (DXA, model QDR-1000 S.A. Hologic Europe, Brussels). Calibration of densitometers, scan quality control, and scan performance were carried out by one qualified densitometry operator. All daily spine phantom quality controls were within $1.5 \%$ of the reference value. The coefficient of variation for the anatomical phantom $(1.0354 \mathrm{~g} / \mathrm{cm} 2)$ for the duration of the study was $0.54 \%$. All scans were performed in the supine position. BMD of the lumbar spine was measured at baseline, and at 12 and 24 months of follow-up. Treatment success was defined as an increase in BMD, expressed as the percentage change score between BMD at two years and baseline BMD. A positive change (increase in BMD or no change) was labelled 'responder', while a negative change (decrease in BMD) was labelled 'non-responder'.

Data are expressed as mean \pm standard deviation. Correlations are estimated using Pearson's correlation coefficient. The relationship between compliance and change in BMD was investigated with the $\chi^{2}$ test and by linear regression analysis, and by when compliance was related to success of treatment. All calculations were performed in SPSS version 7.5 for Windows 95. 


\section{Results}

The data from four caps could not be retrieved: two had been lost, and two were not readable.

Nine women had almost finished the study by the time the electronic monitors became available and therefore did not participate in this arm of the study. Thirty-one women dropped out of the study for several reasons, for example, adverse events such as epigastric pain and nausea, protocol violation, and motivation problems. Therefore, compliance data were available for 86 women. Table 1 shows the patients' characteristics and demographic data.

\section{Table 1: Baseline characteristics of the 86 women}

Characteristics

mean $\pm \mathrm{SD}$

Age (years)

Body mass index

Time since menopause

(months)

Bone Mineral Density

Lumbar Spine $(\mathrm{g} / \mathrm{cm} 2)$
$51.5 \pm 2.5$

$24 \pm 3.5$

$17 \pm 11$

$0.883 \pm 0.08$

A total of 38.268 days (105 patient-years) were monitored in 86 patients (average $450 \pm 93$ days of follow-up). Taking compliance was high: $90.4 \%$ of all tablets were taken, of which $86.3 \%$ were taken as prescribed (once daily), whereas on $11.7 \%$ of the days, no medication was taken, and on $1.9 \%$ of the days, extra medication was taken. Figure 1 shows a histogram of the distribution of taking compliance. Analysis of timing compliance showed that the majority of the prescribed doses $(77.7 \%)$ were taken at $24 \pm 6$ hourly intervals. However, $4.4 \%$ were taken too early and $8.2 \%$ too late. Since timing compliance uses the prescribed number of doses as its denominator, which is higher than the number of recorded openings, these do not add up to $100 \%$.

Distribution of the timing of drug intake revealed that $24.8 \%$ of all doses were taken in the morning (arbitrarily defined as between 6.00 and 10.00 a.m., average 7.45 a.m.), while $55.6 \%$ were taken in the evening (arbitrarily defined as between 15.00 p.m. and 19.00 p.m., average 16.45 p.m.). Figure 2 shows the distribution of the timing of drug intake.

Distribution of the timing of drug intake revealed that $24.8 \%$ of all doses were taken in the morning (arbitrarily defined as between 6.00 and 10.00 a.m., average 7.45 a.m.), while $55.6 \%$ were taken in the evening (arbitrarily defined as between 15.00 p.m. and 19.00 p.m., average 16.45 p.m.). Figure 2 shows the distribution of the timing of drug intake.

Drug holidays, defined as three or more consecutive days without evidence of dosing, ${ }^{20.21}$ were not uncommon: 47 of 86 patients ( $55 \%$ ) had at least one holiday, and overall there were 216 drug holidays ( $55 \%$ of all dose-free days), with an average duration of eight days. There were eight exceptionally long drug holidays (>30 days), the longest of which lasted for 89 days. The correlation coefficient between the returned tablet count and taking compliance was low (0.52.). Figure 3 shows that returned tablet counts led to the overestimation of compliance in the majority of patients. 
Figure 1: Taking compliance of pamidronate

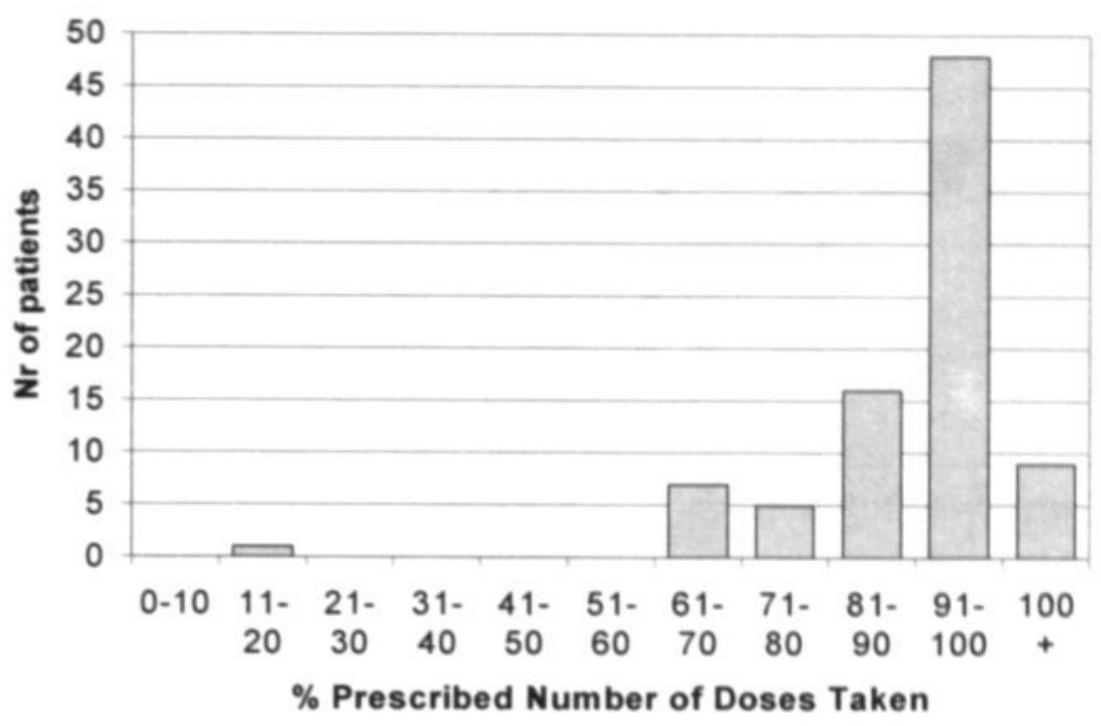

We specifically studied patients with correct timing of drug intake, defined as $>30$ minutes and $<120$ minutes before breakfast or dinner, in order to test whether there was a relationship between time of drug intake and change in lumbar spine BMD. Forty-nine women had an increase in BMD of the lumbar spine after two years, and 37 women had a decline in their lumbar spine BMD. Of the 49 responders, 24 took their medication within the predefined time window, while 25 did not. Of the 37 non-responders, 24 women took their medication on time, while 13 did not $\left(\chi^{2}=2.16, p=0.14\right)$.

\section{Discussion}

In general, no drug can work if it is not taken, and it is reasonable to assume that large deviations from the prescribed dosing regimen result in sub-optimal results. A general property of all bisphosphonates is their low absorption (usually $<2 \%$ ) and significant food-drug interactions, 13 necessitating attention to the timing of their intake. This is the first study in which an electronic instrument has recorded the time and date of the opening of medication phials. This maneuver allowed detailed investigation of patient compliance and of the relationship between the intake of pamidronate and the change in BMD of the lumbar spine.

Overall, the taking and timing compliance were high compared to studies with a variety of other drugs, such as antihypertensives, cholesterol lowering and non-steroid anti-inflammatory drugs, anti-epileptics, migraine and anti-AIDS drugs ${ }^{16.22-27}$. This was surprising because of the asymptomatic nature of low BMD. Several factors may have contributed to the high compliance in this population, including the selection procedure utilized in the enrolment, the relatively high visit frequency, and the fact that patients were aware of the monitoring capacity of the caps. 
Figure 2: Time distribution of drug intake.

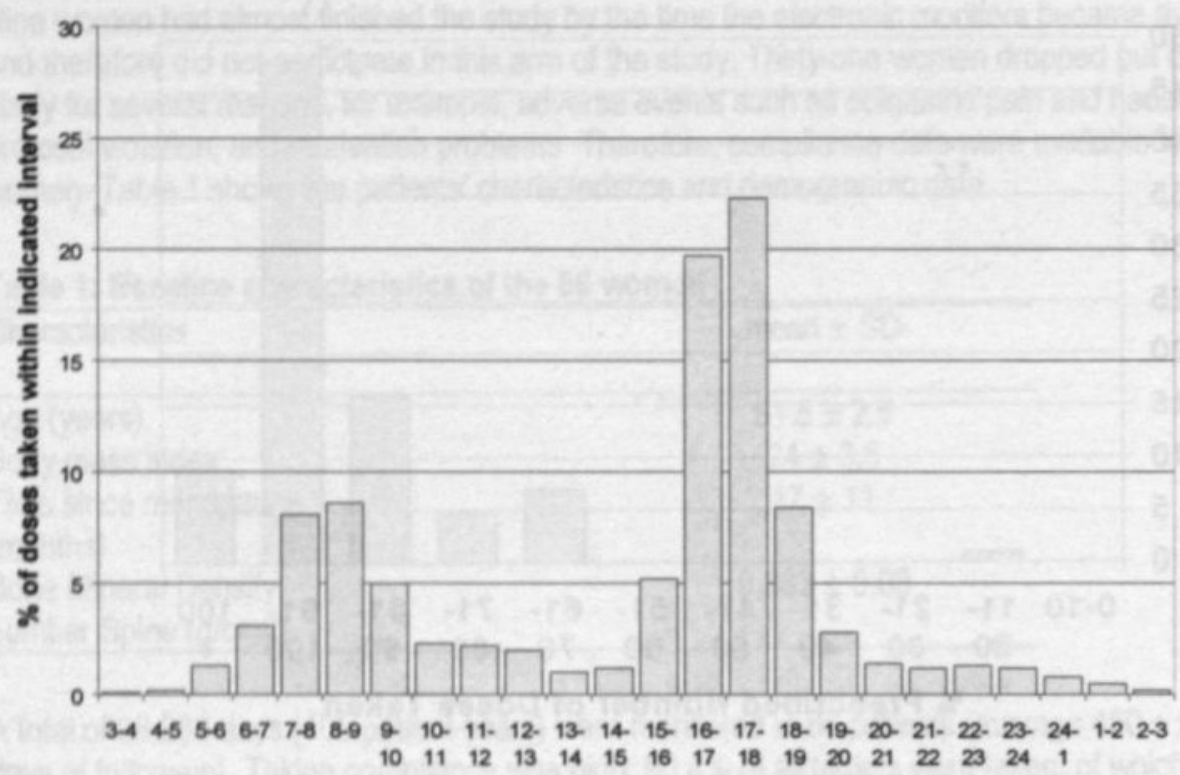

hour of intake

Linear regression analysis showed a positive but weak association between taking compliance and percentage change in BMD. However, this association was not statistically significant.

Study enrolment comprised a three-step selection process. Participating women were selected from the lowest tertile for lumbar BMD of a population-based cohort of 8.00 women (step 1); they were invited by telephone to visit the doctor and were informed of their low BMD (step 2); and finally made a conscious decision, in a consultation with the physician lasting approximately one hour, to participate in the study (step 3). Since each of these steps requires the active cooperation of the patients, it is possible that these steps resulted in a relatively compliant population.

After inclusion in the study, the women were seen by the same physician every three months for two years. This is more frequent than the usual follow-up of patients who are at risk for osteoporosis, and a more frequent follow-up may result in better patient compliance. 


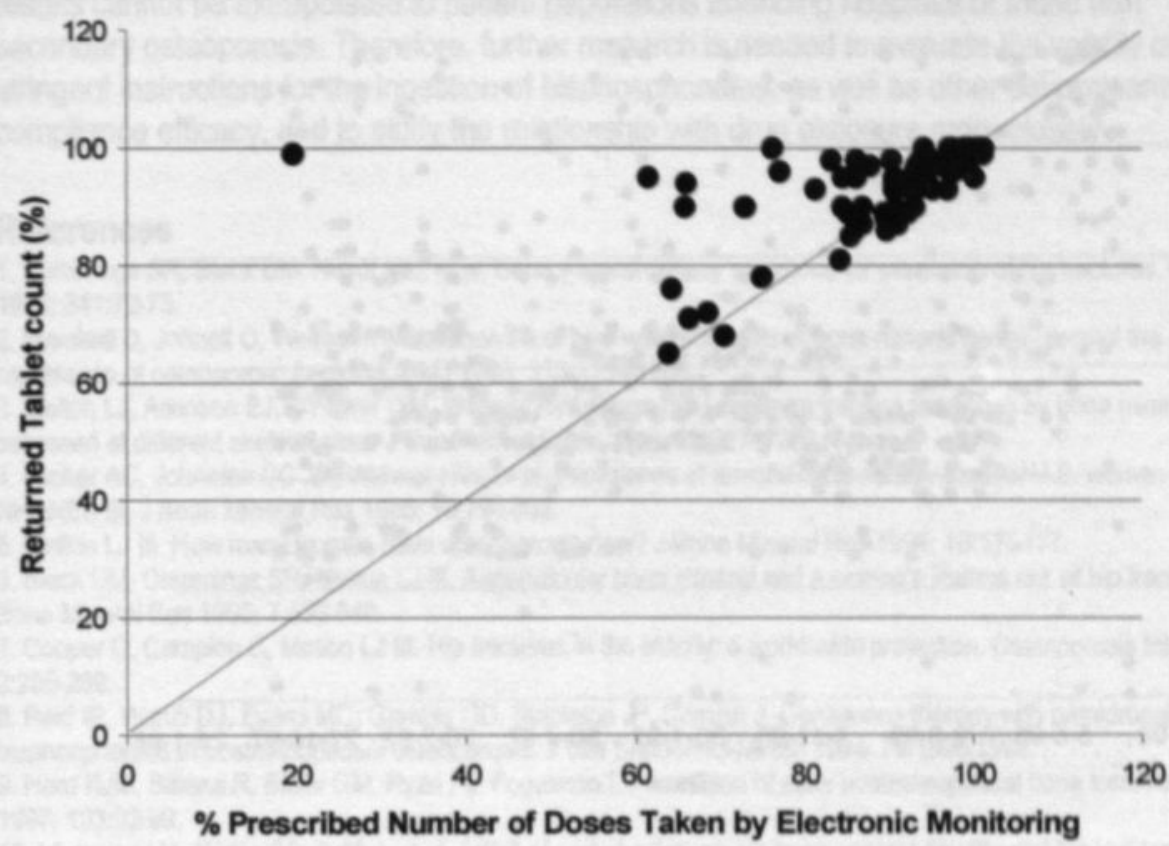

Although all patients in the pamidronate group were informed that compliance was measured electronically, this seems an unlikely explanation for the good compliance rate observed, because compliance was also high in the other study groups, based on tablet counting (calcium, 82.1\%; HRT, 90.5\%). Furthermore, during the study, no feedback was given on compliance measurements. Finally, the monitoring technique used in this study has been used in many other fields, such as hypertension ${ }^{16}$ and epilepsy, ${ }^{24}$ where compliance was much lower, making it unlikely that knowledge of electronic monitoring is commonplace.

Bisphosphonates such as pamidronate and alendronate are given with instructions regarding the time of ingestion, because of the above-mentioned low gastrointestinal absorption and drugfood interaction. Therefore, we evaluated the relationship between time of ingestion during the day (morning or evening) and time of meals (breakfast or dinner) to changes in BMD. Given the design of our study, it was possible to evaluate the relationship between the time of bisphosphonate intake and changes in lumbar spine BMD. Surprisingly, there was no difference in BMD response between women who took pamidronate correctly (more than 30 and less than 120 minutes before breakfast or dinner) and those who took it at other times intervals. In addition, there was no difference in BMD response between the women who took the bisphosphonate in the morning and those who took it in the evening. Of particular practical significance was the much higher preference for taking pamidronate in the evening, which underscores the inconvenience of currently recommended regimens. These results suggest that the instructions regarding medication ingestion, as given for the bisphosphonates, may perhaps be too stringent and need to be further evaluated. 
Figure 4a: Chronology plot of a responder

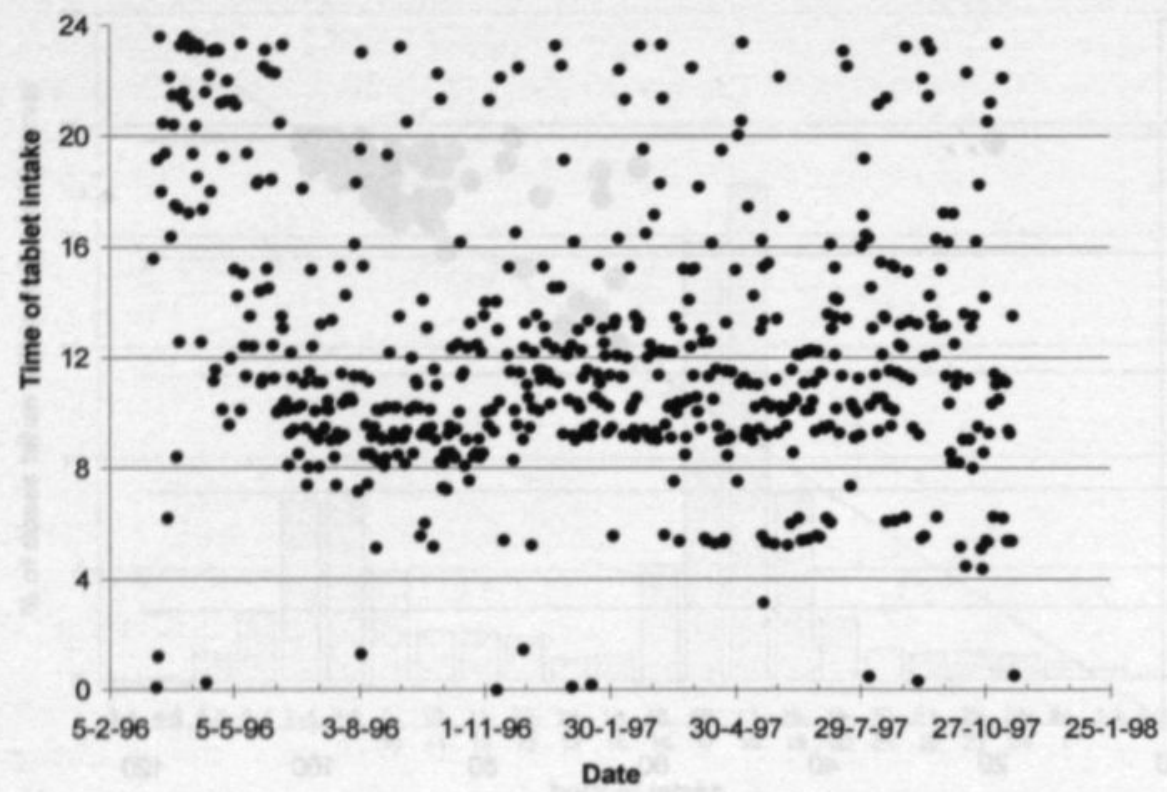

Figure 4b: Chronology plot of a non responder

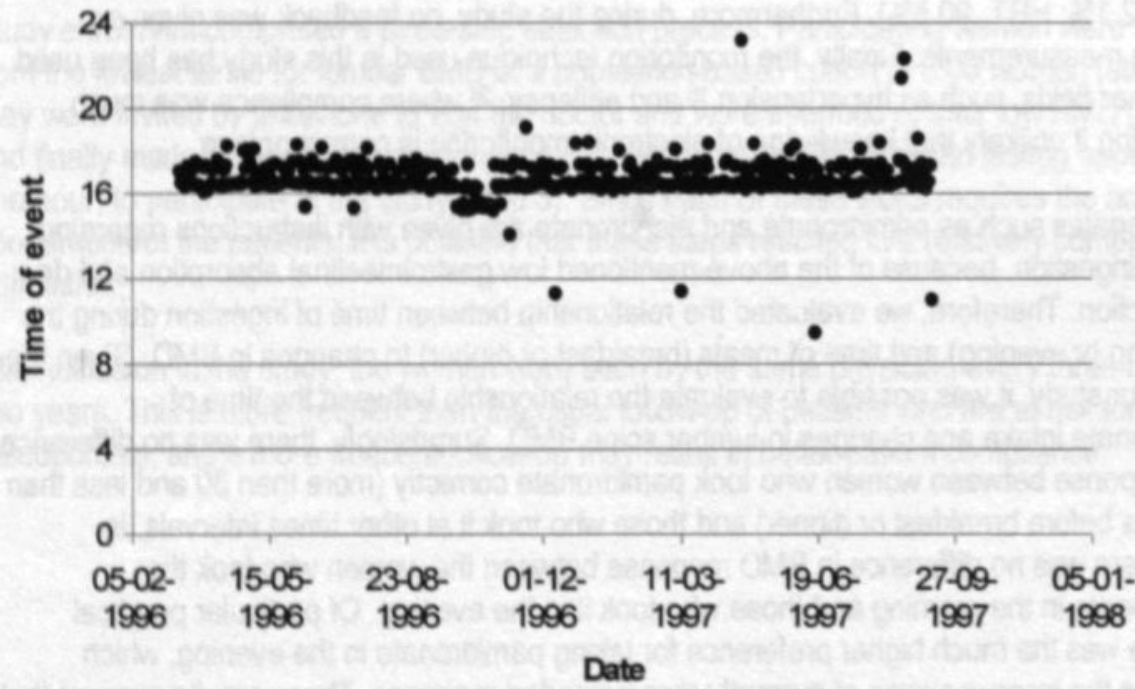


The current study had a high rate of compliance, making it impossible to draw any conclusions on factors regarding non-compliance. Furthermore, the study was population-based and the results cannot be extrapolated to patient populations attending hospitals or those with secondary osteoporosis. Therefore, further research is needed to evaluate the validity of stringent instructions for the ingestion of bisphosphonates, as well as other determinants of compliance efficacy, and to study the relationship with drug exposure more closely.

\section{References}

1. Cummings SR, Black DM, Nevitt MC, et al. Bone mineral density at various for prediction of hip fractures. Lancet 1993: 341:72-75.

2. Marshall D, Johnell O, Wedell H. Meta-analysis of how well measures of bone mineral density predict the occurrence of osteoporotic fractures. BMU 1996; 312:12541259.

3. Melton LJ, Atkinson EJ, O'Fallon WM, Wahner HW, Riggs BL. Longterm fracture prediction by bone mineral assessed at different skeletal sites. J Bone Mineral Res 1993; 8:1227- 1233.

4. Looker AC, Johnston CC JR, Wahner HW, et al. Prevalence of femoral bone density in older U.S. women from NHANES III. J Bone Mineral Res 1995; 10:796-802.

5. Melton LJ III. How many women have osteoporosis now? J Bone Mineral Res 1995; 10:175177.

6. Black DM, Cummings SR, Melton LJ III. Appendicular bone mineral and a women's lifetime risk of hip fracture. J Bone Mineral Res 1992; 7:639646.

7. Cooper C, Campion C, Melton LJ III. Hip fractures in the elderly, a world wide projection. Osteoporosis Int 1992; 2:285-289.

8. Reid IR, Wattie DJ, Evans MC, Gamble GD, Stapleton P, Comish J. Continuous therapy with pamidronate a potent bisphosphonate in postmenopausal osteoporosis. J Clin Endocrinol Metab 1994; 79:1595-1599.

9. Herd RJM, Balena R, Blake GM, Ryan PJ, Fogelman I. Prevention of early postmenopausal bone loss. Am J Med 1997; 103:92-99.

10. Liberman UA, Weiss SR, Broll J, et al. Effect of oral alendronate on bone mineral density and the incidence of fractures in postmenopausal osteoporosis. N Engl J Med 1995; 333:1437-1443.

11. Black DM, Cummings SR, Karpf DB, et al. Randomized trial of alendronate on

risk of fracture in women with existing vertebral fractures. Lancet 1996; 348:1535-1541.

12. Hosking D, Clair ED, Chilvers D, et al. Prevention of bone loss with alendronate in postmenopausal women under 60 years of age. N Engl J Med 1998; 338:485-492.

13. Bisphosphonates pharmacology and use in the treatment of osteoporosis. In: Osteoporosis Academic Press, Inc 1996.

14. Gertz BJ, King WF, Matuszewski BK, Sacco JF, Lasseter KC, Porras AG. Oral bioavailability and dose proportionality of alendronate in postmenpausal women. J Bone Mineral Res 1991; Suppl 1, S281.

15. Smeets-Goevaers CG, Leusink GL, Papapoulos SE, Maartens LW, Keyzer JJ, Weerdenburg JP, et al. The prevalence of low mineral bone density in Dutch perimenopausa women: the Eindhoven Perimenopausal Osteoporosis Study. Osteoporosis Int 1998; 8:404-409.

16. Magometschnigg D. Patient compliance of hypertensive patients in the physician's practice. Wen Med Wochenschr 1995; 145:360-364.

17. Bond WS, Hussar DA. Detection methods and strategies for improving medication compliance. Am J Hosp Pharm 1991; 48:1978-1988.

18. De Klerk E. Measurement of patient compliance on drug therapy. In: Vingerhoets A (ed) Advances in Behavioral Medicine Assessment/Advances in Behavioral Medicine Assessment; 1998.

19. Urquhart J. Patient non-compliance with drug regimens: measurement, clinical correlates, economic impact. Eur Heart J 1996; 17 Suppl A:8-15.

20. Urquhart J, Chevalley C. Impact of unrecognized dosing errors on the cost and efectiveness of pharmaceuticals. Drug Inf J 1988; 22:363-378.

21. De Klerk E, Van der Linden S, Van der Heijde D, Urquhart J. Facilitated analysis of data on drug regimen compliance. Statist Med 1997; 16:1653-1664.

22. Kruse W, Nikolaus T, Rampmaier J, Weber E, Schlierf G. Actual versus prescribed timing of lovastatin doses assessed by electronic compliance monitoring. Eur J Clin Pharmacol 1993; 45:211215.

23. De Klerk E, Van der Linden SJ. Compliance monitoring of NSAID drug therapy in ankylosing spondylits, experiences with an electronic monitoring device. Br J Rheumatol 1996; 35:6065.

24. Cramer JA, Mattson RH, Prevey ML, Scheyer RD, Ouellette VL. How oflen is medication taken as prescribed? A novel assessment technique. JAMA 1989; 261:3273-3277. 
25. Cramer JA. Medication compliance in epilepsy. Arch Intern Med 1991; 151:1236-1237.

26. Steiner TJ, Catarci T, Hering R, Whitmarsh T, Couturier EG. If migraine prophylaxis does not work, think about compliance. Cephalalgia 1994; 14:463-464.

27. Vanhove GF, Schapiro JM, Winters MA, Merigan TC, Blaschke TF. Patient compliance and drug failure in protease inhibitor monotherapy. JAMA 1996; 276:1955-1956. 


\section{Discussion and Summary of Results}

The precision and utility of measurement of patient compliance increased in the late eighties with the development of chemical marker methods and electronic monitors'. These methods, discussed in detail in chapter 1 and 2, are not perfect, but to create a record of good compliance with them requires exceptional and sustained commitment to open the monitored package. We were surprised in 1995, when we analyzed and published the results of theoxicam study in ankylosing spondylitis ${ }^{2}$, that we did not find any studies in the literature with a comparable quality of compliance measurement to compare our results against. We recognized this as a lack of data in the scientific literature and decided to initiate the COUGAR project (Compliance Unveiled in Gout, Arthritis and Rheumatism) to further explore patterns and determinants of variable patient compliance in rheumatology.

From the scientific literature it is clear that there are at least 2 (intimately related) general reasons to obtain compliance information: to better understand the determinants of variable patient compliance, and to explain treatment failures. Given the lack of data with electronic monitors in rheumatology, and the difficulties of measuring patient outcome in a variety of rheumatic diseases we decided to focus exclusively on the exploration of patterns $\alpha$ variable patient compliance and understanding its determinants.

Chapter 1 discusses the measurement of patient compliance with drug therapy. It comprises an overview of all available measurement instruments for patient compliance, and discusses extensively the advantages and disadvantages. Since there is no gold standard to detect noncompliance, a strategy is proposed to tailor the choice of the measurement instrument to the research question. For example, while patient questionnaires may be attractive to detect reasons for non-compliance, they are not capable of catching dosing variations over time. And while chemical markers such as sub-therapeutic doses of phenobarbitone or digoxine prove ingestion, sampling problems as well as the inter-patient pharmacokinetic differences may render these methods useless in a situation where the focus is on improving compliance to therapeutically adequate levels. Finally, while the electronic monitoring system that is widely used in this thesis provides unprecedented accuracy in detecting variations in timing of medication intake; they do not provide any information on the reasons for non-compliance. The chapter concludes that no 'gold standard' for compliance measurement exists, and none is foreseeable. A combination of measurement instruments with a clear view of the advantages and disadvantages will often provide better information than any other instrument alone.

It is interesting, in this respect, that a recent paper by Liu et al combining electronic monitoring, pillcounts and patient interviews, showed a modest improvement in the relationship between compliance and outcome ${ }^{3}$, as demonstrated in figure 1. The authors developed, for this purpose, an algorithm where the basis of the composite adherence score (CAS) is the MEMS score, but in selected cases information from interviews or pilt-counts is added to the MEMS score into a CAS score. 
Figure 1: Example of ROC curve showing that a composite adherence score is (slightly) better than individual adherence measurements.

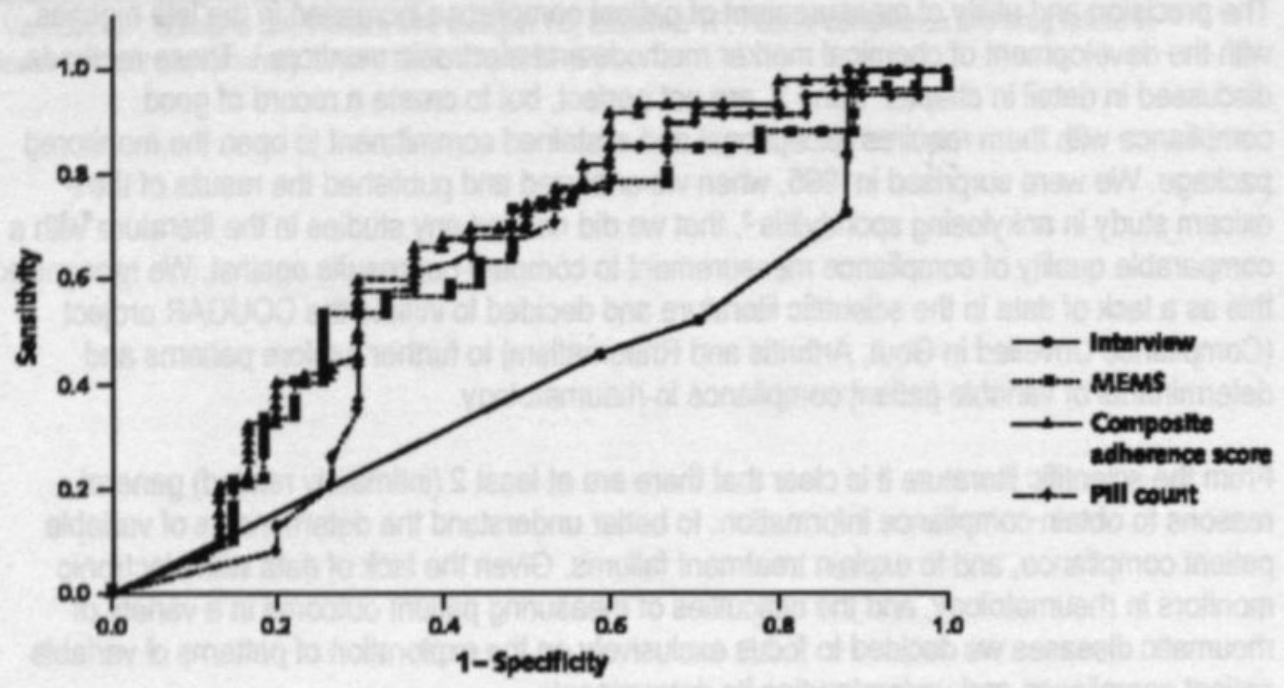

Closer examination of the article reveals that most of the gain of the CAS over the MEMS-only score is attributable to patients who use dose-organizers. In the COUGAR study these patients were not included, and we have therefore not attempted to create a CAS within the COUGAR study.

Chapter 2 provides an overview of contending paradigms for the interpretation of data on patient compliance. It discusses a variety of topics including pharmacologic aspects of variable compliance, a detailed discussion of the comparison of the 2 most recent methods to measure compliance, slow-turnover chemical markers and electronic monitoring, and the consequences of poor compliance. An important concept, forgiving versus unforgiving drugs, is introduced, followed by a discussion that the current trend in the development of new drugs, all going towards once-daily dosing, may in fact not be beneficial for a large sub-group of patients with imperfect compliance. We discuss that when the pharmacologic properties of the drugs are combined with various patterns of non-compliance, once-daily dosing may in fact be inferior to twice daily dosing, even while the simplest quantitative expression of compliance - $\%$ of prescribed doses taken - may be numerically superior in once-daily dosing.

Chapter 3 summarizes the results of a randomized controlled phase III clinical trial to compare once-daily $20 \mathrm{mg}$ piroxicam versus once-daily $20 \mathrm{mg}$ tenoxicam in ankylosing spondylitis.

Compliance was measured using the electronic monitoring system. This trial provided the first data with this measurement instrument in a group of patients with a reumatic disease.

Compliance was summarized in a variety of ways, including taking compliance; correct dosing and timing compliance, missed doses, extra doses and the frequency distribution of variable compliance. An attempt was made to correlate these various measures of compliance with clinical outcome (expressed as morning stiffness and patient-reported pain score on a VAS). We concluded that the physicians' strict dosing instructions of once-daily one tablet were followed by only $20 \%$ of all patients. Other patients showed variations from the prescribed 
dosing regimen that varied from very minor to substantial variations. No-dosing days were much more common then extra-dosing days. We discussed these results against the nature of the disease, which could be described as a 'biological alarm-clock for non-compliance'. This study, and its findings, warranted further research that is described in the next chapters.

Chapter $\mathbf{4}$ describes a spreadsheet method for concisely summarizing patients' drug dosing histories, to facilitate identification of dosing correlates of clinically important events. The method clearly shows, graphically, the extent of variable compliance and makes one aware of the wide differences between patients. It is clear that summarizing electronic dosing histories into simple summary variables like 'taking compliance', 'correct dosing', and 'timing compliance' on a group level result in the loss of important information. Furthermore, the chapter provides the first method to summarize drug holidays in a way where not only the frequency but also the duration of the drug holidays is adequately characterized.

Chapter 5 describes the development of the Compliance Questionnaire Rheumatology (CQR), a patient-oriented questionnaire that measures patient compliance with the drug regimen and identifies factors that contribute to suboptimal compliance in patients with rheumatoid arthritis, polymyalgia and gout. The development procedure, based on the model for questionnaire development used in quality-of-life questionnaires, as well as the item-reduction procedure, is described in detail. In short: thirty-two patients participated in semi standardized home interviews about their attitude toward their anti-rheumatic medication, actual drug intake and reasons for not taking medication. Additionally, a focus group with 7 patients was held, and following an advertisement in the rheumatology patient organization magazine a number of patients called and explained their reasons for noncompliance. All interviews were recorded on tape, transcribed and independently reviewed by 2 investigators. Thirty-one statements were selected and were tested, after a field test, by sending them by mail to 117 consecutive rineumatology outpatients. The answers on the 31 statements, answered on a 4 point Likert scale, were then used to determine the psychometric properties of the questionnaire and to perform an item reduction procedure.

On statistical basis, 12 items were excluded because of low or high corrected item-total correlation or skewed distribution of the answers. Therefore, the final version of the questionnaire comprises 19 items, and was named the CQR (Compliance Questionnaire Rheumatology). Internal consistency was moderate (Cronbach's Alpha of 0.71 ), indicating sufficient heterogeneity of the different topics addressed in the CQR. Discriminant analysis with an overall patient self-report compliance measure showed a sensitivity of $98 \%$, a specificity of $67 \%$, and a Cohen's Kappa of 0.71 . We found these parameters encouraging and concluded that the remaining 19-item questionnaire was useful to detect possible barriers for optimal compliance and to predict patient compliance to drug regimen.

Chapter 6 comprises the validation of the CQR against the chosen gold standard: electronic monitoring of patient compliance. In a heterogeneous rheumatic patient population of 127 patients, with RA-, gout- and polymyalgia rheumatica patients on various combinations of antirneumatic therapy, it was clear that the questionnaire performed rather well to predict poor compliance. A total of 85 patients had complete questionnaire and electronic monitoring data. Multiple linear regression analyses showed that the total, weighted CQR score significantly and adequate predicts taking compliance $\left(p=0.001, R^{2}=0.46\right)$ and correct dosing ( $p=0.004$, $R^{2}=0.42$ ). Discriminant analyses showed that specificity and sensitivity to detect good taking 
compliance were $95 \%$ and $62 \%$, respectively. The predictive value to detect unsatisfactory taking compliance was $86 \%$, to detect good taking compliance was $83 \%$. The likelihood ratio of the CQR-19 to detect low taking compliance was 11.6. Four items were especially predictive: (a) fear of forgetting to take the drug, (b) being able to function well, (c) routines in daily life and (d) side-effects (combined R2: 0.35). We therefore concluded that these results support the validity of the CQR. To aid the use of the CQR, a CQR-calculator was developed which is freely available from the author of this thesis or via the Internet (www.project.demon.nl).

Chapter 7 describes the results of the COUGAR project, in which a heterogeneous patient population was followed with the use of electronic medication event monitoring. This study provides the first in-depth description of patient compliance with electronic monitoring on a variety of anti-rheumatic drugs.

One hundred twenty seven consenting consecutive patients were enrolled, among which $81 R A$ patients, taking NSAIDS (diclophenac three times daily or naproxen twice daily), and DMARDs (sulfasalazine twice daily or methotrexate once-weekly), 17 PMR patients starting with prednisolone once daily and 29 patients with gout starting with colchicine (once daily) or starting with uric acid lowering agents (once daily). All patients received first prescriptions and were instructed to take the medication as prescribed. Follow-up was 6 months (gout: 12 months). More than 73 patient-years) were monitored.

The main conclusions are that wide differences in patient compliance were shown between drugs, and between patients. Compliance on twice daily sulfasalazine was surprisingly low, while compliance on once-weekly methotrexate was very good. Compliance on NSAIDs was approximately similar to the compliance reported for ankylosing spondylitis (chapter 3), while compliance with steroids for polymyalgia rheumatica was rather good. Compliance with antigout medication, perhaps as expected, was frequently poor. Missed doses occurred more frequently than taking extra doses. We observed a decline of compliance over time in all study medication groups. Multiple regression analyses showed that the class of medication (symptom modifying or disease controlling), the dosing frequency, the gender, coping pattem (avoidance, passive reaction pattern and expression of emotions), and the overall health (total Nottingham Health Profile score) together explained $67 \%$ of the variance in taking compliance (adjusted R²) $(p=0.002)$.

Chapter 8 deals with the prevention of osteoporosis, which is another meumatological condition. In particular, this chapter describes the results of the Eindhoven Perimenopausal Osteoporosis Study (EPOS) project, a single open-label, controlled, randomized study to investigate the efficacy of 2 treatment regimens compared to calcium for preventing postmenopausal bone loss in women in the lowest tertile of the DXA measurements after screening. Patients in the oral pamidronate group ( $100 \mathrm{mg}$, once daily prescribed) received their medication in electronic medication event monitors. The women were instructed to take the pamidronate half an hour before breakfast or dinner. Eighty-six women were followed for a total duration of 104 patients-years.

In general, compliance was rather high, which was surprising given the symptom free nature of low bone mineral density. There was no relationship between patient compliance and decrease 
in BMD. Also, no difference was found in BMD response between women who took pamidronate in the mornings and those who took it in the evening.

In summary, this thesis shows that patient compliance in ineumatology has many faces. A few patients show almost perfect compliance, but a much larger proportion of the patients studied used their medication differently than prescribed. Chapters 3,4 and 7 clearly show the between-patient variation. This should have a number of consequences for every day clinical practice and for scientific research.

Within the scope of daily clinical practice, there are 2 main directions that can be taken. The first is that for patients who do no respond sufficiently to anti-meumatic drug therapy, especially When the rheumatologist considers changing therapy or increasing doses, one could perform a trial of MEMS monitoring as a diagnostic instrument to determine patient compliance. If compliance is sufficient, the change in therapy should be executed but if compliance is insufficient, changing therapy or increasing daily dose would be a poor clinical choice. In that case, a compliance intervention would be much more rational before changing therapy or increasing the dose. While such an intervention is not part of the current thesis, we are currently investigating whether a compliance intervention based on the principle of Measurement Guided Medication Management (MGMM) is effective and useful in daily clinical practice. The intervention is modeled on the work of Cramer and Burnier ${ }^{4,5}$, and relies on (1): identification of areas that negatively influence compliance through the use of the CQR, (2) on applying the discriminant functions of the CQR to predict whether a patient will be sufficiently compliant or not, and (3), finally the patient receives a MEMS. The results of the chronology plot of the MEMS are discussed with the patients. If necessary, the area's that became apparent from the CQR as having a negative influence on compliance are discussed.

Within the scope of everyday clinical practice it would also be a great help to know'how much compliance is enough'. Unfortunately, no such data exist. Therefore it is very difficult to judge the clinical relevance of the various compliance patterns described in this thesis, as the clinical consequences of such behavior is unknown. It is therefore mandatory that within the field of meumatology, attention should be given in future research on 'how much compliance is enough'.

On the other hand, within the field of scientific research, especially within randomized controlled trials, variable patient compliance threatens the validity of intention to treat analysis 6,7 .

Assuming that every patient who was included in the trial was dosing perfectly results in a conservative estimate of efficacy. Since we can now measure patient compliance in detail, it would be natural to develop techniques that take advantage of variable compliance in the analysis of the data. Examples of such techniques are the recovery of the true doseresponse curve from the compliance-response curve ${ }^{8}$, causal inference ${ }^{9}$, which allows for modeling the expected difference between a patien's potential response on the treatment arm and potential response on the placebo arm as a function of observed compliance on the treatment arm and baseline predictors, and the use of compliance data to reduce the bias and improve precision in PKJPD population studies ${ }^{10}$.

Finally, within rheumatology, the routine use of compliance monitoring in clinical trials would result in an increase in the statistical power of such studies, making it either more likely to 
detect the clinically important effects or to reduce the number of patients necessary to find the answer.

It is hoped that this thesis may contribute to such future use of compliance monitoring, both in daily clinical practice as well as in scientific research.

Erik de Klerk, August 2002

\section{References}

1. Urquhart J. Variable patient compliance in ambulatory trials-nuisance, threat, opportunity. J Antimicrob Chemother 1993; 32:643-9

2. de Klerk E, van der Linden SJ. Compliance monitoring of NSAID drug therapy in ankylosing spondylitis, experiences with an electronic monitoring device. Br J Rheumatol 1996; 35:60-5

3. Liu H, Golin C, Miller L, et al. A comparison study of multiple measures of adherence to HIV protease inhibitors. Annals of Internal Medicine 2001; 134:968-77.

4. Burnier M, Chiolero A, Fallab Stubi CL, Brunner HR. Electronic compliance monitoring in resistant hypertension: the basis for rational therapeutic decisions. J Hypertens 2001; 19:335-41.

5. Cramer JA. Compliance with medication regimens for mental and physical disorders. Psychiatric Services 1998; 49:196-201.

6. Sheiner LB. The intellectual health of clinical drug evaluation [see comments]. Clin Pharmacol Ther 1991: 50:49

7. Sheiner LB, Rubin DL. Intention to treat andysis and the goals of clinical trials. .

8. Efron B, Feldman D. Compliance as an explanatory variable in clinical trials. Joumal of the American Statistical Association. 1991; 86:-26.

9. Fischer-Lapp K. Practical properties of some structural mean analyses of the effect of compliance in randomized trials. Controlled Clinical Trials 1999; 20:531-46.

10. Vrijens B. Analyzing time-varying patterns of human exposure to xenobiotics and their biomedical impact.

Vakgroep Toegepaste Wiskunde en Informatica. Gent Universiteit van Gent, 2002:190. 


\section{Discussie en Samenvatting van de resultaten}

De nauwkeurigheid en praktische bruikbaarheid van meetinstrumenten voor therapietrouw zijn sinds de jaren ' 80 fors toegenomen met de ontwikkeling van de methoden 'chemical markers' en 'electronic monitoring'. Deze methoden, die in detail besproken worden in hoofdstuk 1 en 2 , zijn niet perfect, maar om een valse indruk van therapietrouw te geven vereisen ze uitzonderlijke vasthoudendheid qua openen van de medicatie verpakking. Wij waren verbaasd, tijdens de analyses en publicatie van de resultaten van de -oxicam studie bij de ziekte van Bechterew in $1995^{2}$, dat we geen vergelijkbare studies in de wetenschappelijke literatuur vonden om onze resultaten te vergelijken. Wij zagen dit gebrek aan objectieve data als een lacune in de wetenschappelijke literatuur en besioten de COUGAR studie op te zetten (Compliance Unveiled in Gout, Arththritis and Rheumatism). Het doel van de COUGAR studie was om de patronen en determinanten van variabele therapietrouw in de reumatologie te documenteren.

Het is inmiddels duidelijk dat er minstens 2 (gerelateerde) redenen zijn om therapietrouw te bestuderen: om te begrijpen welke determinanten ten grondslag liggen aan therapie-ntrouw en om het falen van behandeling te verklaren. Gegeven het gebrek aan data met electronische monitors in de reumatologie, en het feit dat het in het algemeen moeilijk is om binnen de reumatologie verbetering in gezondheid te meten, hebben wij besloten om ons binnnen het COUGAR project te richten op de exploratie van patronen van variabele therapietrouw en de determinanten die er aan ten grondslag liggen.

Hoofdstuk 1 bespreekt het meten van therapietrouw bij geneesmiddelen. Het bevat een overzicht van alle beschikbare meetinstrumenten voor therapietrouw, en bespreekt uitgebreid de voor- en nadelen van elk. Omdat er geen gouden standaard is voor het meten van therapie ontrouw, wordt een strategie voorgesteld om met een combinatie van meetinstrumenten in iedere situatie de beste meting te verkrijgen. Bijvoorbeeld, vragenlijsten kunnen aantrekkelijk zijn omdat ze redenen voor therapie-ontrouw kunnen meten, maar het is niet mogelijk om variaties in therapietrouw over tijd te meten. Een ander voorbeeld zijn de chemische markers zoals fenobarital en digoxine, die als voordeel hebben dat ze inname van geneesmiddel bewijzen maar als nadeel hebben dat er biologisch material verzamelt moet worden, dat er behoorlijke verschillen in pharmacokinetiek tussen patienten bestaan, en dat patïnten de neiging hebben rond klinische visites extra therapietrouw te zijn, waardoor de methode zinloos is in situaties waar falen van de behandeling onderzocht wordt.

Het electronische meetsysteem, waar in deze thesis veel gebruik van wordt gemaakt, geet een unieke precisie in het detecteren van variaties in therapietrouw over de tijd, maar geeft geen inzicht in de redenen voor therapieontrouw. Het hoofdstuk concludeert dat er geen 'gouden standaard' is voor het meten van therapietrouw, en dat die binnenkort ook niet te verwachten valt. Een combinatie van meetinstrumenten met een duidelijk beeld van de voor- en nadelen zal vaak een beter beeld van therapietrouw geven dan ieder van de instrumenten afzonderlijk.

Het is dan ook interessant dat een recent artikel van Liu et al ${ }^{3}$ door het combineren van 'electronic monitoring', pillcounts en interviews een betere relatie kunnen vinden tussen therapietrouw en uitkomst (in dit geval viral load, figuur 1). De auteurs hebben hiertoe een algorythme ontwikkeld dat bestaat uit de MEMS score, maar daar waar nodig wordt informatie 
uit de pillcounts en interviews toegevoegd om zo tot een 'Composite Adherence Score' (CAS) te komen.

Figuur 1: Voorbeeld van een ROC curce die laat zien dat de CAS score (wat) beter is dan de individuele meetintstrumenten.

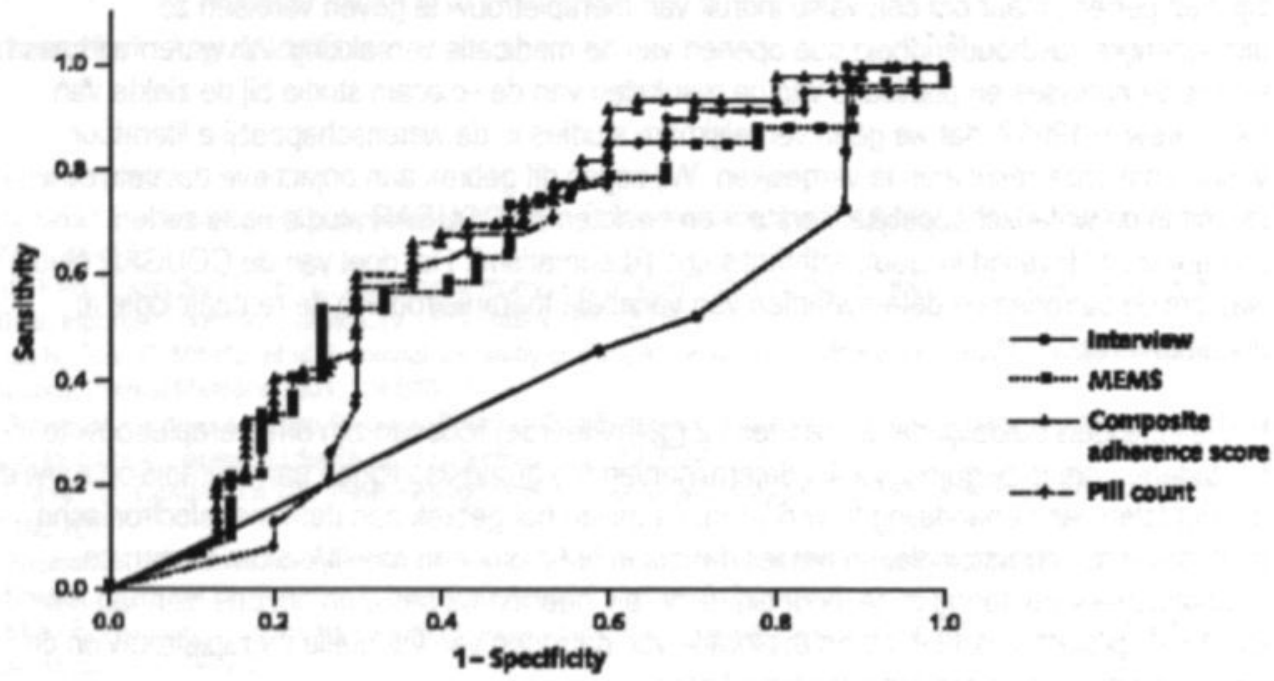

Nauwkeurige bestudering van het artikel brengt echter aan het licht dat de meeste verbetering van de CAS boven de MEMS veroorzaakt wordt door patienten die pillendoosjes gebruiken waarin de medicatie overzichtelijk opgeborgen kan worden. In de COUGAR studie werden deze patiënten niet geincludeerd, en we hebben dus niet getracht een CAS voor het COUGAR project te maken.

Hoofdstuk 2 geeft een overzicht van de huidige stand van zaken omtrent de interpretatie van data over therapietrouw. Een verscheidenheid van onderwerpen komt aan bod, waaronder de farmacologische aspecten van therapieontrouw, een discussie over de 2 meest recente methoden om therapietrouw te meten, en de klinische consequenties van therapieontrouw. Een nieuw concept, 'forgiving' vs 'unforgiving drugs' wordt geintroduceerd, gevolgd door een discussie dat de huidige trend in de ontwikkeling van nieuwe geneesmiddelen, in de richting van eenmaal daags, in feite niet goed zou kunnen zijn voor de grote minderheid van de patiënten waar therapietrouw niet optimaal is. We beschrijven onder andere dat voor sommige geneesmiddelen de combinatie van farmacologische eigenschappen en verschillende patronen van therapieontrouw, eenmaal daags doseren feitelijk inferieur kan zijn dan twee- of zelfs driemaal daags doseren.

Hoofdstuk 3 vat de resultaten samen van een gerandomiseerde, gecontroleerde fase III onderzoek die eenmaal daags $20 \mathrm{mg}$ tenoxicam vergeleek met eenmaal daags $20 \mathrm{mg}$ piroxicam bij patienten met de ziekte van Bechterew. Therapietrouw werd gemeten met behulp van 'electronic monitoring'. Dit onderzoek was de eerste keer dat gegevens met dit instrument bij patienten met een reumatische aandoening werden gepubliceerd. Therapietrouw werd op verschillende manieren samengevat, als 'taking compliance, 'correct dosing' en 'timing compliance', gemiste - en extra doses, en de frequentie distributie van variabele therapietrouw. 
Daarnaast werd geprobeerd de therapietrouw aan klinische uitkomstmaten te relateren (ochtendstiffheid en pijn gerapporteerd op een VAS). We concludeerden dat de strikte doserings instructies van eenmaal daags 1 tablet slechts door $20 \%$ van alle patienten werd gevolgd. Andere patienten lieten meer of minder gevarieerde afwijkingen van het voorgeschreven regime zien. Dagen waarop niet gedoseerd werd kwamen veel vaker voor dan dagen waarop extra medicatie werd genomen. We bespreken deze resultaten met inachtneming van de kenmerken van de ziekte van Bechterew, die in zekere zin gezien kan worden als een 'biologische alarmklok voor therapieontrouw. Deze studie, en de bevindingen, hebben ons doen besluiten verder te gaan met dit type onderzoek, hetgeen beschreven is in de volgende hoofdstukken.

Hoofdstuk 4 beschrijt een tabulaire methode voor het samenvatten van de doseringsgeschiedenis van patienten, om zo significante klinische momenten te kunnen relateren aan de therapietrouw. De methode laat duidelijk grafisch zien in welke mate therapieontrouw voorkomt en geeft inzicht in de variatie tussen patienten daarin. Het samenvatten van therapietrouw in variabelen als 'taking compliance', 'correct dosing' en 'timing compliance' op groepsnivo resulteert in het verlies van belangrijke informatie. Verder bevat het hoofdstuk de eerste methode om therapietrouw samen te vatten op een manier waarbij voor 'drug holidays' niet alleen de frequentie maar ook de duur adequaat gerapporteerd kan worden.

Hoofdstuk 5 beschrijt de ontwikkeling van de Compliance Questionnaire Rheumatology (CQR), een patiënt georienteerde vragenlijst die therapietrouw meet voor voorgeschreven geneesmiddelen en tevens factoren meet die kunnen bijdragen aan sub-optimale therapietrouw bij reumatoide arthritis (RA), polymyalgia rheumatica (PMR) en jicht. De ontwikkeling van de $C Q R$, gebaseerd op de ontwikkeling van quality of life questionnaires, alsmede de item-reductie procedure worden in detail beschreven.

In het kort: 32 patiënten participeerden in gestandaardiseerde thuisinterviews over hun houding ten aanzien van hun anti-reumatische medicatie, actuele geneesmiddelengebruik en redenen voor het niet innemen van hun medicatie. Tevens werd er een focusgroep interview met 7 patiënten gehouden, gevolgd door een advertentie in het patëntenblad van de vereniging voor reumapatiënten waarbij gevraagd werd om te bellen over redenen van therapieontrouw. Alle interviews werden op tape opgenomen, getranscribeerd en onafhankelijk beoordeeld door 2 reviewers. Eenendertig uitspraken werden geselecteerd en, na getest te zijn in een field-test, getest als vragenlijst opgestuurd naar 117 patiënten die achtereenvolgens de reuma-polikliniek hadden bezocht. De antwoorden op de 31 vragen, gescoord op een 4 punts Likert schaal, werden gebruikt om de psychometrische eigenschappen van de vragenlijst te bepalen en om de item-reductie procedure uit te voeren.

Twaalf items werden geëxcludeerd op statische basis (lage of hoge gecorrigeerde item-totaal correlatie of scheve verdeling van de antwoorden). De definitieve versie van de CQR bestaat daarom uit 19 items. Interne consistentie, gemeten met de Cronbach's alpha was redelijk goed (0.71) hetgeen aangeeft dat de CQR voldoende heterogeniteit meet. Een discriminant analyse met door de patienten zelf gerapporteerde therapietrouw liet een sensitiviteit van $98 \%$, een specificiteit van $67 \%$ en een Cohen's Kappa van 0.71 zien. Wij vonden deze resultaten bemoedigend en concludeerden dat de CQR-19 bruikbaar was om knelpunten in therapietrouw op te sporen en tevens om therapietrouw voor geneesmiddelen te voorspellen. 
Hoofdstuk 6 bevat de validatie van de CQR tegen de gouden standaard: electronic monitoring. In een heterogene groep reumatische patiënten met RA, PMR en jicht die verschillende vormen van anti-reumatische therapie kregen, werd het duidelijk dat de CQR behoorlijk goed therapietrouw kan voorspellen. Voor 85 patiënten waren er complete vragenlijsten en electronische doseringsgeschiedenissen beschikbaar. Multipele lineaire regressie liet zien dat de totale gewogen CQR score significant en adequaat taking compliance $\left(p=0.0001, R^{2}=0.46\right)$ en correct dosing ( $p=0.004, R^{2}=0.42$ ) voorspelt. Discriminant analyse liet zien dat de specificiteit en sensitiviteit om goede taking compliance te detecteren $95 \%$ en $62 \%$ waren, respectievelijk. De predictieve waarde om slechte taking compliance te detecteren was $86 \%$, om goede taking compliance te detecteren $83 \%$. De likelihood-ratio van de CQR-19 om lage taking compliance te detecteren was 11.6. Vier items waren in het bijzonder predictief: $a$. angst om het geneesmiddel vergeten in te nemen, b. het vermogen hebben om goed te functioneren, $c$. regelmaat in het dagelijkse leven en d. bijwerkingen (gecombineerde $\mathrm{R}^{2}: 0.35$ ). Wij concludeerden dat deze resultaten de validiteit van de CQR bevestigen. Om de CQR beter bruikbaar te maken werd een CQR-calculator gemaakt, die gratis verkrijgbaar is bij de auteur of via het Internet (www.project.demon.n).

Hoofdstuk 7 beschrijt de resultaten van het COUGAR project, waarbij een heterogene patientenpopulatie gevolgd werd met electronic monitoring. Dit is de eerste studie die een uitgebreide beschrijving geeft van therapietrouw voor anti-rheumatica met electronische monitors.

Honderdzevenentwintig opeenvolgende patiënten werden ingesloten, bestaande uit 81 RA patiënten die NSAIDs (drie maal daags diclofenac of twee maal daags naproxen) of DMARDs (twee maal daags sulfasalazine of eenmaal wekelijks methotrexaat) gebruikten, 17 PMR patiënten die startten met eenmaal daags prednison en 29 patënten met jicht die met colchicine (eenmaal daags) of urinezuurverlagende therapie (eenmaal daags) starten. Alle patiënten werden ingesloten bij hun eerste prescriptie en alle voorschriften waren "innemen zoals voorgeschreven". De patiënten werden gedurende 6 maanden gevolgd (jicht: 12 maanden). Op deze wijze werden meer dan 73 patiëntjaren aan data verzameld.

De belangrijkste conclusie was dat er forse verschillen in therapietrouw bestaan tussen patiënten en tussen geneesmiddelen. Therapietrouw voor tweemaal daags sulfasalazine was verrassend laag, terwijl therapietrouw voor eenmaal wekelijks MTX heel goed was. Therapietrouw voor NSAIDs bij RA was ongeveer hetzelfde als therapietrouw voor NSAIDs bij de ziekte van Bechterew (hoofdstuk 3), terwijl therapietrouw voor steroiden bij PMR behoorijk goed was. Gemiste doses kwamen vaker voor dan extra doses. We observeerden een fors verval in therapietrouw over de tijd in alle medicatiegroepen. Multipele regressie analyse liet zien dat de klasse medicatie (symptoom modificerend of ziekte-controlerend), de doseringsfequentie, het geslacht, het coping patroon (vermijdend, passief reactie patroon en expressie van emoties) en de algemene gezondheid (uitgedrukt als Nottingham Health Profile score) in totaal $67 \%$ van alle variantie in taking compliance verklaarde (aangepaste $R^{2}, p=0.002$ ).

Hoofdstuk 8 behandelt de preventie van osteporose, een andere reumatische aandoening. Het beschrijft de resultaten van de Eindhoven Perimenopauzale Osteoporse Studie (EPOS), een open-label, gerandomizeerd, gecontroleerd onderzoek naar de werkzaamheid van 2 verschillende behandelingsmodaliteiten vergeleken met calcium bij preventie van 
postmenopauzaal botverlies bij vrouwen in de laagste tertiel van DXA meting na screening. Patiēnten in de orale pamidronaat groep ( $100 \mathrm{mg}$, eenmaal daags voorgeschreven) ontvingen hun medicatie in het MEMS systeem. De vrouwen werden geinstrueerd om de pamidronaat steeds een half uur voor ontbijt of diner in te nemen. Zesentachtig vrouwen werden gevolgd voor een totale duur van 104 patiëntjaren.

In het algemeen was de therapietrouw hoog, hetgeen mischien verrassend is voor een symptoomloze aandoening als lage botdichtheid. Er was geen relatie tussen therapietrouw en BMD-veranderingen. Tevens was er geen verschil in de BMD response tussen vroumen die pamidronaat 's ochtends namen versus vrouwen die de pamidronaat 's avonds namen.

Samenvattend laat deze thesis zien dat therapietrouw in de reumatologie vele gezichten kent. Enkele patiënten laten perfecte therapietrouw zien, maar de meerderheid van de patiënten gebruikt hun medicatie anders dan voorgeschreven. Hoofdstukken 3, 4 en 7 laten duidelijk de mate van tussen-patient variatie zien. Dit zou een aantal consequenties moeten hebben voor de dagelijkse klinische praktijk en voor wetenschappelijk onderzoek.

In de dagelijkse klinische praktijk zijn er 2 richtingen waar de informatie uit deze thesis gebruikt zou kunnen worden. Allereerst zou bij patiënten die geen goede klinische respons laten zien op anti-reumatische therapie, en in het bijzonder wanneer de reumatoloog overweegt de therapie te veranderen / de dosering te verhogen, er eerst een periode met de MEMS gemeten zou kunnen worden. Indien therapietrouw dan goed blijkt te zijn kan de verandering in therapie doorgevoerd worden maar als dit niet het geval blijkt te zijn, zou een dergelijke verandering of verhoging een slechte klinische keuze zijn. In dat geval zou een therapietrouw interventie een logische eerste keus zijn. Hoewel een dergelijke interventie niet beschreven staat in deze thesis, zijn we momenteel bezig met een onderzoek waarbij gekeken wordt of Medication Guided Medication Measurement (MGMM) effectief kan zijn in de reumatologische praktijk. De interventie is gemodelleerd op het werk van Cramer en van Bumier 4, 5, en bestaat uit: 1. identificatie van factoren die de therapietrouw negatief beinvloeden middels het gebruik van de $C Q R, 2$. het toepassen van de discriminant functies van de CQR om te voorspellen of een patient therapietrouw zal zijn of niet en 3. de patient een MEMS geven. De resultaten van de chronology plot van de MEMS worden bediscussieerd met de patiënt. Indien toepasbaar, kunnen tevens de gebieden die extra attentie behoeven (CQR) besproken worden.

Binnen de dagelijkse reumatologische praktijk zou het ook waardevol zijn te weten 'hoeveel therapietrouw genoeg is'. Helaas bestaan deze gegevens niet. Het is daarom erg moeilijk om te beoordelen wat de klinische relevantie is van de bevindingen in deze thesis, omdat de klinische consequenties onbekend zijn. Het is daarom noodzakelijk dat de reumatologie aandacht gaat besteden aan de vraag 'hoevel therapietrouw is genoeg'.

Aan de andere kant, binnen het wetenschappelijk onderzoek, en dan in het bijzonder in gerandomizeerde, gecontroleerde onderzoeken, bedreigt variabele therapietrouw de validiteit van het resultaat van intention-to-treat analysis ${ }^{6,7}$. De aanname dat iedere patient die in de trial geincludeerd was ook een perfecte therapietrouw had resulteerd in een conservatieve schatting van de werkzaamheid van het geneesmiddel. Omdat we nu therapietrouw tot in detail kunnen meten, zou het logsich zijn om technieken te ontwikkelen die een verbeterde schatting kunnen geven van de effectiviteit van het geneesmiddel. Voorbeelden zijn de herleiding van de doses 
response curve uit de therapietrouw-response curve ${ }^{8}$, causal inference ${ }^{9}$, dat een model kan bouwen tussen de patients' potentiële respons binnen de behandelingsarm en de potentiële respons binnen de placebo arm als functie van de geobserveerde therapietrouw en baseline voorspellers, en het gebruik van therapietrouw data om de bias te reduceren en de precisie te verbeteren binnen PKJPD studies 10 .

Tenslotte, binnen de reumatologie, kan het routine gebruik van therapietrouw meting in klinische trials resulteren in een hogere statistische power, waarbij het dus waarschijnlijker wordt dat klinisch relevante effecten ook daadwerkelijk gevonden worden, of in een mogelijke reductie van het aantal patiënten dat noodzakelijk is om zo'n effect te vinden.

Ik hoop dat deze thesis kan bijdragen bij zulk gebruik van therapietrouw meting in de toekomst, zowel in de dagelijkse zorg voor reumatologische patiënten als in wetenschappelijk onderzoek.

Erik de Klerk, Augustus 2002.

\section{References}

1. Urquhart J. Variable patient compliance in ambulatory trials-nuisance, threat, opportunity. J Antimicrob Chemother $1993 ; 32: 643-9$

2. de Klerk E, van der Linden SJ. Compliance monitoring of NSAID drug therapy in ankylosing spondylitis, experiences with an electronic monitoring device. Br J Rheumatol 1996; 35:60-5

3. Liu H, Golin C, Miller L, et al. A comparison study of multiple measures of adherence to HIV protease inhibitors. Annals of Internal Medicine 2001; 134:968-77.

4. Burnier M, Chiolero A, Fallab Stubi CL, Brunner HR. Electronic complance monitoring in resistant hypertension: the basis for rational therapeutic decisions. J Hypertens 2001; 19:335-41.

5. Cramer JA. Compliance with medication regimens for mental and physical disorders. Psychiatric Services 1998; 49:196-201.

6. Sheiner LB. The intellectual health of clinical drug evaluation [see comments]. Clin Pharmacol Ther 1991; 50:49 7. Sheiner LB, Rubin DL. Intention to treat analysis and the goals of clinical trials.

8. Efron B, Feldman D. Compliance as an explanatory variable in dinical trials. Journal of the American Statistical Association. 1991; 86:9-26.

9. Fischer-Lapp K. Practical properties of some structural mean analyses of the effect of compliance in randomized trials. Controlled Clinical Trials 1999; 20:531-46.

10. Vrijens B. Analyzing time-varying patterns of human exposure to xenobiotics and their biomedical impact.

Vakgroep Toegepaste Wiskunde en Informatica. Gent: Universiteit van Gent, 2002:190. 


\section{Dankwoord}

Mijn dank gaat in eerste instantie uit naar alle patïnten die bereid waren om met het onderzoek mee te werken, daarvoor gedurende lange tijd het MEMS potje te gebruiken en, niet te onderschatten, alle vragenlijsten bij het begin van het onderzoek (en nog eens bij het einde), in te vullen.

Daarnaast ben ik zeer erkentelijk voor de hulp van de reumatologen die hebben gezorgd voor de patiënten instroom: Sjef van der Linden, Désireé van der Heijde, Marijke van Santen, Annelies Boonen, Henk GoeiThe, Harry Houben, Hille van der Tempel, Peter Dubbeld, Liesbeth Heuft, Anneke Spoorenberg. Een bijzondere plaats verdient Robert Landewé, die de studie, op het moment dat de patiënten instroom geheel plat leek te liggen, door zijn betrokkenheid en volhoudendheid de instroom weer vlot heeft getrokken, wat voor een groot deel de reden is dat het project toch geslaagd genoemd kan worden.

Een speciaal woord van dank zou ik willen richten aan Zuzana de Jong en Carla Bakker, die met de -oxicam studie de initiële data hebben verzameld die mij op het 'compliance' pad gezet hebben. De analyse van de doppen, die destijds nog gewoon in een doos lagen, hebben mij op een pad gezet waarvan ik tot op de dag van vandaag nog steeds de vruchten van pluk.

Mijn promotoren Sjef van der Linden en Désireé van der Heijde wil ik bedanken voor de tijd en moeite die zij in mijn begeleiding gestopt hebben, en het vertrouwen dat ze in mij gesteld hebben qua opzet en uitvoering van de studie, en met name ook in de afronding van het proefschrift. Co-promotor Robert Landewé (later toegevoegd aan de commissie maar met een heel eigen plaats daarin) en zeker ook John Urquhart wil ik beide bedanken voor hun geheel eigen inzicht in het probleem van therapietrouw en de analyse en interpretatie van de resultaten.

De "jonkies" van de reuma, Simone Gorter, Yolanda Brauer, Guy Schulpen , Karin Bruynestein, Astrid van Tubergen, Astrid Wanders, wil ik bedanken voor alle sociale contacten en support, die ook een belangrijk positief deel hebben gevormd van mijn dagelijkse werkomgeving.

Jean-Michel Metry, Pierre-Alain Gaillard en John Urquhart hebben mij vrijwel ongelimiteerde mogelijkheden gegeven om mij verder te verdiepen in het gebied van electronisch meten van therapietrouw en hebben mij geweldig veel vertrouwen in de toekomst gegeven. Ook alle tijd die ik tijdens mijn huidige werk aan het afronden van de thesis heb mogen geven wordt zeer gewaardeerd.

Geraline Leusink en Jules Keijser ben ik dankbaar voor de mogelijkheid mee te mogen werken aan de analyse van 'de doppen van de EPOS'. Het was een leuk en welkom project dat ik goed naast de dagelijkse werkzaamheden kon doen, en ik ben blij dat we samen de resultaten hebben kunnen publiceren.

John Urquhart, mijn grote Leraar en Inspiratiebron: dit hele proefschrift, en feitelijk mijn hele carrière tot nu toe heb ik voor een belangrijk deel te danken aan jouw inzet, en de geweldige hoeveelheden informatie, tijd, inspiratie en lekker eten en drinken die je mij gaf. Hartelijk, 
hartelijk bedankt daarvoor, het zal nog vele jaren duren voordat ik de volledige impact van jouw aanwezigheid in mijn leven zal bevatten.

Bettina, Iris, Carmen, Bart, wat vind ik het fijn dat jullie in mijn leven zijn gekomen. En wat een geweldige verrassing dat Maarten er ook nog bij kwam! Wat een turbulente fase is in ons leven is het geweest, en wat fijn dat alles zo heeft mogen uitpakken.

Lieve, lieve Sven, ik had je zo ontzettend graag meer willen bieden dan nu het geval is. Papa houd enorm veel van je, en ik hoop, weet zeker, dat je dat later zult beseffen.

Four seasons in one day... 


\section{Curriculum Vitae}

De auteur van dit proefschrift werd op 31 augustus 1968 geboren the Amhem. Na het behalen van het HAVO diploma in 1985 en het WWO diploma in 1987, beide aan de Rijksscholengemeenschap Winkler Prins te Veendam startte hij met de studie Gezondheidswetenschappen aan de Rijksuniversiteit van Maastricht. In 1989 startte hij aldaar tevens met de studie Geneeskunde.

Na student-assistentschappen bij de werkgroep Reumatologie ontving hij in 1993 het doctoraal diploma Gezondheidswetenschappen (afstudeerrichting Bewegingswetenschappen) en het doctoraal diploma Geneeskunde. Vanaf 1993 heeft hij op free-lance basis bij het Provinciaal Steunpunt Gezondheidszorg te Sittard gewerkt aan een wetenschappelijke verantwoording voor een aantal Meer Bewegen Voor ... projecten. De zomer van 1995 werd doorgebracht als research-fellow bij het department of Statistics, Stanford University (USA) (prof. B. Efron). In 1996 ontving hij het artsdiploma van de Universiteit van Maastricht.

Tijdens de co-schappen werd door het Nationaal Reumafonds subsidie toegekend voor het COUGAR project (Compliance Unveiled in Gout, Arthritis and Rheumatism) waaraan in mei 1996 werd begonnen, met een dienstverband bij de werkgroep Reumatologie (hoofd: prof. dr.

$\mathrm{S}$. van der Linden) in het Academisch Ziekenhuis Maastricht.

Sinds augustus 1999 werkt hij als Medical Director bij AARDEX Ltd, Sion, Zwitserland (standplaats: Maastricht) alwaar hij verder werkt aan de wetenschappelijke ontwikkeling van het MEMS systeem, dat de basis is voor dit proefschrift. 
